\title{
Kidney transplantation form donors after cardiac death : ways to improve DCD kidney donation and transplantation
}

Citation for published version (APA):

Hoogland, P. E. R. P. (2014). Kidney transplantation form donors after cardiac death : ways to improve DCD kidney donation and transplantation. [Doctoral Thesis, Maastricht University]. Universitaire Pers Maastricht. https://doi.org/10.26481/dis.20140328ph

Document status and date:

Published: 01/01/2014

DOI:

10.26481/dis.20140328ph

Document Version:

Publisher's PDF, also known as Version of record

Please check the document version of this publication:

- A submitted manuscript is the version of the article upon submission and before peer-review. There can be important differences between the submitted version and the official published version of record.

People interested in the research are advised to contact the author for the final version of the publication, or visit the DOI to the publisher's website.

- The final author version and the galley proof are versions of the publication after peer review.

- The final published version features the final layout of the paper including the volume, issue and page numbers.

Link to publication

\footnotetext{
General rights rights.

- You may freely distribute the URL identifying the publication in the public portal. please follow below link for the End User Agreement:

www.umlib.nl/taverne-license

Take down policy

If you believe that this document breaches copyright please contact us at:

repository@maastrichtuniversity.nl

providing details and we will investigate your claim.
}

Copyright and moral rights for the publications made accessible in the public portal are retained by the authors and/or other copyright owners and it is a condition of accessing publications that users recognise and abide by the legal requirements associated with these

- Users may download and print one copy of any publication from the public portal for the purpose of private study or research.

- You may not further distribute the material or use it for any profit-making activity or commercial gain

If the publication is distributed under the terms of Article $25 \mathrm{fa}$ of the Dutch Copyright Act, indicated by the "Taverne" license above, 


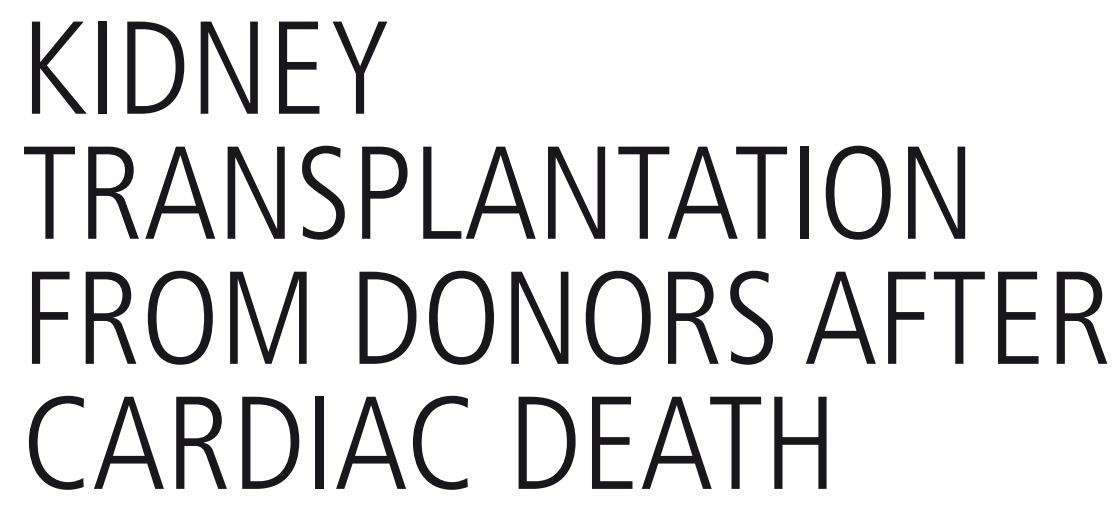

WAYS TO IMPROVE DCD KIDNEY DONATION AND TRANSPLANTATION 
ISBN:

9789461593184

Layout: $\quad$ Jeroen van den Berg

Cover: Jeroen van den Berg

Production: Datawyse / Universitaire Pers Maastricht

Copyright (C) 2014 E.R.P. Hoogland, Maastricht

Printing of this thesis was financially supported by Organ Recovery Systems, Maatschap Heelkunde Atrium Medisch Centrum, Astellas and Genzyme/Sanofi.

All rights reserved. No part of this thesis may be reproduced or transmitted in any form or by any means, electronic or mechanical, including photocopying, recording or any information storage or retrieval system, without permission in writing from the author, or, when appropriate, from the publishers of the publications. 


\section{KIDNEY \\ TRANSPLANTATION FROM DONORS AFTER CARDIAC DEATH}

WAYS TO IMPROVE DCD KIDNEY DONATION AND TRANSPLANTATION

\section{PROEFSCHRIFT}

ter verkrijging van de graad van doctor

aan de Universiteit Maastricht

op gezag van de Rector Magnificus,

Prof. dr. L.L.G. Soete

volgens het besluit van het College van Decanen,

in het openbaar te verdedigen

op vrijdag 28 maart 2014 om 12:00 uur

door

Erik Rijpke Pieter Hoogland 


\section{Promotor:}

Prof. dr. L.W.E. van Heurn

\section{Beoordelingscommissie:}

Prof. dr. G.W.H. Schurink (voorzitter)

Prof. dr. J.A. Bradley (University of Cambridge, Verenigd Koninkrijk)

Prof. dr. J.P. van Hooff

Prof. dr. J.N.M. IJzermans (Erasmus MC Rotterdam)

Prof. dr. L.P.S. Stassen 


\section{CONTENTS}

\begin{tabular}{|c|c|c|}
\hline Chapter 1 & General introduction & 7 \\
\hline Chapter 2 & $\begin{array}{l}\text { Outcome of kidney transplantations from uncontrolled donors after } \\
\text { cardiac death compared with controlled donors after cardiac death }\end{array}$ & 23 \\
\hline Chapter 3 & Which kidneys from uncontrolled donors after cardiac death do worse? & 39 \\
\hline Chapter 4 & Improvements in kidney transplantation from donors after cardiac death & 55 \\
\hline Chapter 5 & $\begin{array}{l}\text { The value of perfusate biomarker concentration of machine perfused } \\
\text { DCD kidneys in predicting transplant outcome }\end{array}$ & 71 \\
\hline Chapter 6 & $\begin{array}{l}\text { Renovascular resistance of machine perfused DCD kidneys is associated } \\
\text { with primary non-function }\end{array}$ & 89 \\
\hline Chapter 7 & $\begin{array}{l}\text { Measurement of renovascular circulating volume during hypothermic } \\
\text { organ perfusion of porcine kidneys }\end{array}$ & 105 \\
\hline Chapter 8 & Machine perfusion viability testing - a review & 119 \\
\hline Chapter 9 & The value of donor NGAL in predicting short term graft function & 133 \\
\hline Chapter 10 & The effect of anti-Mincle on kidney injury & 147 \\
\hline Chapter 11 & $\begin{array}{l}\text { Thromboxane receptor signaling in experimental renal ischemia } \\
\text { reperfusion injury }\end{array}$ & 159 \\
\hline Chapter 12 & General discussion and summary & 173 \\
\hline & Samenvatting & 187 \\
\hline & Dankwoord & 203 \\
\hline & Curriculum vitae & 209 \\
\hline & List of publications & 213 \\
\hline & Abbreviations & 217 \\
\hline
\end{tabular}




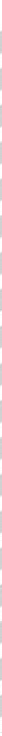


CHAPTER 1

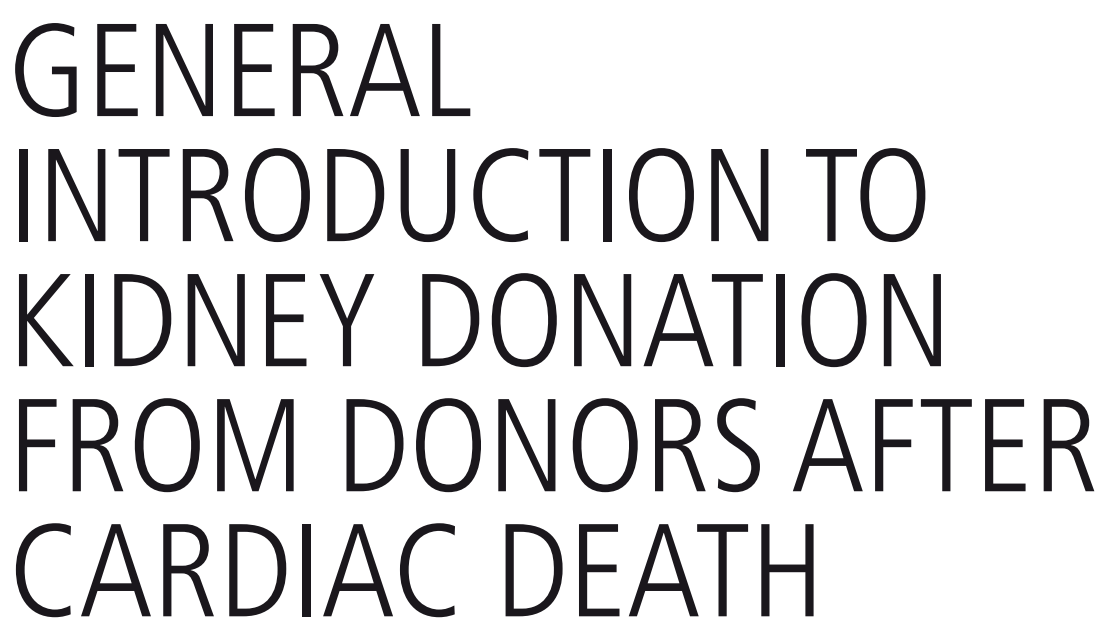




\section{ABSTRACT}

Kidney transplantation is the optimal treatment for patients with endstage renal disease. The imbalance between supply and demand of kidneys for transplantation has led to a progressive expansion of the deceased donor pool. However, there is still a general reluctance to use donors after cardiac death for kidney donation and transplantation, because of a relatively high incidence of delayed graft function and primary non-function compared to conventional donors after brain death. However, transplanted kidneys that do not experience these complications survive as long as conventional kidneys from donors after brain death. Optimal organ preservation and careful selection of kidneys form donors after cardiac death may reduce the risk of delayed graft function and primary non-function.

The purpose of this chapter is to describe the definition of donation after cardiac death, the current kidney preservation techniques for donors after cardiac death and to give insight in new developments that may reduce the warm ischemia times and therefore improve graft function after transplantation.

\section{Derived from}

E.R. Pieter Hoogland, Maarten G.J. Snoeijs and L.W. Ernest van Heurn. DCD kidney transplantation: results and measures to improve outcome. Curr Opin Organ Transplant 2010; 15(2):177-182 


\section{INTRODUCTION}

Kidney transplantation is the treatment of choice for patients with end-stage renal disease. Transplantation of kidneys from deceased donors results in longer life expectancy and superior quality of life compared with dialysis treatment (1-3). However, its use is limited due to the shortage of organ donors (1). The imbalance between supply and demand of kidneys for transplantation has led to a progressive expansion of the deceased donor pool. Liberal use of kidneys from donors after cardiac death ( $D C D$ ) holds the potential to increase the number of organ donors by 2.5 - 4 times, which is sufficient to stabilize or reduce the waiting lists for kidney transplantation $(4,5)$. In contrast to donation after brain death (DBD), however, organs from DCD donors inevitably sustain a period of warm ischemia from circulatory arrest until initiation of organ preservation. This causes ischemic acute kidney injury, which results in an increased incidence of delayed graft function (DGF) and primary nonfunction (PNF) as compared to kidney transplantation from conventional brain-dead donors (6). These early complications associated with DCD kidney transplantation have led to a reluctance to use these kidneys for transplantation and have restricted the expansion of DCD kidney donation to its full potential.

In this chapter we describe firstly the results of kidney transplantation from DCD donors, secondly kidney preservation techniques and their results and thirdly to give insight in new developments and optimal donor management to reduce warm ischemia times in order to reduce the incidence of DGF and PNF.

\section{DEFINITIONS OF DCD DONATION}

DCD donation can be defined as donation of organs from patients who have died with circulatory arrest. Therefore, DCD kidneys always sustain a period of warm ischemia. At the first international workshop on DCD-donation in Maastricht, 1995, four types of DCD donors were discussed and accepted to categorize DCD kidneys according to their period of warm ischemia (Table 1.1) (7). Maastricht category 1 donors have the longest warm ischemia time, Maastricht category 3 and 4 have potentially the shortest. Maastricht category 1 donors are patients who are declared dead outside the hospital and are subsequently transferred to the hospital with the purpose of organ donation. There are only a few donation programs in which category 1 DCD donors are implemented, mainly in Spain and France $(8,9)$. Maastricht category 2 donors are patients who die in the hospital, mostly on the emergency department, after unsuccessful resuscitation. Both category 1 and 2 occur unexpectedly and therefore are referred to as 'uncontrolled' donors. Maastricht category 3 donors are patients on the intensive care unit (ICU) who do not meet brain death criteria, but for whom further medical treatment is considered to be futile and therefore is withdrawn. This gives the donation staff the opportunity to schedule the procedure and to meet legal and logistic requirements before organ recovery. 
Because of this planned fashion, category 3 donors are referred to as 'controlled' DCD donors. Maastricht category 4 donors are brain-dead donors who die of unexpected cardiac arrest before organ procurement.

Maastricht categories of donation after cardiac death

\begin{tabular}{lll}
\hline Category & Definition & Type \\
\hline 1 & Dead on arrival & Uncontrolled \\
\hline 2 & Unsuccessful resuscitation & Uncontrolled \\
\hline 3 & Awaiting cardiac arrest & Controlled \\
\hline 4 & Cardiac arrest while brain dead & Controlled / Uncontrolled \\
\hline
\end{tabular}

\section{RESULTS OF KIDNEY TRANSPLANTATION FROM DONORS AFTER CARDIAC DEATH}

Previous comparisons of the results of DCD and DBD kidney transplantation have shown a relatively high incidence of PNF in DCD kidneys, which has been attributed to the ischemic injury suffered before organ recovery. Depending on the threshold to discard or to accept DCD kidneys for transplantation, the incidence of PNF may be as high as $15-25 \%$. More restrictive selection criteria will improve the results of DCD kidney transplantation, but will inevitably be associated with the discard of viable kidneys.

Kootstra et al. compared several international studies on DCD kidney transplantation, and concluded that the incidence of DGF of $20-80 \%$ in DCD kidneys is significantly higher in DCD kidneys compared to DBD kidneys, with an incidence between $20-30 \%$. However, the short- and medium term graft function of functioning grafts is similar in both groups (10). Interestingly, also the long-term graft survival of DCD kidneys that overcome the early postoperative period seems to be similar to that of DBD kidneys, more than 10 years after transplantation. In contrary to DBD kidneys, the relatively high incidence of DGF in DCD kidneys does not seem to affect the eventual outcome (11-17). However, less is known about graft survival rates after 10 years.

The Leicester group recently (2009) showed that the results of functioning DCD kidneys are similar to DBD kidneys after a follow-up period ranging from 5 to 15 years for mainly uncontrolled (Maastricht category II) kidneys, despite higher rates of DGF (18). This confirms our own results, which show that the long-term outcome (follow-up up to 25 years) of viable DCD kidneys is equivalent to grafts recovered from brain-dead donors (19). 


\section{STANDARD PRESERVATION TECHNIQUES FOR DONORS AFTER CARDIAC DEATH}

Kidneys from DCD donors are inevitably associated with circulatory arrest prior to cold preservation and, therefore, with warm ischemic damage to the organs. To reduce this damage, rapid cooling of the organs is indicated. In many centers in situ preservation (ISP) is the method of choice for uncontrolled (Maastricht category I and II) DCD donors. It is an indispensable technique that may provide the opportunity to meet legal and logistical requirements for organ recovery without excessive warm ischemia times and, depending on the legal opportunities, can be initiated prior to consent for organ donation. It is usually performed in the emergency room after failed resuscitation $(10,20,21)$. Preservation measures are started after a five minutes 'no touch' period, the interval between cessation of cardiopulmonary resuscitation and the moment that preservation measures are started. This minimally invasive surgical technique consists of the insertion of a double-balloon triple-lumen (DBTL) catheter through the femoral artery into the aorta. After partial inflation of the abdominal balloon, the catheter is pulled back until it hooks onto the aortic bifurcation (22). The thoracic balloon, which is positioned above the renal arteries, is then inflated so that it occludes the aorta proximally to the kidneys and the fully inflated abdominal balloon occludes at the aorta's bifurcation. The third lumen of the catheter is used to flush the organs with hypothermic organ preservation solution, flushing and cooling the kidneys in situ until organ recovery. A large Foley catheter is placed in the femoral vein for decompression (Figure 1.1A). For adolescents, a 16 Ch DBTL catheter with a balloon distance of $25 \mathrm{~cm}$, and a fully inflated balloon diameter of $40 \mathrm{~mm}$ (AJ6516, Porgès, Le Plessis-Robinson, France) is available. For children between approximately 5 and 12 years of age, a smaller 12 Ch DBTL catheter with a balloon distance of $15 \mathrm{~cm}$ and a balloon diameter of 30mm (61.630.12.080, Meddev, Holm, Germany) can be used (23). An infusion system is connected to the catheter and cold perfusate is infused until donor nephrectomy. To reduce the chance of capillary occlusion and warm ischemic damage to the organs heparin and streptokinase are administered at the initial flush after the cannula has been inserted (24). Within two hours after starting ISP, the deceased is taken to the operating room for organ recovery.

In Maastricht category III donors, withdrawal of life support usually takes place in the ICU. After cardiac arrest and the obligatory no-touch period, the patient is transported to the operating room where prepared surgical staff is waiting. After arrival in the operating room, rapid laparotomy is done with direct cannulation of the aorta (Figure 1.1B). In general, the warm ischemia time with this technique can be limited to 20 minutes. One of the conditions to use this preservation method is a short distance between the ICU and the operating room, so that the transportation time can be kept to a minimum. Others prefer to withdraw medical treatment in the operating room so that no time is lost to transport the deceased to the operating room and the warm ischemia time is reduced. However, withdrawal of treatment in the operating room may influence good end of life care and, if the patient's heart does not stop beating after the cessation of medical treatment, the patient has to be transported back to the ICU, with potentially negative feelings for relatives and 
involved medical staff. Irrespective of where treatment is withdrawn, after a no-touch period of at least 5 minutes during which no invasive or medical donor treatment is given, the organs are rapidly flushed and cooled, immediately procured and stored on melting ice or preserved on a machine (23).
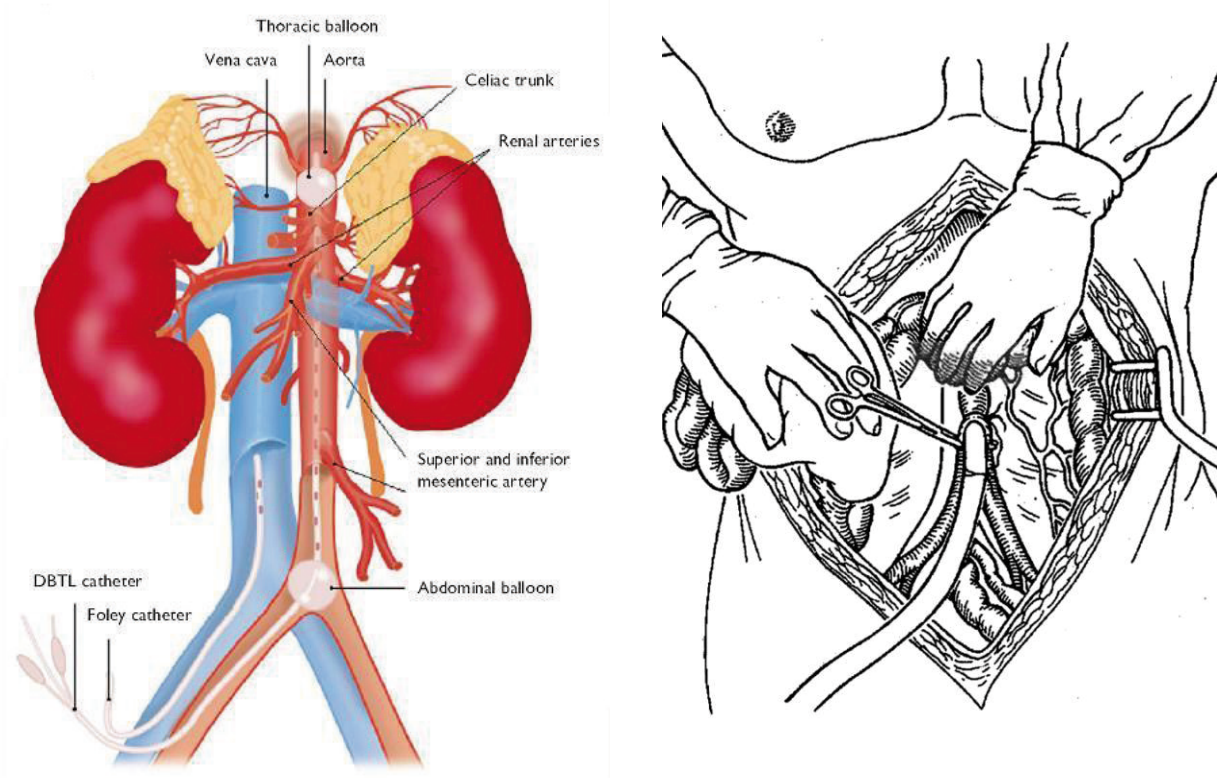

Figuur 1.1 Surgical techniques for organ preservation in donors after cardiac death. (A) In situ preservation technique. Reproduced with permission from "Nederlands Tijdschrift voor Geneeskunde". (B) After rapid laparotomy, the abdominal organs are perfused through an aortic cannula. The figure was adapted from Casavilla et al. (25)

\section{RESULTS OF ISP AND DIRECT CANNULATION OF THE AORTA}

Only a minority of initiated ISP procedures leads to transplantation. Often it is done in patients with a contra-indication to donation, or consent to procure the organs is not obtained. Furthermore, there are technical complications of the procedure itself, such as an inaccessible femoral artery for catheter insertion, wrong position of the DBTL catheter or rupture of the abdominal balloon that are responsible for unsuccessful donation. A prolonged catheter insertion time is associated with poor transplant outcome, which not only depends on the longer warm ischemia time, but also on the quality of the arterial tract. For controlled DCD donors, rapid laparotomy and direct cannulation of the aorta lead to a significantly superior graft 
survival compared to DCD donor kidneys that are preserved in situ. These donors have shorter warm ischemia times and lower rates of discard. Concluding, rapid laparotomy and direct aortic cannulation is considered preferable above in situ perfusion using double-balloon triple-lumen catheters as the method for initiation of organ preservation in controlled DCD donors (21).

\section{KIDNEY PRESERVATION AFTER RECOVERY}

After organ procurement, kidneys can be preserved by static cold storage (CS), which is currently the standard technique for organ preservation, or by hypothermic machine perfusion (HMP) (26). The latter method has many advantages over CS for the donor kidney. In theory, continuous pulsatile flow through the kidney can provide nutrients and oxygen and it can eliminate metabolic by-products and toxins. It decreases vasospasm and protects the endothelium, possibly due to flowdependant genes. Furthermore, HMP offers the opportunity to apply therapeutic interventions, like the addition of pharmacological agents or even gene therapy $(27,28)$. A meta-analysis showed that a $20 \%$ reduction in the relative risk of DGF of both DBD and DCD donor kidneys can be achieved by using HMP instead of CS (29). More recent studies in human kidney transplantation show high level evidence that HMP is associated with a decreased risk of DGF and improved one-year and 3-year graft survival, although the latter was only proven for DBD kidneys and not for DCD kidneys (30-33).

In addition to improving graft function, HMP offers a good opportunity to test the viability of deceased donor kidneys in order to prevent transplantation of non-viable grafts. In the past, machine viability testing has been used to decide if kidneys should be discarded or accepted for transplantation. Many studies evaluated the perfusate biomarker concentration and machine perfusion parameters as a tool to estimate graft viability. However, its use was often justified by the argument that results of transplantation had improved after the introduction of machine perfusion viability testing. High quality evidence was usually not available (34-37). Recently, we described that viability testing has not offered clinicians the expected tools to decide whether to discard or accept a kidney for transplantation. There is little evidence that current viability tests during HMP are reliable enough to make a decision prior to transplantation. Expanding viability testing with new biomarkers and novel techniques may provide tests with better predictive value, but their values have to be proven. Viability testing during normothermic perfusion offers a novel opportunity to assess the quality of a donor kidney, as the function of metabolically active organs is tested, instead of surrogate indicators, which measure cell death, inflammation or other kidney injury. 


\section{DONOR MANAGEMENT BEFORE AND DURING ORGAN PRESERVATION; NEW DEVELOPMENTS}

Donor kidneys are sustained to a period of warm ischemia from cardiac arrest until preservation. To reduce ischemic damage to the kidney of a potential donor, maintaining an adequate circulation after the cessation of treatment or cardiac arrest and a no-touch period of 5 minutes, CPR can be used while preservation measures are taken. CPR primarily aims to increase cardiac and cerebral perfusion, whereas blood flow to visceral organs is relatively low. Indeed, renal blood flow in dogs was reduced by $85 \%$ during resuscitation as measured by radioactively labeled micro spheres (38). When adrenalin was administered during resuscitation, renal blood flow was further reduced down to $2 \%$ of the blood flow before cardiac arrest (39). These data indicate that despite CPR, donor kidneys suffer extensive warm ischemic injury. This can potentially be reduced by automated chest compression devices. Manual CPR is a simple and quick technique for maintaining a circulation during cardiac arrest. However, limitations of manual CPR are inconsistency of rate and depths of chest compression, regardless of the experience of the person performing the chest compressions, resulting in less blood flow through vital organs (40). In order to improve CPR by performing consistent rates and depths of chest compressions, a variety of automated chest compression devices have been studied. Improved hemodynamic effects and better coronary perfusion with increased peak aortic pressure over manual CPR have been described. This suggests a better perfusion of visceral organs using an automated chest compression device after cardiac death $(40,41)$. Chest compression devices, such as the Autopulse (ZOLL Circulation, Sunnyvale, California) (Figure 1.2), are also used to preserve DCD donor organs from cardiac arrest until in situ cooling using a DBTL-catheter (42). In a group of uncontrolled category 1 donors, supported by the Autopulse, the 6 month graft survival after transplantation was $89 \%$ (9). The use of automated chest compression devices may contribute to a better perfusion of visceral organs, resulting in less ischemic injury and better graft function after transplantation. However, proper positioning of the device is essential for adequate chest compressions and to limit intra-abdominal damage. Bilateral rib fractures, a fractured manubrium of the sternum, lateral cutaneous lacerations, a ruptured spleen and liver were found at autopsy of a 49-year-old patient, admitted because of an outof-hospital resuscitation, which may have been related to inappropriate placement of the Autopulse (43). Therefore, it is recommended that proper positioning of the device is regularly checked when the Autopulse is used.

Extracorporeal membrane oxygenation (ECMO) has the potential to improve organ quality by providing normal tissue perfusion after cardiac death (45). Since its introduction in the early 1970, it has become a standard therapy to provide temporary circulatory support and systemic oxygenation for patients with reversible cardiac or respiratory failure that cannot be supported with conventional mechanical ventilation. The use of ECMO after cardiac death in order to maintain sufficient oxygenation of potential donor organs has been evaluated in several studies (4649). In Spain, the ECMO is used for uncontrolled category I donors. Once death is declared, an automated chest compression device is used while perfusion catheters 
are being inserted in the femoral artery and vein. When the catheters are in place, the compression device is turned off and an occlusive balloon is placed in the thoracic aorta. Extracorporeal circulation is then begun using a heat exchanger in the circuit to maintain normal body temperature (Figure 1.3).

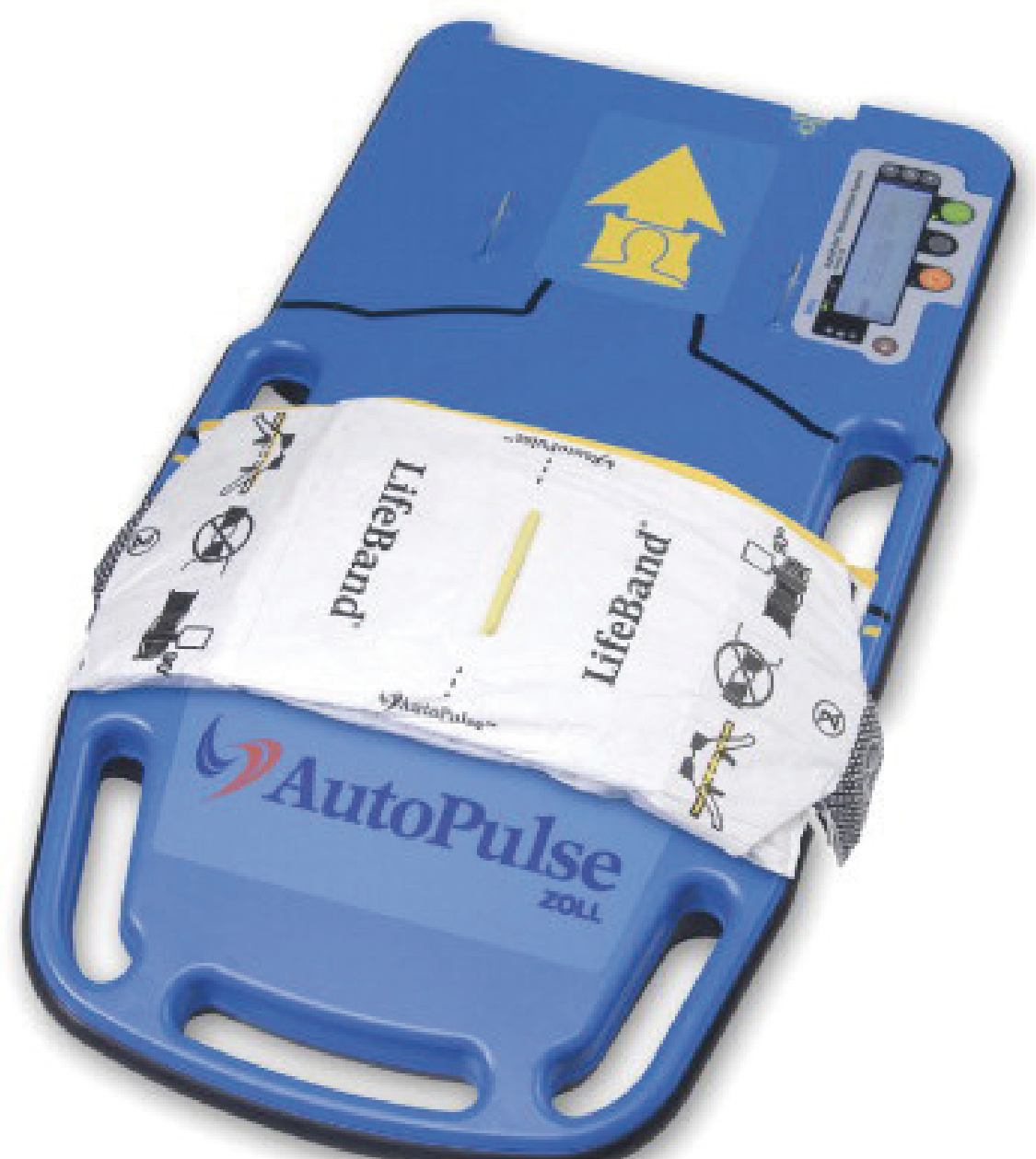

Figure 1.2 The AutoPulse (ZOLL Circulation, Sunnyvale, California) for delivery of chest compressions during cardiopulmonary resuscitation. The figure was adapted from Risom et al. (44) 


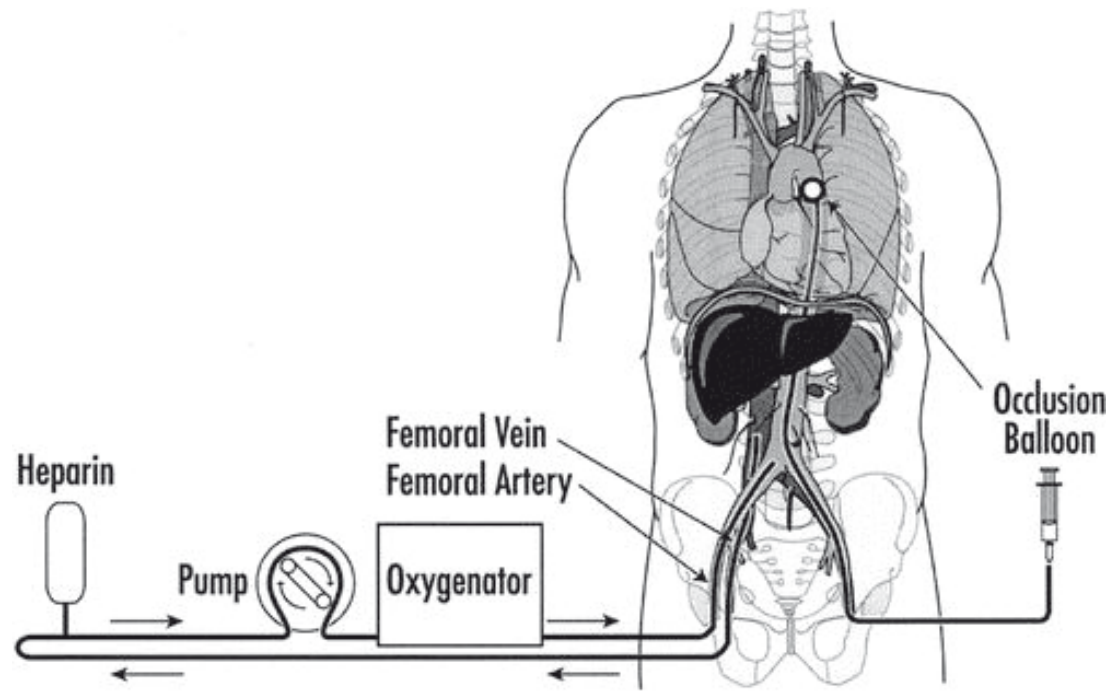

Figure 1.3 Extracorpereal membrane oxygenation configuration. The figure was adapted from Magliocca et al. (47)

A group from Madrid demonstrated a substantial expansion of the DCD donor pool after ECMO use. Donor criteria were a witnessed arrest, age between 7 and 55 years and initiation of CPR within 10 minutes after cardiac arrest. Time limit from cardiac arrest until organ preservation is fixed at 120 minutes, time limit until organ procurement is fixed at $\mathbf{2 4 0}$ minutes from cardiac arrest. Kidney function is stated to be as good or better than kidneys obtained from DBD donors, with a superior longterm graft survival (50).

For controlled donors, once consent has been obtained for ECMO use after cardiac death when treatment has been withdrawn, the University of Michigan places the femoral artery and venous catheters and a thoracic occlusion balloon before cardiac arrest occurs, without activating the system. When death is declared by the treating physician, the thoracic balloon is inflated and the ECMO support starts. Without any rush, organ recovery can take place by first cooling the organs by adding cold perfusate solution to the arterial catheter of the ECMO, which is then turned off. With this latter method, measures to preserve donor organs are taken before death has occurred, which limits its use because of legal or ethical objections. The organs are removed using conventional organ recovery techniques (46). Graft survival of controlled, ECMO assisted donors appears to be similar or even better than kidneys obtained from conventional brain-dead donors $(46,47,51,52)$. Normothermic ECMO with the donor's own blood reduces the incidence of DGF and PNF compared to the ISP perfusion with the DBTL catheter and to total body cooling with a cardiopulmonary bypass. Normothermic ECMO also enables the use of other organs than kidneys for transplantation, such as the liver and lungs (53). 


\section{Preservation and assessment of kidneys after recovery}

After successful organ recovery from donors after cardiac death, kidneys are stored either on melting ice or on a hypothermic pulsatile perfusion machine. Machine perfusion may provide a useful platform to assess kidney function by several viability tests (54-59), however, these tests have insufficient diagnostic accuracy to be clinical useful in deciding whether to transplant or discard DCD kidneys that have suffered prolonged warm ischemia time (60).

Next to assessment of acute ischemic injury, kidneys from older donors may have chronic degenerative changes. Among several selection criteria, the only proven predictor for graft function and survival is histological assessment of degenerative changes in pre-transplant kidney biopsies in donors aged 60 or older. In contrast to donor age, kidney function, kidney weight and perfusion parameters, pre-implantation histological kidney damage is associated with premature graft loss in older donors (61). Histological assessment of pre-transplant kidney biopsies is reproducible among pathologists and evaluation of small needle biopsies give a reasonable estimate of degenerative changes in the entire kidney (62). Therefore, histological assessment of renal biopsies is a clinically useful tool to select kidneys from donors with satisfactory outcome and this approach may be more appropriate than setting arbitrary age limits for kidney donation.

\section{CONCLUSION}

In this chapter, we show that the liberal use of organs from donors after cardiac death greatly increases the number of available donor kidneys. However, kidney transplantations from DCD donors are characterized by a higher incidence of PNF and DGF. Nevertheless, viable grafts that do not experience PNF survive as long as conventional kidneys from donors after brain death, and wait-listed dialysis patients experience a survival benefit from DCD kidney transplantation. The risk of DGF and PNF with DCD kidneys can be reduced firstly by organ preservation using rapid laparotomy and direct aortic cannulation for controlled DCD donors and secondly by reducing the warm ischemia time using automated chest compression devices and extracorporeal membrane oxygenation. Expansion of the donor pool by using more uncontrolled donors supported with ECMO is of paramount importance to improve the treatment of wait-listed dialysis patients. Major efforts should continue to be made to improve the quality of DCD kidneys and thereby expand the utilization of this large pool of donor kidneys to its full potential. 


\section{AIMS OF THE THESIS}

Based on this chapter, there is a discrepancy between the number of patients on the waiting list for a kidney transplantation and the number of kidney donors. One method to increase the donor pool is by using uncontrolled DCD donors, however, there is still a general reluctance to accept kidneys from these donors because of the potential higher risk of complications after transplantation. Therefore, this thesis focuses on methods to increase the number and quality of DCD kidney donation and transplantation.

Firstly, Chapter 2 provides results of uncontrolled DCD kidneys compared with controlled DCD kidneys. Insight into the short-term and long-term results of uncontrolled DCD kidneys is indispensible to decide whether or not to start or continue expensive kidney donation programs. Next, we investigated which variables in uncontrolled DCD donors are of importance in order to assess organ viability (Chapter 3), and how the results of DCD kidney donation and transplantation can be improved (Chapter 4).

Secondly, this thesis aims to identify strategies to predict PNF of DCD kidneys, which is extremely important as PNF is a serious complication of kidney transplantation (Chapters 5-8). A better selection of DCD kidneys before transplantation may reduce the incidence of PNF, which results in a better quality of care.

Thirdly, we investigated new potential therapies in experimental models to protect the kidney from ischemia-reperfusion injury in order to prevent or treat ischemic acute renal injury after DCD kidney transplantation (Chapters 9-11). 


\section{REFERENCES}

1. Wolfe RA, Ashby VB, Milford EL, Ojo AO, Ettenger RE, Agodoa LY, et al. Comparison of mortality in all patients on dialysis, patients on dialysis awaiting transplantation, and recipients of a first cadaveric transplant. N Engl J Med. 1999 Dec 2;341(23):1725-30.

2. Evans RW, Manninen DL, Garrison LP, Jr., Hart LG, Blagg CR, Gutman RA, et al. The quality of life of patients with end-stage renal disease. N Engl J Med. 1985 Feb 28;312(9):553-9.

3. Snoeijs MG, Schaubel DE, Hene R, Hoitsma AJ, Idu MM, ljzermans JN, et al. Kidneys from donors after cardiac death provide survival benefit. J Am Soc Nephrol. 2010 Jun;21(6):1015-21.

4. Terasaki PI, Cho YW, Cecka JM. Strategy for eliminating the kidney shortage. Clinical transplants. 1997:265-7.

5. Daemen JW, Oomen AP, Kelders WP, Kootstra G. The potential pool of non-heart-beating kidney donors. Clinical transplantation. 1997 Apr;11(2):149-54.

6. Wijnen RM, Booster MH, Stubenitsky BM, de Boer J, Heineman E, Kootstra G. Outcome of transplantation of non-heart-beating donor kidneys. Lancet. 1995 Apr 29;345(8957):1067-70.

7. Kootstra G, Daemen JH, Oomen AP. Categories of non-heart-beating donors. Transplantation proceedings. 1995 Oct;27(5):2893-4.

8. Sanchez-Fructuoso Al. Kidney transplantation from non-heart-beating donors. Transplantation proceedings. 2007 Sep;39(7):2065-7.

9. Fieux F, Losser MR, Bourgeois E, Bonnet F, Marie O, Gaudez F, et al. Kidney retrieval after sudden out of hospital refractory cardiac arrest: a cohort of uncontrolled non heart beating donors. Critical care (London, England). 2009;13(4):R141.

10. Kootstra G, van Heurn E. Non-heartbeating donation of kidneys for transplantation. Nature clinical practice Nephrology. 2007 Mar;3(3):154-63.

11. Nicholson ML, Metcalfe MS, White SA, Waller JR, Doughman TM, Horsburgh T, et al. A comparison of the results of renal transplantation from non-heart-beating, conventional cadaveric, and living donors. Kidney international. 2000 Dec;58(6):2585-91.

12. Sanchez-Fructuoso Al, Marques M, Prats D, Conesa J, Calvo N, Perez-Contin MJ, et al. Victims of cardiac arrest occurring outside the hospital: a source of transplantable kidneys. Annals of internal medicine. 2006 Aug 1;145(3):157-64.

13. Weber M, Dindo D, Demartines N, Ambuhl PM, Clavien PA. Kidney transplantation from donors without a heartbeat. N Engl J Med. 2002 Jul 25;347(4):248-55.

14. Cho YW, Terasaki PI, Cecka JM, Gjertson DW. Transplantation of kidneys from donors whose hearts have stopped beating. N Engl J Med. 1998 Jan 22;338(4):221-5.

15. Cooper JT, Chin LT, Krieger NR, Fernandez LA, Foley DP, Becker YT, et al. Donation after cardiac death: the university of wisconsin experience with renal transplantation. Am J Transplant. 2004 Sep;4(9):1490-4.

16. Gok MA, Buckley PE, Shenton BK, Balupuri S, El-Sheikh MA, Robertson $H$, et al. Long-term renal function in kidneys from non-heart-beating donors: A single-center experience. Transplantation. 2002 Sep 15;74(5):664-9.

17. Renkens JJ, Rouflart MM, Christiaans MH, van den Berg-Loonen EM, van Hooff JP, van Heurn LW. Outcome of nonheart-beating donor kidneys with prolonged delayed graft function after transplantation. Am J Transplant. 2005 Nov;5(11):2704-9.

18. Barlow AD, Metcalfe MS, Johari Y, Elwell R, Veitch PS, Nicholson ML. Case-matched comparison of longterm results of non-heart beating and heart-beating donor renal transplants. The British journal of surgery. 2009 Jun;96(6):685-91.

19. Snoeijs MG, Winkens B, Heemskerk MB, Hoitsma AJ, Christiaans MH, Buurman WA, et al. Kidney transplantation from donors after cardiac death: a 25-year experience. Transplantation. 2010 Nov 27;90(10):1106-12.

20. Booster MH, Wijnen RM, Vroemen JP, van Hooff JP, Kootstra G. In situ preservation of kidneys from nonheart-beating donors--a proposal for a standardized protocol. Transplantation. 1993 Sep;56(3):613-7.

21. Snoeijs MG, Dekkers AJ, Buurman WA, van den Akker L, Welten RJ, Schurink GW, et al. In situ preservation of kidneys from donors after cardiac death: results and complications. Annals of surgery. 2007 Nov;246(5):844-52. 
22. Kootstra G, van Hooff JP. [In-situ preservation of kidneys of 'non-heart-beating' donors: a possible way to offset the shortage of donor kidneys]. Nederlands tijdschrift voor geneeskunde. 1998 Dec 26;142(52):283843. In-situpreservatie van nieren bij 'hartdode' donoren: mogelijkheid voor het opheffen van het tekort aan donornieren.

23. de Vries EE, Snoeijs MG, van Heurn E. Kidney donation from children after cardiac death. Critical care medicine. 2010 Jan;38(1):249-53.

24. Gok MA, Shenton BK, Buckley PE, Peaston R, Cornell C, Soomro N, et al. How to improve the quality of kidneys from non-heart-beating donors: a randomised controlled trial of thrombolysis in non-heartbeating donors. Transplantation. 2003 Dec 27;76(12):1714-9.

25. Casavilla A, Ramirez C, Shapiro R, Nghiem D, Miracle K, Bronsther O, et al. Experience with liver and kidney allografts from non-heart-beating donors. Transplantation. 1995 Jan 27;59(2):197-203.

26. St Peter SD, Imber CJ, Friend PJ. Liver and kidney preservation by perfusion. Lancet. 2002 Feb 16;359(9306):604-13.

27. Yuan X, Theruvath AJ, Ge X, Floerchinger B, Jurisch A, Garcia-Cardena G, et al. Machine perfusion or cold storage in organ transplantation: indication, mechanisms, and future perspectives. Transpl Int. 2010 Jun;23(6):561-70.

28. Taylor MJ, Baicu SC. Current state of hypothermic machine perfusion preservation of organs: The clinical perspective. Cryobiology. 2010 Jul;60(3 Suppl):S20-35.

29. Wight JP, Chilcott JB, Holmes MW, Brewer N. Pulsatile machine perfusion vs. cold storage of kidneys for transplantation: a rapid and systematic review. Clinical transplantation. 2003 Aug;17(4):293-307.

30. Moers C, Smits JM, Maathuis MH, Treckmann J, van Gelder F, Napieralski BP, et al. Machine perfusion or cold storage in deceased-donor kidney transplantation. N Engl J Med. 2009 Jan 1;360(1):7-19.

31. Moers C, Pirenne J, Paul A, Ploeg RJ, Machine Preservation Trial Study G. Machine perfusion or cold storage in deceased-donor kidney transplantation. N Engl J Med. 2012 Feb 23;366(8):770-1.

32. Treckmann J, Moers C, Smits JM, Gallinat A, Maathuis MH, van Kasterop-Kutz M, et al. Machine perfusion versus cold storage for preservation of kidneys from expanded criteria donors after brain death. Transpl Int. 2011 Jun;24(6):548-54.

33. Gallinat A, Moers C, Treckmann J, Smits JM, Leuvenink HG, Lefering R, et al. Machine perfusion versus cold storage for the preservation of kidneys from donors $>=65$ years allocated in the Eurotransplant Senior Programme. Nephrol Dial Transplant. 2012 Dec;27(12):4458-63.

34. Bhangoo RS, Hall IE, Reese PP, Parikh CR. Deceased-donor kidney perfusate and urine biomarkers for kidney allograft outcomes: a systematic review. Nephrol Dial Transplant. 2012 Aug;27(8):3305-14.

35. Jochmans I, Pirenne J. Graft quality assessment in kidney transplantation: not an exact science yet! Current opinion in organ transplantation. $2011 \mathrm{Apr} ; 16(2): 174-9$.

36. Moers C, Varnav OC, van Heurn E, Jochmans I, Kirste GR, Rahmel A, et al. The value of machine perfusion perfusate biomarkers for predicting kidney transplant outcome. Transplantation. 2010 Nov 15;90(9):96673.

37. Jochmans I, Moers C, Smits JM, Leuvenink HG, Treckmann J, Paul A, et al. The prognostic value of renal resistance during hypothermic machine perfusion of deceased donor kidneys. Am J Transplant. 2011 Oct;11(10):2214-20.

38. Voorhees WD, Babbs CF, Tacker WA, Jr. Regional blood flow during cardiopulmonary resuscitation in dogs. Critical care medicine. 1980 Mar;8(3):134-6.

39. Ralston SH, Voorhees WD, Babbs CF. Intrapulmonary epinephrine during prolonged cardiopulmonary resuscitation: improved regional blood flow and resuscitation in dogs. Annals of emergency medicine. 1984 Feb;13(2):79-86.

40. Wigginton JG, Miller AH, Benitez FL, Pepe PE. Mechanical devices for cardiopulmonary resuscitation. Current opinion in critical care. 2005 Jun;11(3):219-23.

41. Timerman S, Cardoso LF, Ramires JA, Halperin H. Improved hemodynamic performance with a novel chest compression device during treatment of in-hospital cardiac arrest. Resuscitation. 2004 Jun;61(3):273-80.

42. Morozumi J, Sakurai E, Matsuno N, Ito M, Yokoyama T, Ohtaka Y, et al. Successful kidney transplantation from donation after cardiac death using a load-distributing-band chest compression device during long warm ischemic time. Resuscitation. 2009 Feb;80(2):278-80. 
43. Wind J, Bekkers SC, van Hooren LJ, van Heurn LW. Extensive injury after use of a mechanical cardiopulmonary resuscitation device. Am J Emerg Med. 2009 0ct;27(8):1017 e1- e2.

44. Risom M, Jorgensen $H$, Rasmussen LS, Sorensen AM. Resuscitation, prolonged cardiac arrest, and an automated chest compression device. The Journal of emergency medicine. 2010 May;38(4):481-3.

45. Punch J. Extracorporeal circulatory-assisted non-heart-beating organ donation. In: Organ donation and transplantation after cardiac death. Edition 1. Edited by Talbot D., A.M. D'Alessandro. Oxford University Press: 2009. pp 153-159

46. Gravel MT, Arenas JD, Chenault R, 2nd, Magee JC, Rudich S, Maraschio M, et al. Kidney transplantation from organ donors following cardiopulmonary death using extracorporeal membrane oxygenation support. Ann Transplant. 2004;9(1):57-8.

47. Magliocca JF, Magee JC, Rowe SA, Gravel MT, Chenault RH, 2nd, Merion RM, et al. Extracorporeal support for organ donation after cardiac death effectively expands the donor pool. The Journal of trauma. 2005 Jun;58(6):1095-101; discussion 101-2.

48. McCunn M, Reed AJ. Critical care organ support: a focus on extracorporeal systems. Current opinion in critical care. 2009 Dec;15(6):554-9.

49. Rudich SM, Arenas JD, Magee JC, Gravel MT, Chenault RH, 2nd, Kayler LK, et al. Extracorporeal support of the non-heart-beating organ donor. Transplantation. 2002 Jan 15;73(1):158-9.

50. Nunez JR, Del Rio F, Lopez E, Moreno MA, Soria A, Parra D. Non-heart-beating donors: an excellent choice to increase the donor pool. Transplantation proceedings. 2005 Nov;37(9):3651-4.

51. Lee CY, Tsai MK, Ko WJ, Chang CJ, Hu RH, Chueh SC, et al. Expanding the donor pool: use of renal transplants from non-heart-beating donors supported with extracorporeal membrane oxygenation. Clinical transplantation. 2005 Jun;19(3):383-90.

52. Farney AC, Singh RP, Hines MH, Rogers J, Hartmann EL, Reeves-Daniel A, et al. Experience in renal and extrarenal transplantation with donation after cardiac death donors with selective use of extracorporeal support. Journal of the American College of Surgeons. 2008 May;206(5):1028-37; discussion 37.

53. Wind J, Hoogland EP, van Heurn LE. Preservation techniques for donors after cardiac death kidneys. Current opinion in organ transplantation. 2011 Apr;16(2):157-61.

54. Tesi RJ, Elkhammas EA, Davies EA, Henry ML, Ferguson RM. Pulsatile kidney perfusion for evaluation of high-risk kidney donors safely expands the donor pool. Clinical transplantation. 1994 Apr;8(2 Pt 1):134-8.

55. Matsuno N, Konno 0, Mejit A, Jyojima Y, Akashi I, Nakamura Y, et al. Application of machine perfusion preservation as a viability test for marginal kidney graft. Transplantation. 2006 Dec 15;82(11):1425-8.

56. Baxby K, Taylor RM, Anderson M, Johnson RW, Swinney J. Assessment of cadaveric kidneys for transplantation. Lancet. 1974 Oct 26;2(7887):977-9.

57. Daemen JW, Oomen AP, Janssen MA, van de Schoot L, van Kreel BK, Heineman E, et al. Glutathione S-transferase as predictor of functional outcome in transplantation of machine-preserved non-heartbeating donor kidneys. Transplantation. 1997 Jan 15;63(1):89-93.

58. Gok MA, Pelsers M, Glatz JF, Bhatti AA, Shenton BK, Peaston R, et al. Comparison of perfusate activities of glutathione $S$-transferase, alanine aminopeptidase and fatty acid binding protein in the assessment of non-heart-beating donor kidneys. Annals of clinical biochemistry. 2003 May;40(Pt 3):252-8.

59. de Vries B, Snoeijs MG, von Bonsdorff L, Ernest van Heurn LW, Parkkinen J, Buurman WA. Redox-active iron released during machine perfusion predicts viability of ischemically injured deceased donor kidneys. Am J Transplant. 2006 Nov;6(11):2686-93.

60. Sonnenday CJ, Cooper M, Kraus E, Gage F, Handley C, Montgomery RA. The hazards of basing acceptance of cadaveric renal allografts on pulsatile perfusion parameters alone. Transplantation. 2003 Jun 27;75(12):2029-33.

61. Snoeijs MG, Buurman WA, Christiaans MH, van Hooff JP, Goldschmeding R, van Suylen RJ, et al. Histological assessment of preimplantation biopsies may improve selection of kidneys from old donors after cardiac death. Am J Transplant. 2008 Sep;8(9):1844-51.

62. Snoeijs MGJ, Boonstra LA, Buurman WA, Goldschmeding R, van Suylen RJ, van Heurn LWE, et al. Histological assessment of pre-transplant kidney biopsies is reproducible and representative. Histopathology. 2010 Jan;56(2):198-202. 


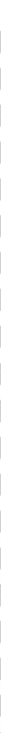


CHAPTER 2

OUTCOME OF KIDNEY
TRANSPLANTATIONS
FROM UNCONTROLLED

DONORS AFTER

CARDIAC DEATH

COMPARED WITH

CONTROLLED DONORS

AFTER CARDIAC DEATH 


\section{ABSTRACT}

Background: Kidney donation after cardiac death has been popularized over the last decade. The majority of these kidneys are from controlled donors. The number of organs for transplantation can be further increased by uncontrolled donors after cardiac death. The outcome of uncontrolled compared to controlled donor kidney transplantation is relatively unknown.

Methods: We compared the long-term outcome of kidney transplantation from uncontrolled $(\mathrm{N}=128)$ and controlled $(\mathrm{N}=208)$ donor kidneys procured in the Maastricht region from 01/01/1981 until 01/01/2008, and transplanted in the Eurotransplant region.

Results: The incidence of primary non-function and delayed graft function in both uncontrolled and controlled donor kidneys is relatively high ( $22 \%$ vs. $21 \%$, and $61 \%$ vs. $56 \%, p=0.43$, respectively). Ten-year graft and recipient survival are similar in both groups ( $50 \%$ vs. $46 \%, p=0.74$ and $61 \%$ vs. $60 \%, p=0.76$, respectively). Estimated glomerular filtration rates one year after transplantation are $40 \pm 16$ vs. $42 \pm 19 \mathrm{~mL} / \mathrm{min} / 1.73 \mathrm{~m} 2, \mathrm{p}=0.55$, with a yearly decline thereafter of $0.67 \pm 3$ vs. $0.70 \pm 7$ $\mathrm{mL} / \mathrm{min} / 1.73 \mathrm{~m} 2 /$ year, $\mathrm{p}=0.97$.

Conclusion: The outcome of kidney transplantation from uncontrolled and controlled donors after cardiac death is equivalent. This justifies the expansion of the donor pool with uncontrolled donors to reduce the still growing waiting list for renal transplantation, and may stimulate the implementation of uncontrolled kidney-donation programs.

\section{Published as}

E.R.P. Hoogland, M.G.J. Snoeijs, B. Winkens, M.H.L. Christiaans, L.W.E. van Heurn. Kidney Transplantation from Donors after Cardiac Death: Uncontrolled versus Controlled Donation. Am J Transplant 2011; 11(7): 1427-1434 


\section{INTRODUCTION}

Kidney transplantation is the treatment of choice for patients with end-stage renal disease, but its use is limited due to the shortage of organ donors (1). The number of patients on the waiting list for renal transplantation is still increasing while the number of donors after brain death remains stable. One method to expand the donor pool is by the use of organs from donors after cardiac death (2). These kidneys are increasingly used and recipients of these kidneys have comparable long-term survival rates as recipients of kidneys from brain-dead donors (3). Recently, it has been shown that for patients on dialysis, transplantation with a kidney from a donor after cardiac death results in a survival benefit compared to staying on dialysis and wait for a kidney from a brain-dead donor (4).

Kidneys from donors after cardiac death sustain an inevitable period of warm ischemia between cardiac arrest and flushing of the organs. This period of warm ischemic damage may result in higher incidences of primary non-function and delayed graft function. In controlled donation after cardiac death, organs are recovered after withdrawal of futile treatment. The donor characteristics are usually known and the warm ischemic injury to the organs can be estimated by the duration of the hypotensive period after the cessation of treatment and the period between cardiac arrest and the time that preservation of the organs has been started. In uncontrolled donation, donors die after failed resuscitation. There is a period without circulation, after which cardiopulmonary resuscitation is initiated. The period of circulatory arrest is usually not exactly known and the efficacy of cardiopulmonary resuscitation is difficult to assess. The relatively unknown extent of ischemic injury to uncontrolled donor kidneys and the unplanned fashion of its preservation and procurement has led to a general reluctance to use these kidneys for transplantation.

The pool of controlled donors after cardiac death is limited. Only a small proportion of intensive care patients, in whom further treatment is considered to be futile and who are not brain dead, meet donation criteria. The number of patients who die after failed resuscitation is much higher. Therefore, we assessed if this large donor potential could be safely used for renal transplantation to reduce the period on the waiting list for patients with end-stage renal disease. 


\section{MATERIALS AND METHODS}

\section{Study design}

Kidneys from donors after cardiac death, procured in the Maastricht region from 01/01/1981 until 01/01/2008 were included in the current observational study. Patients were followed until the earliest of death or 01/01/2009. The initial function and the long-term graft and recipient survival of the included uncontrolled and controlled donor kidneys transplanted within the Eurotransplant region were assessed.

\section{Data sources and definitions}

Data on all kidney transplantations from donors after cardiac death were extracted from our periodically updated database. Patient follow-up information was submitted by the transplant centers on a regular basis. Missing data were supplemented by chart review at the transplant center at the request of the study coordinator. In the controlled group, five patients ( $2.5 \%)$ were lost to follow-up after a minimum follow-up period of 0.4 years, of whom all had experienced graft loss. One patient $(0.8 \%)$ was lost to follow-up in the uncontrolled group after a followup period of 5.8 years with a functioning graft. Patient data were collected, stored and used in agreement with the code of conduct 'Use of data in health research' put forward by the federation of Dutch medical scientific societies (http://www.federa. org/).

Warm ischemia time in uncontrolled donors is defined as the time between cessation of cardiopulmonary resuscitation and the start of organ perfusion. For controlled donors, warm ischemia time is defined as the time from cardiac arrest (no arterial pulse) to the start of organ perfusion. Both include the obligatory notouch period of five minutes. Graft function in the early postoperative period was defined as 1) immediate function, without the need for dialysis treatment after transplantation, 2) delayed graft function, temporary dialysis treatment initiated in the first week after transplantation and 3) primary non-function, inadequate renal function, necessitating continuation of dialysis treatment or re-transplantation.

Renal function after transplantation was assessed using the estimated glomerular filtration rate which was calculated with the abbreviated Modification of Diet in Renal Disease equation (5-7). Estimated glomerular filtration rate at one year after transplantation and the rate of decline in estimated glomerular filtration rate thereafter were studied as measures of kidney function. Graft failure, censored for death, was defined as permanent return to dialysis treatment or retransplantation.

Expanded criteria donors (ECD) were defined as any donor aged 60 years or older or over 50 years old with at least two of the following risk factors: hypertension history, serum creatinine $>130 \mathrm{mmol} / \mathrm{mL}$, or death caused by cerebrovascular accident (8). 


\section{Management of donors after cardiac death}

Kidneys from uncontrolled donors included Maastricht category II kidneys only (Table 2.1). The donor criteria for uncontrolled donation during the study period are listed in Table 2.2. Organs were preserved with the in situ preservation technique, described previously (9). In short, after unsuccessful resuscitation and an obligatory no-touch period of five minutes, during which no interventions to the donor were taken, a double-balloon triple-lumen catheter was inserted into the aorta via one of the femoral arteries, followed by in situ preservation of the donor kidneys with histidine-tryptophan-ketoglutarate solution (Custodiol, Dr. Franz Köhler Chemie, Alsbach, Germany) with heparin $300 \mathrm{IE} / \mathrm{kg}$ and occasionally streptokinase added to the preservation fluid (Chapter 1, Figure 1.1A) $(10,11)$. This technique is minimally invasive, can be performed in the emergency department and allows fast and effective organ preservation by surgeons with limited experience in donation procedures. After preservation and consent for organ donation, the organs were procured in the operating room.

Controlled donor kidneys included only Maastricht category III kidneys after withdrawal of futile medical treatment (Table 2.1). This gives the donation-staff the opportunity to schedule the procedure and to meet legal and logistic requirements before organ recovery. Withdrawal of life support took place in the intensive care unit (ICU). After cardiac arrest and the no-touch period, organs were either preserved in the intensive care unit with a double-balloon triple-lumen catheter, or the deceased was immediately transported to the operating room, where prepared surgical staff was waiting. A rapid laparotomy and direct cannulation of the aorta was then performed and organs were procured afterwards. The maximum time between withdrawal of life support (ventilator switch-off) and cardiac arrest was set at two hours.

Maastricht categories of donation after cardiac death

\begin{tabular}{lll}
\hline Category & Definition & Type \\
\hline 1 & Dead on arrival & Uncontrolled \\
\hline 2 & Unsuccessful resuscitation & Uncontrolled \\
\hdashline 3 & Awaiting cardiac arrest & Controlled \\
\hdashline 4 & Cardiac arrest while brain dead & Controlled / Uncontrolled \\
\hline
\end{tabular}

Following recovery, most of the kidneys were machine perfused $(82 \%$ vs. $84 \%$ for uncontrolled and controlled donors, respectively), initially, on a Gambro PF-3B machine and after 2006, on a Lifeport (Organ Recovery Systems, Des Plaines, IL). Preservation fluids used included Eurocollins before $1985(\mathrm{~N}=8)$ and University of Wisconsin machine perfusion solution (UW-MPS) since 1985 (12).

Kidneys were allocated by Eurotransplant, according to the Kidney Allocation System and consequently transplanted in the Eurotransplant region (13). 
Donor criteria for uncontrolled donation after cardiac death.

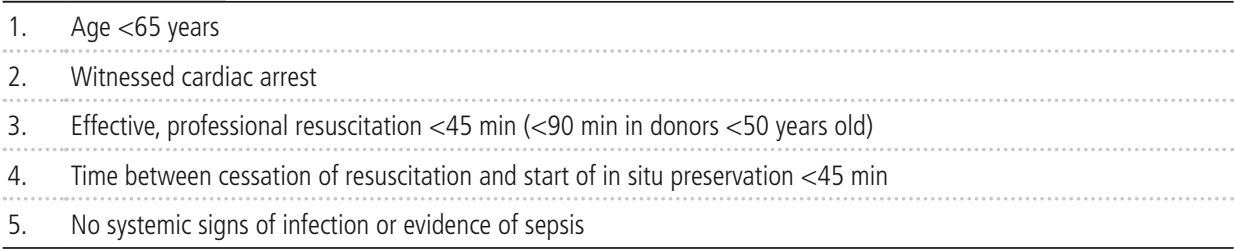

\section{Statistical analysis}

Continuous variables are presented as means \pm standard deviations (SD) if normally distributed (histogram), and as median and inter-quartile range otherwise. Categorical variables are presented as percentages. Baseline donor, preservation and recipient characteristics are compared between donor types (uncontrolled vs. controlled) with the independent-samples t-tests for approximately normally distributed continuous variables, with the Mann-Whitney U-tests if the distribution clearly deviated from normality and with chi-square tests for categorical variables. The rate of decline in estimated glomerular filtration rate is calculated for each patient by simple linear regression from yearly glomerular filtration rate estimates, starting at one year after transplantation. The difference in mean estimated glomerular filtration rate was tested using the independent-samples t-test.

Graft and patient survival are calculated with the Kaplan-Meier method; the log-rank test was used to compare the survival curves between donor types.

The effects of donor type and other potential risk factors on PNF were tested with univariate logistic regression analysis. All clinically relevant potential risk factors associated with PNF were selected for further analysis in a multivariate logistic regression model, with correction for those characteristics that are considered to be potential confounders, defined by the $10 \%$ change-in-estimate rule (14). Similarly, Cox-regression analyses were performed to assess the effect of donor type on recipient survival and to identify potential risk factors associated with graft failure.

Additionally, a subgroup analysis was done for standard criteria donors (SCD) versus expanded criteria donors (ECD) and their relation with PNF.

All analyses were performed using Statistical Package for the Social Sciences (SPSS) software version 15.0 for Windows, and a $p$-value $\leq 0.05$ was considered statistically significant. 


\section{RESULTS}

From 01/01/1981 until 01/01/2008, 535 kidneys from donors after cardiac death (267 uncontrolled and 268 controlled) were procured in the Maastricht region, of which 174 (129 uncontrolled and 45 controlled) from 111 donors were discarded. Twenty-two kidneys were transplanted outside the Eurotransplant region. From 3 recipients, no data was available. The remaining 336 kidneys (128 uncontrolled and 208 controlled) transplanted in the Eurotransplant region entered analyses. Kidneys from 5 controlled donors were transplanted en bloc and were analyzed as one single kidney.

\section{Baseline characteristics of uncontrolled and controlled kidney donation and transplantations}

Hundred twenty-nine (48\%) kidneys were discarded in the uncontrolled group versus $45(17 \%)$ in the controlled group ( $p<0.001)$. Reasons for discard were often multifactorial, including poor flush out, unfavorable donor characteristics, anatomical variations, surgical damage of the kidney or if no suitable recipients were available (9). Donors of discarded kidneys were not significantly different in the uncontrolled and the controlled group for age ( $51 \pm 12$ vs. $56 \pm 12, \mathrm{p}=0.11)$ and warm ischemia time (32 \pm 15 vs. $34 \pm 13, p=0.56$ ).

The donor, graft and recipient characteristics of transplanted kidneys are presented in Table 2.3. The warm ischemia time was similar in uncontrolled and controlled donors $(25 \pm 14$ vs. $25 \pm 10$ minutes respectively, $\mathrm{p}=0.96)$. Uncontrolled donors had more often a cardiac cause of death and organs were always preserved with the double-balloon triple-lumen catheter $(100 \%$ vs. $88 \%$ in controlled donors, $\mathrm{p}=0.001)$. Uncontrolled donors had a significantly higher serum creatinine (124 \pm 39 vs. $86 \pm 33, p<0.001$ ), however, the relevance of this finding is limited as blood samples were usually taken after the initiation of CPR.

Recipient characteristics were not significantly different for age, sex, anastomosis time and HLA-mismatches. Recipients of controlled kidneys more often received induction therapy ( $21 \%$ vs. $9 \%, p=0.003)$ and mycophenolate mofetil $(54 \%$ vs. $23 \%, p<0.001)$. The cold ischemia time was shorter in the controlled donation group ( $26 \pm 7$ vs. $28 \pm 6$ hours, $p=0.02$ ) and dialysis time was longer ( $4 \pm 3$ vs. 3 \pm 3 years, $\mathrm{p}=0.02$ ) (Table 2.3). Controlled $D C D$ kidneys were significantly less often transplanted at our unit $(41 \%$ vs. $64 \%, \mathrm{p}<0.001)$. All kidneys were allocated to a total of 26 centers throughout the Eurotransplant region. 


\begin{tabular}{|c|c|c|c|}
\hline \multirow[t]{2}{*}{ Table 2.3} & \multicolumn{3}{|c|}{ uncontrolled and controlled kidney } \\
\hline & $\begin{array}{l}\text { Uncontrolled } \\
(\mathrm{N}=83)^{\mathrm{b}}\end{array}$ & $\begin{array}{l}\text { Controlled } \\
(\mathrm{N}=111)^{\mathrm{b}}\end{array}$ & $p$ \\
\hline \multicolumn{4}{|l|}{ Donor characteristics } \\
\hline Age (years) & $46 \pm 15$ & $46 \pm 17$ & 0.84 \\
\hline Sex (male / female) & $72 / 28 \%$ & $60 / 40 \%$ & 0.08 \\
\hline Cause of death (cardiovascular / other) & $75 / 25 \%$ & $2 / 98 \%$ & $<0.001$ \\
\hline Serum creatinine $(\mu \mathrm{mol} / \mathrm{L})^{c}$ & $124 \pm 39$ & $86 \pm 33$ & $<0.001$ \\
\hline Hypertension (yes / no) & $11 / 89 \%$ & $15 / 85 \%$ & 0.47 \\
\hline Donor BMI (kg/m2) & $26 \pm 3(N=21)$ & $25 \pm 3(N=39)$ & 0.22 \\
\hline \multicolumn{4}{|l|}{ Preservation characteristics } \\
\hline CPR time $(\min )^{d}$ & $44 \pm 25$ & - & - \\
\hline Ventilator switch-off time (min)e & - & $20(14-47)$ & - \\
\hline Warm ischemia time $(\min )^{f}$ & $25 \pm 14$ & $25 \pm 10$ & 0.96 \\
\hline \multirow[t]{2}{*}{ Preservation technique (ISP / aorta cannulation) } & $100 / 0 \%$ & $88 / 12 \%$ & 0.001 \\
\hline & $N=128^{g}$ & $N=203^{g}$ & $P$ \\
\hline Preservation type (cold storage / machine perfusion) & $18 / 82 \%$ & $16 / 84 \%$ & 0.59 \\
\hline Cold ischemia time (hours) & $28 \pm 6$ & $26 \pm 7$ & 0.02 \\
\hline Anastomosis time (min) & $39 \pm 14$ & $39 \pm 16$ & 0.99 \\
\hline Standard vs. expanded criteria donor kidneys & $79 / 21 \%$ & $77 / 23 \%$ & 0.92 \\
\hline \multicolumn{4}{|l|}{ Recipient characteristics } \\
\hline Age & $51 \pm 13$ & $51 \pm 13$ & 0.98 \\
\hline Sex (male / female) & $68 / 32 \%$ & $65.5 / 34.5 \%$ & 0.68 \\
\hline $\mathrm{BMI}(\mathrm{kg} / \mathrm{m} 2)$ & $24 \pm 3(N=61)$ & $25 \pm 4(N=59)$ & 0.42 \\
\hline Transplant center (regional / export) & $64 / 36 \%$ & $41 / 59 \%$ & $<0.001$ \\
\hline \multicolumn{4}{|l|}{ Transplantation year } \\
\hline $1981-1989$ & $13 \%$ & $9 \%$ & \\
\hline $1990-1998$ & $40 \%$ & $22 \%$ & $<0.001$ \\
\hline $1999-2007$ & $47 \%$ & $69 \%$ & \\
\hline Kidney (single / double) & $100 / 0 \%$ & $97.5 / 2.5 \%$ & 0.07 \\
\hline Kidney disease (renovascular / other) & $16 / 84 \%$ & $26 / 74 \%$ & 0.05 \\
\hline Dialysis time (years) & $3 \pm 3$ & $4 \pm 3$ & 0.02 \\
\hline Dialysis type (haemodialysis / peritoneal dialysis) & $68 / 32 \%$ & $62 / 38 \%$ & 0.30 \\
\hline Retransplantation (yes / no) & $12 / 88 \%$ & $14 / 86 \%$ & 0.56 \\
\hline Total HLA mismatches & $2.44 \pm 1.0$ & $2.54 \pm 1.12$ & 0.43 \\
\hline Peak panel reactive antibody (PRA) & $3.8 \pm 12.6$ & $2.1 \pm 10.7$ & 0.37 \\
\hline Calcineurin inhibitor (cyclosporine / tacrolimus) & $43.5 / 56.5 \%$ & $34 / 66 \%$ & 0.11 \\
\hline $\begin{array}{l}\text { Anti-metabolite (azathioprine / mycophenolate } \\
\text { mofetil / none) }\end{array}$ & $18 / 23 / 59 \%$ & $10 / 54 / 36 \%$ & $<0.001$ \\
\hline Sirolimus (yes / no) & $22 / 78 \%$ & $15 / 85 \%$ & 0.10 \\
\hline Induction therapy (yes / no) & $9 / 91 \%$ & $21 / 79 \%$ & 0.003 \\
\hline Follow-up time (years) & $7.9 \pm 5.8$ & $6.1 \pm 4.9$ & 0.004 \\
\hline
\end{tabular}




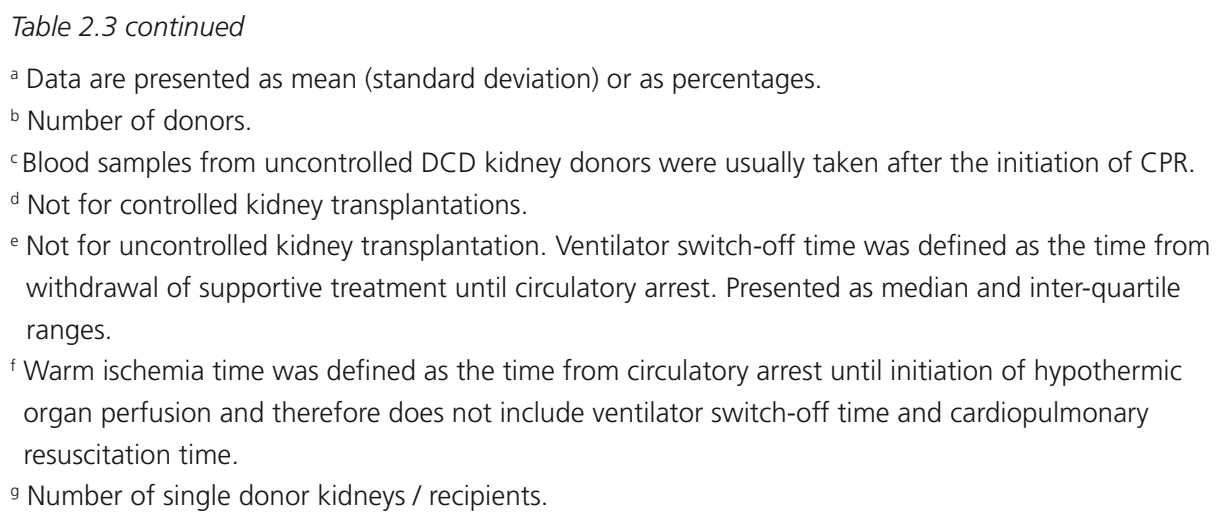

\section{Clinical outcome}

The short-term graft function was similar in the uncontrolled and controlled group (primary non-function: $22 \%$ vs. $21 \%$, delayed graft function: $61 \%$ vs. $56 \%$, immediate function; $17 \%$ vs. $23 \%$, respectively, $\mathrm{p}=0.43$ ).

The estimated glomerular filtration rates of functioning kidneys were comparable in the uncontrolled and controlled group; $37 \pm 16 \mathrm{~mL} / \mathrm{min} / 1.73 \mathrm{~m} 2$ in both groups at 3 months after transplantation $(p=0.96), 40 \pm 16 \mathrm{~mL} / \mathrm{min} / 1.73 \mathrm{~m} 2$ vs. $42 \pm 19$ $\mathrm{mL} / \mathrm{min} / 1.73 \mathrm{~m} 2$ at 1 year $(p=0.55)$ with a yearly decline thereafter of $0.67 \pm 3.1 \mathrm{~mL} /$ $\mathrm{min} / 11.73 \mathrm{~m} 2 /$ year vs. $0.70 \pm 6.9 \mathrm{~mL} / \mathrm{min} / 1.73 \mathrm{~m} 2 /$ year $(p=0.97)$, respectively.

The incidence of PNF in both uncontrolled and controlled DCD kidneys was relatively high due to a liberal acceptance policy. We analyzed the effect of donor type and other potential risk factors for PNF in a multivariate logistic regression model (Table 2.4). Donor type had no significant influence on PNF (OR $0.900,95 \% \mathrm{Cl}$ $0.493-1.644, p=0.73$ ). Increasing warm ischemia time (OR $1.038,95 \% \mathrm{Cl} 1.012-1.065$, $\mathrm{p}=0.004$ ), cold ischemia time (OR $1.046,95 \% \mathrm{Cl} 1.002-1.092, \mathrm{p}=0.04$ ), increasing donor age (OR $1.024,95 \% \mathrm{Cl} 1.002-1.046, \mathrm{p}=0.03)$ and immunosuppressive therapy (OR 1.919, 95\% Cl $1.059-3.476, p=0.03$ ) were independent predictors of PNF.

Graft survival did not significantly differ between both groups with a deathcensored 5 and 10 year graft survival of $63 \%$ vs. $64 \%$ and $50 \%$ vs. $46 \%$ (log-rank $\mathrm{p}=0.74$ ), for uncontrolled and controlled donor kidneys, respectively (Figure 2.1A). The 5 and 10 year recipient survival of the respective groups was $78 \%$ vs. $80 \%$ and $61 \%$ vs. $60 \%$ (log-rank $p=0.76$, Figure $2.1 \mathrm{~B}$ ). In the Cox-regression analysis, only donor age was a risk factor for graft failure (HR 1.016, $95 \% \mathrm{Cl} 1.004-1.027, \mathrm{p}=0.007)$. Donor type had no influence on graft survival (HR $0.670,95 \% \mathrm{Cl} 0.670-1.336, \mathrm{p}=0.75)$ and recipient survival (HR 1.008, 95\% Cl $0.697-1.460, \mathrm{p}=0.96$ ) (data not shown).

The number of SCD kidneys and ECD kidneys was similar in both groups (Table 2.3). A subgroup analysis between SCD and ECD kidneys showed no difference 
in the percentage of PNF for controlled donor kidneys (19\% vs. $26 \%$, respectively, $\mathrm{p}=0.32$ ). For the uncontrolled donor kidneys, ECD kidneys had a significantly higher risk on PNF compared to SCD kidneys ( $37 \%$ vs. $17 \%$, respectively, $\mathrm{p}=0.03$ ).

Logistic regression analysis of risk factors for primary non-function

\begin{tabular}{|c|c|c|c|c|}
\hline & \multicolumn{2}{|l|}{ Univariate analysis } & \multicolumn{2}{|l|}{ Multivariate analysis } \\
\hline & OR $(95 \% \mathrm{Cl})$ & $p$ & OR $(95 \% \mathrm{Cl})$ & $\mathrm{p}$ \\
\hline \multicolumn{5}{|l|}{ Donor characteristics } \\
\hline Donor type & $1.071(0.624-1.837)$ & 0.80 & $0.900(0.493-1.644)$ & 0.73 \\
\hline Age & $1.024(1.005-1.043)$ & 0.01 & $1.024(1.002-1.046)$ & 0.03 \\
\hline Sex (male / female) & $0.876(0.506-1.515)$ & 0.64 & & \\
\hline Serum creatinine $(\mathrm{mmol} / \mathrm{mL})$ & $1.001(0.994-1.007)$ & 0.85 & & \\
\hline Hypertension (yes / no) & $2.059(0.974-4.332)$ & 0.06 & & \\
\hline \multicolumn{5}{|l|}{ Preservation characteristics } \\
\hline Warm ischemia time (min) & $1.013(1.007-1.056)$ & 0.01 & $1.038(1.012-1.065)$ & 0.004 \\
\hline $\begin{array}{l}\text { Preservation technique (ISP / aorta } \\
\text { cannulation) }\end{array}$ & $2.366(0.693-8.077)$ & 0.17 & & \\
\hline $\begin{array}{l}\text { Preservation type (cold storage / } \\
\text { machine perfusion) }\end{array}$ & $0.510(0.219-1.188)$ & 0.12 & & \\
\hline Cold ischemia time (hours) & $1.030(0.989-1.072)$ & 0.15 & $1.046(1.002-1.092)$ & 0.04 \\
\hline Anastomosis time (min) & $1.016(1.000-1.033)$ & 0.05 & $1.017(1.000-1.034)$ & 0.06 \\
\hline \multicolumn{5}{|l|}{ Recipient characteristics } \\
\hline Age & $1.027(1.005-1.049)$ & 0.02 & & \\
\hline Sex (male / female) & $1.236(0.698-2.190)$ & 0.47 & & \\
\hline Transplant center (regional / export) & $0.909(0.536-1.541)$ & 0.72 & & \\
\hline Transplantation year ${ }^{\mathrm{a}}$ & $1.011(0.970-1.053)$ & 0.61 & & \\
\hline $1981-1989$ & $35(11 \%)$ & & & \\
\hline $1990-1998$ & $96(29 \%)$ & & & \\
\hline $1999-2007$ & $200(60 \%$ & & & \\
\hline Kidney disease (renovascular / other) & $0.867(0.427-1.761)$ & 0.69 & & \\
\hline Dialysis time (years) & $1.016(0.928-1.113)$ & 0.73 & & \\
\hline $\begin{array}{l}\text { Dialysis type (haemodialysis / peritoneal } \\
\text { dialysis }\end{array}$ & $0.944(0.540-1.649)$ & 0.84 & & \\
\hline Retransplantation (yes / no) & $1.207(0.561-2.598)$ & 0.63 & & \\
\hline Total HLA mismatches & $1.077(0.839-1.382)$ & 0.56 & & \\
\hline Peak panel reactive antibody (PRA) & $0.992(0.953-1.033)$ & 0.71 & & \\
\hline $\begin{array}{l}\text { Calcineurin inhibitor (cyclosporine / } \\
\text { tacrolimus) }\end{array}$ & $0.799(0.447-1.428)$ & 0.45 & & \\
\hline Anti-metabolite (yes) & $0.471(0.275-0.806)$ & 0.006 & $1.919(1.059-3.476)$ & 0.03 \\
\hline Sirolimus (yes / no) & $1.383(0.716-2.670)$ & 0.33 & & \\
\hline Induction therapy (yes / no) & $1.942(1.016-3.711)$ & 0.045 & & \\
\hline
\end{tabular}

${ }^{a}$ As continuous variable. 
When thirteen controlled DCD donors which were preserved with rapid laparotomy and direct cannulation of the aorta (26 kidneys) were excluded from analysis, the short and long-term graft function of controlled DCD kidneys remained equivalent as previously and there were still no significant differences with uncontrolled DCD kidney transplantation. However, the p-value of cold ischemia as an independent risk factor for kidney failure increased to 0.07 , which may be due to the smaller number of kidneys in this analysis (data not shown).
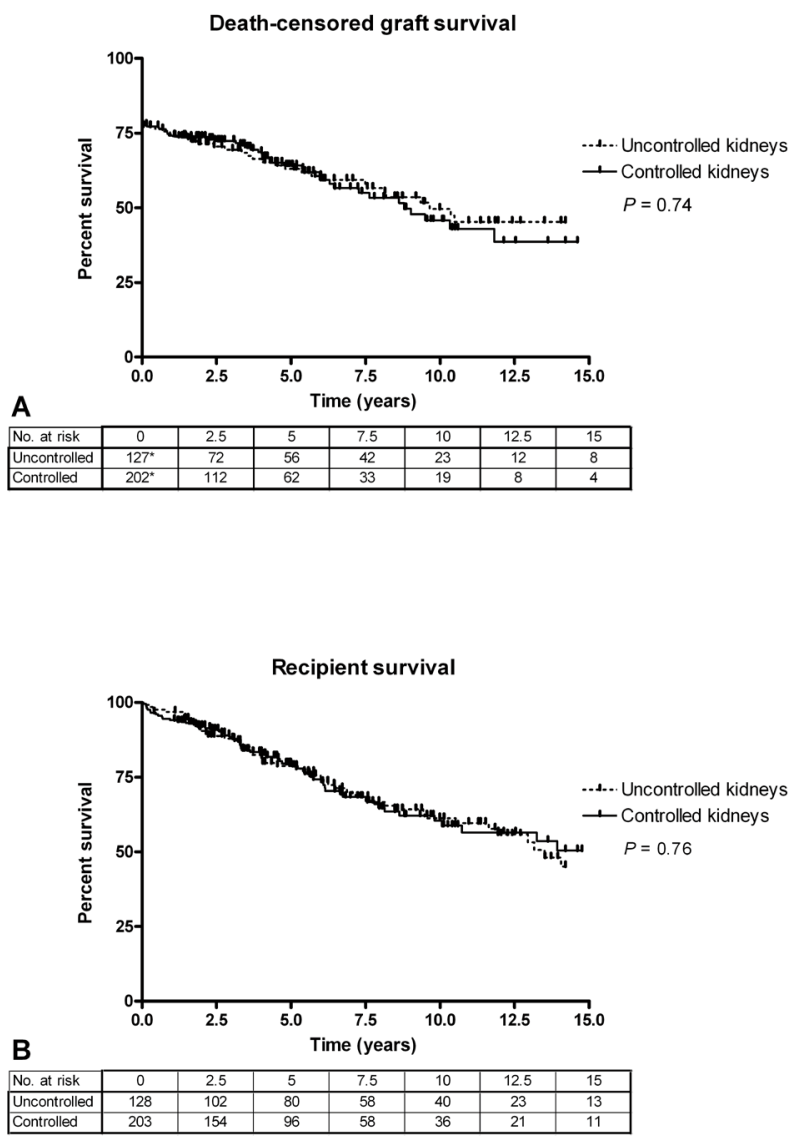

Figure 2.1 Kaplan-Meier curves of uncontrolled and controlled kidney transplantation for (A) deathcensored graft survival and (B) recipient survival of all kidneys.

* One recipient died with an unknown graft function and was excluded from the Kaplan-Meier analysis. 


\section{DISCUSSION}

According to the National Organ Procurement and Transplantation Network (OPTN) in the United States, the total number of candidates waitlisted for a kidneyalone transplantation at the beginning of 2010 rose to 83 321. The United States Renal Data System reported that Medicare spent $\$ 18.5$ billion on the treatment of dialysis patients in 2007. In addition, Medicare pays billions each year for the hospitalization of dialysis patients. Despite the costs, a substantial proportion of dialysis patients die every year. In 2006, $20.1 \%$ of U.S. dialysis patients died, most often of heart disease or infections. In the U.S. and the largest part of Europe, where brain death is legally and culturally acceptable, most donor kidneys are recovered from braindead donors (15). Efforts to increase the number of organ donors have resulted in increases both in living donation and use of deceased donors at the extremes of age (16). Although the use of donors after cardiac death has been popularized in the past decade, the number of organ donors is not sufficient to shorten the waiting list. In the Netherlands, almost $50 \%$ of the deceased donors are donors after cardiac death, which has led to a stable number of deceased organ donors, despite the reduction of brain-dead donors.

In our series, the threshold to discard kidneys is relatively high and therefore the percentage of kidneys from donors after cardiac death with delayed graft function and primary non-function is higher than that of brain-dead donor kidneys. However, the long-term graft survival of functioning kidneys is similar to kidneys from braindead donors and also the recipient survival does not differ (3). Moreover, delayed graft function in kidneys from donors after cardiac death does not adversely affect graft survival as in brain-dead donor grafts (17). Recently it has been shown that, despite the relatively high incidence of never functioning grafts, waitlisted patients who receive a kidney from a donor after cardiac death live longer than patients who continue dialysis treatment with the option of later receiving a brain-dead donor kidney transplantation (4). This justifies a more widespread use of donation after cardiac death.

The pool of controlled donors is relatively small, compared to the potential pool of uncontrolled donors. In the United States, the United Kingdom, and in the Netherlands, most donors after cardiac death are controlled donors. In southern Europe, uncontrolled donation has been increasingly used since 1989 (18). The results of centers in Spain are very promising, but information about the comparison with controlled donation is very limited (19-21). In our center we have used both controlled and uncontrolled donors after cardiac death since 1981. However, as the long-term outcome of uncontrolled compared to controlled donation remained unknown, the use of uncontrolled donor kidneys was relatively limited and nephrologists were reluctant to accept these kidneys for transplantation.

Further obstacles to initiate uncontrolled donor programs include legislation which differs per country, and the relatively complicated infrastructure required to recognize uncontrolled donors and to preserve and procure the organs. Potential 
donors have to be recognized on the streets by the ambulance crew and to be taken to the hospital where trained surgical staff is available to preserve the organs at every moment. In the Netherlands, the law has been changed to allow minimally invasive procedures to preserve potential uncontrolled donor kidneys, prior to consent from relatives.

The insertion of a double-balloon triple-lumen catheter is a minor surgical procedure, but carries a relatively large incidence of complications such as catheter malposition and poor perfusion of the organs, particularly if done by inexperienced doctors. This partly explains the high percentage of discarded uncontrolled kidneys in this study, as in situ preservation in uncontrolled donors is usually done by junior staff. For controlled DCD donors, rapid laparotomy and direct aortic cannulation can be arranged and should be preferred to ISP because it is associated with reduced warm ischemia times, lower discard rate and superior graft survival. Moreover, organs other than kidneys may be procured by this technique (9). In the present series, in only $12 \%$ of the controlled DCD donors, direct aortic cannulation was used. Direct aortic cannulation became the preservation technique of choice since 2006, after introduction of DCD multi organ donation. In donors after cardiac death, warm ischemic damage is the most crucial factor for transplant outcome. In controlled donors, the warm ischemic injury can be estimated from the hypotensive period prior to cardiac death and the period between death and organ preservation. For uncontrolled donors it is difficult to quantify warm ischemic damage. The moment of cardiac arrest is often not exactly known and organ perfusion during resuscitation varies widely. Machine perfusion characteristics and organ viability markers have not been shown to reliably estimate warm ischemic damage and viability of the kidneys $(22,23)$. Therefore, we have used the criteria set in Table 2.2 to accept uncontrolled donor kidneys for transplantation. However, these criteria differ between institutions and depend on resuscitation and preservation methods. Selecting expanded criteria uncontrolled donors should be done with extreme caution, since these kidneys are related with a high risk of PNF. Advances in resuscitation, such as portable automated chest compression devices and the use of extracorporeal membrane oxygenation, may improve organ perfusion during resuscitation or after cardiac death and widen the criteria for donation and increase the number of donors, but are ethically controversial (24).

This study demonstrates that the initial function and long-term outcome of kidneys from uncontrolled donors after cardiac death is comparable with the outcome of kidneys from controlled donors. The majority of the controlled DCD kidneys were preserved with the DBTL-catheter. Future studies with large populations may determine whether direct aortic cannulation improves the results of controlled DCD transplantation. For both groups, a careful selection of both donor kidneys and recipients remains mandatory to reduce the risk of non-functioning grafts. These results justify the expansion of the donor pool with uncontrolled donors to reduce the still growing waiting list for renal transplantations and may stimulate the implementation of uncontrolled kidney donation programs. 


\section{REFERENCES}

1. Wolfe RA, Ashby VB, Milford EL, Ojo AO, Ettenger RE, Agodoa LY, et al. Comparison of mortality in all patients on dialysis, patients on dialysis awaiting transplantation, and recipients of a first cadaveric transplant. N Engl J Med. 1999 Dec 2;341(23):1725-30.

2. Kootstra G, Daemen JH, Oomen AP. Categories of non-heart-beating donors. Transplantation proceedings. 1995 Oct;27(5):2893-4.

3. Barlow AD, Metcalfe MS, Johari Y, Elwell R, Veitch PS, Nicholson ML. Case-matched comparison of longterm results of non-heart beating and heart-beating donor renal transplants. The British journal of surgery. 2009 Jun;96(6):685-91.

4. Snoeijs MG, Schaubel DE, Hene R, Hoitsma AJ, Idu MM, ljzermans JN, et al. Kidneys from donors after cardiac death provide survival benefit. J Am Soc Nephrol. 2010 Jun;21(6):1015-21.

5. Gera M, Slezak JM, Rule AD, Larson TS, Stegall MD, Cosio FG. Assessment of changes in kidney allograft function using creatinine-based estimates of glomerular filtration rate. Am J Transplant. 2007 Apr;7(4):8807.

6. Poge U, Gerhardt T, Palmedo H, Klehr HU, Sauerbruch T, Woitas RP. MDRD equations for estimation of GFR in renal transplant recipients. Am J Transplant. 2005 Jun;5(6):1306-11.

7. Stevens LA, Coresh J, Greene T, Levey AS. Assessing kidney function--measured and estimated glomerular filtration rate. N Engl J Med. 2006 Jun 8;354(23):2473-83.

8. Metzger RA, Delmonico FL, Feng S, Port FK, Wynn JJ, Merion RM. Expanded criteria donors for kidney transplantation. Am J Transplant. 2003;3 Suppl 4:114-25.

9. Snoeijs MG, Dekkers AJ, Buurman WA, van den Akker L, Welten RJ, Schurink GW, et al. In situ preservation of kidneys from donors after cardiac death: results and complications. Annals of surgery. 2007 Nov;246(5):844-52.

10. Heineman E, Daemen JH, Kootstra G. Non-heart-beating donors: methods and techniques. Transplantation proceedings. 1995 Oct;27(5):2895-6; discussion 6-7.

11. Kootstra G, Kievit JK, Heineman E. The non heart-beating donor. British medical bulletin. 1997;53(4):84453.

12. Moers C, Smits JM, Maathuis MH, Treckmann J, van Gelder F, Napieralski BP, et al. Machine perfusion or cold storage in deceased-donor kidney transplantation. N Engl J Med. 2009 Jan 1;360(1):7-19.

13. Keizer KM, de Fijter JW, Haase-Kromwijk BJ, Weimar W. Non-heart-beating donor kidneys in the Netherlands: allocation and outcome of transplantation. Transplantation. 2005 May 15;79(9):1195-9.

14. Maldonado G, Greenland S. Simulation study of confounder-selection strategies. American journal of epidemiology. 1993 Dec 1;138(11):923-36.

15. The Organ Procurement and Transplantation Network. Available at http://www.optn.org. Accessed February 25, 2010.

16. Snoeijs MG, Schaefer S, Christiaans MH, van Hooff JP, van den Berg-Loonen PM, Peutz-Kootstra CJ, et al. Kidney transplantation using elderly non-heart-beating donors: a single-center experience. Am J Transplant. 2006 May;6(5 Pt 1):1066-71.

17. Renkens JJ, Rouflart MM, Christiaans MH, van den Berg-Loonen EM, van Hooff JP, van Heurn LW. Outcome of nonheart-beating donor kidneys with prolonged delayed graft function after transplantation. Am J Transplant. 2005 Nov;5(11):2704-9.

18. Sanchez-Fructuoso Al, Prats D, Torrente J, Perez-Contin MJ, Fernandez C,Alvarez J, et al. Renal transplantation from non-heart beating donors: a promising alternative to enlarge the donor pool. J Am Soc Nephrol. 2000 Feb;11(2):350-8.

19. Sanchez-Fructuoso Al. Kidney transplantation from non-heart-beating donors. Transplantation proceedings. 2007 Sep;39(7):2065-7.

20. Fieux F, Losser MR, Bourgeois E, Bonnet F, Marie O, Gaudez F, et al. Kidney retrieval after sudden out of hospital refractory cardiac arrest: a cohort of uncontrolled non heart beating donors. Critical care (London, 
England). 2009;13(4):R141.

21. Gok MA, Asher JF, Shenton BK, Rix D, Soomro NA, Jaques BC, et al. Graft function after kidney transplantation from non-heartbeating donors according to maastricht category. The Journal of urology. 2004 Dec;172(6 Pt 1):2331-4.

22. de Vries B, Snoeijs MG, von Bonsdorff L, Ernest van Heurn LW, Parkkinen J, Buurman WA. Redox-active iron released during machine perfusion predicts viability of ischemically injured deceased donor kidneys. Am J Transplant. 2006 Nov;6(11):2686-93.

23. Sonnenday CJ, Cooper M, Kraus E, Gage F, Handley C, Montgomery RA. The hazards of basing acceptance of cadaveric renal allografts on pulsatile perfusion parameters alone. Transplantation. 2003 Jun 27;75(12):2029-33.

24. Hoogland ER, Snoeijs MG, van Heurn LW. DCD kidney transplantation: results and measures to improve outcome. Current opinion in organ transplantation. 2010 Apr;15(2):177-82. 


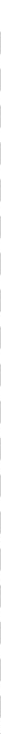


CHAPTER 3

WHICH KIDNEYS FROM

UNCONTROLLED

DONORS AFTER

CARDIAC DEATH DO

WORSE? 


\section{ABSTRACT}

Background: Kidneys from uncontrolled donors after cardiac death (DCD) expand the donor pool, but are associated with more primary non-function (PNF) and delayed graft function (DGF) compared with more conventional donor kidneys. It remains unclear, which factors influence outcome of uncontrolled donation. Therefore, we studied which donor, graft, and recipient characteristics are associated with PNF in a large cohort study.

Methods: The association between different characteristics and short-term graft-function was analyzed for kidneys procured in the Maastricht region from 1 January 1981 until 1 July 2009. Patients were followed until 1 July 2010.

Results: A total of 135 uncontrolled donor kidneys were included in this study. The incidence of PNF and DGF was $22 \%$ and $61 \%$, respectively. Increasing donor age is an independent risk factor for graft failure in a univariate analysis (OR 1.035, $95 \% \mathrm{Cl} 1.004-1.068, \mathrm{p}=0.028$ ). Donor age remains strongly associated with PNF in a multivariate analysis (OR 1.064, 95\% CI 1.013-1.118, $\mathrm{p}=0.014$ ). However, the predictive value of donor age alone is poor (AURC $0.640,95 \% \mathrm{Cl} 0.553-0.721$ ).

Conclusion: Increasing donor age of uncontrolled DCD donors is a major risk factor for PNF. Other clinically relevant variables were not associated with PNF. Donor age is strongly associated with PNF and remains an important parameter in donor selection.

\section{Published as}

E.R. Pieter Hoogland, Tim C. van Smaalen, Maarten H.L. Christiaans, L.W. Ernest van Heurn. Kidneys from uncontrolled donors after cardiac death: which kidneys do worse? Transpl Int 2013;26(5):477-84 


\section{INTRODUCTION}

In the past decades, kidney transplantation using organs obtained from donors after cardiac death (DCD) has gained popularity and a wider acceptance in many countries as a valuable tool to decrease the waiting time for kidney transplantation (1-3). Most DCD kidney donation programs only include kidneys from controlled DCD donors, donors who died after withdrawal of futile medical treatment. Uncontrolled DCD donation has not yet obtained the same wide acceptance, but its use is increasing.

In uncontrolled donors, donors who die after failed resuscitation, the period between circulatory arrest and organ preservation is often not exactly known and the efficacy of cardiopulmonary resuscitation is difficult to assess. Therefore, these kidneys are exposed to unknown ischemic injury during the inevitable period of warm ischemia, which may result in higher incidences of primary non-function (PNF) and delayed graft function (DGF). The relatively unknown ischemic injury and the unplanned situation of the procedure have led to a general reluctance to initiate uncontrolled DCD programs and to accept uncontrolled DCD kidneys for transplantation. There are a limited number of uncontrolled DCD kidney transplantation programs in Spain and France with excellent results $(4,5)$. Furthermore, a recent study shows that the clinical outcome of uncontrolled DCD kidneys is comparable to that of controlled DCD kidneys (6). This justifies a more widespread use of uncontrolled DCD donors to reduce the still growing waiting list for renal transplantation and may stimulate the implementation of uncontrolled DCD kidney programs.

Most studies which assessed DCD kidney transplantation outcomes analyzed either controlled DCD kidneys or uncontrolled and controlled DCD kidneys together. Despite the different mechanism of ischemic injury, the risk factors for the outcome of uncontrolled DCD kidney transplantation have not been studied before. Because of the increased popularity, it is essential to know which uncontrolled DCD kidneys can be accepted for transplantation and which kidneys better can be discarded. Our center has a long-time experience with the use of uncontrolled donor kidneys for transplantation since 1981. To describe the opportunities and limits of uncontrolled DCD kidney transplantations, we assessed the results of our uncontrolled DCD program and determined which factors are associated with PNF or inferior graft function after transplantation of uncontrolled donor kidneys. 


\section{MATERIALS AND METHODS}

\section{Study design}

Kidneys from uncontrolled DCD donors, procured in the Maastricht region from 1 January 1981 until 1 July 2009 and transplanted within the Eurotransplant region, were included in the current observational study. Patients were followed until the earliest of death or 1 July 2010. Kidneys were allocated according to the Eurotransplant allocation rules and were matched for Human Leukocyte Antigen (HLA) and blood group.

\section{Donor and recipient data}

Donor and perfusion characteristics of machine-preserved kidneys were routinely recorded at our institution. Recipient follow-up data were kindly provided by the recipient transplant centers, and was periodically updated in our database. The following graft characteristics were recorded: warm ischemia time (WIT), the period from circulatory arrest or stop of resuscitation until the initial cold flush of the kidneys; cold ischemia time (CIT), the period between the initial flush and the start of first anastomosis of the recipient operation; and the anastomosis period, the time to complete arterial and venous anastomoses.

Short-term graft function after transplantation was classified as 1) primary non-function (PNF): permanent inadequate renal function necessitating continuation of dialysis or retransplantation; 2) delayed graft function (DGF): renal function which was ultimately life sustaining but required temporary dialysis in the first week after transplantation; and 3) immediate function (IF): immediate renal function without the need of postoperative dialysis. Graft survival is defined as functional survival off dialysis.

Renal function after transplantation was assessed using the estimated glomerular filtration rate (eGFR), which was calculated with the abbreviated Modification of Diet in Renal Disease equation (MDRD) (7-9). eGFR at 1 year after transplantation and the rate of decline in eGFR thereafter were studied as measures of kidney function.

Collection, storage, and use of patient data were performed in agreement with the code of conduct 'use of data in health research' from the Dutch Federation of Biomedical Scientific Societies (http://www.federa.org/); According to Dutch law, Institutional Review Board (IRB) approval was not required for scientific analysis of anonymous data.

\section{Management of uncontrolled donors after cardiac death}

Kidneys were procured from uncontrolled (Maastricht category II) donors according to the Maastricht DCD categories $(10,11)$. Organs were preserved with the 
in situ preservation (ISP) technique, as described previously $(11,12)$. In short, after unsuccessful resuscitation and an obligatory no-touch period of five minutes, during which no interventions to the donor were taken, a double-balloon triple-lumen (DBTL) catheter was inserted into the aorta via one of the femoral arteries, followed by ISP of the donor kidneys with histidine-tryptophan-ketoglutarate solution (Custodiol; Dr. Franz Köhler Chemie, Alsbach, Germany) (13, 14). A large Foley catheter is placed in the femoral vein for decompression. This indispensable, minimally invasive technique may provide the opportunity to meet legal and logistical requirements for organ recovery without excessive WITs and, depending on the legal opportunities, can be initiated prior to consent for organ donation. It can be performed in the emergency department and allows fast and effective organ preservation. Insertion of the cannulas can be performed by surgeons with limited experience in donation procedures. After preservation and consent for organ donation, the organs were procured in the operating room. Following recovery of the kidneys in the operating room within two hours after the start of ISP, most of the kidneys were weighed and prepared for machine preservation and were placed in sterile organ chambers on Gambro PF-3B perfusion machines (Gambro, Lund, Sweden) using Belzer's University of Wisconsin machine perfusion solution since 1985, at a mean temperature of $4{ }^{\circ} \mathrm{C}$. Eurocollins preservation solution was used before 1985 (15). Since 2006, the Lifeport (Organ Recovery Systems, Des Plaines, IL, USA) has been used as pulsatile perfusion machine. Added to the solution were $40 \mathrm{IU}$ of insulin, $200.000 \mathrm{U}$ of penicillin and 16 $\mathrm{mg}$ of dexamethason. During machine perfusion, $\mathrm{pH}$ was adjusted to values $>7.10$, using sodium bicarbonate.

\section{Statistical analysis}

Continuous variables are presented as mean \pm standard deviation (SD) if normally distributed, and as median and interquartile range (IQR) otherwise. Categorical variables are presented as percentages. Baseline donor, preservation, and recipient characteristics are compared with the Student's t-tests for normally distributed continuous variables, with the Mann-Whitney U-test if the distribution was not normal, and with chi-square tests for categorical variables. The effects of all variables on PNF were tested with univariate logistic regression analysis. Multivariate logistic regression analysis was performed to identify potential risk factors for PNF, with correction for those characteristics that are considered to be potential confounders, defined by the $10 \%$ change-in-estimate rule (16), or if these criteria were not met, significant variables from the univariate analyses and potential confounders based on clinical relevance were used. The same criteria were used to determine the predictive value for PNF by the area under the ROC-curve (AURC). Sensitivity, specificity, positive predictive value (PPV), and negative predictive value (NPV) were analyzed using MedCalc statistical software.

Cox proportional hazards model was used to assess the effect of variables on death censored graft failure of primarily functioning kidneys, correcting for confounders as described for the multivariate analysis. Graft survival censored for recipient death with a functioning graft and patient survival was calculated with the 
Kaplan-Meier method.

The rate of decline in estimated glomerular filtration rate was calculated for each patient by simple linear regression from yearly glomerular filtration rate estimates, starting at 1 year after transplantation.

Machine-perfused kidneys were further analyzed to determine machine perfusion characteristics that are associated with outcome after transplantation.

All analyses were performed using Statistical Package for the Social Sciences (SPSS) software version 16.0 for Windows, and a $p$-value $<0.05$ was considered statistically significant.

\section{RESULTS}

\section{Patients}

From 1 January 1981 to 1 July 2009, 280 kidneys from uncontrolled donors after cardiac death were procured in the Maastricht region, of which 133 from 85 donors were discarded based on vascular anatomy (e.g. multiple renal arteries, renal artery stenosis, $\mathrm{N}=14$ ), macroscopic appearance (e.g. poor flush-out, cysts, renal capsula tears, $N=33)$, long WIT $(N=17)$, donor related problems (e.g. positive virology, diabetic nephropathy, $N=14)$, malplacement of the cannulas $(N=7)$, if there were no suitable recipients $(N=14)$, if the kidneys were considered too marginal to transplant $(\mathrm{N}=24)$ or not reported $(\mathrm{N}=10)$. Ten kidneys were transplanted outside the Eurotransplant region, data were missing of one transplanted kidney and one recipient died with an unknown graft function. Of the remaining 135 kidneys transplanted in the Eurotransplant region, 110 kidneys were machine perfused and 25 kidneys were stored on melting ice until transplantation (cold-storage).

Donor, graft, and recipient characteristics are summarized in Table 3.1. Mean donor age was $45 \pm 16$ years. The mean WITs and CITs were $26 \pm 11$ minutes and $27 \pm$ 6 hours, respectively. Donors and recipients predominantly comprised of men $(73 \%$ and $68 \%$, respectively). 
Univariate analysis

OR $(95 \% \mathrm{Cl})$

p

\begin{tabular}{|c|c|c|c|}
\hline \multicolumn{4}{|l|}{ Donor related } \\
\hline Age (years) & $45 \pm 16$ & $1.035(1.004-1.068)$ & 0.028 \\
\hline Sex (male) & $99(73 \%)$ & $0.658(0.273-1.585)$ & 0.351 \\
\hline Cause of death (cardiovascular/other) & $71 / 29 \%$ & $2.934(0.843-6.798)$ & 0.101 \\
\hline Hypertension ( $N=107$ ) (yes) & $11 \%$ & $1.479(0.409-5.354)$ & 0.551 \\
\hline Creatinine $(\mu \mathrm{mol} / \mathrm{L})$ & $122 \pm 37$ & $1.002(0.991-1.013)$ & 0.671 \\
\hline Total CPR time (min) ${ }^{a}$ & $48 \pm 25$ & $1.001(0.984-1.018)$ & 0.911 \\
\hline \multicolumn{4}{|l|}{ Graft related } \\
\hline Warm ischemia time (min) & $26 \pm 13$ & $1.021(0.988-1.054)$ & 0.221 \\
\hline Machine perfusion / cold storage ${ }^{b}$ & $81.5 / 18.5 \%$ & $1.625(0.511-5.164)$ & 0.410 \\
\hline Cold ischemia time $(h)$ & $27 \pm 6$ & $0.999(0.935-1.067)$ & 0.972 \\
\hline Of which machine perfusion time (h) & $22 \pm 6$ & $1.026(0.951-1.108)$ & 0.505 \\
\hline Anastomosis time (min) & $39 \pm 14$ & $0.998(0.968-1.028)$ & 0.878 \\
\hline $\mathrm{GST} \mathrm{T}_{4}(\mathrm{U} / \mathrm{L} / 100 \mathrm{~g})$ & $71(52-111)^{c}$ & $1.005(0.999-1.010)$ & 0.089 \\
\hline $\mathrm{LDH} \mathrm{T}_{4}(\mathrm{U} / \mathrm{L} / 100 \mathrm{~g})$ & $565(405-756)^{c}$ & $1.001(1.000-1.001)$ & 0.104 \\
\hline Renovascular resistance $\mathrm{T}_{0}$ & $1.03 \pm 0.63$ & $1.542(0.768-3.093)$ & 0.223 \\
\hline \multicolumn{4}{|l|}{ Recipient related } \\
\hline Age (years) & $51 \pm 13$ & $1.012(0.980-1.044)$ & 0.472 \\
\hline Sex (male) & $92(68 \%)$ & $2.118(0.794-5.651)$ & 0.134 \\
\hline Re-transplantation (yes) & $15(11 \%)$ & $1.301(0.382-4.424)$ & 0.674 \\
\hline Total HLA mismatches & $2.5 \pm 1.1$ & $1.066(0.722-1.572)$ & 0.746 \\
\hline Transplant center (regional / export) & $64 / 36 \%$ & $1.182(0.502-2.782)$ & 0.702 \\
\hline $\begin{array}{l}\text { Kidney disease (renovascular / other) } \\
(\mathrm{N}=116)\end{array}$ & $18 / 82 \%$ & $0.964(0.317-2.931)$ & 0.949 \\
\hline Dialysis time (years) & $3.2 \pm 2.6$ & $1.020(0.874-1.190)$ & 0.799 \\
\hline Dialysis type (hemodialysis) & $88(65 \%)$ & $0.773(0.310-1.931)$ & 0.582 \\
\hline Calcineurin inhibitor (yes) & $118(87 \%)$ & $0.645(0.208-2.003)$ & 0.448 \\
\hline Anti-metabolite (yes) & $55(41 \%)$ & $0.449(0.183-1.099)$ & 0.080 \\
\hline Sirolimus (yes) & $29(21 \%)$ & $1.148(0.436-3.022)$ & 0.780 \\
\hline Induction therapy (yes) & $12(9 \%)$ & $1.185(0.300-4.686)$ & 0.809 \\
\hline
\end{tabular}

a Resuscitation time + CPR after declaration of death.

${ }^{b}$ Odds ratio relates to machine perfusion.

c Expressed as median (interquartile range). 


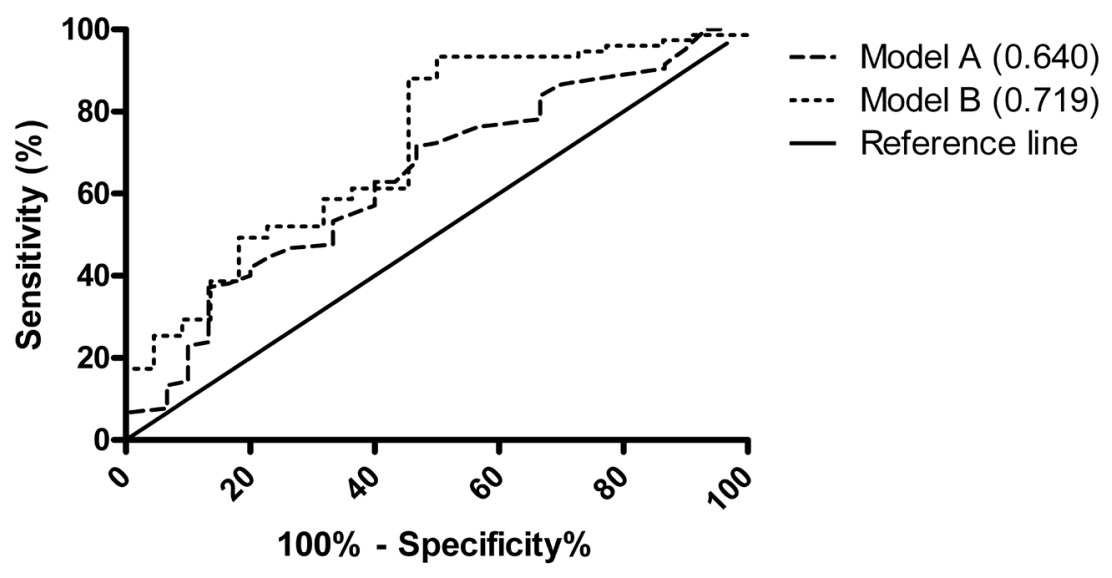

Figure 3.1 Receiver operating characteristics (ROC) curve for PNF: Model A: Donor age; Model B: multivariate model with donor age, warm ischemia time, cold ischemia time and renovascular resistance at $\mathrm{TO}$. The number in brackets indicates the area under the curve for each line.

\section{Short-term graft function}

Of the transplanted kidneys, 30 recipients developed PNF (22\%), 83 recipients DGF $(62 \%)$ and 22 recipients IF (16\%). Donor, graft, and recipient characteristics and their association with PNF are shown in Table 3.1. Only donor age was a significant risk factor for PNF in the univariate analysis (Table 3.1) and remained an independent risk factor for PNF in the multivariate analysis (Table 3.2). Further analysis of donor age, using the ROC-curve and its accompanying table (i.e. the point closest to the [1-1]-corner), showed the strongest association with PNF from an age of 54 years and older with an odds ratio of 2.857 ( $95 \% \mathrm{Cl} 1.242-6.571 ; p=0.013)$. Kidneys from donors of 54 years and older have a higher percentage of PNF compared with younger donor kidneys ( $35 \%$ vs. $16 \%, p=0.012$, respectively).

The predictive value of donor age on PNF was poor (AURC $0.640,95 \% \mathrm{Cl} 0.553$ - 0.721). Adding the variables as used in the multivariate analysis to the model, the predictive value increased to 'fair' (AURC 0.719, 95\% Cl $0.618-0.805$ ) (Figure 3.1, Table 3.3). 
Multivariate analysis of the risk of primary non-function and graft failure ${ }^{a}$

\begin{tabular}{lllll}
\hline & \multicolumn{2}{l}{$\begin{array}{l}\text { Multivariate logistic regression } \\
\text { Odds ratio }(95 \% \mathrm{Cl})\end{array}$} & $\mathrm{p}$ & \multicolumn{2}{l}{$\begin{array}{l}\text { Cox regression } \\
\text { Hazards ratio }(95 \% \mathrm{Cl})\end{array}$} & $\mathrm{p}$ \\
\hline Donor age (years) & $1.064(1.013-1.118)$ & 0.014 & $1.038(1.015-1.060)$ & $<0.001$ \\
\hline Warm ischemia time (min) & $1.045(0.997-1.096)$ & 0.068 & $1.015(0.992-1.039)$ & 0.202 \\
\hline Cold ischemia time (hours) & $1.047(0.946-1.158)$ & 0.376 & $1.045(0.996-1.096)$ & 0.074 \\
\hline $\begin{array}{l}\text { Renovascular Resistance T0 } \\
(\mathrm{mmHg} / \mathrm{mL} / \mathrm{min} / 100 \mathrm{~g})\end{array}$ & $1.256(0.602-2.618)$ & 0.544 & - & - \\
\hline
\end{tabular}

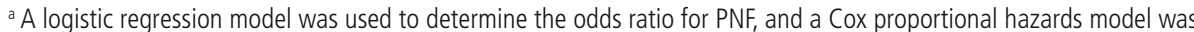
used to determine the hazards ratio for death censored graft failure of primarily functioning kidneys.

\section{Long-term outcomes}

The median period of follow-up after transplantation was 6.5 (IQR 3.5 12.2) years. Graft survival at 1 and 5 years after transplantation was $75 \%$ and $63 \%$, respectively; kidneys with PNF included. Figure 3.2 shows graft survival, censored for recipient death with a functioning graft, of all transplanted kidneys (Figure 3.2A) and functioning kidneys alone (Figure 3.2B), with donor age categorized in groups. Graft survival of all transplanted kidneys was significantly lower for donor kidneys of 54 years and older, but graft survival of functioning kidneys was equivalent in both groups. Recipient survival was similar in both groups (Figure 3.2C).

Mean eGFR of functioning grafts was $36.2 \mathrm{~mL} / \mathrm{min} / 1.73 \mathrm{~m} 2$ at 3 months, 40.7 $\mathrm{mL} / \mathrm{min} / 1.73 \mathrm{~m} 2$ at 1 year, and $45.0 \mathrm{~mL} / \mathrm{min} / 1.73 \mathrm{~m} 2$ at 5 years after transplantation. Donor age was significantly correlated with a decrease in eGFR (Pearson's $r=-.418$, $\mathrm{p}<0.001$ ) at 1 year after transplantation and at 5 years after transplantation (Pearson's $r=-.497, p<0.001)$.

In the Cox proportional hazards model, donor age was significantly associated with death censored graft failure of primarily functioning kidneys (HR $1.038,95 \% \mathrm{Cl}$ $1.015-1.060, p<0.001$ ) (Table 3.2).

Predictive values of donor age for PNF

\begin{tabular}{|c|c|c|c|c|c|}
\hline & AURC (95\% CI) & Sensitivity & Specificity & PPV & NPV \\
\hline Model A & $0.640(0.553-0.721)$ & 0.533 & 0.714 & 0.348 & 0.843 \\
\hline Model B & $0.719(0.618-0.805)$ & 0.500 & 0.933 & 0.687 & 0.864 \\
\hline
\end{tabular}

Model A: Donor age alone; Model B: Donor age, warm ischemia time, cold ischemia time, and renovascular resistance at $\mathrm{T}_{0}$. PPV: positive predictive value, NPV: negative predictive value. 


\section{DISCUSSION}

The use of kidneys from controlled Maastricht category III DCD donors for transplantation is generally accepted in most countries where it is legal to withdraw futile medical treatment $(17,18)$. The pool of controlled donors after cardiac death, however, is limited. Only a small proportion of intensive care patients, in whom further treatment is considered to be futile and who are not brain-dead, meet donation criteria. The number of patients who die after failed resuscitation is much higher (6). Therefore, these patients can be a valuable addition to the DCD donor pool as uncontrolled Maastricht category I and II DCD donors. However, uncontrolled DCD donor kidneys are rarely used. There is a general reluctance to use uncontrolled DCD kidneys, with only a few uncontrolled DCD programs, mainly in Spain and in France (19).

In the present study, Maastricht categories I and II are analyzed together as 'uncontrolled donors'. It is difficult to distinguish category I from category II DCD donors, estimate resuscitation time, and ischemic damage. In the Netherlands, patients are not taken to the hospital after declaration of death on the street as category I donors are in Spain. It is forbidden to transport dead people to a hospital, but allowed for resuscitation only. So, potential donors are resuscitated and if the patient dies, only in the hospital death is declared. This results in longer resuscitation periods of our category II donors than the category I donors in Spain.

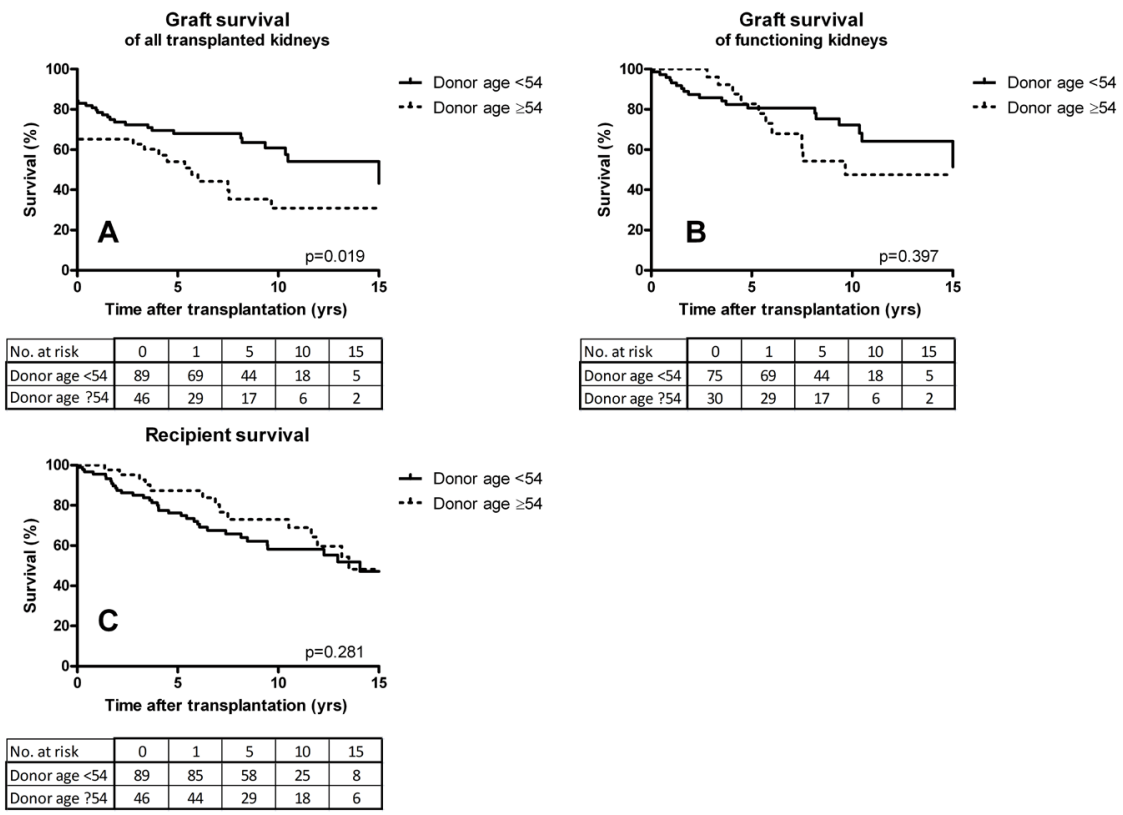

Figure 3.2 Kaplan-Meier graft survival curves of A) all transplanted uncontrolled DCD kidneys, B) functioning kidneys only, all censored for recipient death with a functioning graft, and C) recipient survival. 
The use of uncontrolled kidney donors has led to an increase in the number of available donor kidneys for transplantation at our center. A recent study from our group showed no difference in transplant outcomes of uncontrolled compared with controlled donor kidneys (6).

The incidence of PNF was relatively high in this group of patients, which enabled us to adequately assess risk factors for non-function after transplantation. Reasons for the high incidence of PNF may be influenced by several factors. First, the definition of PNF used in our center is permanent inadequate renal function necessitating continuation of dialysis or retransplantation. This includes kidneys which failed because of hyperacute rejection, graft thrombosis, and surgical complications. Second, the CIT with a mean period of 27 hours is much longer than in other studies. All kidneys are allocated according to the Eurotransplant allocation rules. As many centers are reluctant to accept marginal DCD kidneys and decline an organ offer, it usually takes hours before kidneys are finally offered to our center. Third, because of the shortage of donor organs, we had a liberal acceptance strategy for DCD kidneys. Despite our finding of a higher incidence of PNF and DGF in kidneys from DCD donors, patients who receive a DCD kidney have better survival rates than patients who continue dialysis treatment while waiting for a kidney from a conventional brain-dead donor $(3,20,21)$.

Kidneys from DCD donors that overcome the early post-transplantation period function as long as DBD (donation after brain death) kidneys. Contrary to DBD kidneys, DGF in DCD kidneys hardly affects graft survival $(22,23)$. As transplantation of non-viable kidneys results in unnecessary risk of surgery and immunosuppression, and sensitizes the recipient for future transplants, it is essential, particularly for DCD kidneys with a relatively high risk of PNF, to adequately assess the risk of non-function after transplantation (21).

Our results show that only donor age is independently associated with PNF. The predictive value of donor age only was poor, but adding the clinically important variables WIT, CIT and renovascular resistance during machine perfusion to the model, the predictive value increased to fair. Kidneys from donors of 54 years and older do worse than younger donor kidneys; however, like in controlled DCD kidneys, an absolute cut-off value cannot be provided. In a relatively large group of controlled and uncontrolled DCD kidneys, the results of pre-transplant biopsy increase the predictive value for graft survival in older donor kidneys (24).

Kidneys from DCD donors are inevitably subjected to a period of warm ischemia. Our data, however, shows no significant association between WIT and PNF. This may be biased as a total WIT longer than 45 minutes was a reason to discard kidneys for transplantation. Despite this potential bias, we found a trend towards significance in the multivariate analysis. In controlled DCD kidneys, a WIT longer than 45-60 minutes is also associated with an increased risk of PNF and DGF $(25,26)$. 
In our present study of uncontrolled DCD kidneys only, renovascular resistance was not associated with PNF. In a previous study from our group, we have shown that renovascular resistance of all Maastricht category II and III machine perfused DCD kidneys at the beginning of machine perfusion is independently associated with PNF, however, its predictive value is low (27).

Perfusate biomarkers of machine-perfused kidneys, including glutathione S-transferase (GST) and lactate dehydrogenase (LDH), have been used to identify risk factors for PNF and DGF in DCD kidneys (28-31). In some studies, GST has a strong correlation with graft viability, but others have not been able to confirm this association (29-31). For LDH concentration, no correlations were found with shortterm graft function $(29,31,32)$. This makes it hard to discard DCD kidneys based purely on perfusate biomarker concentrations. In the present study, GST and LDH concentrations were not correlated with PNF.

Direct cannulation of the aorta is the method of choice to preserve kidneys of DCD donors (33). In the Netherlands, minor invasive procedures are allowed to preserve the organs of potential donors before consent of the relatives and if a patient is not registered with objection in the national donor registry. Therefore, laparotomy with direct cannulation of the aorta is not feasible in uncontrolled donors. In this study, ISP with cold perfusate has been used to preserve donor kidneys. This technique is associated with longer WITs, a higher discard rate, and inferior graft survival compared to direct aortic cannulation (6). The use of normothermic extracorporeal membrane oxygenation (ECMO) after cardiac arrest may be a valuable alternative for hypothermic ISP with the DBTL-catheter. Advantages of ECMO include recirculation of oxygenated blood until organ procurement, maintaining or restoring adenosine levels, and it may offer the opportunity of viability testing of normothermic perfused kidneys $(34,35)$. This technique has the potential to improve organ quality of ischemically damaged uncontrolled DCD kidneys with better graft function and graft survival $(36,37)$. In addition, preservation with ECMO after cardiac death may provide the opportunity to procure more organs, including the liver, so that they can be used for transplantation (34). However, more clinical evidence of the benefits of ECMO is necessary (38).

It cannot be excluded that there are more risk factors for poor uncontrolled DCD kidney function than old age. Despite the relatively high percentage of PNF, which increases the power to identify risk factors and, compared with other studies, the large group of DCD transplantations, the number of analyzed donor kidneys remains relatively small to identify all possible risk factors for PNF.

The present study shows that donor age is associated with graft function of uncontrolled DCD kidneys, so this may influence the decision to accept or discard an uncontrolled DCD kidney. 


\section{REFERENCES}

1. Barlow AD, Metcalfe MS, Johari Y, Elwell R, Veitch PS, Nicholson ML. Case-matched comparison of longterm results of non-heart beating and heart-beating donor renal transplants. The British journal of surgery. 2009 Jun;96(6):685-91.

2. Ledinh H, Bonvoisin C, Weekers L, de Roover A, Honore P, Squifflet JP, et al. Results of kidney transplantation from donors after cardiac death. Transplantation proceedings. 2010 Sep;42(7):2407-14.

3. Snoeijs MG, Schaubel DE, Hene R, Hoitsma AJ, Idu MM, ljzermans JN, et al. Kidneys from donors after cardiac death provide survival benefit. J Am Soc Nephrol. 2010 Jun;21(6):1015-21.

4. Sanchez-Fructuoso Al. Kidney transplantation from non-heart-beating donors. Transplantation proceedings. 2007 Sep;39(7):2065-7.

5. Fieux F, Losser MR, Bourgeois E, Bonnet F, Marie O, Gaudez F, et al. Kidney retrieval after sudden out of hospital refractory cardiac arrest: a cohort of uncontrolled non heart beating donors. Critical care (London, England). 2009;13(4):R141.

6. Hoogland ER, Snoeijs MG, Winkens B, Christaans MH, van Heurn LW. Kidney Transplantation from Donors after Cardiac Death: Uncontrolled versus Controlled Donation. Am J Transplant. 2011 Jul;11 (7):1427-34.

7. Gera M, Slezak JM, Rule AD, Larson TS, Stegall MD, Cosio FG. Assessment of changes in kidney allograft function using creatinine-based estimates of glomerular filtration rate. Am J Transplant. 2007 Apr;7(4):8807.

8. Poge U, Gerhardt T, Palmedo H, Klehr HU, Sauerbruch T, Woitas RP. MDRD equations for estimation of GFR in renal transplant recipients. Am J Transplant. 2005 Jun;5(6):1306-11.

9. Stevens LA, Coresh J, Greene T, Levey AS. Assessing kidney function--measured and estimated glomerular filtration rate. N Engl J Med. 2006 Jun 8;354(23):2473-83.

10. Kootstra G, Daemen JH, Oomen AP. Categories of non-heart-beating donors. Transplantation proceedings. 1995 Oct;27(5):2893-4.

11. Snoeijs MG, Dekkers AJ, Buurman WA, van den Akker L, Welten RJ, Schurink GW, et al. In situ preservation of kidneys from donors after cardiac death: results and complications. Annals of surgery. 2007 Nov;246(5):844-52.

12. Hoogland ER, Snoeijs MG, van Heurn LW. DCD kidney transplantation: results and measures to improve outcome. Current opinion in organ transplantation. 2010 Apr;15(2):177-82.

13. Heineman E, Daemen JH, Kootstra G. Non-heart-beating donors: methods and techniques. Transplantation proceedings. 1995 Oct;27(5):2895-6; discussion 6-7.

14. Kootstra G, Kievit JK, Heineman E. The non heart-beating donor. British medical bulletin. 1997;53(4):84453.

15. Moers C, Smits JM, Maathuis MH, Treckmann J, van Gelder F, Napieralski BP, et al. Machine perfusion or cold storage in deceased-donor kidney transplantation. N Engl J Med. 2009 Jan 1;360(1):7-19.

16. Maldonado G, Greenland S. Simulation study of confounder-selection strategies. American journal of epidemiology. 1993 Dec 1;138(11):923-36.

17. Snoeijs MGJ, Heurn LWEv, Mook NKAv, Christiaans MH, Hooff JPv. Controlled donation after cardiac death: a European perspective. Transplant rev. 2007;21(4):219-29.

18. Brook NR, Waller JR, Nicholson ML. Nonheart-beating kidney donation: current practice and future developments. Kidney international. 2003 Apr;63(4):1516-29.

19. Dominguez-Gil B, Haase-Kromwijk B, Van Leiden H, Neuberger J, Coene L, Morel P, et al. Current situation of donation after circulatory death in European countries. Transpl Int. 2011 Jul;24(7):676-86.

20. Cho YW, Terasaki PI, Cecka JM, Gjertson DW. Transplantation of kidneys from donors whose hearts have stopped beating. N Engl J Med. 1998 Jan 22;338(4):221-5.

21. Snoeijs MG, Winkens B, Heemskerk MB, Hoitsma AJ, Christiaans MH, Buurman WA, et al. Kidney transplantation from donors after cardiac death: a 25-year experience. Transplantation. 2010 Nov 27;90(10):1106-12. 
22. Renkens JJ, Rouflart MM, Christiaans MH, van den Berg-Loonen EM, van Hooff JP, van Heurn LW. Outcome of nonheart-beating donor kidneys with prolonged delayed graft function after transplantation. Am J Transplant. 2005 Nov;5(11):2704-9.

23. Gok MA, Shenton BK, Buckley PE, Balupuri S, Soomro N, Manas D, et al. Long-term renal function after transplantation from non-heart-beating donor kidneys. Transplantation proceedings. 2002 Nov;34(7):25989.

24. Snoeijs MG, Buurman WA, Christiaans MH, van Hooff JP, Goldschmeding R, van Suylen RJ, et al. Histological assessment of preimplantation biopsies may improve selection of kidneys from old donors after cardiac death. Am J Transplant. 2008 Sep;8(9):1844-51.

25. Reich DJ, Mulligan DC, Abt PL, Pruett TL, Abecassis MM, D’Alessandro A, et al. ASTS recommended practice guidelines for controlled donation after cardiac death organ procurement and transplantation. Am J Transplant. 2009 Sep;9(9):2004-11.

26. Manara AR, Murphy PG, O'Callaghan G. Donation after circulatory death. British journal of anaesthesia. 2012 Jan;108 Suppl 1:i108-21.

27. de Vries EE, Hoogland ER, Winkens B, Snoeijs MG, van Heurn LW. Renovascular resistance of machineperfused DCD kidneys is associated with primary nonfunction. Am J Transplant. 2011 Dec;11(12):2685-91.

28. Daemen JH, Heineman E, Kootstra G. Viability assessment of non-heart-beating donor kidneys during machine preservation. Transplantation proceedings. 1995 0ct;27(5):2906-7; discussion 7-8.

29. Daemen JW, Oomen AP, Janssen MA, van de Schoot L, van Kreel BK, Heineman E, et al. Glutathione S-transferase as predictor of functional outcome in transplantation of machine-preserved non-heartbeating donor kidneys. Transplantation. 1997 Jan 15;63(1):89-93.

30. Gok MA, Pelzers M, Glatz JF, Shenton BK, Buckley PE, Peaston R, et al. Do tissue damage biomarkers used to assess machine-perfused NHBD kidneys predict long-term renal function post-transplant? Clinica chimica acta; international journal of clinical chemistry. 2003 Dec;338(1-2):33-43.

31. Moers C, Varnav OC, van Heurn E, Jochmans I, Kirste GR, Rahmel A, et al. The value of machine perfusion perfusate biomarkers for predicting kidney transplant outcome. Transplantation. 2010 Nov 15;90(9):96673.

32. Jochmans I, Pirenne J. Graft quality assessment in kidney transplantation: not an exact science yet! Current opinion in organ transplantation. 2011 Apr;16(2):174-9.

33. Wind J, Snoeijs MG, van der Vliet JA, Winkens B, Christiaans MH, Hoitsma AJ, et al. Preservation of kidneys from controlled donors after cardiac death. The British journal of surgery. 2011 Jun;98(9):1260-6.

34. Fondevila C. Is extracorporeal support becoming the new standard for the preservation of DCD grafts? Am J Transplant. 2010 Jun;10(6):1341-2.

35. Net M, Valero R, Almenara R, Barros P, Capdevila L, Lopez-Boado MA, et al. The effect of normothermic recirculation is mediated by ischemic preconditioning in NHBD liver transplantation. Am J Transplant. 2005 Oct;5(10):2385-92.

36. Lee JH, Hong SY, Oh CK, Hong YS, Yim H. Kidney transplantation from a donor following cardiac death supported with extracorporeal membrane oxygenation. Journal of Korean medical science. 2012 Feb;27(2):115-9.

37. Magliocca JF, Magee JC, Rowe SA, Gravel MT, Chenault RH, 2nd, Merion RM, et al. Extracorporeal support for organ donation after cardiac death effectively expands the donor pool. The Journal of trauma. 2005 Jun;58(6):1095-101; discussion 101-2.

38. Moers C, van Rijt G, Ploeg RJ, Leuvenink HG. The effect of normothermic recirculation before cold preservation on post-transplant injury of ischemically damaged donor kidneys. Transpl Int. 2012 Feb;25(2):210-7. 
WHICH KIDNEYS FROM UNCONTROLLED DONORS AFTER CARDIAC DEATH DO WORSE? 


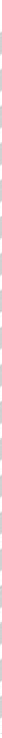


CHAPTER 4

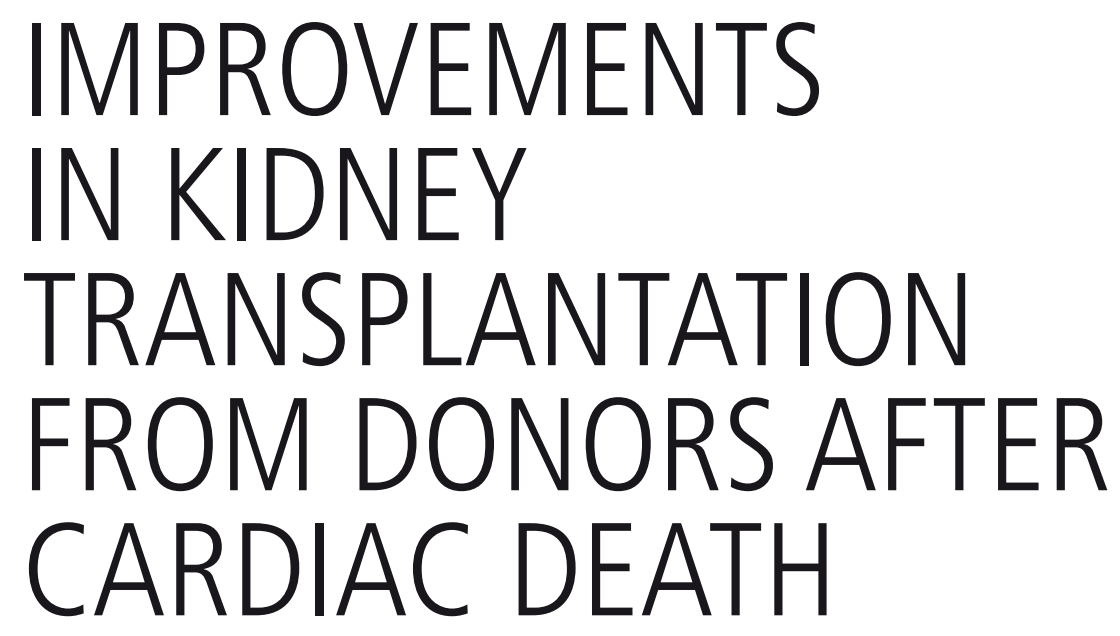




\section{ABSTRACT}

Background: To reduce the growing waiting list for kidney transplantation, we explored the limits of kidney transplantation from donors after cardiac death by liberally accepting marginal donor kidneys for transplantation. As the percentage of primary non-function (PNF) increased, we evaluated our transplantation program and implemented changes to reduce the high percentage of PNF in 2005, followed by a second evaluation over the period 2006 - 2009.

Methods: Recipients of a kidney from a donor after cardiac death between 1998 and 2005 were analyzed, with PNF as outcome measure.

Results: During the period 2002 - 2005, the percentage of PNF increased and crossed the upper control limit of $12 \%$ which was considered as unacceptably high. After implementation of changes, this percentage was reduced to $5 \%$, without changing the number of kidney transplantations from donors after cardiac death.

Conclusion: Continuous monitoring of the quality of care is essential as the boundaries of organ donation and transplantation are sought. Meticulous donor, preservation and recipient management make extension of the donor-potential possible, with good results for the individual recipient. Liberal use of kidneys from donors after cardiac death may contribute to a reduction in the waiting list for kidney transplantation and dialysis associated mortality.

\section{Published as}

E.R.P. Hoogland, M.G.J. Snoeijs, M.A.W. Habets, D.S. Brandsma, C.J. Peutz- Kootstra, M.H.L. Christiaans, L.W.E. van Heurn. Improvements in kidneys transplantation from donors after cardiac death. Clin Transplant 2013;27(3):E295-301 


\section{INTRODUCTION}

The Maastricht University Medical Center (MUMC) started a kidney transplantation program in 1980. At that moment, only excellent donor kidneys from young, brain-dead donors (DBD) were used for transplantation. While the waiting list for kidney transplantation was growing, the number of organ donors remained stable. Therefore, the need for additional sources of organ donors became more important, and the pool of donor organs was expanded by the use of kidneys from donors after cardiac death (DCD). In the early years of the transplant program, DCD kidneys were only occasionally used. However, the demand for donor organs increased and DCD kidney transplantation was stimulated. We started using organs from older DCD donors and with longer periods of warm ischemia for transplantation. In the early nineties, $25 \%$ of the deceased donors were DCD donors.

The promising results of DCD kidney transplantation, which were equivalent to the results of DBD kidney transplantation, made us to further expand the criteria for DCD donation (1). Unfortunately, the expanded use of DCD kidneys was accompanied with an increase of the percentage primary non-function (PNF) of transplanted kidneys. Therefore, we evaluated the quality of care at our center and assessed if improvements could be made to reduce the high PNF rate.

\section{MATERIALS AND METHODS}

\section{Study design}

All patients who received a kidney from a DCD donor at the surgical department of the Maastricht University Medical Center were analyzed. Their data were extracted from our periodically updated database. The quality of DCD kidney transplantation was monitored with the incidence of PNF as quality indicator. An incidence of PNF of $12 \%$ was considered to be the upper limit of good clinical practice.

Initially, the quality of care was monitored for DCD kidneys transplanted between 1998 and 2006. When our results crossed the upper control limit of good clinical practice, possible risk factors for unfavorable outcome were identified, and a change to our practice was implemented. Four years after the implementation of drastic measures to reduce PNF, a second analysis was performed of all DCD kidney transplantations from 01/01/2006 until 01/01/2010.

\section{Data source and definitions}

Data of all kidney transplantations from DCD donors were extracted from our periodically updated database. 
Warm ischemia time in uncontrolled donors was defined as the time between cessation of cardiopulmonary resuscitation and the start of organ perfusion. For controlled donors, warm ischemia time was defined as the time from cardiac arrest (no arterial pulse) to the start of organ perfusion. Both included the obligatory notouch period of five minutes. The management of DCD donors has been described previously (2).

PNF was defined as an inadequate renal function after transplantation, which necessitated continuation of dialysis treatment or retransplantation. This definition included kidneys that failed because of hyperacute rejection, graft thrombosis, and surgical complications.

Graft failure, censored for recipient death with a functioning graft, was defined as permanent return to dialysis treatment or retransplantation.

The immunosuppressive regimen evolved over the study period and depended on different trials. Immunosuppression was mainly based on a combination of a calcineurin inhibitor (cyclosporin or tacrolimus) and prednisolone. Depending on the protocol at the time, these were combined with azathioprine, mycophenolate mofetil, sirolimus or daclizumab in recipients with an increased immunological risk (e.g., HLA immunization and retransplants).

Collection, storage and use of patient data was performed in agreement with the code of conduct 'use of data in health research' from the Dutch Federation of Biomedical Scientific Societies (http://www.federa.org/); According to Dutch law, Institutional Review Board (IRB) approval was not required for scientific analysis of anonymous data.

\section{Statistical analyses}

Continuous variables are presented as means \pm standard deviations (SD) if normally distributed (histogram), and as median and inter-quartile range otherwise. Categorical variables are presented as percentages.

Transplantation outcome, with PNF as outcome measure, was monitored using a funnel plot; the standard deviation was calculated with the formula " $\sigma=\sqrt{ } p(1-p) / n$ ", where $p$ is our pre-selected standard of good clinical care, and $n$ is the number of transplantations. Within the funnel plot, upper control limits were set at 2 ('alert') and 3 ('alarm') standard deviations above the target standard. The funnel plot shows the percentage of PNF on the $y$-axis against case number on the $x$-axis.

Baseline donor, preservation, and recipient characteristics are compared between the periods 1998 - 2001, 2002 - 2005 and 2006 - 2009 with the ANOVA test for approximately normally distributed continuous variables and with chi-square tests for categorical variables. 
All analyses were performed using Statistical Package for the Social Sciences (SPSS) software version 16.0 for Windows, and a $p$-value $\leq 0.05$ was considered statistically significant.

\section{RESULTS}

From 1/1/1998 until 12/31/2005, 173 DCD kidneys were transplanted at the Maastricht University Medical Center. Of these, four kidneys were excluded because the recipient died with an unknown graft function within 24 hours after transplantation due to cardiac failure $(\mathrm{N}=3)$ or the recipient underwent transplant nephrectomy due to a malignancy found after donor autopsy $(\mathrm{N}=1)$. Two kidney pairs were transplanted en bloc and analyzed as one. Initially, the PNF rate was $11 \%$ in the period $1998-2001$, but it gradually increased in the period $2002-2005$, during which the PNF percentage followed the alert line in 2003 and 2004 and crossed the upper control limit (the alarm line) of good clinical practice in 2005 (Figure 4.1 and 4.2).

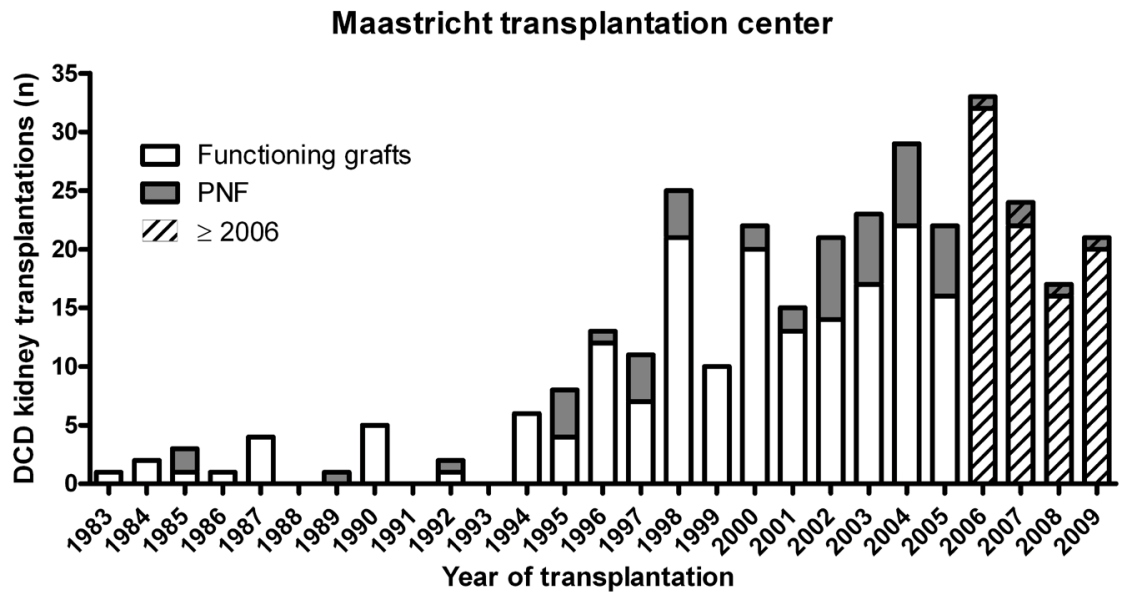

Figure 4.1 Number of primary non-function of all DCD kidneys transplanted in Maastricht University Medical Center. Dashed bars represent numbers after implementation of strategies to reduce the high rate of primary non-function.

To assess if the high percentage of PNF could be reduced, room for improvement of donor, preservation, and recipient characteristics that potentially affect the outcome after transplantation in our previously treated group of transplants 
were evaluated. Potential risk factors for poor outcome that were analyzed included: 1) donor age; 2) DCD category; 3 ) warm ischemia time, including duration and the method of in situ preservation (ISP); and 4) duration of cold ischemia time (CIT) (2-5).

1. DCD kidneys from donors aged 60 years or older showed a higher incidence of PNF and inferior graft survival compared to kidneys from younger donors $(3,6,7)$. The worse results in this age-group were correlated with the results of pre-implantation histology, defined by Remuzzi et al. (3, 7, 8).

2. The incidence of PNF in controlled and uncontrolled DCD donors was equivalent (2).

3. Prolonged in situ preservation with a duration of preservation longer than 17 minutes was associated with a higher percentage of PNF. The association was stronger than for warm ischemia time (including the notouch period and ISP insertion time) (4). Moreover, direct cannulation of the aorta was superior to ISP for controlled donors (5).

4. Duration of cold ischemia was tried to be kept to a minimum.

Consequently, the following changes were implemented: Firstly, in donors older than 60 years, the decision to transplant a kidney, to use both kidneys as dual transplant or to discard the donor kidney was made with the help of pre-implantation histology. If the Remuzzi score was $\geq 4$, kidneys were generally discarded or, if available, used for dual transplantation. If the score was $\leq 3$, kidneys were accepted for transplantation (3). Secondly, donor kidneys with ISP insertion time longer than 30 minutes were generally discarded. Thirdly, for controlled DCD donors, direct aortic cannulation rather than ISP became the preservation method of choice. Fourthly, extra attention was paid to emphasize the importance of shorter CIT by reducing waiting time for operating theatre availability.

To assess if these changes were effective and resulted in a lower incidence of PNF, we performed a second evaluation. In the period 1/1/2006 until 1/1/2010, 100 DCD kidney transplantations were performed. Three patients with an unknown short-term graft function were excluded from analysis. Reasons for exclusion were recipient death due to cardiac failure $(N=1)$, removal of transplanted kidney due to a Grawitz-tumor detected after transplantation $(\mathrm{N}=1)$, and a surgical complication during transplantation $(\mathrm{N}=1)$. Three kidney pairs were transplanted en bloc and were analyzed as one. 
The implemented changes resulted in the following improvements:

1. Biopsies were routinely taken for donors older than 60 years of age. Four kidneys from two donors older than 60 years of age were transplanted en bloc in the 2006-2009 period, compared to none in the 2002 - 2005 period.

2. The percentage of transplanted kidneys with an ISP duration $\geq 30$ minutes was reduced to $19 \%$ compared to $28 \%$ before; however, due to a small number, this difference was not statistically significant $(p=0.398)$.

3. Direct aortic cannulation was used in $66 \%$, compared with $36 \%$ in the period 2002 - 2005 (Pearson chi square; $p<0.001$ ), while the percentage of controlled donors was similar in both periods ( $73 \%$ and $81 \%, p=0.181$ ) (Table 4.1).

4. The total CIT was reduced with an average of three hours ( $21 \pm 5$ vs. $24 \pm 7$, p<0.001, for the periods 2006 - 2009 vs. 2002 - 2005, respectively) (Table 4.1).

The incidence of PNF of DCD kidneys transplanted at our center decreased to $5 \%$ in the period $2006-2009$ (5 out of 94 transplants), significantly lower than in the period $2002-2005$ (Pearson chi-square; $p<0.001$ ), and was well below the limits of our standard of good clinical care (Figure 4.1). The number of DCD donors (57 vs. 55 during the periods 2002 - 2005 and 2006 - 2009, respectively) and the percentage of DCD donors of all deceased donors ( $60 \%$ vs. $56 \%$ ), have not changed since 1/1/2006. The donor age was higher in the period $2006-2009$ (53 \pm 15 vs. 45 $\pm 18, p=0.003)$; kidneys were less often preserved on a perfusion machine and a different immunosuppressive regimen was followed, which was a result of different trials during the study periods (Table 4.1). 


\section{Donor and recipient characteristics of DCD kidney transplantation in the} period 1998-2001, 2002-2005 and 2006-2009. ${ }^{a}$

\begin{tabular}{|c|c|c|c|c|}
\hline & $1998-2001$ & $2002-2005$ & $2006-2009$ & \\
\hline & $N=72$ & $N=95$ & $N=94$ & $p$ \\
\hline \multicolumn{5}{|l|}{ Donor related } \\
\hline Age (years) & $47 \pm 14$ & $45 \pm 18$ & $53 \pm 15$ & 0.004 \\
\hline Sex (male) & $64 \%$ & $60 \%$ & $61 \%$ & 0.866 \\
\hline Donor type (controlled / uncontrolled) & 67 / 33\% & $73 / 27 \%$ & $81 / 19 \%$ & 0.111 \\
\hline Donor center (MUMC / other) $)^{b}$ & $79 / 21 \%$ & $39 / 61 \%$ & 37 / 63\% & $<0.001$ \\
\hline \multicolumn{5}{|l|}{ Graft related } \\
\hline Warm ischemia time $(\mathrm{min}){ }^{c}$ & $26 \pm 9$ & $23 \pm 9$ & $23 \pm 11$ & 0.082 \\
\hline ISP method (DBTL / aortic cannulation) & $98 / 2 \%$ & $64 / 36 \%$ & $34 / 66 \%$ & $<0.001$ \\
\hline $\begin{array}{l}\text { Preservation type (cold storage I } \\
\text { machine perfusion) }\end{array}$ & $7 / 93 \%$ & $46 / 54 \%$ & $63 / 37 \%$ & $<0.001$ \\
\hline Cold ischemia time (h) & $28 \pm 6$ & $24 \pm 7$ & $21 \pm 5$ & $<0.001$ \\
\hline Anastomosis time (min) & $35 \pm 9$ & $38 \pm 19$ & $42 \pm 16$ & 0.023 \\
\hline \multicolumn{5}{|l|}{ Recipient related } \\
\hline Age (years) & $54 \pm 12$ & $54 \pm 13$ & $57 \pm 13$ & 0.215 \\
\hline Sex (male) & $58 \%$ & $64 \%$ & $67 \%$ & 0.508 \\
\hline Re-transplantation (yes) & $10 \%$ & $11 \%$ & $21 \%$ & 0.067 \\
\hline Total HLA mismatches & $2.5 \pm 0.9$ & $2.6 \pm 1.1$ & $2.9 \pm 1.3$ & 0.208 \\
\hline Dialysis time (years) & $3.2 \pm 2.7$ & $3.8 \pm 2.8$ & $4.1 \pm 3.0$ & 0.101 \\
\hline $\begin{array}{l}\text { Dialysis type (hemodialysis / } \\
\text { peritoneal dialysis) }\end{array}$ & $71 / 29 \%$ & $57 / 43 \%$ & $59 / 41 \%$ & 0.157 \\
\hline Cyclosporine/tacrolimus/none (\%) & $0 / 100 / 0 \%$ & $1 / 87 / 12 \%$ & $0 / 78 / 22 \%$ & $<0.001$ \\
\hline Anti-metabolite (yes) & $46 \%$ & $37 \%$ & $23 \%$ & 0.009 \\
\hline Sirolimus (yes) & $15 \%$ & $64 \%$ & $53 \%$ & $<0.001$ \\
\hline Induction therapy (yes) & $6 \%$ & $8 \%$ & $1 \%$ & 0.065 \\
\hline
\end{tabular}

a Data are presented as mean \pm standard deviation, or as percentages.

b MUMC: Maastricht University Medical Center.

c Warm ischemia time was defined as the time from circulatory arrest until initiation of hypothermic organ perfusion and therefore does not include ventilator switch-off time and cardiopulmonary resuscitation time. 


\section{Funnel plot}

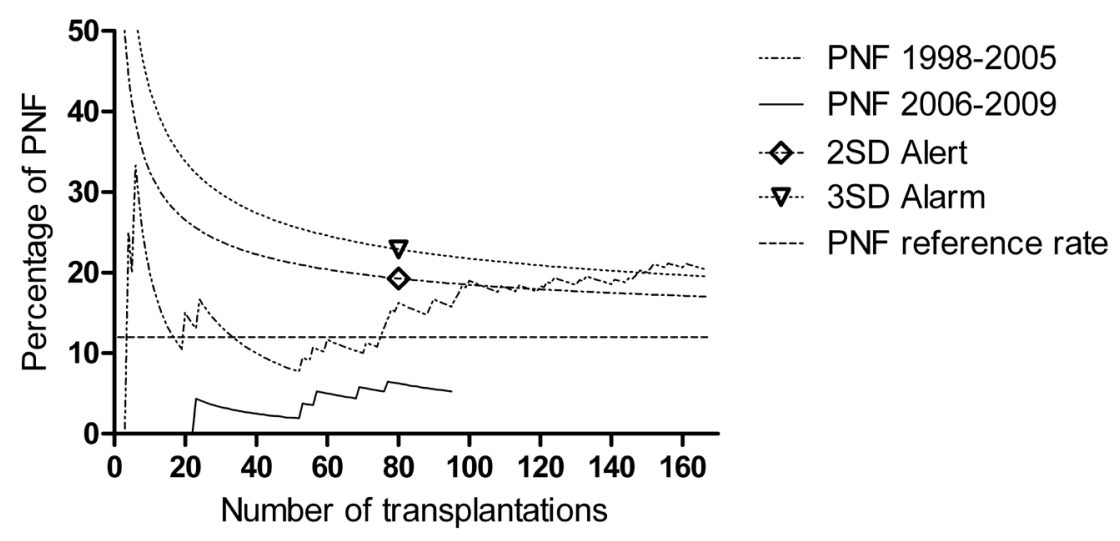

Figure 4.2 Funnel plot of the percentage of primary non-function during the time period $1998-2005$ and during 2006 - 2009, after implementation of strategies to reduce the high rate of primary non-function. Upper control limits can be seen to funnel towards the standard as procedure number increases.

\section{DISCUSSION}

Continuous efforts to improve the quality of care have become an important point of interest in health care organizations. Collection and repeated analysis of clinical data are indispensable steps in quality improvement, ensuring the highest quality of care for patients. To guarantee the optimal use of the limited number and often marginal donor organs on one side, and, in the meantime, to keep the outcomes of our DCD kidney transplantations within the limits of good clinical practice, the quality of the DCD kidney transplantations at our center is continuously monitored with primary non-function as outcome measure. Delayed graft function (DGF) is less appropriate as outcome measure, because DGF does not or hardly affect long-term graft survival in DCD kidneys (9-11).

At the moment of the first evaluations, it was unknown at which percentage of PNF the individual patient still benefits from transplantation with a DCD kidney. Therefore, we had arbitrarily set the PNF percentage at $12 \%$ as the standard of good clinical care. A PNF percentage of $12 \%$ seems unacceptably high in clinical practice compared with other studies (United States 1.6\% (12), United Kingdom 3\% (13)), because it results in unnecessary risk of surgery and immunosuppression, and sensitizes the recipient for future transplants. However, the yearly mortality of patients on the waiting list for kidney transplantation is between 6 and 10\%. A more restrictive acceptance policy for transplantation of marginal kidneys would lead to discard of 
many viable organs. To make sure that our policy had not lead to unacceptable risk for transplant recipients, we have addressed this dilemma. We showed that patients on the waiting list for kidney transplantation benefit from DCD transplantations, despite an incidence of PNF of $12 \%$, instead of staying on the waitlist and wait for a conventional DBD kidney transplantation; DCD kidney transplantation was associated with a mean survival benefit of 2.4 months in the first 4 years after transplantation (14). Therefore, we think that $12 \%$ is an acceptable standard; however, every effort must be taken to get the PNF percentage below $5 \%$.

To compare the outcome with the standard of good clinical care, it is essential to use an adequate number of patients. If the evaluation period is too short, deviation from the standard may be due to chance. If the period is too long, results may be obscured by previous data in the evaluated period. A period of 4 years with approximately 100 transplants seems appropriate to adjust for deviations.

The rate of PNF was compared with the standard rate of $12 \%$ in a funnel chart. These charts measure performance over time and 'signal' if there is a deviation from accepted standards (15). If the line of 3 standard deviations is exceeded, one must conclude that a change must be implemented to return to the standard level of PNF. This would imply either to restrict the number of DCD donor transplants by stricter acceptance policy or to improve the complete process of DCD kidney transplantation which includes donor selection and management, preservation, and recipient care. In our series, we implemented four changes after which a re-evaluation was performed. These changes were derived from studies at our institute, from available literature and based on assumptions of factors which may affect short-term graft function. Kidneys from older donors have a worse outcome than kidneys from younger donors (7). The selection of kidneys for transplantation from DBD donors aged 60 years and older can be improved with histological assessment of chronic renal injury in pre-implantation biopsies $(7,16,17)$. We confirmed these findings in our group of DCD kidneys and showed that histological assessment of pre-implantation biopsies is superior to other selection algorithms such as donor age and donor glomerular filtration rate (GFR) to predict short term graft function and graft survival (3). Since 2006, all DCD donor kidneys from donors aged 60 years or older are histologically examined before implantation at our transplant unit $(3,8)$.

The quality of uncontrolled (Maastricht category II) DCD donor kidneys is intuitively considered to be less than the quality of controlled DCD kidneys. The warm ischemia time of uncontrolled kidneys is often not exactly known, and the effectiveness of cardiopulmonary resuscitation can hardly be assessed. In the analysis of our results, the short-term renal function and long-term graft survival were equivalent, so the uncontrolled DCD program was continued. Because the number of patients who die after failed resuscitation is relatively high compared with the number of controlled DCD donors, uncontrolled donors may be an important population to consider for kidney donation. An uncontrolled DCD program is a potential way to further expand the donor pool. 
Warm ischemia time and organ preservation techniques which limit warm ischemic injury to the organs are important variables for the outcome of DCD transplantation. Prolonged ISP is associated with poor outcome. This does not only reflect prolonged warm ischemia, but is also caused by difficult insertion of the ISP catheter in donors with severe atherosclerosis. We lowered the threshold to discard DCD kidneys with prolonged and difficult insertion of the cannulas. Furthermore, direct cannulation of the aorta with a laparotomy results in superior graft survival and has therefore become the preservation method of choice in controlled DCD donors. In uncontrolled donors, the use of extra corporeal membrane oxygenation (ECMO) may also improve preservation quality (18). In this study, the agonal phase, also known as ventilator switch-off time, was not analyzed. Data suggests that transplant outcome of DCD kidneys is not compromised by lengthening the minimum waiting time after withdrawal of life-supporting treatment (WLST) from one to four hours (19). In the Netherlands, the maximum agonal phase after WLST is two hours or an 02 saturation $<80 \%$ and/or a mean arterial pressure $<50 \mathrm{mmHg}$ longer than 15 minutes within those two hours. If these phases are exceeded, the donation procedure normally is abandoned. In agreement with the recipient centers, longer agonal phases can be accepted $(19,20)$.

Several studies have reported that optimized peri-operative hemodynamic management of DBD donor kidney recipients is associated with a reduction of DGF (21-28). For the best initial graft function, adequate perfusion of the transplanted kidney is required. To achieve this, careful selection of the recipients is mandatory. Patients with a low blood pressure, including young recipients and recipients with cardiac failure, may not be able to generate a high enough blood pressure to adequately perfuse a kidney with ischemia reperfusion injury, which also may be adapted to the often higher blood pressure of the donor, and may not be suitable candidates to receive a DCD kidney. Optimal hemodynamic management is further achieved by expansion of the intravascular volume of the recipient. Dialysis with fluid extraction prior to transplantation is avoided. Together with the anaesthesiologists, we revised the operative and post-operative fluid management protocol with better expansion of the intravascular volume and, if necessary, inotropic support. However, this implemented change was difficult to quantify.

One major limitation of this study is that it is difficult to assess the degree of contribution of each implementation specifically. Other developments may also have affected graft outcome including a significant reduction of the long cold ischemia times $(29,30)$. Although beneficial, the percentage of kidneys which were preserved by machine perfusion decreased after 2006. It remains routine to preserve most DCD kidneys which are procured in our own region during the Eurotransplant organ allocation process. DCD kidneys procured in other regions are not routinely machine perfused, unless prolonged cold ischemia times are expected. Additionally, in DCD donors younger than 50 years of age, machine perfusion is a risk factor for graft failure (Hazards ratio 1.35, $\mathrm{p}=0.02$ ) (12). Therefore, these kidneys are not routinely machine perfused. 
Expansion of the donor pool is necessary to reduce the growing waiting list for kidney transplantation. Therefore, we have explored the limits of DCD kidney transplantation by liberally accepting marginal DCD kidneys for transplantation. This has led to a high percentage of PNF, which necessitated a change of our practice either by a restriction of our liberal acceptance strategy for DCD kidneys, which would undoubtedly have led to a reduction of the number of organ donors, or by improvement of our care. With our 'aggressive' DCD program, equivalent graft survival of primarily functioning DCD and DBD kidneys was achieved (31). Therefore, we continued our program after implementation of changes, without a reduction in the number of DCD donors. The latter has resulted in a significant decrease in the PNF rate without a reduction in the number of transplanted donor kidneys.

Continuous monitoring of the quality of care is essential if the boundaries in organ transplantation are searched for. Meticulous donor, preservation, and recipient management make expansion of the donor potential possible with a favorable result for the individual recipient, who is better off with a marginal DCD kidney transplantation than staying on the waiting list and wait for a better organ. Another effort to be made is a further reduction of cold ischemia times in the Netherlands, because this may positively affect graft function (29). Too strict standards of good clinical care may contribute to an inadequate use of potential marginal donors for transplantation. If the PNF rate in our hospital remains substantially below our standard of good clinical practice, the threshold to accept kidneys for transplantation will be gradually lowered. In general, a liberal approach to accept marginal DCD donors for transplantation may contribute to a more widespread strategy to transplant DCD kidneys with a reduction of the number of patients on the waiting list with the dialysis associated mortality. However, such strategy requires careful monitoring of transplant outcome to guarantee that results remain within the limits of acceptable practice. 


\section{REFERENCES}

1. Wijnen RM, Booster MH, Stubenitsky BM, de Boer J, Heineman E, Kootstra G. Outcome of transplantation of non-heart-beating donor kidneys. Lancet. 1995 Apr 29;345(8957):1067-70.

2. Hoogland ER, Snoeijs MG, Winkens B, Christaans MH, van Heurn LW. Kidney Transplantation from Donors after Cardiac Death: Uncontrolled versus Controlled Donation. Am J Transplant. 2011 Jul;11(7):1427-34.

3. Snoeijs MG, Buurman WA, Christiaans MH, van Hooff JP, Goldschmeding R, van Suylen RJ, et al. Histological assessment of preimplantation biopsies may improve selection of kidneys from old donors after cardiac death. Am J Transplant. 2008 Sep;8(9):1844-51.

4. Snoeijs MG, Dekkers AJ, Buurman WA, van den Akker L, Welten RJ, Schurink GW, et al. In situ preservation of kidneys from donors after cardiac death: results and complications. Annals of surgery. 2007 Nov;246(5):844-52.

5. Wind J, Snoeijs MG, van der Vliet JA, Winkens B, Christiaans MH, Hoitsma AJ, et al. Preservation of kidneys from controlled donors after cardiac death. The British journal of surgery. 2011 Jun;98(9):1260-6.

6. Kuo PC, Johnson LB, Schweitzer EJ, Alfrey EJ, Waskerwitz J, Bartlett ST. Utilization of the older donor for renal transplantation. American journal of surgery. 1996 Nov;172(5):551-5; discussion 6-7.

7. Remuzzi G, Grinyo J, Ruggenenti P, Beatini M, Cole EH, Milford EL, et al. Early experience with dual kidney transplantation in adults using expanded donor criteria. Double Kidney Transplant Group (DKG). J Am Soc Nephrol. 1999 Dec;10(12):2591-8.

8. Snoeijs MG, Boonstra LA, Buurman WA, Goldschmeding R, van Suylen RJ, van Heurn LW, et al. Histological assessment of pre-transplant kidney biopsies is reproducible and representative. Histopathology. Jan;56(2):198-202.

9. Renkens JJ, Rouflart MM, Christiaans MH, van den Berg-Loonen EM, van Hooff JP, van Heurn LW. Outcome of nonheart-beating donor kidneys with prolonged delayed graft function after transplantation. Am J Transplant. 2005 Nov;5(11):2704-9.

10. Weber M, Dindo D, Demartines N, Ambuhl PM, Clavien PA. Kidney transplantation from donors without a heartbeat. N Engl J Med. 2002 Jul 25;347(4):248-55.

11. Nicholson ML, Metcalfe MS, White SA, Waller JR, Doughman TM, Horsburgh T, et al. A comparison of the results of renal transplantation from non-heart-beating, conventional cadaveric, and living donors. Kidney international. 2000 Dec;58(6):2585-91.

12. Locke JE, Segev DL, Warren DS, Dominici F, Simpkins CE, Montgomery RA. Outcomes of kidneys from donors after cardiac death: implications for allocation and preservation. Am J Transplant. 2007 Jul;7(7):1797-807.

13. Summers DM, Johnson RJ, Allen J, Fuggle SV, Collett D, Watson CJ, et al. Analysis of factors that affect outcome after transplantation of kidneys donated after cardiac death in the UK: a cohort study. Lancet. 2010 Oct 16;376(9749):1303-11.

14. Snoeijs MG, Schaubel DE, Hene R, Hoitsma AJ, Idu MM, ljzermans JN, et al. Kidneys from donors after cardiac death provide survival benefit. J Am Soc Nephrol. 2010 Jun;21(6):1015-21.

15. Axelrod DA, Kalbfleisch JD, Sun RJ, Guidinger MK, Biswas P, Levine GN, et al. Innovations in the assessment of transplant center performance: implications for quality improvement. Am J Transplant. 2009 Apr;9(4 Pt 2):959-69.

16. Leunissen KM, Bosman FT, Nieman FH, Kootstra G, Vromen MA, Noordzij TC, et al. Amplification of the nephrotoxic effect of cyclosporine by preexistent chronic histological lesions in the kidney. Transplantation. 1989 Oct;48(4):590-3.

17. Lopes JA, Moreso F, Riera L, Carrera M, Ibernon M, Fulladosa X, et al. Evaluation of pre-implantation kidney biopsies: comparison of Banff criteria to a morphometric approach. Kidney international. 2005 Apr;67(4):1595-600.

18. Fondevila C. Is extracorporeal support becoming the new standard for the preservation of DCD grafts? Am J Transplant. 2010 Jun;10(6):1341-2.

19. Reid AW, Harper S, Jackson CH, Wells AC, Summers DM, Gjorgjimajkoska O, et al. Expansion of the kidney 
donor pool by using cardiac death donors with prolonged time to cardiorespiratory arrest. Am J Transplant. 2011 May;11(5):995-1005.

20. van Heurn LW. Transplantation: Prolonged agonal time--not a contraindication for transplantation. Nature reviews. 2011 Aug;7(8):432-3.

21. Carlier M, Squifflet JP, Pirson Y, Decocq L, Gribomont B, Alexandre GP. Confirmation of the crucial role of the recipient's maximal hydration on early diuresis of the human cadaver renal allograft. Transplantation. 1983 Oct;36(4):455-6.

22. Tiggeler RG, Berden JH, Hoitsma AJ, Koene RA. Prevention of acute tubular necrosis in cadaveric kidney transplantation by the combined use of mannitol and moderate hydration. Annals of surgery. 1985 Feb;201(2):246-51.

23. Rajagopalan PR, Kay NA, Fitts CT, Majeski JA. Prevention of acute tubular necrosis after transplantation: effect of pretransplantation volume expansion. Southern medical journal. 1986 Aug;79(8):972-4.

24. Thomsen HS, Lokkegaard H, Munck 0 . Influence of normal central venous pressure on onset of function in renal allografts. Scandinavian journal of urology and nephrology. 1987;21(2):143-5.

25. Shackleton CR, Keown PA, McLoughlin MG, Nigro MK, Meloche RM, Schudamore CH, et al. Cadaver kidney transplantation with minimal delayed function: experience with perioperative strategies to enhance initial renal allograft function. Transplantation proceedings. 1995 Feb;27(1):1075-7.

26. Carlier M, Squifflet JP, Pirson Y, Gribomont B, Alexandre GP. Maximal hydration during anesthesia increases pulmonary arterial pressures and improves early function of human renal transplants. Transplantation. 1982 Oct;34(4):201-4.

27. Dawidson I, Berglin E, Brynger H, Reisch J. Intravascular volumes and colloid dynamics in relation to fluid management in living related kidney donors and recipients. Critical care medicine. 1987 Jul;15(7):631-6.

28. Anderson $\mathrm{CB}$, Etheredge EE. Human renal allograft blood flow and early renal function. Annals of surgery. 1977 Nov;186(5):564-7.

29. Warle MC, Cheung CL, Teerenstra S, Hoitsma AJ, van der Vliet JA. Cold ischaemia time and outcome of renal transplantation. Nederlands tijdschrift voor geneeskunde. 2010;154:B539. Koude-ischemietijd en resultaat niertransplantatie. Nederland, 1990-2007.

30. Moers C, Smits JM, Maathuis MH, Treckmann J, van Gelder F, Napieralski BP, et al. Machine perfusion or cold storage in deceased-donor kidney transplantation. N Engl J Med. 2009 Jan 1;360(1):7-19.

31. Snoeijs MG, Winkens B, Heemskerk MB, Hoitsma AJ, Christiaans MH, Buurman WA, et al. Kidney transplantation from donors after cardiac death: a 25-year experience. Transplantation. 2010 Nov 27;90(10):1106-12. 
IMPROVEMENTS IN KIDNEY TRANSPLANTATION FROM DONORS AFTER CARDIAC DEATH 


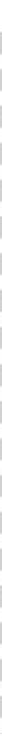


CHAPTER 5

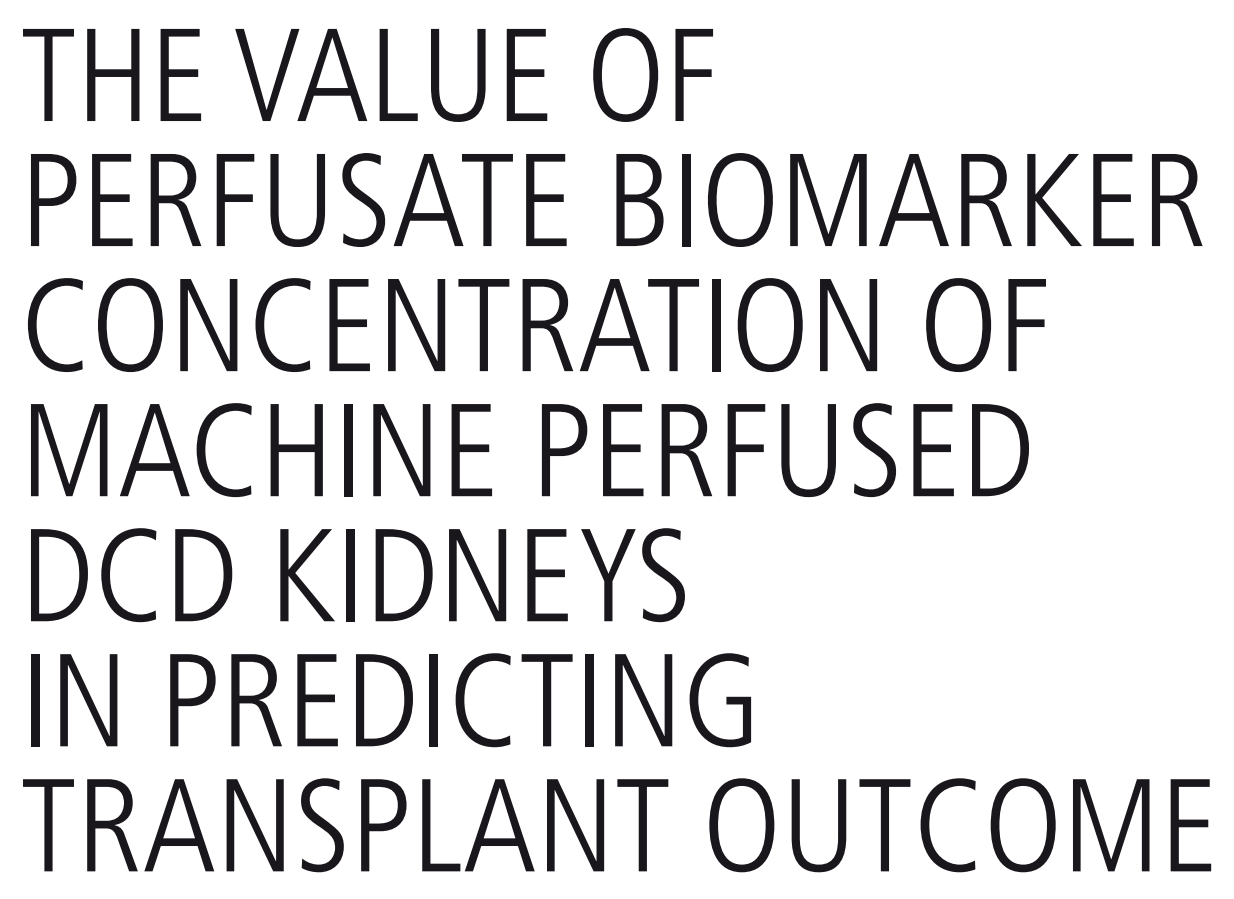




\section{ABSTRACT}

Background: Donation after cardiac death (DCD) increases the number of donor kidneys but is associated with more primary non-function (PNF) and delayed graft function (DGF). It has been suggested that biomarkers in the preservation solution of machine perfused kidneys may predict PNF, although evidence is lacking.

Methods: We analyzed the diagnostic accuracy of the perfusate biomarkers GST, LDH, H-FABP, redox-active iron, IL-18 and NGAL to predict PNF and DGF in 335 DCD kidneys preserved by hypothermic machine perfusion at our center between 1 January 1997 and 1 January 2008. The diagnostic accuracy of these biomarkers to predict PNF was evaluated with the area under the receiver operator characteristics curves (AURC). Additionally, the risk of DGF and graft failure was assessed.

Results: LDH and IL-18 concentrations were associated with PNF (OR 1.001, 95\% Cl $1.000-1.002, p=0.005$ and $1.001,95 \% \mathrm{Cl} 1.000-1.002, p=0.003$, respectively) in a multivariate analysis; the diagnostic accuracy for PNF was 'poor' for all biomarkers, but increased to 'fair' for redox-active iron and IL-18 in a multivariate analysis (AURC 0.701 and 0.700 , respectively). LDH and IL-18 concentrations were associated with DGF; biomarker concentration was not associated with 1-year graft survival.

Conclusions: The diagnostic accuracy of the perfusate biomarkers GST, LDH, H-FABP, redox-active iron, IL-18 and NGAL to predict viability of DCD kidneys varies from 'poor' to 'fair'. Therefore, DCD kidneys should not be discarded because of high biomarker perfusate concentration.

\section{Published as}

E.R.P. Hoogland, E.E. de Vries, M.H.L. Christiaans, B. Winkens, M.G.J. Snoeijs, L.W.E. van Heurn. The value of machine perfusion biomarker concentration in DCD kidney transplantation. Transplantation 2013;95(4):603-10 


\section{INTRODUCTION}

Renal transplantation is the treatment of choice for patients with endstage renal disease on dialysis treatment $(1,2)$. The growing waiting list for kidney transplantation has led to the use of kidneys from donors after cardiac death (DCD) as alternative organ source. Kidneys from these donors inevitably suffer from a period of warm ischemia (WIT), resulting in a higher percentage of delayed graft function (DGF) and primary non-function (PNF) compared with kidneys from conventional brain-dead donors (DBD) (3-5).

In recent years, kidney preservation by hypothermic machine perfusion has experienced renewed interest. In addition to the intended benefit of improved tissue preservation, machine perfusion also provides the opportunity to assess organ viability with the help of perfusion parameters and biomarkers in the perfusate (6, 7). The assessment of organ viability is especially important in marginal kidneys with their increased risk of developing DGF and particularly PNF. Perfusate biomarkers, including glutathione S-transferase (GST) and lactate dehydrogenase (LDH), are promising or accepted tools to accept or discard kidneys for transplantation (810). However, the value of perfusate biomarkers to predict organ viability is not or hardly known. Previous studies only assessed the value of biomarker concentration in selected kidneys and described the improvement of the results of DCD transplantation after the introduction of perfusate biomarkers to assess organ viability. Other studies included limited numbers of kidneys with an a priori good prognosis, and therefore without adequate power to determine if perfusate biomarker concentration can be safely used to discard valuable kidneys for transplantation (10-14).

We evaluated the predictive value of the concentration of perfusate biomarkers GST, LDH, heart-type fatty acid binding protein (H-FABP) and redoxactive iron of a large unselected group of DCD kidneys with a relative poor prognosis and a high incidence of graft failure, in which perfusion parameters and biomarkers have not been used to discard the organs. Additionally, new potential biomarkers interleukin (IL)-18 and neutrophil gelatinase-associated lipocalin (NGAL) were measured.

\section{MATERIALS AND METHODS}

All DCD kidneys preserved with hypothermic pulsatile machine perfusion at our center between 1 January 1997 and 1 January 2008, which were transplanted within the Eurotransplant region, were analyzed. This included kidneys procured at our center and kidneys procured elsewhere which were transplanted either at our center or elsewhere. 


\section{Organ procurement and preservation}

Kidneys were procured from uncontrolled (category 1 and 2) and controlled donors (category 3 and 4 ) according to the Maastricht DCD categories $(15,16)$. Kidneys were preserved with in situ preservation using a double-balloon triple-lumen (DBTL) catheter or with direct aortic cannulation after rapid laparotomy $(16,17)$. After donor nephrectomy, the kidneys were weighed and placed in sterile organ chambers on Gambro PF-3B perfusion machines (Gambro, Lund, Sweden). Kidneys were perfused with $500 \mathrm{~mL}$ of UW-MPS (Belzer MPS, Trans-Med Corporation, MN, USA) at a mean temperature of $4{ }^{\circ} \mathrm{C}$. After connection of the kidney to the machine, perfusion flow was set to a systolic pressure of $55 \mathrm{mmHg}$, which was maintained during the first 60 minutes by adjusting machine flow. After this, renal flow was kept constant. During perfusion, $\mathrm{pH}$ was adjusted to values more than 7.10.

\section{Sample collection and measurement}

Perfusate samples for biochemical analysis were taken at 1, 2 and 4 hours of perfusion (T1, T2 and T4, respectively). Samples were immediately stored at $-80^{\circ} \mathrm{C}$. The assays used for detection of GST and LDH were routine assays from our local laboratory. GST activity was determined by measuring the enzyme-catalyzed conjugation of GST with 1-chloro-2,4-dinitrobenzene, using a spectrophotometer at $\lambda 340 \mathrm{~nm}$. LDH measurement is based on the measurement of NAD+ formed via the enzymatic reaction of $\mathrm{LDH}$ with pyruvate and $\mathrm{NADH}$, using a spectrophotometer at $\lambda 340 \mathrm{~nm}$. For H-FABP, standard enzyme-linked immunosorbent assay (ELISA) kits (Human H-FABP ELISA kit, cat. number HK401; Hycult Biotechnology, Uden, The Netherlands) were used. For redox-active iron measurements, the bleomycin detectable iron assay, used before by our group, was applied (18).

At T0 to T4, machine perfusion characteristics (temperature, pressure, flow, and renovascular resistance) were registered. Perfusate biomarker concentration is expressed per $100 \mathrm{~g}$ kidney weight.

Additionally, IL-18 and NGAL concentrations (of transplanted kidneys only) at 4 hours after start of machine perfusion were measured. For NGAL and IL-18, standard ELISA kits were used (Human Lipocalin-2 ELISA kit, cat. number orb50149 and Human IL-18 ELISA kit, cat. number orb50153, respectively; Biorbyt, Cambridge, UK).

\section{Donor and recipient data}

Donor and perfusion characteristics were routinely recorded at our institution. Recipient follow-up data were kindly provided by the recipient transplant centers and was periodically updated in our database. The following graft characteristics were recorded: warm ischemia time (WIT), the period from circulatory arrest or stop of resuscitation until the initial cold flush; cold ischemia time (CIT), the period between the initial flush and the start of first anastomosis; and the anastomosis 
period, the time to complete both vascular anastomoses. Short-term graft function after transplantation was classified as 1) PNF: permanent inadequate renal function necessitating continuation of dialysis or retransplantation; 2) DGF: renal function that was ultimately life sustaining but required temporary dialysis in the first week after transplantation; and 3) immediate function (IF): renal function without the need of postoperative dialysis.

The immunosuppressive regimen evolved over the study period and depended on different trials. Immunosuppression was mainly based on a combination of a calcineurin inhibitor (cyclosporin or tacrolimus) and prednisolone. Depending on the protocol at the time, these were combined with azathioprine, mycophenolate mofetil, sirolimus or daclizumab in recipients with an increased immunological risk (e.g. HLA immunization and re-transplants).

Collection, storage and use of patient data were performed in agreement with the code of conduct 'use of data in health research' from the Dutch Federation of Biomedical Scientific Societies (http://www.federa.org/); According to Dutch law, Institutional Review Board (IRB) approval was not required for scientific analysis of anonymous data.

\section{Statistical analysis}

Continuous variables are presented as means \pm standard deviations (SD) if approximately normally distributed, and as median and interquartile range (IQR) otherwise. Categorical variables are presented as percentages.

Biomarker concentrations at four hours after the start of machine perfusion (T4) of discarded kidneys were compared with the biomarker concentrations of all transplanted kidneys and kidneys with PNF, using a Mann-Whitney-U test, and compared with their contralateral kidneys using a paired samples t-test or Wilcoxon signed rank test where appropriate.

The association between biomarker concentration at T4 and transplant outcome was first tested with univariate logistic regression analysis. For each biomarker, a multivariate logistic regression model was then applied to the data, correcting for potential confounders based on clinically relevance. Additionally, Cox proportional hazards model was used to assess the effect of these biomarkers on graft failure of functioning kidneys within one year after transplantation, correcting for the same confounders.

The predictive value of individual biomarker concentrations and of biomarker concentrations in addition to clinically relevant confounders were assessed by the area under the ROC-curve (AURC).

Correlations between biomarkers and estimated GFR (eGRF), calculated with the abbreviated modification of diet in renal disease equation (MDRD), at one 
year after transplantation and between biomarkers and perfusate hemoglobin were evaluated with the Pearson's test for normally distributed data and the Spearman's test otherwise.

Graft survival censored for recipient death with a functioning graft was calculated with the Kaplan-Meier method; the log-rank test was used to compare the survival curves of the specific biomarker concentration below and above the median.

All analyses were performed using Statistical Package for the Social Sciences (SPSS) software version 16.0; a p-value $\leq 0.05$ was considered statistically significant.

\section{RESULTS}

\section{Patients}

Between January 1997 and 2007, 517 DCD kidneys were machine perfused. From these kidneys, 153 were discarded based on vascular anatomy (e.g., multiple renal arteries, renal artery stenosis), macroscopic appearance (e.g., poor flush-out, cysts, renal capsula tears), long WIT, or if there were no suitable recipients. Of the remaining 364 kidneys, one pair of kidneys was a dual transplant and analyzed as one. Excluded from the analysis were 16 kidneys with major leakage at the arterial connection to the machine or without complete machine perfusion records, 10 kidneys transplanted outside the Eurotransplant region, and two recipients who died with an unknown graft function. The remaining 335 machine perfused DCD kidneys entered the analysis.

The donor, graft, and recipient characteristics are summarized in Table 5.1. Mean donor age was $45 \pm 16$ years. Most kidneys were from controlled donors ( $73 \%)$. The mean WIT and CIT were $26 \pm 11$ minutes and $27 \pm 6$ hours, respectively. Donors and recipients predominantly comprised men (61\% and $63 \%$, respectively). 


\begin{tabular}{|c|c|c|c|}
\hline & \multicolumn{3}{|c|}{ Univariate analysis } \\
\hline & & OR $(95 \% \mathrm{Cl})$ & $p$ \\
\hline \multicolumn{4}{|l|}{ Donor related } \\
\hline Age (years) & $45 \pm 16$ & $1.017(0.998-1.035)$ & 0.076 \\
\hline Sex (male) & $205(61 \%)$ & $0.895(0.513-1.559)$ & 0.694 \\
\hline Donor creatinine $(\mu \mathrm{mol} / \mathrm{L})$ & $93 \pm 38$ & $1.002(0.995-1.009)$ & 0.612 \\
\hline Maastricht category (uncontrolled) & $91(27 \%)$ & $1.078(0.594-1.955)$ & 0.806 \\
\hline Donor center (MUMC / other) $)^{b}$ & $34 / 66 \%$ & $1.052(0.595-1.858)$ & 0.862 \\
\hline \multicolumn{4}{|l|}{ Graft related } \\
\hline Warm ischemia time (min) & $26 \pm 11$ & $1.029(1.004-1.054)$ & 0.024 \\
\hline Cold ischemia time $(h)$ & $27 \pm 6$ & $0.997(0.955-1.041)$ & 0.890 \\
\hline Of which machine perfusion time (h) & $21 \pm 6$ & $1.004(0.961-1.049)$ & 0.854 \\
\hline Anastomosis time $(\mathrm{min})$ & $42 \pm 17$ & $1.015(1.000-1.030)$ & 0.051 \\
\hline GST T4 (U/L/100g) & $59.1(37.5-91.6)^{a}$ & $1.004(1.000-1.009)$ & 0.043 \\
\hline LDH T4 (U/L/100g) & $495(340-740)^{\mathrm{a}}$ & $1.001(1.001-1.002)$ & 0.001 \\
\hline H-FABP T4 (pg/L/100g) & $55.2(36.1-95.3)^{\mathrm{a}}$ & $1.004(1.000-1.007)$ & 0.048 \\
\hline $\begin{array}{l}\text { Redox-active iron T4 } \\
(\mu \mathrm{mol} / \mathrm{L} / 100 \mathrm{~g})(\mathrm{N}=187)\end{array}$ & $3.9 \pm 1.1$ & $1.522(1.077-2.152)$ & 0.017 \\
\hline IL-18 (pg/mL/100g) $(\mathrm{N}=299)$ & $373(226-600)^{a}$ & $1.001(1.000-1.002)$ & 0.001 \\
\hline NGAL T4 (ng/mL/100g) $(\mathrm{N}=290)$ & $18.4(10.2-29.1)^{a}$ & $0.996(0.979-1.013)$ & 0.323 \\
\hline Renovascular resistance T0 & $1.06 \pm 0.69$ & $1.896(1.306-2.752)$ & 0.001 \\
\hline \multicolumn{4}{|l|}{ Recipient related } \\
\hline Age (years) & $51 \pm 13$ & $1.011(0.990-1.033)$ & 0.294 \\
\hline Sex (male) & $210(63 \%)$ & $0.854(0.494-1.477)$ & 0.572 \\
\hline Re-transplantation (yes) & $48(14 \%)$ & $0.911(0.418-1.988)$ & 0.815 \\
\hline Total HLA mismatches & $2.6 \pm 1.1$ & $0.906(0.705-1.165)$ & 0.443 \\
\hline Transplant center (regional / export) & $42 / 58 \%$ & $1.000(0.581-1.721)$ & $>0.999$ \\
\hline Kidney disease (renovascular / other) & $26 / 74 \%$ & $0.938(0.486-1.807)$ & 0.847 \\
\hline Dialysis time (years) & $3.1 \pm 2.4$ & $1.132(1.022-1.254)$ & 0.017 \\
\hline Dialysis type (hemodialysis) & $202(61 \%)$ & $1.170(0.670-2.045)$ & 0.581 \\
\hline Peak PRA & $4.1 \pm 14.1$ & $0.986(0.948-1.026)$ & 0.499 \\
\hline Cyclosporine/tacrolimus/none (\%) & $28 / 68 / 4 \%$ & $1.136(0.612-2.109)$ & 0.687 \\
\hline Anti-metabolite (yes) & $208(62 \%)$ & $0.601(0.350-1.031)$ & 0.065 \\
\hline Sirolimus (yes) & $60(18 \%)$ & $1.132(0.572-2.240)$ & 0.722 \\
\hline Induction therapy (yes) & $42(13 \%)$ & $1.105(0.501-2.437)$ & 0.805 \\
\hline
\end{tabular}

a Expressed as median (interquartile range).

b MUMC: Maastricht University Medical Center. 


\section{Discarded kidneys}

GST and LDH concentrations (in U/L/100 g) at T4 of discarded kidneys were higher than that of transplanted kidneys (median 101.3 vs. $59.1 ; \mathrm{p}<0.001$ and 682.7 vs. 495.8; $\mathrm{p}<0.001$, respectively). Compared with the transplanted kidneys with PNF, GST was significantly higher in the discarded kidneys (median 65.6 vs. 101.3; $p<0.001$, respectively). A paired-samples test, however, showed no significant difference in GST $(\mathrm{N}=25)$ and LDH $(\mathrm{N}=22)$ concentrations between discarded kidneys and their contralateral transplanted kidney (median, 80.0 vs. 88.2 for GST and 715.2 vs. 726.0 for $\mathrm{LDH} ; \mathrm{p}=0.989$ and $\mathrm{p}=0.506$, Wilcoxon signed rank test, respectively).

Differences in biomarker concentration of functioning kidneys and kidneys with PNF.

\begin{tabular}{llll}
\hline & No PNF & PNF & p \\
\hline GST $(\mathrm{U} / \mathrm{L} / 100 \mathrm{~g})^{\mathrm{a}}$ & $55.7(36.5-87.7)$ & $65.6(48.1-100.7)$ & 0.034 \\
\hline LDH $(\mathrm{U} / \mathrm{L} / 100 \mathrm{~g})^{\mathrm{a}}$ & $477.5(330.4-679.6)$ & $631.3(417.3-870.9)$ & 0.002 \\
\hline H-FABP $(\mathrm{pg} / \mathrm{L} / 100 \mathrm{~g})^{\mathrm{a}}$ & $53.9(36.1-94.3)$ & $67.3(35.8-142.9)$ & 0.176 \\
\hline Redox-active iron $(\mu \mathrm{mol} / \mathrm{L} / 100 \mathrm{~g})$ & $3.8 \pm 1.1$ & $4.3 \pm 1.1$ & 0.015 \\
\hline IL-18 $(\mathrm{pg} / \mathrm{mL} / 100 \mathrm{~g})^{\mathrm{a}}$ & $357.6(225.7-533.5)$ & $472.9(227.0-933.4)$ & 0.031 \\
\hline NGAL $(\mathrm{ng} / \mathrm{mL} / 100 \mathrm{~g})^{\mathrm{a}}$ & $17.6(10.2-29.2)$ & $19.3(10.4-26.1)$ & 0.953 \\
\hline
\end{tabular}

a Expressed as median (interquartile range).

\section{Short-term graft function}

Of the transplanted kidneys, 67 kidneys developed PNF (20\%), 205 kidneys DGF (61\%), and 63 kidneys IF (19\%).

The perfusate concentrations of the different biomarkers at T4 of functioning kidneys and kidneys with PNF are shown in Table 5.2. In separate multivariate analyses of biomarker concentrations at T4, only LDH and IL-18 were independent risk factors for PNF and LDH, redox-active iron and IL-18 were independent risk factors for DGF (Table 5.3).

The ROC-curves of all individual biomarker concentrations are shown in Figure 5.1A and 5.1B with the AURC and $95 \% \mathrm{Cl}$ shown between brackets. The predictive values of LDH and redox-active iron at T4 for PNF were highest but poor. Adding biomarker concentrations to a multivariate model with clinical risk factors only (donor age, donor category, WIT, CIT, anastomosis time, and renovascular resistance at T0) with an AURC of $0.686,95 \% \mathrm{Cl} 0.612-0.760$ (graph not shown), showed a modest improvement for LDH, redox-active iron and IL-18 (Figure 5.1C and 5.1D). 
A

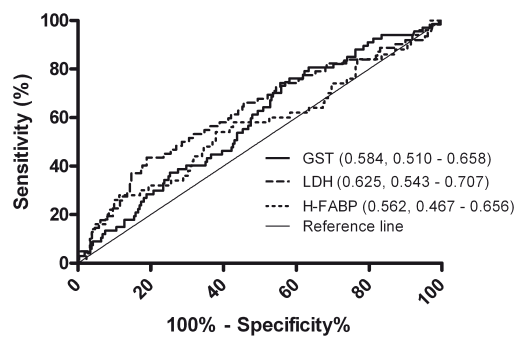

C

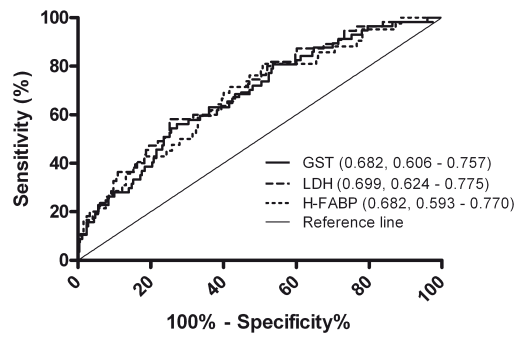

B

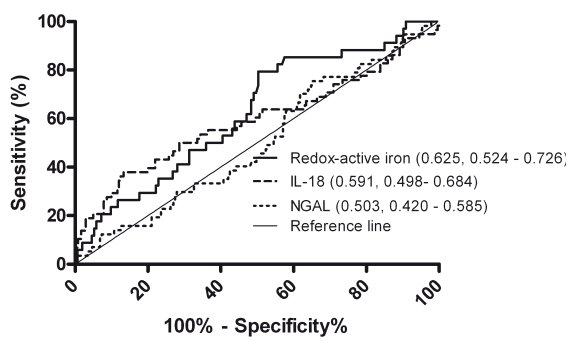

D

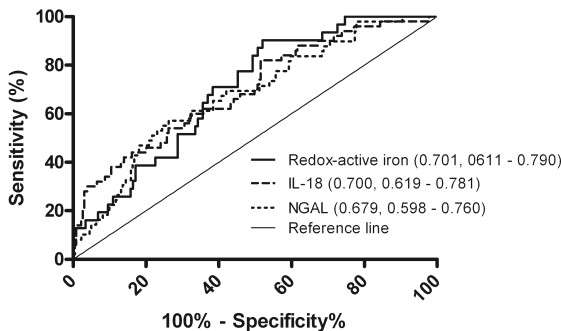

Figure 5.1 Receiver operating characteristics (ROC)-curve for PNF: (A) individual GST, LDH and $\mathrm{H}$-FABP concentrations at T4, (B) individual redox-active iron, IL-18 and NGAL concentrations at T4, (C) ROC-curve of the multivariate model with individual biomarkers (GST, LDH and H-FABP); other variables are donor age, donor category (uncontrolled/controlled), warm ischemia time, cold ischemia time, anastomosis time and renovascular resistance at T0 and (D) multivariate model with individual biomarkers (redox-active iron, IL-18 and NGAL), with the same variables as (C). The number in brackets indicates the area under the curve for each line and the accompanying $95 \% \mathrm{Cl}$.

Redox-active iron and LDH concentrations were weakly correlated with perfusate haemoglobin concentration $(r=.216, p=0.004$ and $r s=.362, p<0.001$, respectively), indicating that iron and $\mathrm{LDH}$ release from erythrocytes still present in the graft after flush-out may represent a minor contribution to the perfusate redoxactive iron and LDH concentration. 
Multivariate analysis for primary non-function, delayed graft function, and graft failure ${ }^{a}$

\begin{tabular}{|c|c|c|}
\hline & Odds ratio $(95 \% \mathrm{Cl})$ & $p$ \\
\hline \multicolumn{3}{|c|}{ Risk of PNF (biomarker concentration at T4) } \\
\hline GST & $1.004(0.998-1.009)$ & 0.161 \\
\hline $\mathrm{LDH}$ & $1.001(1.000-1.002)$ & 0.005 \\
\hline $\mathrm{H}-\mathrm{FABP}$ & $1.002(0.998-1.007)$ & 0.280 \\
\hline Redox-active iron & $1.462(0.974-2.195)$ & 0.067 \\
\hline IL-18 & $1.001(1.000-1.002)$ & 0.003 \\
\hline NGAL & $0.999(0.980-1.018)$ & 0.919 \\
\hline \multicolumn{3}{|c|}{ Risk of DGF (biomarker concentration at T4) } \\
\hline GST & $1.006(0.999-1.013)$ & 0.112 \\
\hline $\mathrm{LDH}$ & $1.002(1.001-1.004)$ & 0.007 \\
\hline H-FABP & $1.007(1.000-1.014)$ & 0.064 \\
\hline Redox-active iron & $1.532(1.045-2.245)$ & 0.029 \\
\hline IL-18 & $1.003(1.001-1.004)$ & 0.002 \\
\hline \multirow[t]{2}{*}{ NGAL } & $1.000(0.982-1.018)$ & 0.994 \\
\hline & Hazards ratio $(95 \% \mathrm{CI})$ & $\mathrm{p}$ \\
\hline \multicolumn{3}{|c|}{$\begin{array}{l}\text { Risk of graft failure within the first year } \\
\text { posttransplant }\end{array}$} \\
\hline GST & $0.993(0.978-1.008)$ & 0.348 \\
\hline $\mathrm{LDH}$ & $0.998(0.996-1.001)$ & 0.223 \\
\hline H-FABP & $0.987(0.969-1.005)$ & 0.165 \\
\hline Redox-active iron & $0.999(0.552-1.808)$ & 0.997 \\
\hline IL-18 & $1.000(0.998-1.002)$ & 0.996 \\
\hline NGAL & $0.996(0.961-1.032)$ & 0.819 \\
\hline
\end{tabular}

a For each biomarker, a separate multivariate analysis was done. Only odds ratios and p-values for the specific biomarker are given. Other variables in each model were donor age, donor category (uncontrolled/controlled), warm ischemia time, cold ischemia time, anastomosis time, and renovascular resistance at T0.

${ }^{\mathrm{b}}$ Cox proportional hazards model of functional kidneys, censored for death with a functioning graft.

\section{Long-term graft survival}

The median follow-up after transplantation was 6.8 (IQR 4.0 - 9.3) years. Death censored graft survival at 1 and 5 years after transplantation was $76 \%$ and $68 \%$, respectively.

In multivariate Cox proportional hazards models, biomarker concentrations were not significantly associated with the risk of graft failure in the first year after transplantation (Table 5.3). 
Only LDH was significantly correlated with eGFR at one year after transplantation ( $r s=-177 ; p=0.006$ ). Other biomarkers showed a non-significant negative correlation with eGFR (data not shown), except for redox-active iron ( $r s=.023, p=0.785$ ).

Figure 5.2 shows the graft survival of all transplanted kidneys for biomarker concentrations below and above the mean or median. For GST, LDH and H-FABP, a concentration above the median resulted in a significantly shorter graft survival. Graft survival was equivalent for kidneys with redox-active iron, IL-18, and NGAL concentrations below or above the mean or median. Additionally, Cox proportional hazards model was used to see whether this effect of biomarker concentrations above the median persisted after correction for potential confounders. None of the biomarkers remained significant in this analysis (data not shown).

\section{DISCUSSION}

Kidneys from DCD donors are a valuable extension of the donor pool, but have higher rates of DGF and, in some studies, PNF compared to kidneys from DBD donors $(4,19,20)$. Despite higher rates of DGF and PNF, recipients of DCD kidneys have better survival rates than patients who continue dialysis treatment while waiting for a kidney from a DBD donor (21). The long-term graft survival of functioning DCD kidneys is similar to kidneys from DBD donors and between uncontrolled and controlled DCD kidneys; also, the recipient survival does not differ significantly $(20,22)$.

It remains a challenge to reduce the PNF rate of transplanted kidneys without the discard of too many viable organs. PNF is associated with unnecessary risks of surgery and immunosuppression and recipients may become sensitized to donor antigens, which decreases the opportunities for retransplantation (19). Interventions to reduce the risk of PNF include organ preservation by rapid laparotomy and direct aortic cannulation for controlled DCD donors, selection of kidneys from old DCD donors by histological assessment of pre-implantation biopsies, and careful management of recipient hemodynamics during transplantation to ensure adequate reperfusion of the graft $(16,23,24)$. Machine perfusion offers the opportunity for pretransplantation viability assessment of the procured kidney and includes perfusion characteristics and perfusate biomarker concentrations. However, the predictive value of perfusate biomarkers to assess PNF remains unknown. Although Moers et al. (2012) concluded that perfusate biomarker concentrations should not lead to kidney discard, the PNF percentage in this study, $2.3 \%$ overall and $2.7 \%$ in 75 DCD kidneys, makes predictive value assessment for PNF, the most important reason for kidney discard, virtually impossible (12). 

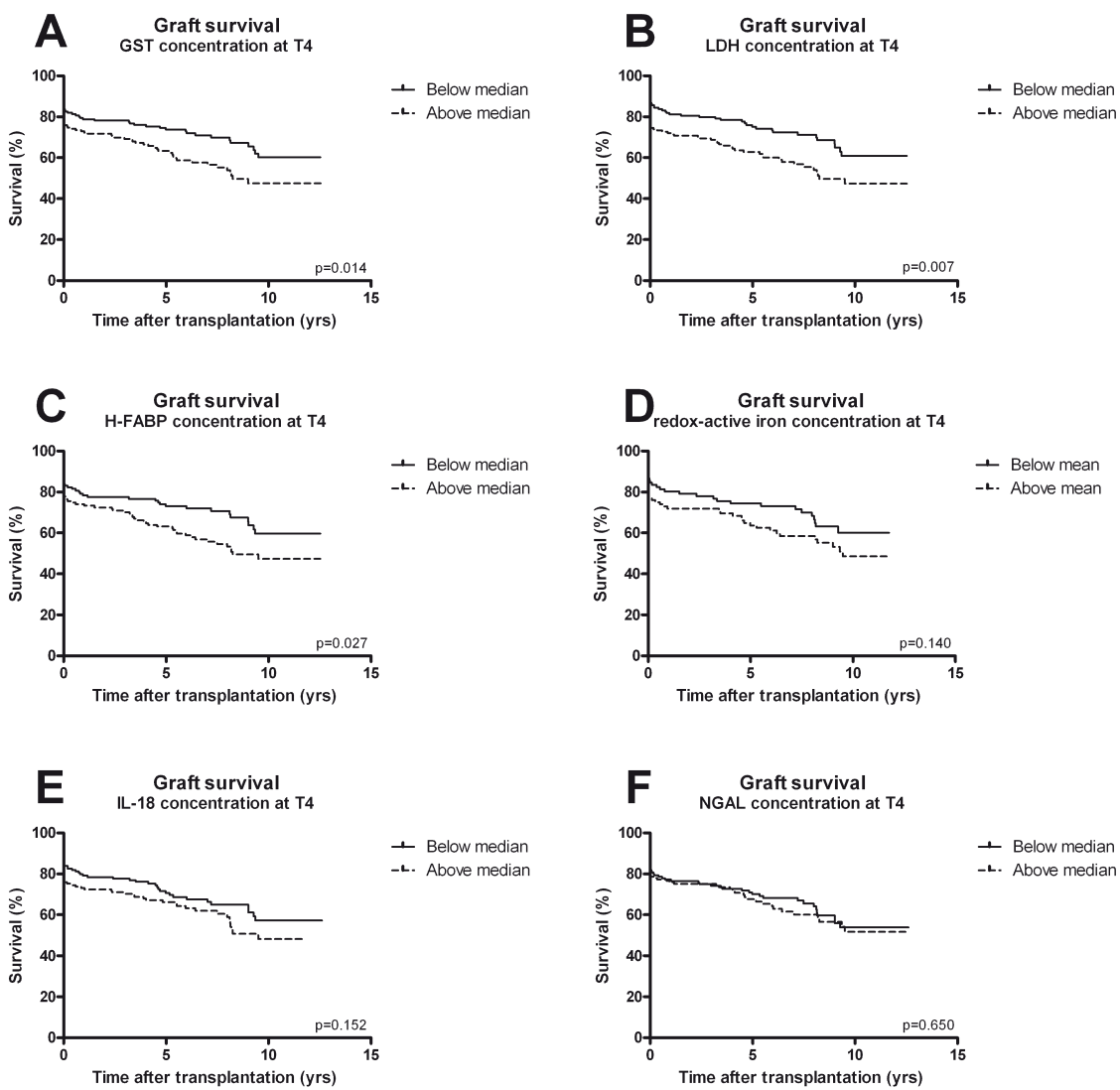

Figure 5.2 Kaplan-Meier graft survival curves of all transplanted machine perfused DCD kidneys. Graft survival of kidneys with A) GST, B) LDH, C) H-FABP, D) redox-active iron, E) IL-18 and F) NGAL concentrations below and above the mean or median concentration at T4, all censored for recipient death with a functioning graft.

In Maastricht, all procured DCD kidneys were machine preserved for study purposes, regardless of their condition, and included very marginal kidneys, which explains the high discard rate. Kidneys were not discarded because of machine perfusion characteristics: the data were not provided to the recipients' nephrologists, who decided to accept an organ for transplantation.

GST, an enzyme localized in the renal tubules, has been frequently used for viability testing $(9,10,12)$. Also our group has shown a correlation between machine perfusate GST concentration and short-term kidney function (10). However, when kidneys with high GST concentrations showed a favorable outcome, we discontinued its use for viability testing. Therefore, only kidneys transplanted since 1997 were included in this study. 
In this study, LDH and IL-18 showed a significant association with early kidney function. LDH is a nonspecific cellular injury marker which is found in almost all body tissues. LDH measured in machine perfusate is either released by the perfused kidney or by hemolytic erythrocytes from the capillaries of the perfused kidneys (25). DCD kidneys sustain a period of warm ischemia with stasis of blood in the organs. This may be associated with a relatively high concentration of erythrocytes and blood clots in the capillaries after a poor initial flush after cardiac arrest. This may explain the relatively good association of $\mathrm{LDH}$ and the initial graft function in this study, because only DCD kidneys were included. In the present study, a weak correlation between $\mathrm{LDH}$ and hemoglobin was found. In other studies, with mainly kidneys from braindead donors, LDH was not correlated with early post-transplant outcome (12).

$\mathrm{H}-\mathrm{FABP}$ is a cytosolic protein localized in the distal tubules and is involved in transportation of free fatty acids from cytosol to mitochondria for catabolism. $\mathrm{H}-\mathrm{FABP}$ has been associated with early release following tissue injury to the kidneys (11). Its clinical value as perfusate viability marker is relatively unknown.

Redox-active iron has been implicated in the pathophysiology of I/R injury in several organ systems. Redox-active iron is released during I/R injury and is believed to catalyze the formation of oxygen-free radicals, which are known to induce apoptotic and necrotic cell death and subsequent inflammatory responses (26). In the present study, redox-active iron was strongly associated with PNF in the univariate analysis, but did not remain significantly associated when corrected for confounders.

IL-18 is a pro-inflammatory cytokine produced by macrophages and other cell types present in the kidney during I/R injury and contributes to inflammatory reactions such as modulation of macrophage activity. IL-18 may promote immune- or nonimmune-mediated tissue damage via a multitude of mechanisms $(27,28)$.

NGAL, also known as lipocalin-2, is generally expressed in several human tissues, including the kidney. NGAL expression is induced in injured epithelia and has recently been discovered as a novel biomarker of acute kidney injury (29). However, in this study, NGAL concentration was not associated with short-term graft function.

Enzymes released after cell death relate to each other. However, most biomarkers represent a measure of different processes of I/R injury, including cell death and inflammation, and biomarkers are present in different cells. Depending on the severity of the injury and the period of time afterwards, the association between $\mathrm{I} / \mathrm{R}$ injury and biomarker concentration may vary.

There are several potential confounders that may influence the reliability of these biomarkers in this study, including the volume of preservation fluid used during in situ perfusion, before procurement, and the volume and period of flushing on the back-table. This will also result in a certain amount of wash-out of these biomarkers before these kidneys are connected to the perfusion machine. 
The concentration of biomarkers of machine perfused kidneys also depends on the proportion of the kidney which is perfused and thus flow through the kidney. When parts of the renal microcirculation are occluded by thrombosis or oedema, the flow $(\mathrm{mL} / \mathrm{min} / 100 \mathrm{~g})$ will be relatively low, which results in poor washout of biomarkers released from damaged cells. We have shown previously that renovascular resistance itself was associated with short-term graft function (30). Furthermore, it is unknown if age affects the perfusate biomarker concentration. This is difficult to assess as age itself is an important risk factor for poor kidney function in DCD kidneys (31). Additionally, results may be biased by the unknown outcome of discarded kidneys. However, there are no possibilities to correct for this potential confounder.

All tested biomarkers, except for NGAL, were associated with PNF in the univariate analyses. As all these biomarkers were associated with PNF, separate multivariate analyses were done to correct for confounding factors. LDH and IL-18 remained significantly associated with PNF in the multivariate analyses. Associations with DGF are less important, and have little clinical implications, because long-term survival rates of DCD kidneys with DGF do not significantly differ from DCD kidneys with IF $(3,32-34)$. The predictive value of individual biomarkers for PNF was poor. Only redox-active iron and IL-18 improved to 'fair' after including clinically relevant confounders in a multivariate analysis.

We have shown for the first time that the diagnostic accuracy of the commonly used perfusate biomarkers GST, LDH, and H-FABP and newly assessed biomarkers redox-active iron, IL-18, and NGAL in predicting viability of DCD kidneys is poor. These biomarkers should not lead to discard of DCD kidneys. Presently, there are no other potential viability markers which have shown an improvement in the assessment of kidney viability. 


\section{REFERENCES}

1. Wolfe RA, Ashby VB, Milford EL, Ojo AO, Ettenger RE, Agodoa LY, et al. Comparison of mortality in all patients on dialysis, patients on dialysis awaiting transplantation, and recipients of a first cadaveric transplant. N Engl J Med. 1999 Dec 2;341(23):1725-30.

2. Rabbat CG, Thorpe KE, Russell JD, Churchill DN. Comparison of mortality risk for dialysis patients and cadaveric first renal transplant recipients in Ontario, Canada. J Am Soc Nephrol. 2000 May;11(5):917-22.

3. Weber M, Dindo D, Demartines N, Ambuhl PM, Clavien PA. Kidney transplantation from donors without a heartbeat. N Engl J Med. 2002 Jul 25;347(4):248-55.

4. Cho YW, Terasaki PI, Cecka JM, Gjertson DW. Transplantation of kidneys from donors whose hearts have stopped beating. N Engl J Med. 1998 Jan 22;338(4):221-5.

5. Snoeijs MGJ, Heurn LWEv, Mook NKAv, Christiaans MH, Hooff JPv. Controlled donation after cardiac death: a European perspective. Transplant rev. 2007;21(4):219-29.

6. Jochmans I, Moers C, Smits JM, Leuvenink HG, Treckmann J, Paul A, et al. Machine perfusion versus cold storage for the preservation of kidneys donated after cardiac death: a multicenter, randomized, controlled trial. Annals of surgery. 2010 Nov;252(5):756-64.

7. Moers C, Smits JM, Maathuis MH, Treckmann J, van Gelder F, Napieralski BP, et al. Machine perfusion or cold storage in deceased-donor kidney transplantation. N Engl J Med. 2009 Jan 1;360(1):7-19.

8. St Peter SD, Imber CJ, Friend PJ. Liver and kidney preservation by perfusion. Lancet. 2002 Feb 16;359(9306):604-13.

9. Navarro AP, Sohrabi S, Colechin E, Griffiths C, Talbot D, Soomro NA. Evaluation of the ischemic protection efficacy of a laparoscopic renal cooling device using renal transplantation viability assessment criteria in a porcine model. The Journal of urology. 2008 Mar;179(3):1184-9.

10. Daemen JW, Oomen AP, Janssen MA, van de Schoot L, van Kreel BK, Heineman E, et al. Glutathione S-transferase as predictor of functional outcome in transplantation of machine-preserved non-heartbeating donor kidneys. Transplantation. 1997 Jan 15;63(1):89-93.

11. Gok MA, Pelzers M, Glatz JF, Shenton BK, Buckley PE, Peaston R, et al. Do tissue damage biomarkers used to assess machine-perfused NHBD kidneys predict long-term renal function post-transplant? Clinica chimica acta; international journal of clinical chemistry. 2003 Dec;338(1-2):33-43.

12. Moers C, Varnav OC, van Heurn E, Jochmans I, Kirste GR, Rahmel A, et al. The value of machine perfusion perfusate biomarkers for predicting kidney transplant outcome. Transplantation. 2010 Nov 15;90(9):96673.

13. Kievit JK, Nederstigt AP, Oomen AP, Janssen MA, Schoot L, Kootstra G. Release of alpha-glutathione S-transferase (alpha GST) and pi-glutathione S-transferase (pi GST) from ischemic damaged kidneys into the machine perfusate--relevance to viability assessment. Transplantation proceedings. 1997 Dec;29(8):3591-3.

14. Kievit JK, Oomen AP, Janssen MA, van Kreel BK, Heineman E, Kootstra G. Viability assessment of nonheart-beating donor kidneys by alpha glutathione $S$-transferase in the machine perfusate. Transplantation proceedings. 1997 Feb-Mar;29(1-2):1381-3.

15. Kootstra G, Daemen JH, Oomen AP. Categories of non-heart-beating donors. Transplantation proceedings. 1995 Oct;27(5):2893-4.

16. Snoeijs MG, Dekkers AJ, Buurman WA, van den Akker L, Welten RJ, Schurink GW, et al. In situ preservation of kidneys from donors after cardiac death: results and complications. Ann Surg. 2007 Nov;246(5):844-52.

17. Wind J, Snoeijs MG, van der Vliet JA, Winkens B, Christiaans MH, Hoitsma AJ, et al. Preservation of kidneys from controlled donors after cardiac death. The British journal of surgery. 2011 Jun;98(9):1260-6.

18. de Vries B, Snoeijs MG, von Bonsdorff L, Ernest van Heurn LW, Parkkinen J, Buurman WA. Redox-active iron released during machine perfusion predicts viability of ischemically injured deceased donor kidneys. Am J Transplant. 2006 Nov;6(11):2686-93.

19. Snoeijs MG, Winkens B, Heemskerk MB, Hoitsma AJ, Christiaans MH, Buurman WA, et al. Kidney 
transplantation from donors after cardiac death: a 25-year experience. Transplantation. 2010 Nov 27;90(10):1106-12.

20. Barlow AD, Metcalfe MS, Johari Y, Elwell R, Veitch PS, Nicholson ML. Case-matched comparison of longterm results of non-heart beating and heart-beating donor renal transplants. The British journal of surgery. 2009 Jun;96(6):685-91.

21. Snoeijs MG, Schaubel DE, Hene R, Hoitsma AJ, Idu MM, ljzermans JN, et al. Kidneys from donors after cardiac death provide survival benefit. J Am Soc Nephrol. 2010 Jun;21(6):1015-21.

22. Hoogland ER, Snoeijs MG, Winkens B, Christaans MH, van Heurn LW. Kidney Transplantation from Donors after Cardiac Death: Uncontrolled versus Controlled Donation. Am J Transplant. 2011 Jun 10.

23. Snoeijs MG, Buurman WA, Christiaans MH, van Hooff JP, Goldschmeding R, van Suylen RJ, et al. Histological assessment of preimplantation biopsies may improve selection of kidneys from old donors after cardiac death. Am J Transplant. 2008 Sep;8(9):1844-51.

24. Snoeijs MG, Wiermans B, Christiaans MH, van Hooff JP, Timmerman BE, Schurink GW, et al. Recipient hemodynamics during non-heart-beating donor kidney transplantation are major predictors of primary nonfunction. Am J Transplant. 2007 May;7(5):1158-66.

25. Cohen JA, Brecher ME, Bandarenko N. Cellular source of serum lactate dehydrogenase elevation in patients with thrombotic thrombocytopenic purpura. Journal of clinical apheresis. 1998;13(1):16-9.

26. de Vries B, Walter SJ, von Bonsdorff L, Wolfs TG, van Heurn LW, Parkkinen J, et al. Reduction of circulating redox-active iron by apotransferrin protects against renal ischemia-reperfusion injury. Transplantation. 2004 Mar 15;77(5):669-75.

27. Wu H, Craft ML, Wang P, Wyburn KR, Chen G, Ma J, et al. IL-18 contributes to renal damage after ischemiareperfusion. J Am Soc Nephrol. 2008 Dec;19(12):2331-41.

28. Wang J, Long Q, Zhang W, Chen N. Protective effects of exogenous interleukin 18-binding protein in a rat model of acute renal ischemia-reperfusion injury. Shock (Augusta, Ga. 2012 Mar;37(3):333-40.

29. Mishra J, Dent C, Tarabishi R, Mitsnefes MM, Ma Q, Kelly C, et al. Neutrophil gelatinase-associated lipocalin (NGAL) as a biomarker for acute renal injury after cardiac surgery. Lancet. 2005 Apr 2-8;365(9466):1231-8.

30. de Vries EE, Hoogland ER, Winkens B, Snoeijs MG, van Heurn LW. Renovascular Resistance of MachinePerfused DCD Kidneys Is Associated with Primary Nonfunction. Am J Transplant. 2011 Oct 3.

31. Snoeijs MG, Schaefer S, Christiaans MH, van Hooff JP, van den Berg-Loonen PM, Peutz-Kootstra CJ, et al. Kidney transplantation using elderly non-heart-beating donors: a single-center experience. Am J Transplant. 2006 May;6(5 Pt 1):1066-71.

32. Renkens JJ, Rouflart MM, Christiaans MH, van den Berg-Loonen EM, van Hooff JP, van Heurn LW. Outcome of nonheart-beating donor kidneys with prolonged delayed graft function after transplantation. Am J Transplant. 2005 Nov;5(11):2704-9.

33. Wijnen RM, Booster MH, Stubenitsky BM, de Boer J, Heineman E, Kootstra G. Outcome of transplantation of non-heart-beating donor kidneys. Lancet. 1995 Apr 29;345(8957):1067-70.

34. Sanchez-Fructuoso Al, Marques M, Prats D, Conesa J, Calvo N, Perez-Contin MJ, et al. Victims of cardiac arrest occurring outside the hospital: a source of transplantable kidneys. Annals of internal medicine. 2006 Aug 1;145(3):157-64. 
THE VALUE OF PERFUSATE BIOMARKER CONCENTRATION OF MACHINE PERFUSED DCD KIDNEYS 


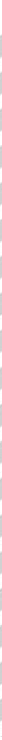


CHAPTER 6

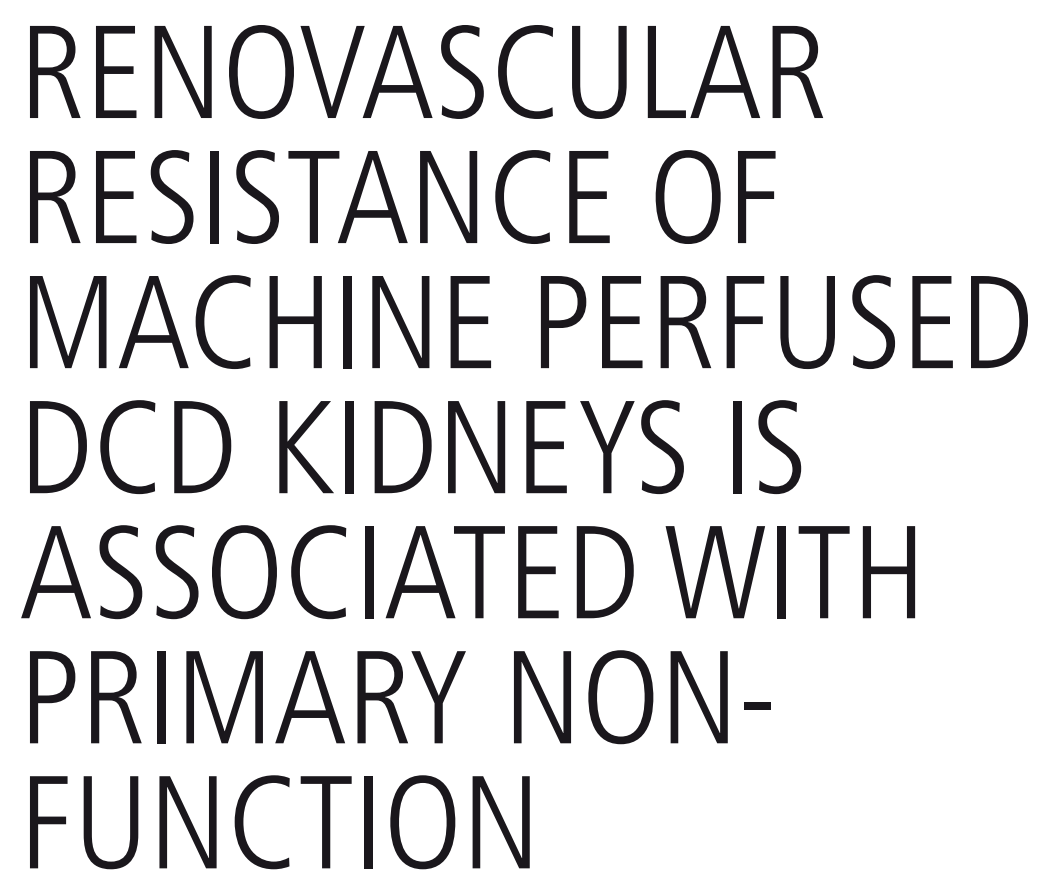




\section{ABSTRACT}

Background: Donation after cardiac death (DCD) has shown to be a valuable extension of the donor pool despite a higher percentage of primary non-function (PNF). Limiting the incidence of PNF is of vital importance. Renovascular resistance is believed to predict graft outcome; however, the literature is inconsistent. Therefore, we studied whether renovascular resistance is associated with PNF and whether this parameter should be used to discard donor kidneys.

Methods: All transplanted DCD kidneys preserved by machine perfusion at our center between 1993 and 2007 were analyzed $(N=440)$. The effects of renovascular resistance on PNF, delayed graft function (DGF), and graft and patient survival were examined using multivariate analyses; predictive quality by calculating the area under the curve (AUC).

Results: We showed that renovascular resistance at the start of machine perfusion was significantly and independently associated with PNF (OR $2.040,95 \% \mathrm{CI}$ 1.362 - 3.056; $p=0.001)$, and DGF (OR 2.345, 95\% Cl 1.110 - 4.955; $p=0.025)$. Predictive quality was moderate $(0.609,95 \% \mathrm{Cl} 0.538-0.681)$. Graft and patient survival were not associated with renovascular resistance.

Conclusion: Renovascular resistance is an independent risk factor for PNF in DCD kidneys; however, the predictive value is relatively low.

\section{Published as}

E.E. de Vries, E.R.P. Hoogland, B. Winkens, M.G.J. Snoeijs, L.W.E. van Heurn. Renovascular resistance of machineperfused DCD kidneys is associated with primary non-function. Am J Transplant 2011;11(12):2685-91 


\section{INTRODUCTION}

Kidney transplantation is the treatment of choice for patients with end stage renal disease (1-3). The increasing demand for organ donors has led to the use of alternative sources of grafts to expand the donor pool. One of these alternatives includes organs from donation after cardiac death (DCD). These kidneys suffer from a period of warm ischemia between cardiac arrest and cold flushing. As a result a higher percentage of kidneys suffer from primary non-function (PNF) and delayed graft function (DGF) (4-6).

In recent years, kidney preservation by hypothermic machine perfusion has experienced renewed interest. In addition to the intended benefit of improved tissue preservation, machine perfusion also provides the opportunity to determine perfusion parameters including perfusion pressure, perfusion flow and renovascular resistance. These parameters have been advocated to predict graft function after transplantation (7-10). The assessment of organ viability is especially important in marginal kidneys with their increased risk of developing PNF. However, the value of machine perfusion parameters to predict PNF is relatively unknown, as the incidence of PNF after transplantation is generally low. DGF, as an alternative outcome measure, is less useful because DGF does not affect long-term survival in DCD kidneys (4-6, 1114).

In a large group of marginal machine perfused DCD kidneys in which perfusion parameters were not used to discard the organs, we primarily studied whether renovascular resistance is independently associated with PNF and whether renovascular resistance can be safely used to discard donor kidneys. Additionally, we studied whether renovascular resistance is associated with DGF and long term graft and patient survival.

\section{MATERIALS AND METHODS}

All DCD kidneys, which were machine perfused at our center between March 1993 and May 2007 and were transplanted in the Eurotransplant region, as well as their contralateral kidney, were included in this study. This group consisted of (1) kidneys procured at our center, (2) kidneys taken to our center for machine preservation until transplanted elsewhere, or (3) kidneys procured elsewhere, but machine perfused until transplanted at our center. Kidneys were either accepted or discarded, based on donor characteristics, warm ischemia time, macroscopic appearance or anatomical variances of the graft. Kidneys were procured from donors after cardiac death according to the Maastricht DCD categories (15-17). Maastricht categories 1 and 2 together were classified as uncontrolled. Collection, storage and use of patient data were performed in agreement with the code of conduct "use of data in health research" from the Dutch federation of biomedical scientific societies; 
ethics approval was not required. Donor, graft, machine perfusion and recipient characteristics were prospectively documented. The predonation GFR was estimated by the abbreviated Modification of Diet in Renal Disease formula (MDRD) (18). The following graft characteristics were recorded: warm ischemia time, the period from circulatory arrest or stop of resuscitation until the initial cold flush of the kidneys; cold ischemia time, the period between the initial flush and the start of first anastomosis of the recipient operation; and the anastomosis period, the time to complete both vascular anastomoses. Short-term graft function after transplantation was classified as 1) PNF: inadequate renal function necessitating continuation of dialysis or retransplantation; 2) DGF: renal function which was ultimately life sustaining but required temporary dialysis after transplantation; and 3) IF: immediate renal function without the need of postoperative dialysis. Recipients were followed up for graft and patient survival. GFR was reported 3 months after transplantation and yearly thereafter. The allograft failure date was defined as the date of return to dialysis or retransplantation, whichever comes first.

\section{Preservation}

After organ recovery, kidneys were weighed and machine preserved on a Gambro PF-3B pulsatile perfusion machine (Gambro, Lund, Sweden) with Belzer's hypothermic machine preservation UW gluconate solution at a mean temperature of $4^{\circ} \mathrm{C}$. Added to the solution were $40 \mathrm{IU}$ of insulin, 200,000 $\mathrm{U}$ of penicillin and $16 \mathrm{mg}$ of dexamethasone. After connection of the kidney to the machine, perfusion flow was set to a systolic pressure of $55 \mathrm{mmHg}$, which was maintained during the first $60 \mathrm{~min}$ by adjusting machine flow. After $60 \mathrm{~min}$, the renal flow was kept constant. Flow and pressure parameters were recorded at the start of machine perfusion, and after 1, 2 and $4 \mathrm{~h}$ of perfusion (T0, T1, T2 and T4, respectively). The renovascular resistance was calculated by dividing mean pressure by the registered flow and was corrected for kidney weight ( $\mathrm{mmHg} / \mathrm{ml} / \mathrm{min}$ per $100 \mathrm{~g}$ kidney weight). During machine perfusion, $\mathrm{pH}$ was adjusted to values $>7.10$, using sodium bicarbonate.

The immunosuppressive regimen evolved over the study period as different trials were conducted. Immunosuppression was mainly based on a combination of a calcineurin inhibitor (cyclosporine or tacrolimus) and prednisolone. Depending of the protocol at the time, these were combined with azathioprine, mycophenolate mofetil, sirolimus or daclizumab in recipients with an increased immunological risk (e.g., HLA immunization and retransplants).

\section{Statistics}

Continuous variables were presented as mean \pm standard deviation unless noted otherwise. Categorical variables were presented as absolute numbers and percentages. Renovascular resistance of discarded kidneys was compared with the resistance of all transplanted kidneys and kidneys with PNF, using an independent samples t-test, and compared with their contralateral kidneys using a paired samples t-test. Multivariate logistic regression analysis was performed to identify whether 
renovascular resistance is an independent risk factor for PNF and DGF, correcting for known prognostic factors and significant variables from the univariate analyses. To avoid multicollinearity only renovascular resistance with the lowest $p$-value in univariate analyses was included in the model. The effect of renovascular resistance at each time point and the renovascular resistance area under the curve (AUC) on PNF and DGF were determined by univariate logistic regression analyses. Predictive measurements were performed by calculating a ROC curve. Positive and negative predictive values were computed using the predictive probability with maximum combination of sensitivity and specificity from the ROC curve, i.e. the point closest to the $[1,1]$-corner. We performed a Cox proportional hazard model to assess the association between renovascular resistance and graft survival in functioning grafts, censored for recipient death with a functioning graft, and patient survival. The long-term effects were visualized by the Kaplan-Meier curves, where renovascular resistance groups were created based on randomly chosen rounded numbers of renovascular resistance (in $\mathrm{mmHg} / \mathrm{ml} / \mathrm{min} / 100 \mathrm{~g}$ ) at T0 (group 1: $<1$, group 2: 1-1.99, group 3: $\geq 2$ ). A linear mixed model was used to analyze the association between renovascular resistance at T0 and GFR, since it accounts for missing values due to graft failures or recipient death and for the repeated measurements within each recipient. $p$-Values equal or lower than 0.05 were considered statistically significant. Statistical analysis was performed with SPSS for Windows version 16.0.

\section{RESULTS}

\section{Patients}

Between March 1993 and May 2007, 440 machine perfused DCD kidneys from 293 donors were transplanted in 439 patients; 2 kidneys were transplanted as a dual transplant. One hundred forty-six donors (50\%) had both kidneys machine perfused and transplanted, from 108 donors (37\%) only one kidney was machine perfused and from 39 donors (13\%) both kidneys were perfused but only one kidney was transplanted. Kidney discard $(\mathrm{N}=39)$ was based on vascular anatomy $(\mathrm{N}=8)$, no suitable recipient $(\mathrm{N}=8)$, macroscopic appearance $(\mathrm{N}=12)$, machine malfunction ( $\mathrm{N}$ $=2)$, cancelled surgery due to recipients problems $(N=2)$, or unknown $(N=7)$. Donor, graft and recipient characteristics are summarized in Table 6.1. Mean donor age was $45 \pm 16$ years. Most kidneys were from controlled Maastricht category $3(\mathrm{~N}=285)$ or category $4(\mathrm{~N}=19)$ donors. The mean warm and cold ischemia times were $26 \mathrm{~min}$ and $28 \mathrm{~h}$, respectively. The mean kidney weight was $235 \mathrm{~g}$. Donors and recipients predominantly comprised men (63\% men; for donors and recipients). 
Baseline characteristics and their association with primary non-function

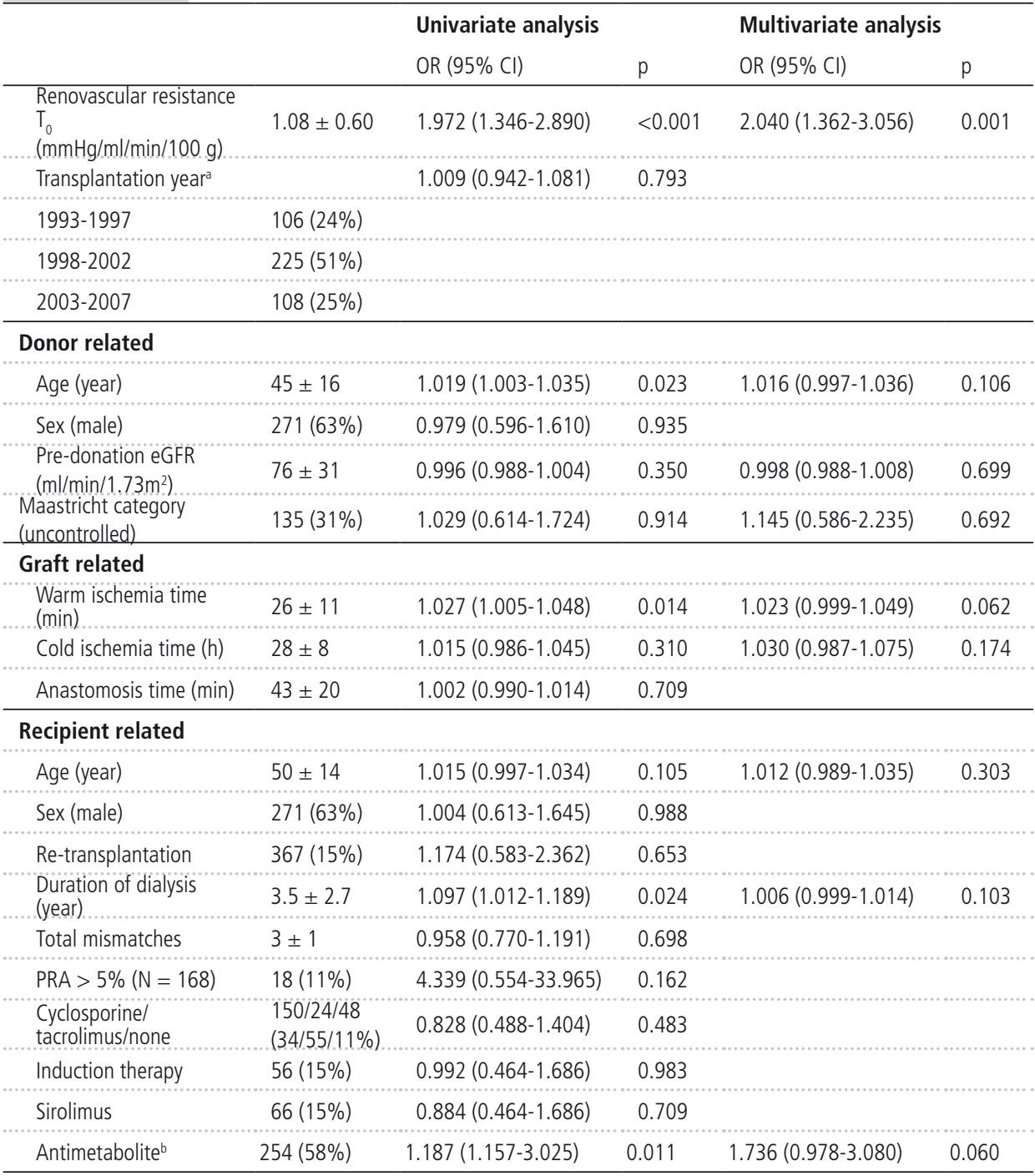

Renovascular resistance $\mathrm{T}_{0}$ : renovascular resistance at the start of machine perfusion.

a As continuous variable in the univariate analysis.

b Azathioprine or mycophenolate mofetil.

\section{Short-term graft outcome}

Nine patients $(2 \%)$ were lost to follow up or died before short-term graft function could be defined. Kidneys transplanted in these patients were excluded from analysis. Among the others, 84 recipients developed PNF (19.5\%), 262 recipients DGF $(61 \%)$ and 84 recipients IF (19.5\%). Resistance in all groups decreased during machine preservation (Figure 6.1, Table 6.2). 
Univariate logistic regression analysis for the risk of A) Primary non-function (PNF), and B) delayed graft function (DGF) in machine perfused kidneys.

\begin{tabular}{|c|c|c|c|c|c|c|}
\hline A & N & $\begin{array}{l}\text { Non PNF } \\
(\mathrm{N}=346)\end{array}$ & $\mathrm{N}$ & $\begin{array}{l}\text { PNF } \\
(N=84)\end{array}$ & OR $(95 \% \mathrm{Cl})$ & p \\
\hline RR T0 & 318 & $1.02 \pm 0.03$ & 74 & $1.32 \pm 0.11$ & 1.972 (1.346 to 2.890$)$ & $<0.001$ \\
\hline RR T1 & 342 & $0.92 \pm 0.02$ & 84 & $1.12 \pm 0.07$ & 1.916 (1.263 to 2.906$)$ & 0.002 \\
\hline RR T2 & 341 & $0.87 \pm 0.02$ & 83 & $1.04 \pm 0.07$ & 1.835 (1.182 to 2.850$)$ & 0.007 \\
\hline RR T4 & 342 & $0.81 \pm 0.02$ & 83 & $0.94 \pm 0.05$ & 1.891 (1.122 to 3.188$)$ & 0.017 \\
\hline AUC & 314 & $0.89 \pm 0.02$ & 72 & $1.09 \pm 0.07$ & 2.240 (1.353 to 3.709$)$ & 0.002 \\
\hline B & $\mathrm{N}$ & $\begin{array}{l}\text { IF } \\
(N=84)\end{array}$ & $\mathbf{N}$ & $\begin{array}{l}\text { DGF } \\
(N=262)\end{array}$ & OR $(95 \% \mathrm{Cl})$ & $\mathrm{p}$ \\
\hline RR T0 & 78 & $0.90 \pm 0.04$ & 240 & $1.06 \pm 0.03$ & $2.368(1.212$ to 4.628$)$ & 0.012 \\
\hline RR T1 & 82 & $0.82 \pm 0.04$ & 260 & $0.95 \pm 0.03$ & 2.390 (1.156 to 4.942$)$ & 0.019 \\
\hline RR T2 & 81 & $0.78 \pm 0.04$ & 260 & $0.89 \pm 0.03$ & 2.327 (1.088 to 4.978$)$ & 0.029 \\
\hline RR T4 & 81 & $0.73 \pm 0.04$ & 261 & $0.83 \pm 0.02$ & 2.302 (1.025 to 5.168$)$ & 0.043 \\
\hline AUC & 76 & $0.80 \pm 0.04$ & 238 & $0.92 \pm 0.03$ & 2.580 (1.155 to 5.766$)$ & 0.021 \\
\hline
\end{tabular}

RR: Renovascular resistance in $\mathrm{mmHg} / \mathrm{mL} / \mathrm{min} / 100 \mathrm{~g}$; AUC: area under the curve; IF: immediate function. Reported values are mean \pm standard error of the mean.

Renovascular resistance (in $\mathrm{mmHg} / \mathrm{ml} / \mathrm{min} / 100 \mathrm{~g}$ ) at T0 of discarded kidneys was higher than that of transplanted kidneys, 1.340 vs. $1.085(p=0.021)$ and comparable with kidneys with PNF 1.340 vs. 1.325 ( $p=0.930)$. A paired samples t-test, however, showed no significant difference in renovascular resistance between discarded kidneys $(\mathrm{N}=39)$ and their contralateral transplanted kidneys (1.340 vs. 1.178 , respectively; $\mathrm{p}=0.412$ ).

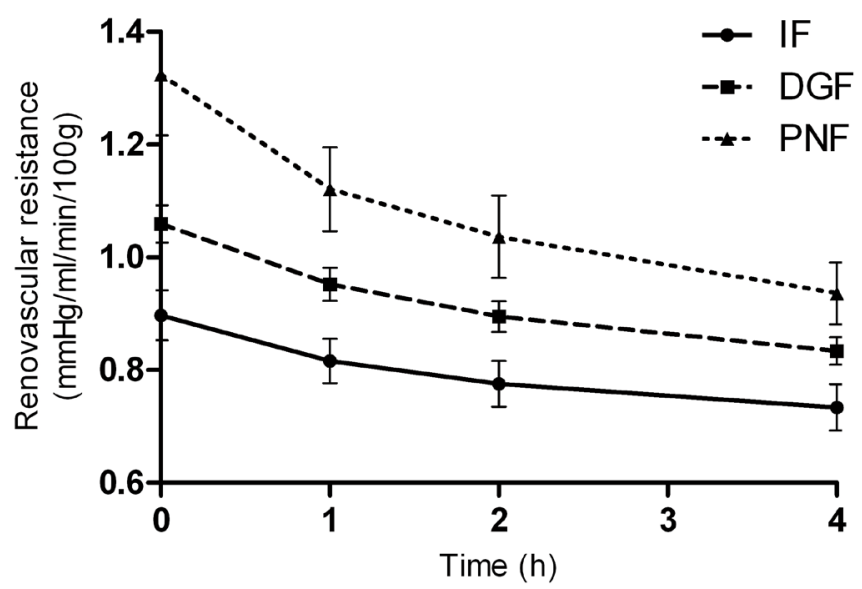

Figure 6.1 Renovascular resistance and its association with primary non-function (PNF), delayed graft function (DGF) and immediate function (IF). Data are presented as means and standard error of the mean. 
Renovascular resistance at each time point and renovascular resistance AUC were significantly associated with PNF, where the association was strongest at T0 with an odds ratio of 1.972 (95\% Cl 1.346 to $2.890 ; \mathrm{p}<0.001)$ (Table $6.2 \mathrm{~A})$. Other factors significantly associated with PNF in the univariate analyses include donor age (OR $1.019,95 \% \mathrm{Cl} 1.003$ to $1.035 ; \mathrm{p}=0.023$ ), warm ischemia time (OR $1.027,95 \% \mathrm{Cl} 1.005$ to $1.048 ; p=0.014$ ), recipients' duration of dialysis (OR $1.097,95 \% \mathrm{Cl} 1.012$ to 1.189 ; $\mathrm{p}=0.024$ ), and whether or not an antimetabolite is given (OR $1.187,95 \% \mathrm{Cl} 1.157$ to 3.025; $\mathrm{p}=0.011$ ) (Table 6.1). In the multivariate analyses, renovascular resistance at T0 (OR 2.040, 95\% Cl 1.362 to 3.056; $p=0.001$ ) remained a significant risk factor for PNF. Table 6.3 shows the categorized renovascular resistance at T0 and its accompanying increasing percentage of PNF.

Renovascular resistance values and their accompanying percentage of primary non-function.

\begin{tabular}{|c|c|c|c|c|c|c|}
\hline $\begin{array}{l}\text { Renovascular resistance } \mathrm{T}_{0} \\
(\mathrm{mmHg} / \mathrm{ml} / \mathrm{min} / 100 \mathrm{~g})\end{array}$ & $\geq 0.5$ & $\geq 1.0$ & $\geq 1.5$ & $\geq 2.0$ & $\geq 2.5$ & $\geq 3.0$ \\
\hline $\mathrm{N}$ & 369 & 160 & 61 & 26 & 12 & 7 \\
\hline Primary non-function & $19 \%$ & $25 \%$ & $26 \%$ & $38 \%$ & $58 \%$ & $85 \%$ \\
\hline
\end{tabular}

The area under the ROC curve (AURC), sensitivity, specificity, positive and negative predictive value were determined for (a) renovascular resistance at T0 alone, (b) a model including donor age, pre-donation eGFR, Maastricht category and warm ischemia time, and (c) model b combined with renovascular resistance at T0 (Table 6.4). The AUC of renovascular resistance alone was moderate $(0.609,95 \%$ $\mathrm{Cl} 0.538$ to 0.681 ). By adding renovascular resistance to model b, the AUC slightly increased (model b: $0.636 ; 95 \% \mathrm{Cl} 0.570$ to 0.702 vs. model c: $0.654 ; 95 \% \mathrm{Cl} 0.585$ to 0.723).

Predictive values of renovascular resistance (RR) at $\mathrm{T}_{0}$.

\begin{tabular}{|c|c|c|c|c|c|}
\hline & AUC $(95 \% \mathrm{Cl})$ (c statistic) & Sensitivity & Specificity & PPV & NPV \\
\hline Model a: RR alone & 0.609 (0.538 to 0.681$)$ & 0.554 & 0.623 & 0.255 & 0.857 \\
\hline Model b (without RR) & $0.636(0.570$ to 0.702$)$ & 0.524 & 0.694 & 0.297 & 0.855 \\
\hline Model c (with RR) & $0.654(0.585$ to 0.723$)$ & 0.528 & 0.729 & 0.314 & 0.868 \\
\hline
\end{tabular}

Model b: donor age, pre-donation eGFR, Maastricht category, and warm ischemia time; Model c: donor age, pre-donation eGFR, Maastricht category, warm ischemia time, and renovascular resistance. RR: renovascular resistance; PPV: positive predictive value; NPV: negative predictive value.

In functioning kidneys univariate analyses showed that renovascular resistance at each time point and renovascular resistance AUC were significantly associated with DGF (Table 6.2B). The same multivariate analysis as described above was repeated to determine risk factors for DGF. Renovascular resistance at T0 was an independent risk factor for DGF (OR 2.345, 95\% Cl 1.110 to 4.955; $p=0.025$ ). 


\section{Long-term survival}

The median period of follow up after transplantation was 7.2 (range 0 to 16.2) years, including 21 patients $(4.8 \%)$ with incomplete follow-up. These patients were censored after a median follow up time of 2.7 years (range 0 to 11.3). Graft survival at 1 and 5 years after transplantation was $74 \%$ and $60 \%$, respectively. Mean GFR of functioning grafts was $36 \pm 18 \mathrm{ml} / \mathrm{min} / 1.73 \mathrm{~m} 2$ at 3 months, and $43 \pm 19 \mathrm{ml} / \mathrm{min} / 1.73$ $\mathrm{m} 2$ at 5 years after transplantation. Patient survival was $76 \%$ and $67 \%$ after 1 and 5 years, respectively. Linear mixed models showed that the trend in GFR was not influenced by renovascular resistance at T0 $(p=0.875)$. Resistance at T0 was also not significantly related to graft survival $(p=0.199)$ or patient survival $(p=0.203)$.

Figure 6.2 shows graft survival of all transplanted grafts, delayed functioning and immediate functioning grafts, with resistance categorized in groups. Apparent differences in graft survival between the three resistance groups are mainly caused by PNF rate. Patient survival was similar in all groups (Figure 6.2B).
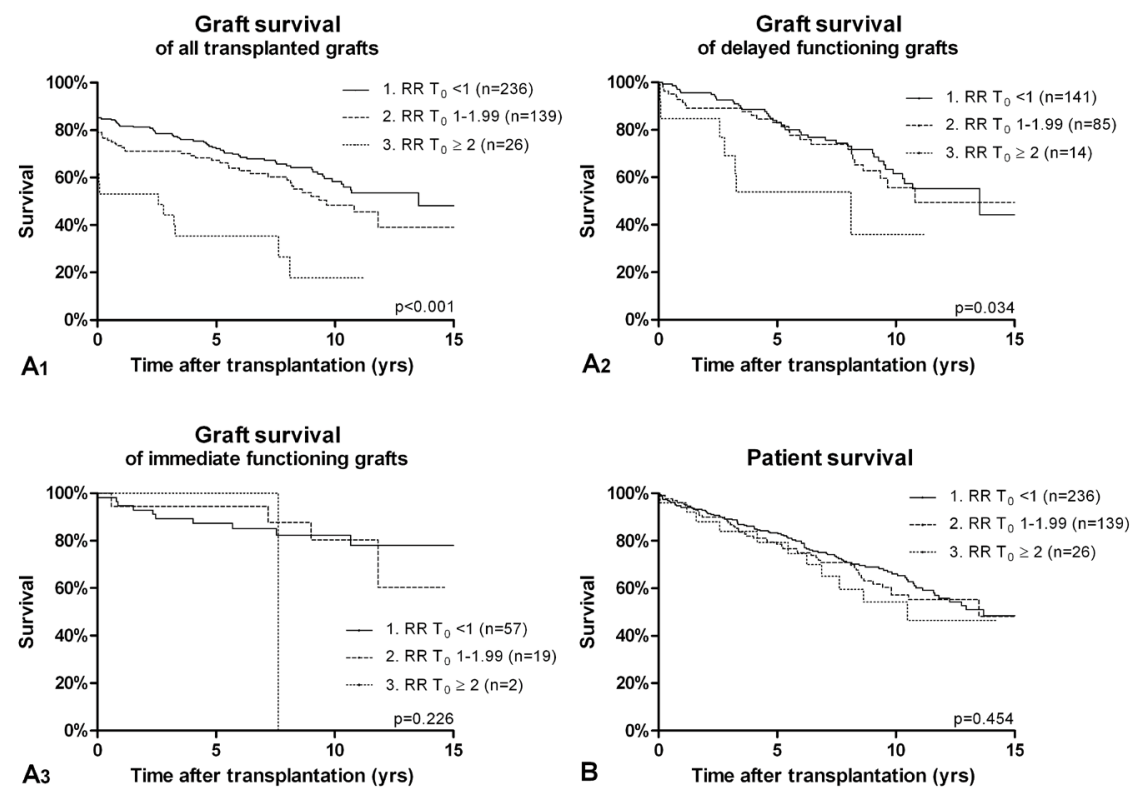

Figure 6.2 Graft and patient survival curves after transplantation of machine perfused donation after cardiac death (DCD) kidneys categorized by renovascular resistance in $\mathrm{mmHg} / \mathrm{ml} / \mathrm{min} / 100 \mathrm{~g}$ (RR), visualized by the Kaplan-Meier curves. (A) Graft survival, in (A1) all transplanted grafts and (A2) delayed functioning grafts and (A3) immediate functioning grafts, all censored for recipient death with functioning graft, and (B) patient survival. 


\section{DISCUSSION}

The use of DCD kidneys provides a valuable extension of the donor pool to meet the constantly growing number of patients on the waiting list for kidney transplantation. Despite the higher percentages of PNF and DGF $(5,19)$, patients who receive a $D C D$ kidney have better survival rates than patients who continue dialysis treatment while waiting for a kidney from a donor after brain death (DBD) (20). Moreover, DCD kidneys that overcome the early posttransplantation period function as long as DBD kidneys. Contrary to DBD kidneys, DGF in DCD kidneys hardly, if at all, affects graft survival $(4,5,13,14,21)$. Therefore it is essential to select kidneys that will never function from those which will either function immediately or after some time. The primary aim of the study was to determine if renovascular resistance, measured during machine perfusion, could provide additional information deciding which kidneys should be discarded and which kidneys have a good chance to eventually function.

The two major methods of preservation are cold storage and machine perfusion. Machine perfusion, generally used for extended criteria donors, has two potential advantages over cold storage. First, it may improve marginal kidneys by preventing interstitial edema, decreasing oxidative stress, improving ATP availability upon reperfusion and by washing out thrombi and harmful metabolic products (22, 23). Two recently published randomized controlled trials comparing both preservation methods showed conflicting results. Moers et al. (2000) demonstrated the benefit of machine perfusion compared to cold storage in DCD and DBD kidneys with a reduced risk of DGF and improved graft survival in the first year after transplantation (24), whereas Watson et al. (2000) described that machine perfusion does not offer advantages over cold storage for DCD kidneys (25). Secondly, machine perfusion allows measurement of pre-transplantation parameters such as perfusion flow, pressure and renovascular resistance, providing information about the quality of the graft. The evidence that renovascular resistance is a valuable predictor of transplant outcome is poor although several resistance cut off points have been described (10, 26). In Maastricht, from 1993, all procured DCD kidneys were preserved by machine perfusion regardless of preprocurement conditions, a group including very marginal kidneys with a high PNF rate. Therefore we were able to study variables associated with PNF including renovascular resistance by performing multivariate analyses.

Our results show that renovascular resistance at the start of machine perfusion (T0) is independently associated with PNF. Mean renovascular resistance decreases over time and its decline is more pronounced in PNF kidneys implying that the discriminatory value of renovascular resistance decreases towards transplantation. This is in line with results of Brook et al. (2000)(27) showing that only early renovascular resistance until $60 \mathrm{~min}$ of machine perfusion accurately reflects differences in warm ischemia time in porcine kidneys. In human kidney transplantation the value of renovascular resistance at T0 as discriminative time point has not been previously described. Earlier studies only report the mean value of perfusion parameters $(8,9$, $26,28)$, or values at T4 $(10,29)$. Our finding, that recommends the use of renovascular 
resistance at T0, could be advantageous because early viability assessment enables to decide in an early stage whether or not to use the kidney for transplantation.

The predictive quality of renovascular resistance is moderate and the decision to either accept or discard a kidney remains multifactorial. Nevertheless, we think that renovascular resistance can be a valuable parameter next to other factors to decide whether to transplant a kidney or not. Moreover, in our series, 6 out of 7 kidneys with a renovascular resistance at T0 of $>3.0 \mathrm{mmHg} / \mathrm{ml} / \mathrm{min} / 100 \mathrm{~g}$ resulted in PNF, which is unacceptably high because transplantation of nonviable kidneys results in unnecessary risk of surgery and immunosuppression, and sensitizes the recipient for future transplants (30). Kidneys with DGF had a higher renovascular resistance than immediately functioning kidneys; this finding, however, should not have clinical implications, as long-term survival rates of DCD kidneys with DGF do not significantly differ from DCD kidneys with IF $(4,5,13,19,20,31)$.

The reported mean renovascular resistance in the present study is higher than values reported by others. First, this may be caused by the relatively poor quality of the perfused DCD kidneys, which becomes apparent from the relatively high percentage of PNF. Second, we have corrected the renovascular resistance for kidney weight, which generally implies a two to threefold increase of the measured resistance value.

We showed that differences in graft survival among transplanted grafts were mainly caused by the presence of PNF. In functioning kidneys there was no statistical association between graft survival and renovascular resistance at T0; neither was patient survival associated with renovascular resistance. These findings indicate that renovascular resistance is particularly useful in predicting PNF.

There could have been a selection bias, if kidneys in our series were discarded based on renovascular resistance, but renovascular resistance was not a parameter to discard kidneys for transplantation. All kidneys were accepted for transplantation by the recipient's nephrologists, based on the combination of donor, graft and recipients characteristics. They were not informed of machine preservation parameters. Resistance of the discarded kidneys was equivalent to the resistance of transplanted contralateral kidneys. However, the number of kidneys that could be compared was too small to draw firm conclusions from this finding. Furthermore, unobserved arterial leakage during perfusion may have affected flow and pressure registration. This could have resulted in an underestimation of the measured renovascular resistance in poorly functioning kidneys. Moreover, the number of variables included into the analysis was limited to optimize statistical accuracy. This implies that other possibly relevant risk factors were not included in the multivariate risk analysis.

In conclusion, we demonstrated that renovascular resistance at the start of machine perfusion is an independent risk factor for PNF; however, the predictive value is relatively low. 
CHAPTER 6 


\section{REFERENCES}

1. Wolfe RA, Ashby VB, Milford EL, Ojo AO, Ettenger RE, Agodoa LY, et al. Comparison of mortality in all patients on dialysis, patients on dialysis awaiting transplantation, and recipients of a first cadaveric transplant. N Engl J Med. 1999 Dec 2;341(23):1725-30.

2. Rabbat CG, Thorpe KE, Russell JD, Churchill DN. Comparison of mortality risk for dialysis patients and cadaveric first renal transplant recipients in Ontario, Canada. J Am Soc Nephrol. 2000 May;11(5):917-22.

3. McDonald SP, Russ GR. Survival of recipients of cadaveric kidney transplants compared with those receiving dialysis treatment in Australia and New Zealand, 1991-2001. Nephrol Dial Transplant. 2002 Dec;17(12):2212-9.

4. Weber M, Dindo D, Demartines N, Ambuhl PM, Clavien PA. Kidney transplantation from donors without a heartbeat. N Engl J Med. 2002 Jul 25;347(4):248-55.

5. Cho YW, Terasaki PI, Cecka JM, Gjertson DW. Transplantation of kidneys from donors whose hearts have stopped beating. N Engl J Med. 1998 Jan 22;338(4):221-5.

6. Cooper JT, Chin LT, Krieger NR, Fernandez LA, Foley DP, Becker YT, et al. Donation after cardiac death: the university of wisconsin experience with renal transplantation. Am J Transplant. 2004 Sep;4(9):1490-4.

7. Matsuno N, Konno O, Mejit A, Jyojima Y, Akashi I, Nakamura Y, et al. Application of machine perfusion preservation as a viability test for marginal kidney graft. Transplantation. 2006 Dec 15;82(11):1425-8.

8. Sung RS, Christensen LL, Leichtman AB, Greenstein SM, Distant DA, Wynn JJ, et al. Determinants of discard of expanded criteria donor kidneys: impact of biopsy and machine perfusion. Am J Transplant. 2008 Apr;8(4):783-92.

9. Nyberg SL, Baskin-Bey ES, Kremers W, Prieto M, Henry ML, Stegall MD. Improving the prediction of donor kidney quality: deceased donor score and resistive indices. Transplantation. 2005 Oct 15;80(7):925-9.

10. Mozes MF, Skolek RB, Korf BC. Use of perfusion parameters in predicting outcomes of machine-preserved kidneys. Transplantation proceedings. 2005 Jan-Feb;37(1):350-1.

11. Renkens JJ, Rouflart MM, Christiaans MH, van den Berg-Loonen EM, van Hooff JP, van Heurn LW. Outcome of nonheart-beating donor kidneys with prolonged delayed graft function after transplantation. Am J Transplant. 2005 Nov;5(11):2704-9.

12. Troppmann C, Gillingham KJ, Gruessner RW, Dunn DL, Payne WD, Najarian JS, et al. Delayed graft function in the absence of rejection has no long-term impact. A study of cadaver kidney recipients with good graft function at 1 year after transplantation. Transplantation. 1996 May 15;61(9):1331-7.

13. Wijnen RM, Booster MH, Stubenitsky BM, de Boer J, Heineman E, Kootstra G. Outcome of transplantation of non-heart-beating donor kidneys. Lancet. 1995 Apr 29;345(8957):1067-70.

14. Gok MA, Buckley PE, Shenton BK, Balupuri S, El-Sheikh MA, Robertson H, et al. Long-term renal function in kidneys from non-heart-beating donors: A single-center experience. Transplantation. 2002 Sep 15;74(5):664-9.

15. Kootstra G, Daemen JH, Oomen AP. Categories of non-heart-beating donors. Transplantation proceedings. 1995 Oct;27(5):2893-4.

16. Snoeijs MG, Dekkers AJ, Buurman WA, van den Akker L, Welten RJ, Schurink GW, et al. In situ preservation of kidneys from donors after cardiac death: results and complications. Annals of surgery. 2007 Nov;246(5):844-52.

17. de Vries EE, Snoeijs MG, van Heurn E. Kidney donation from children after cardiac death. Critical care medicine. 2010 Jan;38(1):249-53.

18. Poge U, Gerhardt T, Palmedo H, Klehr HU, Sauerbruch T, Woitas RP. MDRD equations for estimation of GFR in renal transplant recipients. Am J Transplant. 2005 Jun;5(6):1306-11.

19. Snoeijs MG, Winkens B, Heemskerk MB, Hoitsma AJ, Christiaans MH, Buurman WA, et al. Kidney transplantation from donors after cardiac death: a 25-year experience. Transplantation. 2010 Nov 27;90(10):1106-12. 
20. Snoeijs MG, Schaubel DE, Hene R, Hoitsma AJ, Idu MM, ljzermans JN, et al. Kidneys from donors after cardiac death provide survival benefit. J Am Soc Nephrol. 2010 Jun;21(6):1015-21. 21. arlagadda SG, Coca SG, Formica RN, Jr., Poggio ED, Parikh CR. Association between delayed graft function and allograft and patient survival: a systematic review and meta-analysis. Nephrol Dial Transplant. 2009 Mar;24(3):1039-47.

22. Maathuis MH, Manekeller S, van der Plaats A, Leuvenink HG, t Hart NA, Lier AB, et al. Improved kidney graft function after preservation using a novel hypothermic machine perfusion device. Annals of surgery. 2007 Dec;246(6):982-8.

23. McLaren AJ, Friend PJ. Trends in organ preservation. Transpl Int. 2003 Oct;16(10):701-8.

24. Moers C, Smits JM, Maathuis MH, Treckmann J, van Gelder F, Napieralski BP, et al. Machine perfusion or cold storage in deceased-donor kidney transplantation. N Engl J Med. 2009 Jan 1;360(1):7-19.

25. Watson CJ, Wells AC, Roberts RJ, Akoh JA, Friend PJ, Akyol M, et al. Cold machine perfusion versus static cold storage of kidneys donated after cardiac death: a UK multicenter randomized controlled trial. Am J Transplant. 2010 Sep;10(9):1991-9.

26. Guarrera JV, Goldstein MJ, Samstein B, Henry S, Reverte C, Arrington B, et al. 'When good kidneys pump badly': outcomes of deceased donor renal allografts with poor pulsatile perfusion characteristics. Transpl Int. 2009 Apr 1;23(4):444-6.

27. Brook NR, Knight AJ, Nicholson ML. Intra-renal resistance reflects warm ischaemic damage, and is further increased by static cold storage: a model of non-heart-beating donor kidneys. Med Sci Monit. 2003 Jul;9(7):BR271-5.

28. Sonnenday CJ, Cooper M, Kraus E, Gage F, Handley C, Montgomery RA. The hazards of basing acceptance of cadaveric renal allografts on pulsatile perfusion parameters alone. Transplantation. 2003 Jun 27;75(12):2029-33.

29. Daemen JH, de Vries B, Kootstra G. The effect of machine perfusion preservation on early function of nonheart-beating donor kidneys. Transplantation proceedings. 1997 Dec;29(8):3489.

30. Billen EV, Christiaans MH, Lee J, van den Berg-Loonen EM. Donor-directed HLA antibodies before and after transplantectomy detected by the luminex single antigen assay. Transplantation. 2009 Feb 27;87(4):563-9.

31. Sanchez-Fructuoso Al, Marques M, Prats D, Conesa J, Calvo N, Perez-Contin MJ, et al. Victims of cardiac arrest occurring outside the hospital: a source of transplantable kidneys. Annals of internal medicine. 2006 Aug 1;145(3):157-64. 
RENOVASCULAR RESISTANCE OF MACHINE PERFUSED DCD KIDNEYS IS ASSOCIATED WITH PRIMARY NON-FUNCTION 


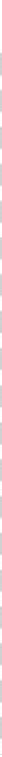

\section{4}


CHAPTER 7

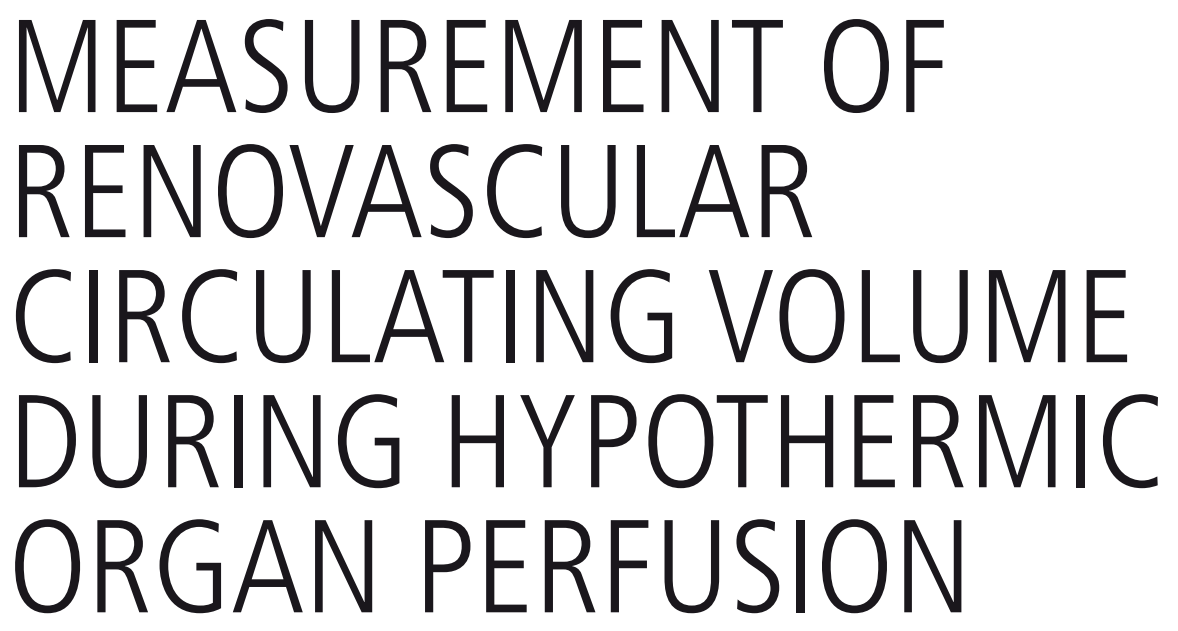




\section{ABSTRACT}

Background: Kidney donation after cardiac death leads to vascular damage as a result of warm ischemia, affecting renovascular circulating volume. Novel ultrasound dilution techniques may be used to measure renovascular circulating volumes during hypothermic machine perfusion of donor kidneys.

Methods: Renovascular circulating volumes of machine perfused porcine kidneys were repeatedly measured by ultrasound dilution at different perfusion pressures $(30,40,50$, and $60 \mathrm{mmHg}$ ), durations of perfusion (1 and 24 hours) and warm ischemia times (15 and $45 \mathrm{~min}$ ). Validity of ultrasound dilution was assessed by comparing volume changes after clamping of renal artery branches.

Results: Repeatability of ultrasound dilution measurements of renovascular circulating volumes was good (mean coefficient of variation: 7.6\%). Renovascular circulating volumes significantly increased with higher perfusion pressures, remained constant over time, and significantly decreased with longer warm ischemia times. Changes in ultrasound dilution measurements after renal artery branch clamping did not correlate with changes in actual perfused volumes.

Conclusions: Ultrasound dilution is a reproducible method to assess renovascular circulating volumes in machine-perfused kidneys, which is susceptible to changes in warm ischemia times. Future studies should evaluate the value of renovascular volume in pretransplantation kidney viability testing.

\section{Published as}

E.E. de Vries, T.C. van Smaalen, J. Boer, E.R.P. Hoogland, N.M. Krivitski, M.G.J. Snoeijs, L.W.E. van Heurn. Measurement of renovascular circulating volume during hypothermic organ perfusion. Transplantation 2013;95(9):1100-4 


\section{INTRODUCTION}

Kidney transplantation in patients with end-stage renal disease leads to superior life expectancy and better quality of life compared to dialysis (1). In the past decades, there is an increasing shortage of donor kidneys. Organs from donors after cardiac death (DCD) have become generally accepted to expand the donor pool and meet the demand for additional donor kidneys. However, transplantation of DCD kidneys is associated with an increased incidence of initial graft dysfunction $(2,3)$.

The higher incidence of graft dysfunction in DCD kidneys, compared with kidneys from donation after brain death (DBD) donors, can be attributed to the prolonged period of warm ischemia before organ procurement. This period of warm ischemia leads to more capillary damage resulting from thrombosis, vasoconstriction, and edema, and may consequently result in a decreased renovascular circulating volume. Therefore, pre-implantation renovascular circulating volume of the kidney may be associated with the severity of warm ischemic injury and could be a valuable predictor of transplantation outcome.

The dilution technique is used to measure circulating volume in hemodialyzer fibre bundles. It determines the dilution of an injected saline bolus with ultrasound flow probes before and after transit of the dialyzer. In hemodialyzer volume assessment, this technique is accurate, and its results are reproducible (4-6). The same technique can be used to measure renovascular circulating volume in donor kidneys. Renovascular circulating volume may be a valuable viability marker in ischemically damaged donor kidneys if measured before transplantation. Therefore, we studied the dilution technique to measure renovascular circulating volume in machineperfused porcine kidneys and determined if renovascular circulating volume is associated with warm ischemia time.

\section{MATERIALS AND METHODS}

The experiments were carried out with porcine kidneys, which were recovered from a regional slaughterhouse. Pigs were between 6 and 7 months of age and had a mean weight of $105 \mathrm{~kg}$. In the highly standardized slaughtering process, the time from death until recovery of the kidneys took exactly 15 minutes. After receiving an 'en bloc' pair of kidneys, kidneys were separated and then flushed with $0.5 \mathrm{~L}$ of Histidine-Tryptophan-Ketoglutarate (HTK) preservation solution for 20 minutes at the site. For transport to the preservation laboratory, kidneys were temporarily stored on ice. Two hours after recovery, kidneys were connected to a pulsatile perfusion machine (LifePort Kidney Transporter, model number LKT-100-P, Organ Recovery Systems, Des Plaines, IL, USA) and perfused with $500 \mathrm{~mL}$ University of Wisconsin (UW) solution. During machine perfusion, pressure $(\mathrm{mmHg})$, flow $(\mathrm{mL} / \mathrm{min})$, and resistance $(\mathrm{mmHg} / \mathrm{mL} / \mathrm{min}$ ) were recorded using the Lifeport Kidney Transporter. 
According to national legislation, study approval by the local animal experiments committee (DEC) was not required. Our study did not interfere with the standardized slaughtering process; kidneys were obtained after death.

\section{Dilution technique}

Renovascular circulating volume was assessed with the dilution technique. This technique has been described in detail before by others (6). Briefly, the renovascular circulating volume was measured with a dilution monitor (HD02 haemodialysis FlowQC monitor, Transonic Systems Inc, Ithaca, NY) through two reusable ultrasound flow probes (Transonic H4E Flow Probes) installed at $2 \mathrm{~cm}$ distance from the kidney on the arterial tube and on a tube connected to the renal vein. The dilution monitor was connected to a computer installed with HD02 Dialysis Monitoring Software (Figure 7.1). The system was calibrated for UW solution. To obtain measurements, we injected a saline bolus of $2 \mathrm{~mL}$ into the arterial injection port. The indicator is first sensed by the arterial sensor that records the time and volume of injection. The indicator then travels through the renovascular system and is recorded by the venous sensor on the renal vein. The venous sensor measures the change in concentration of saline in the preservation fluid and the transit time through the renovascular system. The renovascular circulating volume is calculated by the equation $\mathrm{V}=\mathrm{Q} \times \mathrm{MTT}$. In this equation, $\mathrm{Q}$ is defined as the flow in the system, and MTT (mean transit time) as the average transit time of the indicator. The first bolus was injected one hour after the start of perfusion ( $\mathrm{T} 1$ ) to ensure a balanced state of perfusion. The additional volume within the tubing between vein or artery and sensors was kept constant by placing the sensors at a fixed distance from the kidney.

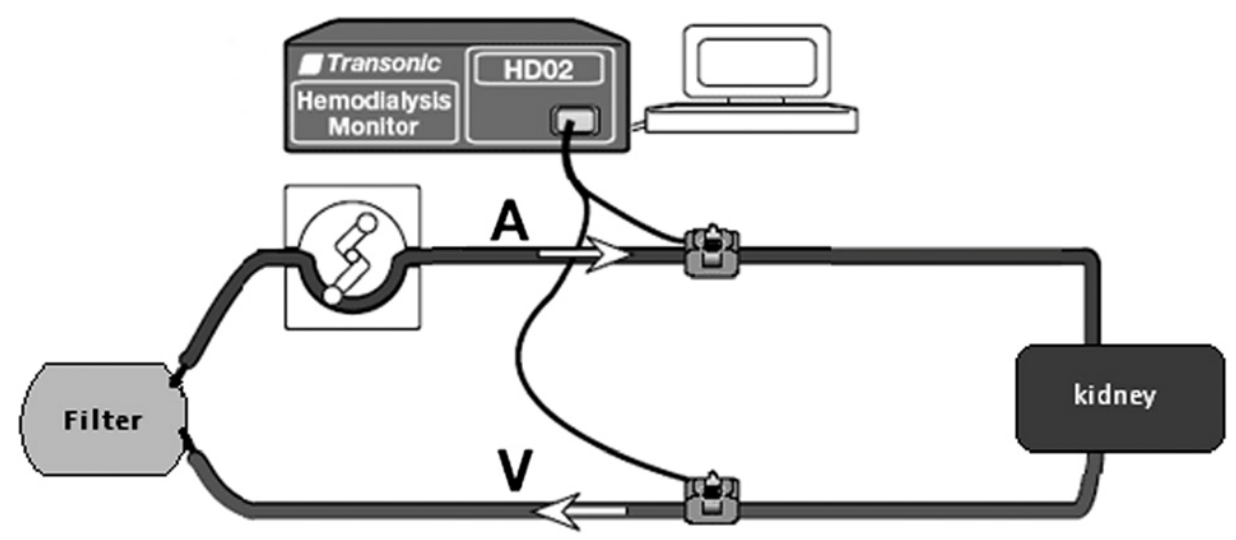

Figure 7.1 Schematic research setting. Sensors were placed in the perfusion machine on the arterial (A) tube, and venous ( $V$ ) tube, connected to the renal vein. The dilution monitor was connected to a computer installed with HD02 Dialysis Monitoring Software. 


\section{Flow measurements}

To assess the correlation between measured flow by ultrasound flow probes and derived from roller pump speed, we performed simultaneous measurements of flow in six kidneys using pressures of 40,50 and $60 \mathrm{mmHg}$. In total, 87 paired measurements were performed. Given the very strong correlation between flow measured by ultrasound flow probes and that derived from roller pump speed, only flow data derived from roller pump speed was used in the calculations.

\section{Repeatability and validation}

To verify repeatability in measuring renovascular circulating volume, we performed sets of six measurements at different perfusion pressures (30, 40, 50 and $60 \mathrm{mmHg}$ ) in 9 kidneys. Per kidney and per pressure, six boluses of saline were injected at one hour after the start of perfusion (T1) and after 24 hours of machine perfusion (T24). A total of 426 measurements (71 data sets) were performed. In addition, of all measurements in this dataset, we plotted the correlation of measured volume against flow as well as volume against resistance.

Although the dilution technique has shown to be accurate in estimating perfused volume in dialyzer circuits, there is no gold standard of measuring renovascular circulating volume. Therefore, we verified validity of the dilution technique by comparing volume ratio and weight ratio in six partially perfused kidneys after the repeatability measurements were performed, at a pressure of 60 $\mathrm{mmHg}$. One of the renal arterial branches was clamped, and the measurements repeated. Next, a bolus of methylene blue was injected into the system, colouring the perfused part of the vascular system. The colored tissue was macroscopically divided from the non-colored tissue, and the percentage of the weight of each part was assessed. Validity was determined by comparing the renovascular circulating volume ratio and weight ratio of perfused and non-perfused parts of the kidney.

\section{Effect of warm ischemia time on renovascular circulating volume}

To assess the effect of warm ischemia on renovascular circulating volume, we performed measurements in five kidney pairs. Each pair contained a kidney exposed to a mean of 15 minutes and a kidney exposed to a mean of 45 minutes of warm ischemia. After retrieval, this was realized by immediate cannulation of one of the renal arteries of the 'en-bloc' kidneys and connecting only this kidney to the perfusion fluid for initial flush. After the initial flush (20 min), kidneys were separated; the first kidney was stored on melting ice, and the contralateral kidney was stored at room temperature until 45 minutes of warm ischemia and then flushed. Measurements were performed after one hour of machine perfusion and after 24 hours (T1 and T24) with a perfusion pressure of $40 \mathrm{mmHg}$.

\section{Data analysis}

Continuous variables are presented as mean \pm standard deviations (SD) if normally distributed (histogram). Correlation coefficients were calculated with the 
Pearson test for normally distributed variables, and with the Spearman test otherwise. To determine repeatability, the coefficient of variation (CV) was calculated as the ratio of mean volume and standard deviation per dataset. Paired sample t-test was used to calculate the significance of differences between time points. Renovascular volume differences after clamping were calculated using the Wilcoxon signed-rank test. We used a paired-samples t-test to analyze differences between the 15 and 45 minutes WIT groups.

Data analysis was performed using SPSS 18.0 and Microsoft Excel 2007 for Windows. A p-value below 0.05 was considered evidence of a significant difference.

\section{RESULTS}

\section{Flow measurements}

The correlation between perfusate flow measured by ultrasound flow probes and derived from roller pump speed was very strong $(R=0.97,95 \% \mathrm{Cl} 0.95-0.98$, $\mathrm{p}<0.001$; Figure 7.2). Mean perfusate flow derived from roller pump speed was $11.0 \pm$ $8.0 \mathrm{~mL}$ higher than that by measured by ultrasound flow probes.

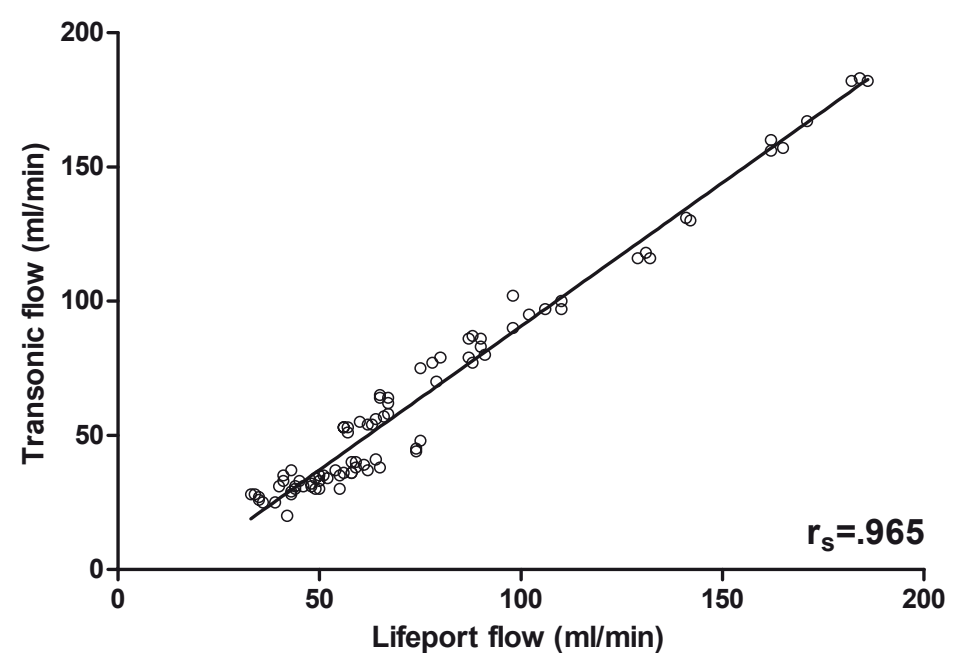

Figure 7.2 Correlation of flow between the machine perfusion system and ultrasound flow probes using Spearman correlation coefficient. 


\section{Repeatability and validation}

In one kidney, the series of measurements at a pressure of $30 \mathrm{mmHg}$ at $\mathrm{T} 1 \mathrm{failed}$ because flow was too low. The mean CV of renovascular circulating volume measured by ultrasound dilution was $7.6 \pm 6.2 \%$ (Table 7.1). The CV did not significantly change with different durations of perfusion (1 and 24 hour; mean CV $6.8 \pm 4.5 \%$ and $8.4 \pm$ $7.5 \%$, respectively; $p=0.166$ ). The mean CV at a perfusion pressure of $30 \mathrm{mmHg}$ was higher than at $40 \mathrm{mmHg}(p=0.007)$, but did not significantly change compared to other pressures ( 40 vs. $50 \mathrm{mmHg} ; \mathrm{p}=0.229 ; 50$ vs. $60 \mathrm{mmHg} ; \mathrm{p}=0.978$ ). Excluding the 30 $\mathrm{mmHg}$ measurements from the analyses showed a decrease of mean CV and SD from $7.6 \pm 6.2 \%$ to $6.2 \pm 3.6 \%$. Correlation of all volume measurements with flow and with resistance was good ( $r s=.921$ and $r s=.766$, respectively) (Figure 7.3).

A
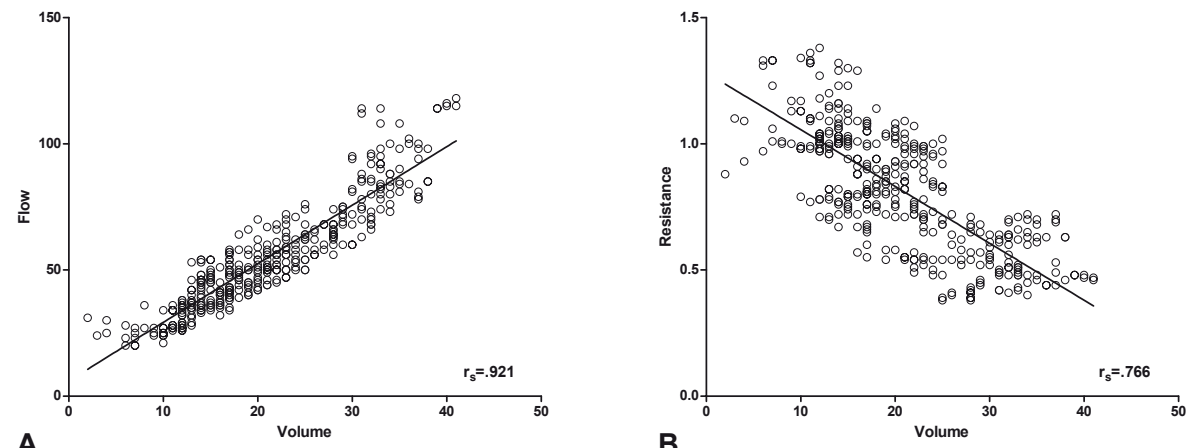

B

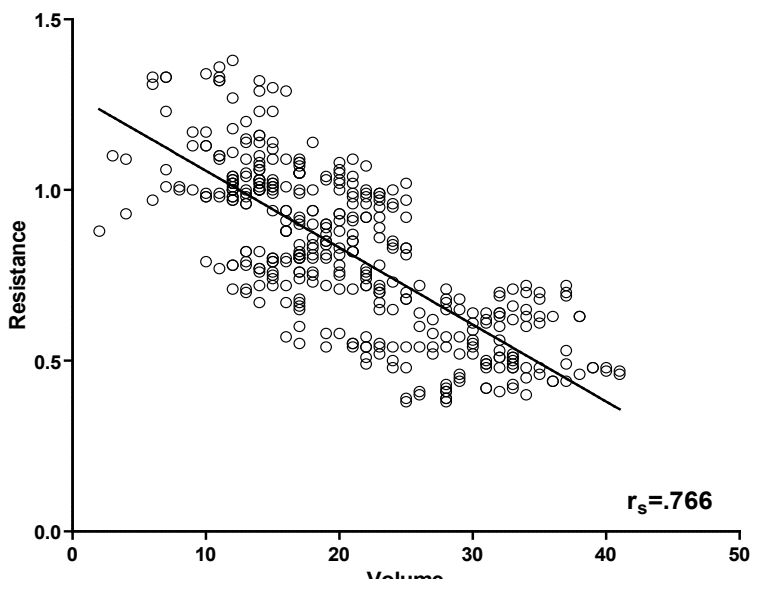

Figure 7.3 Correlation of flow $(\mathrm{mL} / \mathrm{min})(\mathrm{A})$ and resistance $(\mathrm{mmHg} / \mathrm{mL} / \mathrm{min}$ (B) measurements with renovascular circulating volume $(\mathrm{mL})$. 
Characteristics of measurements at different pressures

\begin{tabular}{lllllll}
\hline $\mathbf{P}(\mathbf{m m H g})$ & Time & $\mathbf{N}$ & $\begin{array}{l}\mathbf{V} \\
(\mathbf{m L})\end{array}$ & $\begin{array}{l}\text { CV } \\
(\%)\end{array}$ & $\begin{array}{l}\mathbf{Q} \\
(\mathbf{m L} / \mathbf{m i n})\end{array}$ & $\begin{array}{l}\mathbf{R} \\
(\mathbf{m m H g} / \mathbf{m L} / \mathbf{m i n})\end{array}$ \\
\hline \multirow{2}{*}{30} & T1 & $8^{*} 6=48$ & $15.3 \pm 4.8$ & $11.5 \pm 6.7$ & $37.5 \pm 9.6$ & $0.76 \pm 0.20$ \\
& T24 & $9^{*} 6=54$ & $15.9 \pm 8.2$ & $12.8 \pm 12.3$ & $39.6 \pm 15.3$ & $0.78 \pm 0.31$ \\
\hline \multirow{2}{*}{40} & T1 & $9^{*} 6=54$ & $18.9 \pm 6.2$ & $6.8 \pm 2.1$ & $46.4 \pm 11.4$ & $0.82 \pm 0.19$ \\
& T24 & $9^{*} 6=54$ & $21.0 \pm 8.1$ & $7.1 \pm 6.8$ & $51.7 \pm 18.9$ & $0.79 \pm 0.30$ \\
\hline 50 & T1 & $9^{*} 6=54$ & $21.8 \pm 6.6$ & $4.9 \pm 2.3$ & $55.9 \pm 11.2$ & $0.85 \pm 0.18$ \\
\hline \multirow{2}{*}{60} & T24 & $9^{*} 6=54$ & $23.4 \pm 7.9$ & $6.6 \pm 2.5$ & $62.9 \pm 22.4$ & $0.81 \pm 0.28$ \\
\hline
\end{tabular}

Variables are expressed as mean $\pm \mathrm{SD} . \mathrm{N}=$ number of measurements; $\mathrm{V}=$ volume $(\mathrm{mL}) ; \mathrm{CV}=$ coefficient of variation $(\%) ; \mathrm{Q}=$ flow $(\mathrm{mL} / \mathrm{min}) ; \mathrm{R}=$ resistance $(\mathrm{mmHg} / \mathrm{mL} / \mathrm{min})$.

Renovascular circulating volumes measured by ultrasound dilution decreased after clamping of one of the renal arterial branches (from $25.6 \pm 8.9 \mathrm{~mL}$ to $16.3 \pm 7.6$ $\mathrm{mL} ; \mathrm{p}=0.028$ ). However, these changes in renovascular circulating volume were not correlated with changes in actual perfused volume as measured by methylene blue staining (Figure 7.4).

\section{Effect of perfusion pressure, duration of perfusion, and warm ischemia time on renovascular circulation volume}

Per pressure $(30,40,50$ and $60 \mathrm{mmHg})$, renovascular circulating volume measured by ultrasound dilution did not differ between T1 and T24 ( $p=0.557, p=0.084$, $p=0.126$ and $p=0.833$, respectively; Table 7.1 ). Renovascular circulating volume increased significantly with every $10 \mathrm{mmHg}$ increase of pressure at $\mathrm{T} 1$ and for the increase from $30 \mathrm{mmHg}$ to $40 \mathrm{mmHg}$ at T24. Increasing the duration of hypothermic perfusion from 1 hour to 24 hours did not change renovascular circulating volumes (mean renovascular circulating volume $20.4 \pm 7.3 \mathrm{~mL}$ and $21.5 \pm 8.7 \mathrm{~mL}$, respectively; $\mathrm{p}=0.078$ ).

The mean renovascular circulating volumes of kidneys with 15 minutes of warm ischemia were higher than those of kidneys with 45 minutes of warm ischemia (34.1 $\pm 6.0 \mathrm{~mL}$ vs. $26.8 \pm 5.3 \mathrm{~mL}$, respectively; $\mathrm{p}=0.005)$ at $\mathrm{T} 1$, but did not significantly differ at T24 (36.7 $\pm 11.4 \mathrm{~mL}$ vs. $27.3 \pm 8.0 \mathrm{~mL}$, respectively; $p=0.059)$. 


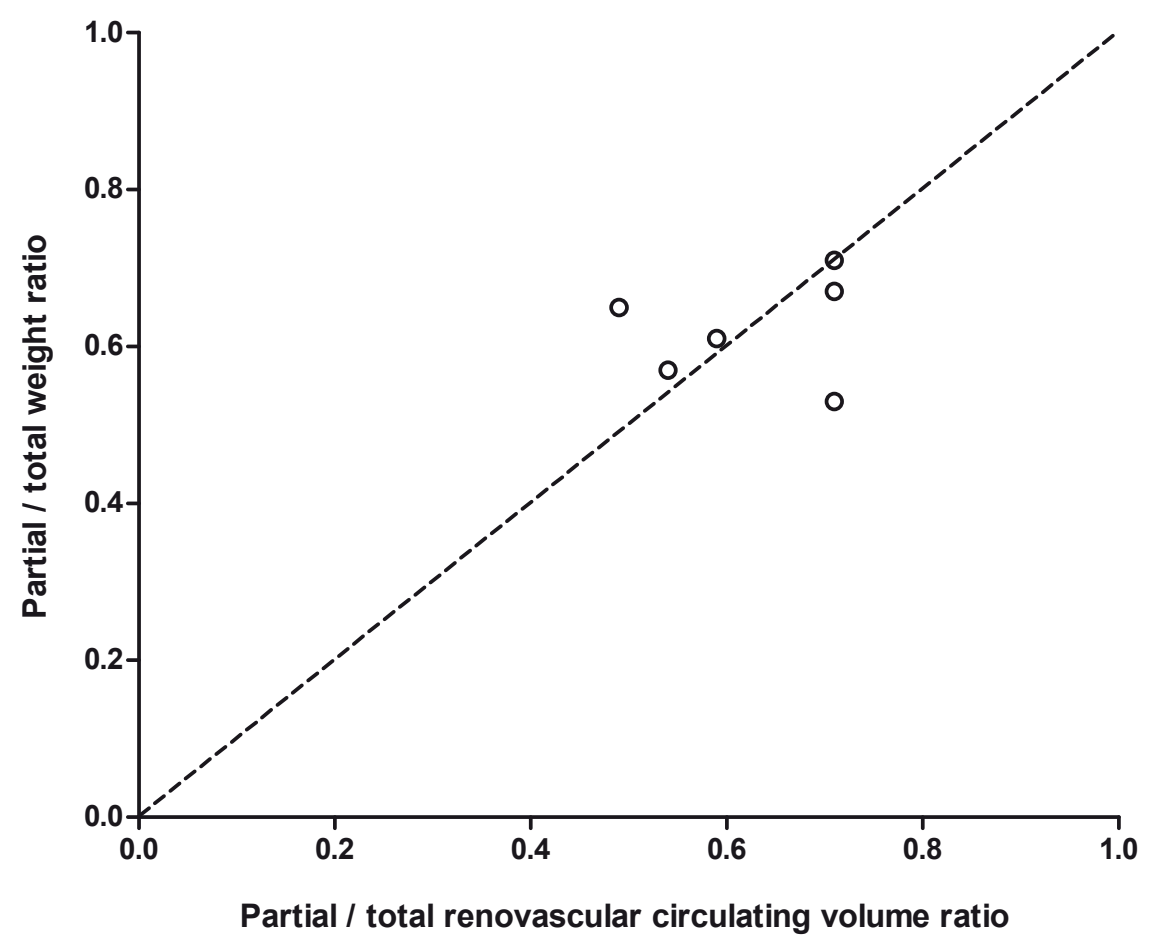

Figure 7.4 Correlation of volume/weight ratios of kidneys before and after clamping one of the arterial branches and methylene blue staining. The dotted line represents equality of both circulatory volume and weight ratio.

\section{DISCUSSION}

Organs from DCD donors have rapidly increased the deceased donor pool, but suffer from warm ischemic injury, resulting in a higher incidence of postoperative graft dysfunction. Pretransplantation assessment of DCD kidneys to select viable grafts for transplantation is crucial to obtain the best results after transplantation. Warm ischemia can lead to microvascular damage, affecting renovascular circulating volume. The dilution technique is a relatively simple method to measure intravascular volume and has not been used before in transplant surgery. As intravascular volume may be associated with organ viability, the dilution technique is a potentially valuable method to use in organ viability assessment. Therefore, we determined the repeatability and the validity of this technique, and we assessed the effect of warm ischemia on renovascular circulating volume in machine-perfused porcine kidneys. 
In 1897, the dilution technique was introduced for cardiac output measurement (7). More recently, this method has been applied to measure regional blood flow in heart and lungs, and this application has gained a wide acceptance (8). Since 1995, a modification of the dilution technique has been used to measure shunt flow, recirculation, and cardiac output during hemodialysis $(4,9)$. This study is the first that applies the dilution technique to measure renovascular volume of machine-perfused kidneys. Given the importance of pretransplantation viability testing in DCD kidneys, we have studied the feasibility of the dilution technique to measure renovascular circulating volume as a new potential viability marker.

We have shown that the dilution technique is a reproducible technique to measure renal blood flow in machine-perfused porcine kidneys. The repeatability of the dilution method was good, with an acceptable CV of $7.6 \%$. Repeatability did not change with duration of perfusion, but did show changes at different perfusion pressures. CV at a pressure of $30 \mathrm{mmHg}$ showed a significantly higher value compared with $40 \mathrm{mmHg}$, indicating that measurements at low pressure and flow are less reliable. This is probably due to equipment adjustments and should be optimized.

If one of the renal arterial branches of the kidney was clamped, measured renovascular volume decreased for all kidneys. Nonetheless, a correlation between volume and weight ratio could not be demonstrated. In four of six kidneys, volume and weight ratio measurements after clamping one arterial branch were almost equivalent, but ratios in two other kidneys were slightly off the line of equality of ratios. One of the limitations is that, in all six kidneys, between 30 to $50 \%$ of the kidney was excluded from perfusion. Moreover, it is not possible to assess if differences between volume and weight ratio measurements are caused by differences in the initial perfusion of one kidney. One part of a kidney may be better perfused with a higher intravascular volume than another.

We think that pretransplantation viability assessment by the dilution technique could have advantages as compared to viability assessment by machine perfusion. Machine perfusion has two potential advantages over cold storage. First, machine perfusion improves early graft function compared to cold storage by preventing interstitial edema, decreasing oxidative stress, improving adenosine triphosphate (ATP) availability, and washing out thrombi and metabolic products (10-16). Second, machine perfusion allows early viability assessment by measuring perfusion characteristics, including flow, pressure and renovascular resistance, or biomarkers (17-22). However, recent studies show that the value of these parameters to predict kidney transplant outcome is limited $(21,23,24)$. Machine perfusion characteristics could be influenced by leakage from the arterial connection resulting from atherosclerosis of the patch or by leakage from small arterial branches that have been damaged during procurement. In the dilution technique, however, leakage cannot influence the measurements, because an exact bolus of saline is assessed. However, the theoretical advantage of the dilution technique in viability testing has to be proven in clinical practice. 
Renovascular volume decreased after a prolonged period of warm ischemia. This may be explained by the manifestation of edema. Cellular volume regulation depends on mechanisms that require sodium-potassium ATPase activity, which is limited by decreased ATP during ischemia $(25,26)$. The significant differences between renovascular circulating volumes between short and long ischemia did not sustain until 24 hours of machine perfusion. This is in line with previous studies, which demonstrate that perfusion differences decrease over time $(23,27)$. In this study, we only compared different warm ischemia times at a machine perfusion pressure of $40 \mathrm{mmHg}$. This is the maximum perfusion pressure used at our and many other transplantation centers to avoid microvascular injury. Higher perfusion pressures may open capillaries, with better perfusion, but are also associated with vascular injury caused by shear stress (28-30). The finding that renovascular circulating volume is associated with warm ischemia time confirms our hypothesis on the relevance of renovascular circulating volume.

Further studies are necessary to assess the value of the dilution technique and renovascular volume measurements in human transplantation. Sterile flow probes for the renal artery and vein are available, which makes testing in human kidneys possible. The assessment of the effect of different pharmacological interventions during machine perfusion including vasodilating and antithrombolytic drugs on circulating volume could be a future application of the dilution technique.

We conclude that the dilution technique is a reproducible way to assess renovascular circulating volume in machine-perfused porcine kidneys, and that the technique is suitable to detect differences in warm ischemia time. 


\section{REFERENCES}

1. Tonelli M, Wiebe N, Knoll G, Bello A, Browne S, Jadhav D, et al. Systematic review: kidney transplantation compared with dialysis in clinically relevant outcomes. Am J Transplant. 2011 Oct;11(10):2093-109.

2. Keizer KM, de Fijter JW, Haase-Kromwijk BJ, Weimar W. Non-heart-beating donor kidneys in the Netherlands: allocation and outcome of transplantation. Transplantation. 2005 May 15;79(9):1195-9.

3. Snoeijs MG, Schaubel DE, Hene R, Hoitsma AJ, Idu MM, ljzermans JN, et al. Kidneys from donors after cardiac death provide survival benefit. J Am Soc Nephrol. 2010 Jun;21(6):1015-21.

4. Krivitski NM. Novel method to measure access flow during hemodialysis by ultrasound velocity dilution technique. Asaio J. 1995 Jul-Sep;41(3):M741-5.

5. Krivitski NM, Kislukhin VV, Snyder JW, MacGibbon DR, Kuznetsova OA, Reasons AM, et al. In vivo measurement of hemodialyzer fiber bundle volume: theory and validation. Kidney international. 1998 Nov;54(5):1751-8.

6. Krivitski NM. Theory and validation of access flow measurement by dilution technique during hemodialysis. Kidney international. 1995 Jul;48(1):244-50.

7. Stewart GN. Researches on the Circulation Time and on the Influences which affect it. The Journal of physiology. 1897 Nov 20;22(3):159-83.

8. Meier $\mathrm{P}$, Zierler KL. On the theory of the indicator-dilution method for measurement of blood flow and volume. J Appl Physiol. 1954 Jun;6(12):731-44.

9. Krivitski NM, Depner TA. Cardiac output and central blood volume during hemodialysis: methodology. Advances in renal replacement therapy. $1999 \mathrm{Jul} ; 6(3): 225-32$.

10. Gorbach AM, Leeser DB, Wang H, Tadaki DK, Fernandez C, Destephano D, et al. Assessment of cadaveric organ viability during pulsatile perfusion using infrared imaging. Transplantation. 2009 Apr 27;87(8):11636.

11. Moers C, Smits JM, Maathuis MH, Treckmann J, van Gelder F, Napieralski BP, et al. Machine perfusion or cold storage in deceased-donor kidney transplantation. N Engl J Med. 2009 Jan 1;360(1):7-19.

12. Schold JD, Kaplan B, Howard RJ, Reed Al, Foley DP, Meier-Kriesche HU. Are we frozen in time? Analysis of the utilization and efficacy of pulsatile perfusion in renal transplantation. Am J Transplant. 2005 Jul;5(7):16818.

13. Matsuoka L, Shah T, Aswad S, Bunnapradist S, Cho Y, Mendez RG, et al. Pulsatile perfusion reduces the incidence of delayed graft function in expanded criteria donor kidney transplantation. Am J Transplant. 2006 Jun;6(6):1473-8.

14. Jochmans I, Moers C, Smits JM, Leuvenink HG, Treckmann J, Paul A, et al. Machine perfusion versus cold storage for the preservation of kidneys donated after cardiac death: a multicenter, randomized, controlled trial. Annals of surgery. 2010 Nov;252(5):756-64.

15. Taylor MJ, Baicu SC. Current state of hypothermic machine perfusion preservation of organs: The clinical perspective. Cryobiology. 2010 Jul;60(3 Suppl):S20-35.

16. Yuan X, Theruvath AJ, Ge X, Floerchinger B, Jurisch A, Garcia-Cardena G, et al. Machine perfusion or cold storage in organ transplantation: indication, mechanisms, and future perspectives. Transpl Int. 2010 Jun;23(6):561-70.

17. Sung RS, Christensen LL, Leichtman AB, Greenstein SM, Distant DA, Wynn JJ, et al. Determinants of discard of expanded criteria donor kidneys: impact of biopsy and machine perfusion. Am J Transplant. 2008 Apr;8(4):783-92.

18. Matsuno N, Konno O, Mejit A, Jyojima Y, Akashi I, Nakamura Y, et al. Application of machine perfusion preservation as a viability test for marginal kidney graft. Transplantation. 2006 Dec 15;82(11):1425-8.

19. Guarrera JV, Goldstein MJ, Samstein B, Henry S, Reverte C, Arrington B, et al. 'When good kidneys pump badly': outcomes of deceased donor renal allografts with poor pulsatile perfusion characteristics. Transpl Int. 2009 Apr 1;23(4):444-6.

20. Hoogland ER, de Vries EE, Christiaans MH, Winkens B, Snoeijs MG, van Heurn LW. The Value of 
Machine Perfusion Biomarker Concentration in DCD Kidney Transplantations. Transplantation. 2013 Feb 27;95(4):603-10.

21. van Smaalen TC, Hoogland ER, van Heurn LW. Machine perfusion viability testing. Current opinion in organ transplantation. 2013 Apr;18(2):168-73.

22. Nyberg SL, Baskin-Bey ES, Kremers W, Prieto M, Henry ML, Stegall MD. Improving the prediction of donor kidney quality: deceased donor score and resistive indices. Transplantation. 2005 Oct 15;80(7):925-9.

23. de Vries EE, Hoogland ER, Winkens B, Snoeijs MG, van Heurn LW. Renovascular resistance of machineperfused DCD kidneys is associated with primary nonfunction. Am J Transplant. 2011 Dec;11(12):2685-91.

24. Jochmans I, Moers C, Smits JM, Leuvenink HG, Treckmann J, Paul A, et al. The prognostic value of renal resistance during hypothermic machine perfusion of deceased donor kidneys. Am J Transplant. 2011 Oct;11(10):2214-20.

25. Siedlecki A, Irish W, Brennan DC. Delayed graft function in the kidney transplant. Am J Transplant. 2011 Nov;11(11):2279-96.

26. Perico N, Cattaneo D, Sayegh MH, Remuzzi G. Delayed graft function in kidney transplantation. Lancet. 2004 Nov 13-19;364(9447):1814-27.

27. Brook NR, Knight AJ, Nicholson ML. Intra-renal resistance reflects warm ischaemic damage, and is further increased by static cold storage: a model of non-heart-beating donor kidneys. Med Sci Monit. 2003 Jul;9(7):BR271-5.

28. Minor T, Manekeller S, Sioutis M, Dombrowski F. Endoplasmic and vascular surface activation during organ preservation: refining upon the benefits of machine perfusion. Am J Transplant. 2006 Jun;6(6):1355-66.

29. Patel SK, Pankewycz OG, Weber-Shrikant E, Zachariah M, Kohli R, Nader ND, et al. Effect of increased pressure during pulsatile pump perfusion of deceased donor kidneys in transplantation. Transplantation proceedings. 2012 Sep;44(7):2202-6.

30. Doorschodt BM, Schreinemachers MC, Behbahani M, Florquin S, Weis J, Staat M, et al. Hypothermic machine perfusion of kidney grafts: which pressure is preferred? Annals of biomedical engineering. 2011 Mar;39(3):1051-9. 


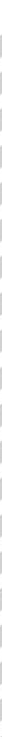

\section{8}


CHAPTER 8

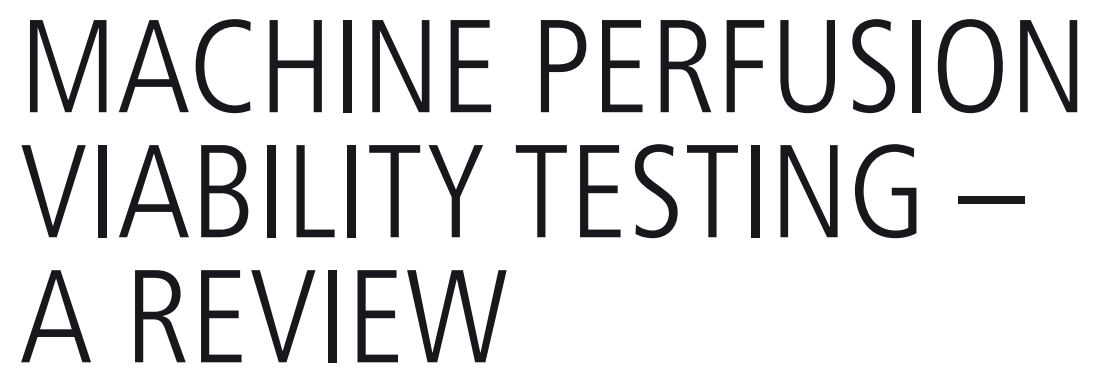




\section{ABSTRACT}

Pretransplant assessment of kidney graft viability may help clinicians to decide whether to accept or discard a kidney for transplantation. With the increasing demand for donor kidneys and the increased use of marginal kidneys, the need of viability markers has increased to pursue superior transplant outcomes. Hypothermic machine perfusion (HMP) provides the theoretical opportunity to assess the viability of donor kidneys. We discuss the novel developments in viability testing during HMP and address the future prospects.

HMP viability testing has focused on the analysis of machine perfusion parameters and perfusate biomarkers. Renal resistance and the biomarkers lactate dehydrogenase, aspartate transaminase, glutathione-S-transferase, N-acetyl-b-Dglucosaminidase, heart-type fatty acid binding protein, lipid peroxidation products, redox-active iron and IL-18 are correlated with transplant outcome in terms of development of delayed graft function or graft survival. However, they all lack adequate predictive value for transplant outcome. New techniques including contrastenhanced ultrasound, three-dimensional ultrasound and magnetic resonance spectrometry are promising methods to test kidney viability during HMP, but their value has to be established. The introduction of normothermic machine perfusion offers other promising opportunities for viability testing.

Machine perfusion characteristics and perfusate biomarkers have been extensively studied. They often correlate with the transplant outcome, but the present viability tests are not reliable predictors of transplant outcome. New developments in kidney graft viability assessment are necessary to have a chance of being clinically useful in the future.

\section{Published as}

T.C. van Smaalen, E.R. Pieter Hoogland, and L.W. Ernest van Heurn. Machine perfusion viability testing. Curr Opin Organ Transplant 2013; 18(2):168-73 


\section{INTRODUCTION}

Selection of suitable kidneys for transplantation is important to reduce the risk of primary non-function (PNF) and delayed graft function (DGF) after transplantation, which is associated with an increased risk of graft loss, acute rejection, longer hospital stay and high costs (1-4). The shortage of donors and the increasing use of marginal donors make donor kidney selection even more important. Although donor characteristics, including age and associated disease, and procurement methods are associated with kidney transplant function, there are no true kidney viability markers. Predicting the kidney function and assessing the chance of graft survival prior to transplantation remain difficult. Because of the increasing use of marginal kidneys, there is an urgent need for better pretransplant viability tests to avoid the risk of poor outcome after transplantation.

Hypothermic machine perfusion (HMP) is a technique to preserve donor kidneys. It has many advantages over cold storage. In theory, continuous pulsatile flow through the kidney can provide nutrients and oxygen to the kidney and it can eliminate metabolic byproducts and toxins. It decreases vasospasm and protects the endothelium, possibly because of flow-dependent genes. Furthermore, HMP offers the opportunity to apply therapeutic interventions, like the addition of pharmacological agents $(5,6)$. In a preclinical animal study, HMP was superior to cold storage in terms of functional recovery, oxidative stress, tissue histology and inflammatory parameters (7). In human kidney transplantation, there is highlevel evidence that HMP is associated with a decreased risk of DGF, improved 1-year and 3-year graft survival, although the last was only proven for donation after brain death (DBD) kidneys and not for donation after cardiac death (DCD) kidneys (8-11).

HMP offers a good opportunity to test the viability of deceased-donor kidneys. In the past, machine viability testing has been used to decide whether kidneys should be discarded or not. Many have evaluated perfusate biomarker concentration and machine perfusion parameters as a tool to estimate graft viability. However, its use was often only justified by the argument that the results of transplantation had improved after the introduction of machine perfusion viability testing. Highquality evidence was usually not available (4). Recent literature provides more information about the association of machine perfusion viability testing and kidney function after transplantation and even more importantly, about its predictive value.

\section{MACHINE PERFUSION PARAMETERS}

During machine perfusion, pressure, flow and renal resistance are easily monitored. There is no common opinion about the best perfusion pressure of kidneys and used pressures vary between 20 and $60 \mathrm{mmHg}(12,13)$. Because pressure measurements are directly subjected to their manual setting, perfusion pressure itself has no role in outcome prediction or viability testing. Renal flow, although more often used than pressure, encounters similar problems. Flow depends on the 
manual pressure settings, making a cut-off value for flow itself not reliable in clinical decision-making (14). Therefore, renal resistance (the ratio of perfusion pressure and renal flow) is used for viability testing instead.

It is estimated that approximately $15 \%$ of all machine-perfused kidneys in the USA are discarded, partly because of high renal resistance (15). However, little information is known about the predictive value of renal resistance and other machine perfusion characteristics on transplant outcome or its use in selecting kidneys for transplantation $(12,14,16,17)$. Two studies have addressed the use of renal resistance as a viability marker without being biased by donor kidney selection prior to transplantation, that is, discarding kidneys because of too high renal resistance or low flow $(18,19)$.

The first study included 336 hypothermic machine-perfused DCD and DBD kidneys of the European machine perfusion trial (8). High renal resistance at the end of machine perfusion was an independent risk factor of DGF (OR 38.1; 95\% Cl 1.56934; $P=0.026)$ and for 1-year graft failure (HR 12.33; 95\% Cl 1.11-136.85; $p=0.004)$. However, the predictive value of renal resistance on DGF was poor (AURC $=0.58)(18)$.

The second study included 440 hypothermic machine-perfused DCD kidneys. This study showed a significant and independent association of renal resistance at the beginning of HMP with PNF (OR 2.040; 95\% Cl 1.362-3.056; $\mathrm{p}=0.001)$ and DGF (OR $2.345 ; 95 \% \mathrm{Cl} 1.110-4.955 ; \mathrm{p}=0.025)$. However, the predictive value for PNF was poor (AURC 0.609) (19). This study focused on PNF instead of DGF, as DGF does not affect long-term survival in DCD kidneys (20).

\section{BIOMARKERS}

Machine perfusion enables viability testing by analyzing the washout of enzymes in the perfusate. These biomarkers include released contents of damaged cells leaked into the interstitial space, free-radical-mediated molecules, measures of antioxidant status or inflammation-associated proteins.

A large variety of biomarkers have been advocated as possible markers of kidney injury: lactate dehydrogenase (LDH), alanine aminopeptidase (Ala-AP), glutathione-S-transferase (GST) in different isoforms, aspartate transaminase (AST), lipid peroxidation products (LPOP), heart-type fatty acid binding protein (H-FABP), lactate, electrolytes, gas pressure ( $\mathrm{pO} 2$ and $\mathrm{pCO} 2$ ), $\mathrm{pH}$, osmolarity, N-acetyl-b-Dglucosaminidase (NAG), redox-active iron, malondialdehyde (MDA), total antioxidant status (TAS), glucose, acid phosphatase, neutrophils gelatinase-associated lipocalin (NGAL), interleukin 18 (IL-18) and proteomics. The most important and recently studied biomarkers are discussed below (Table 8.1) (21-25). 
LDH was correlated with PNF in some studies and more often with DGF only, although its predictive value for DGF was poor (AURC 0.60) $(4,21)$. Very recently, these findings were confirmed in an unselected cohort of 335 DCD kidneys. LDH was associated with PNF as well as DGF in a multivariate analysis, corrected for confounding variables. However, diagnostic accuracy for the development of PNF was poor (AURC $=0.699)(22)$.

\section{Perfusate biomarkers}

\begin{tabular}{|c|c|c|c|c|c|c|}
\hline \multirow{2}{*}{ Biomarker } & \multirow{2}{*}{ Origin } & \multirow{2}{*}{ Marker of } & \multirow{2}{*}{$\begin{array}{l}\text { DCD/DBD } \\
\text { kidneys }^{1}\end{array}$} & \multicolumn{2}{|c|}{$\begin{array}{l}\text { Predictive } \\
\text { value for }\end{array}$} & \multirow{2}{*}{ References } \\
\hline & & & & DGF & PNF & \\
\hline LDH & $\begin{array}{l}\text { Cytoplasm of various body } \\
\text { cells, including brush border } \\
\text { of proximal renal tubule. }\end{array}$ & $\begin{array}{l}\text { Non-specific cellular } \\
\text { injury }\end{array}$ & $\begin{array}{l}\text { DCD, } \\
\text { DBD }\end{array}$ & Poor & Poor & $(21,22,29)$ \\
\hline Ala-AP & $\begin{array}{l}\text { Intestine and brush border of } \\
\text { proximal renal tubule }\end{array}$ & Tubular injury & $\begin{array}{l}\text { DCD, } \\
\text { DBD }\end{array}$ & Poor & - & $(21)$ \\
\hline Total GST & $\begin{array}{l}\text { Cytoplasm of various body } \\
\text { cells, including proximal and } \\
\text { distal renal tubule }\end{array}$ & Tubular injury & $\begin{array}{l}\text { DCD, } \\
\text { DBD }\end{array}$ & Poor & Poor & $(21,22,26,29)$ \\
\hline Alpha-GST & $\begin{array}{l}\text { Cytoplasm of various body } \\
\text { cells, including proximal renal } \\
\text { tubule }\end{array}$ & $\begin{array}{l}\text { Proximal tubular } \\
\text { injury }\end{array}$ & $\begin{array}{l}\text { DCD, } \\
\text { DBD }\end{array}$ & - & - & (26) \\
\hline Pi-GST & $\begin{array}{l}\text { Cytoplasm of various body } \\
\text { cells, including distal renal } \\
\text { tubule }\end{array}$ & Distal tubular injury & $\begin{array}{l}\text { DCD, } \\
\text { DBD }\end{array}$ & - & - & (26) \\
\hline LPOP & Various body cells & Oxidative stress & $\begin{array}{l}\text { DCD, } \\
\text { DBD }\end{array}$ & - & - & (26) \\
\hline $\mathrm{H}-\mathrm{FABP}$ & $\begin{array}{l}\text { Heart, small intestine, skeletal } \\
\text { muscle and distal renal } \\
\text { tubules. }\end{array}$ & $\begin{array}{l}\text { Ischemic cellular } \\
\text { injury }\end{array}$ & $\begin{array}{l}\text { DCD, } \\
\text { DBD }\end{array}$ & Poor & Poor & $(21,22)$ \\
\hline AST & $\begin{array}{l}\text { Several tissues, including } \\
\text { renal parenchymal cells }\end{array}$ & $\begin{array}{l}\text { Parenchymal cell } \\
\text { injury }\end{array}$ & $\begin{array}{l}\text { DCD, } \\
\text { DBD }\end{array}$ & Poor & - & $(21)$ \\
\hline $\begin{array}{l}\text { Redox- } \\
\text { active iron }\end{array}$ & Several organ systems & $\begin{array}{l}\text { Ischemial } \\
\text { reperfusion injury }\end{array}$ & $D C D$ & - & Fair $^{3}$ & $(22,29)$ \\
\hline NAG & $\begin{array}{l}\text { Lysosomes of various tissues, } \\
\text { including proximal renal } \\
\text { tubule }\end{array}$ & $\begin{array}{l}\text { Acute oxidative } \\
\text { stress }\end{array}$ & $\begin{array}{l}\text { DCD, } \\
\text { DBD }\end{array}$ & Poor & - & $(21)$ \\
\hline NGAL & $\begin{array}{l}\text { Several tissues, Renal tubular } \\
\text { epithelial cells }\end{array}$ & $\begin{array}{l}\text { Tubular epithelial } \\
\text { injury }\end{array}$ & $D C D$ & - & Poor & $(22)$ \\
\hline IL-18 & $\begin{array}{l}\text { Produced by macrophages } \\
\text { and other cell types }\end{array}$ & $\begin{array}{l}\text { Inflammatory } \\
\text { reactions during } \\
\text { ischemia/ } \\
\text { reperfusion injury }\end{array}$ & $D C D$ & - & Fair $^{3}$ & $(22)$ \\
\hline $\begin{array}{l}\text { Perfusate } \\
\text { Proteomes }\end{array}$ & Unknown & $\begin{array}{l}\text { Ischemic acute renal } \\
\text { injury }\end{array}$ & $D C D$ & - & - & (31) \\
\hline
\end{tabular}

${ }^{1}$ Kidneys on which a predictive value was based on.

${ }^{2}$ Predictive value was derived from the area under the receiver operating curve of univariate analyses of individual biomarkers (1: perfect; 0.9-1: excellent; 0.8-0.9 good; 0.7-0.8 fair; <0.7: poor).

${ }^{3}$ Predictive value after multivariate analysis. 
Ala-AP is a biomarker used in acute kidney injury and rarely described in a pretransplant setting. Ala-AP was correlated with DGF, however with a poor predictive value (AURC 0.57) $(21,26)$.

GST represents a family of cytosolic, microsomal and membrane-bound enzymes [total GST (tGST)], of which two of the eight cytoplasmic classes identified are of major interest. Alpha-GST, found in the proximal renal tubule, and p-GST, found in the distal renal tubule, are released during ischemia. Proximal tubules are metabolically more active, thus making a-GST in theory a more promising biomarker (26-28). Total GST concentration was elevated in DGF and PNF kidneys, but with poor predictive values for DGF (AURC 0.67) (21) and PNF (AURC 0.58) (22). Analysis of GST in HMP perfusates of 111 kidneys from donors older than 55 years showed that $\mathrm{p}$-GST was not suitable to predict DGF. Alpha-GST had a better positive predictive value than tGST (71.4 and $37.5 \%$, respectively), but is more expensive and time-consuming to measure. After multivariate analysis, none did seem to be an independent predictor of DGF after transplantation (24).

LPOP is a combination of products released after oxidative stress (24). LPOP concentration is proposed to be an index for the effects of reactive oxygen species, which are thought to play a major role in ischemic injury $(3,29,30)$. LPOP concentration was an independent predictor of DGF after transplantation (OR 2.026; 95\% Cl 1.129-3.637; $p=0.018)$ (24).

H-FABP was addressed in two studies. It is involved in the uptake of fatty acid from the cytosol to the mitochondria (28). H-FABP was noted to have a poor predictive value for DGF (AURC 0.64) (21) and PNF (AURC 0.56) (22).

AST showed a significant association with DGF after transplantation with a poor predictive value (AURC 0.61) (21).

Perfusate redox-active iron concentration was significantly higher in DCD kidneys than in DBD kidneys, explained by the increased ischemic injury of DCD kidneys. Perfusate concentration in DCD kidneys was significantly associated with DGF and PNF, with increased risk of DGF (OR 1.532; 95\% Cl 1.045-2.245; $p=0.029)$ and PNF (OR 1.68; 95\% Cl 1.13-2.49; $p=0.01$ ). The predictive value for PNF in a univariate analysis was poor (AURC 0.625), but increased to fair (AURC 0.701) in a multivariate analysis $(22,23)$.

NAG was addressed in one high-quality study. The perfusate sample was taken at the end of machine perfusion and showed a poor predictive value for DGF (AURC $0.64)(21)$.

NGAL is expressed in a wide variety of tissues, including renal tubular epithelium, and rapidly expressed after the injury of tubular epithelium (27). NGAL has been used as a biomarker for acute renal injury; the concentration in perfusate of machine-perfused porcine kidneys was proportionate to the amount of prior 
warm ischemic injury (31). Recently, it has been studied as a viability predictor in DCD kidneys. Although perfusate concentration was associated with transplant outcome, its predictive value for PNF was poor (AURC 0.503) (22).

The proinflammatory cytokine IL-18 has been addressed once. In DCD kidneys, it was associated with an increased risk of PNF and DGF (OR 1.001; 95\% Cl 1.000-1.002; $\mathrm{p}=0.003$ and $\mathrm{OR} 1.003 ; 95 \% \mathrm{Cl} 1.001-1.004 ; \mathrm{p}=0.002$, respectively). Its predictive value for PNF in a univariate analysis was poor (AURC 0.591), but increased to fair (AURC 0.700 ) in a multivariate analysis (22).

A proteomics study of machine perfusate of 18 kidneys (6 DBD, 6 controlled DCD and 6 uncontrolled DCD kidneys) identified 19 unique proteins with the use of twodimensional difference gel electrophoresis and mass spectrometry. In DCD kidneys, two unidentified proteins were significantly upregulated and one protein, identified as haptoglobin, was significantly downregulated, compared with DBD kidneys. Furthermore, two proteins were upregulated in PNF kidneys and 1 protein, identified as a1-antitrypsin, was upregulated in DGF kidneys. Thus, this study introduced a series of novel biomarkers of ischemic acute renal injury in human donor kidneys. However, their diagnostic value in viability testing has to be determined in future studies (25).

\section{NOVELTIES IN VIABILITY TESTING}

In past decades, machine perfusion viability testing mainly focused on perfusate biomarkers and machine perfusion parameters. Contrast-enhanced ultrasound (CEUS) and three dimensional ultrasound (3DUS) have recently been introduced as a new technique for assessing renal transplant perfusion during HMP. Five pig kidneys were procured after a period of $30 \mathrm{~min}$ of warm ischemia and placed on a hypothermic perfusion machine. Following a bolus injection of a contrast solution (tiny bubbles of inert gas, which pass through the capillary bed but not through the interstitial space or blood-brain barrier and which increase ultrasound signal return), 2D and 3D ultrasound scans were performed. These techniques were fast, well tolerated, aseptic and noninvasive methods to assess perfusion of the kidney before transplantation (32). In the future, this might be useful to assess organ viability, in addition to machine perfusion parameters like flow and renal resistance, albeit their value has to be assessed in large human cohorts first.

Magnetic resonance spectrometry (MRS) has been studied before to assess ischemic injury and viability of kidneys on cold storage (33-37). Recently, MRS has been used to assess viability during HMP with a newly developed magnetic resonance compatible perfusion machine (38-40). This machine has been used to oxygenate porcine kidneys during hypothermic preservation and to measure chemical shifts during HMP with the use of $1 \mathrm{H}$ and 31P-MRS. 31P-MRS showed to be a valuable tool to assess ATP levels in kidneys without warm ischemia, if appropriate $\mathrm{O} 2$ tension was 
applied to the preservation medium. MRS during HMP may also be useful to study preservation conditions and warm ischemic effects in a clinical setting (40). Although the number of kidneys studied until now is limited, the idea of measuring ATP levels is interesting and promising as it is a measure of energy depletion after ischemic injury. Its value to predict organ viability has to be proven.

\section{FUTURE PROSPECTS}

Kidney viability testing has benefited from the introduction of HMP, although the predictive value of machine perfusion resistance and of different perfusate biomarkers is too low to obtain a useful predictor of kidney transplant outcome. Normothermic machine perfusion (NMP) may provide new and other opportunities to assess the quality of a donor organ before transplantation. Furthermore, NMP may ameliorate ischemic damage and resuscitate the organ instead of doing further harm and preventing the graft from injury during the preservation period (41).

The Leicester group showed in a porcine kidney autotransplant model that after a period of $20 \mathrm{~h}$ of HMP, kidneys can be safely perfused with NMP for two hours with autologous blood (42). Thereafter, they perfused a human kidney with a warm solution of cross-matched packed red cells with crystalloids, nutrients and some medication, shortly before transplantation, which shows that short-term NMP is feasible in a clinical setting (43). Now NMP seems feasible and well tolerated, it may have large potential to improve machine perfusion viability testing. The major advantage of NMP to test organ viability is the possibility of measuring functional parameters, like diuresis and creatinine clearance. In a normothermic setting with normal kidney metabolism, cellular injury may be diagnosed by cellular dysfunction instead of by markers of cell death, ischemia or inflammation. Functional measurements may provide key parameters of kidney viability and may be more accurate and useful in transplant outcome prediction than any of aforementioned viability markers $(44,45)$.

\section{CONCLUSION}

We conclude that machine perfusion viability testing has not offered clinicians the expected tools to assess kidney viability before transplantation. Currently available viability tests during HMP are not reliable enough to decide to discard a donor kidney prior to transplantation. New biomarkers and novel techniques may provide tests with better predictive value than the tests used today, but their value has to be proven. Viability testing during normothermic perfusion offers a novel opportunity to assess the quality of a donor kidney, as the function of metabolically active organs is tested, instead of surrogate indicators of kidney injury. 


\section{REFERENCES}

1. Yarlagadda SG, Coca SG, Formica RN, Jr., Poggio ED, Parikh CR. Association between delayed graft function and allograft and patient survival: a systematic review and meta-analysis. Nephrol Dial Transplant. 2009 Mar;24(3):1039-47.

2. Huang Y, Samaniego M. Preemptive kidney transplantation: Has it come of age? Nephrologie \& therapeutique. Nov;8(6):428-32.

3. Perico N, Cattaneo D, Sayegh MH, Remuzzi G. Delayed graft function in kidney transplantation. Lancet. 2004 Nov 13-19;364(9447):1814-27.

4. Bhangoo RS, Hall IE, Reese PP, Parikh CR. Deceased-donor kidney perfusate and urine biomarkers for kidney allograft outcomes: a systematic review. Nephrol Dial Transplant. 2012 Aug;27(8):3305-14.

5. Yuan X, Theruvath AJ, Ge X, Floerchinger B, Jurisch A, Garcia-Cardena G, et al. Machine perfusion or cold storage in organ transplantation: indication, mechanisms, and future perspectives. Transpl Int. 2010 Jun;23(6):561-70.

6. Taylor MJ, Baicu SC. Current state of hypothermic machine perfusion preservation of organs: The clinical perspective. Cryobiology. 2010 Jul;60(3 Suppl):S20-35.

7. Vaziri N, Thuillier R, Favreau FD, Eugene M, Milin S, Chatauret NP, et al. Analysis of machine perfusion benefits in kidney grafts: a preclinical study. Journal of translational medicine. 2011;9:15.

8. Moers C, Smits JM, Maathuis MH, Treckmann J, van Gelder F, Napieralski BP, et al. Machine perfusion or cold storage in deceased-donor kidney transplantation. N Engl J Med. 2009 Jan 1;360(1):7-19.

9. Moers C, Pirenne J, Paul A, Ploeg RJ, Machine Preservation Trial Study G. Machine perfusion or cold storage in deceased-donor kidney transplantation. N Engl J Med. 2012 Feb 23;366(8):770-1.

10. Treckmann J, Moers C, Smits JM, Gallinat A, Maathuis MH, van Kasterop-Kutz M, et al. Machine perfusion versus cold storage for preservation of kidneys from expanded criteria donors after brain death. Transpl Int. 2011 Jun;24(6):548-54.

11. Gallinat A, Moers C, Treckmann J, Smits JM, Leuvenink HG, Lefering R, et al. Machine perfusion versus cold storage for the preservation of kidneys from donors $>=65$ years allocated in the Eurotransplant Senior Programme. Nephrol Dial Transplant. 2012 Dec;27(12):4458-63.

12. Patel SK, Pankewycz OG, Weber-Shrikant E, Zachariah M, Kohli R, Nader ND, et al. Effect of increased pressure during pulsatile pump perfusion of deceased donor kidneys in transplantation. Transplantation proceedings. 2012 Sep;44(7):2202-6.

13. Doorschodt BM, Schreinemachers MC, Behbahani M, Florquin S, Weis J, Staat M, et al. Hypothermic machine perfusion of kidney grafts: which pressure is preferred? Annals of biomedical engineering. 2011 Mar;39(3):1051-9.

14. Mozes MF, Skolek RB, Korf BC. Use of perfusion parameters in predicting outcomes of machine-preserved kidneys. Transplantation proceedings. 2005 Jan-Feb;37(1):350-1.

15. Sung RS, Christensen LL, Leichtman AB, Greenstein SM, Distant DA, Wynn JJ, et al. Determinants of discard of expanded criteria donor kidneys: impact of biopsy and machine perfusion. Am J Transplant. 2008 Apr;8(4):783-92.

16. Dikdan GS, Mora-Esteves C, Koneru B. Review of randomized clinical trials of donor management and organ preservation in deceased donors: opportunities and issues. Transplantation. 2012 Sep 15;94(5):42541.

17. Patel SK, Pankewycz OG, Nader ND, Zachariah M, Kohli R, Laftavi MR. Prognostic utility of hypothermic machine perfusion in deceased donor renal transplantation. Transplantation proceedings. 2012 Sep;44(7):2207-12.

18. Jochmans I, Moers C, Smits JM, Leuvenink HG, Treckmann J, Paul A, et al. The prognostic value of renal resistance during hypothermic machine perfusion of deceased donor kidneys. Am J Transplant. 2011 Oct;11(10):2214-20.

19. de Vries EE, Hoogland ER, Winkens B, Snoeijs MG, van Heurn LW. Renovascular resistance of machine- 
perfused DCD kidneys is associated with primary nonfunction. Am J Transplant. 2011 Dec;11(12):2685-91.

20. Renkens JJ, Rouflart MM, Christiaans MH, van den Berg-Loonen EM, van Hooff JP, van Heurn LW. Outcome of nonheart-beating donor kidneys with prolonged delayed graft function after transplantation. Am J Transplant. 2005 Nov;5(11):2704-9.

21. Moers C, Varnav OC, van Heurn E, Jochmans I, Kirste GR, Rahmel A, et al. The value of machine perfusion perfusate biomarkers for predicting kidney transplant outcome. Transplantation. 2010 Nov 15;90(9):96673.

22. Hoogland ER, de Vries EE, Christiaans MH, Winkens B, Snoeijs MG, van Heurn LW. The Value of Machine Perfusion Biomarker Concentration in DCD Kidney Transplantations. Transplantation. 2013 Feb 27;95(4):603-10.

23. de Vries B, Snoeijs MG, von Bonsdorff L, Ernest van Heurn LW, Parkkinen J, Buurman WA. Redox-active iron released during machine perfusion predicts viability of ischemically injured deceased donor kidneys. Am J Transplant. 2006 Nov;6(11):2686-93.

24. Nagelschmidt M, Minor T, Gallinat A, Moers C, Jochmans I, Pirenne J, et al. Lipid peroxidation products in machine perfusion of older donor kidneys. The Journal of surgical research. 2013 Apr;180(2):337-42.

25. Snoeijs MG, Pulinx B, van Dieijen-Visser MP, Buurman WA, van Heurn LW, Wodzig WK. Characterization of the perfusate proteome of human donor kidneys. Annals of clinical biochemistry. $2013 \mathrm{Mar} ; 50$ (Pt 2):140-6.

26. Gok MA, Pelsers M, Glatz JF, Bhatti AA, Shenton BK, Peaston R, et al. Comparison of perfusate activities of glutathione S-transferase, alanine aminopeptidase and fatty acid binding protein in the assessment of non-heart-beating donor kidneys. Annals of clinical biochemistry. 2003 May;40(Pt 3):252-8.

27. Waring WS, Moonie A. Earlier recognition of nephrotoxicity using novel biomarkers of acute kidney injury. Clinical toxicology. 2011 Oct;49(8):720-8.

28. Balfoussia D, Yerrakalva D, Hamaoui K, Papalois V. Advances in machine perfusion graft viability assessment in kidney, liver, pancreas, lung, and heart transplant. Exp Clin Transplant. 2012 Apr;10(2):87-100.

29. Siedlecki A, Irish W, Brennan DC. Delayed graft function in the kidney transplant. Am J Transplant. 2011 Nov;11(11):2279-96.

30. Kosieradzki M, Kuczynska J, Piwowarska J, Wegrowicz-Rebandel I, Kwiatkowski A, Lisik W, et al. Prognostic significance of free radicals: mediated injury occurring in the kidney donor. Transplantation. $2003 \mathrm{Apr}$ 27;75(8):1221-7.

31. Jochmans I, Monbaliu D, Pirenne J. Neutrophil gelatinase-associated lipocalin, a new biomarker candidate in perfusate of machine-perfused kidneys: a porcine pilot experiment. Transplantation proceedings. Nov;43(9):3486-9.

32. Stenberg B, Talbot D, Khurram M, Kanwar A, Ray C, Mownah O, et al. A new technique for assessing renal transplant perfusion preoperatively using contrast-enhanced ultrasound (CEUS) and three-dimensional ultrasound (3DUS)--a porcine model pilot study. Ultraschall in der Medizin. 2011 Dec;32 Suppl 2:E8-13.

33. Beckmann N, Hof RP, Rudin M. The role of magnetic resonance imaging and spectroscopy in transplantation: from animal models to man. NMR Biomed. 2000 0ct;13(6):329-48.

34. Hauet T, Mothes D, Goujon JM, Caritez JC, Le Moyec L, Carretier M, et al. Evaluation of normothermic ischemia and simple cold preservation injury in pig kidney by proton nuclear magnetic resonance spectroscopy. The Journal of surgical research. 1997 Mar;68(2):116-25.

35. Hauet T, Mothes D, Goujon JM, Caritez JC, Carretier M, Eugene M. Evaluation of injury preservation in pig kidney cold storage by proton nuclear magnetic resonance spectroscopy of urine. The Journal of urology. 1997 Mar;157(3):1155-60.

36. Kurkova D, Herynek V, Gintelova J, Taborsky P, Hajek M. Potential of 31P magnetic resonance spectroscopy in monitoring the viability of human renal grafts stored in Euro-Collins perfusion solution. Physiological research / Academia Scientiarum Bohemoslovaca. 1995;44(5):327-32.

37. Bretan PN, Jr., Baldwin N, Novick AC, Majors A, Easley K, Ng T, et al. Pretransplant assessment of renal viability by phosphorus-31 magnetic resonance spectroscopy. Clinical experience in 40 recipient patients. Transplantation. 1989 Jul; $48(1): 48-53$.

38. Buchs JB, Buhler L, Morel P. A new disposable perfusion machine, nuclear magnetic resonance compatible, 
to test the marginal organs and the kidneys from non-heart-beating donors before transplantation. Interactive cardiovascular and thoracic surgery. 2007 Aug;6(4):421-4.

39. Buchs JB, Lazeyras F, Ruttimann R, Nastasi A, Morel P. Oxygenated hypothermic pulsatile perfusion versus cold static storage for kidneys from non heart-beating donors tested by in-line ATP resynthesis to establish a strategy of preservation. Perfusion. 2011 Mar;26(2):159-65.

40. Lazeyras F, Buhler L, Vallee JP, Hergt M, Nastasi A, Ruttimann R, et al. Detection of ATP by "in line" 31P magnetic resonance spectroscopy during oxygenated hypothermic pulsatile perfusion of pigs' kidneys. Magma. 2012 Oct;25(5):391-9.

41. Hosgood SA, Nicholson HF, Nicholson ML. Oxygenated kidney preservation techniques. Transplantation. 2012 Mar 15;93(5):455-9.

42. Hosgood SA, Barlow AD, Yates PJ, Snoeijs MG, van Heurn EL, Nicholson ML. A pilot study assessing the feasibility of a short period of normothermic preservation in an experimental model of non heart beating donor kidneys. The Journal of surgical research. 2011 Nov;171(1):283-90.

43. Hosgood SA, Nicholson ML. First in man renal transplantation after ex vivo normothermic perfusion. Transplantation. 2011 Oct 15;92(7):735-8.

44. Hosgood SA, Nicholson ML. Normothermic kidney preservation. Current opinion in organ transplantation. 2011 Apr;16(2):169-73.

45. Vogel T, Brockmann JG, Coussios C, Friend PJ. The role of normothermic extracorporeal perfusion in minimizing ischemia reperfusion injury. Transplantation reviews. 2012 Apr;26(2):156-62. 


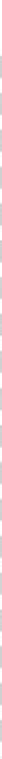


CHAPTER 9

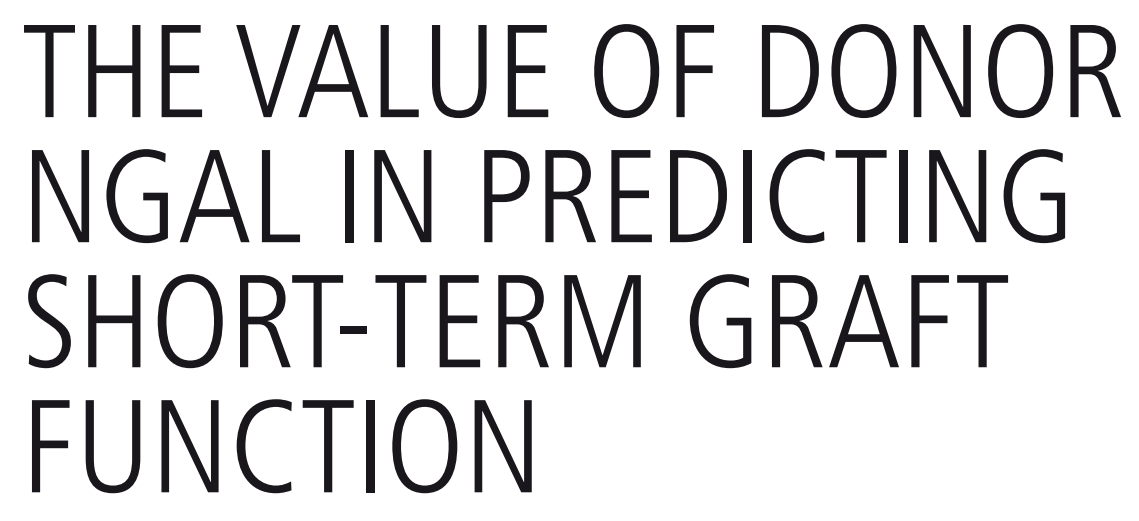




\section{ABSTRACT}

Background: Donation after cardiac death $(D C D)$ may greatly expand the donor pool, but concerns about warm ischemic injury before organ recovery have resulted in reluctance to use DCD kidneys for transplantation. An accurate tool to assess renal injury before donation is lacking. We explored the diagnostic value of donor plasma NGAL concentration as a predictor of early postoperative graft function after kidney transplantation.

Methods: All deceased donor kidneys procured or transplanted at the Maastricht University Medical Center were included in this study. Plasma NGAL concentration was determined in whole donor EDTA-blood of DCD donors and donation after brain-dead (DBD) donors. Correlations of NGAL concentration with donor characteristics and graft function after transplantation were assessed.

Results: A total of 101 kidneys entered analysis. NGAL concentration was not significantly different between DCD and DBD donors $(p=0.333)$. NGAL concentration correlated with donor creatinine $(r s=.451, p<0.001)$, but did not correlate with graft function after transplantation $(p=0.267)$. For functioning DCD kidneys, a significant difference in NGAL concentration between kidneys with delayed graft function (DGF) and immediate function (IF) was observed $(p=0.049)$. NGAL concentration did not correlate with estimated glomerular filtration rate at 1 and 2 years after transplantation ( $p=0.216$ and $p=0.941$, respectively).

Conclusion: We have shown that donor NGAL concentration correlated with donor plasma creatinine. Additionally, NGAL concentrations between DGF and IF of DCD kidneys were significantly different. Its value to predict transplantation outcome is limited.

\section{Published as}

E.R. Pieter Hoogland, Maarten G.J. Snoeijs and L.W. Ernest van Heurn. Plasma neutrophil gelatinase-associated lipocalin of deceased donors as a predictor of posttransplantation kidney function. Manuscript submitted. 


\section{INTRODUCTION}

For patients with end-stage renal disease, kidney transplantation offers better life expectancy and quality of life compared to dialysis therapy. Due to the shortage of donor kidneys, marginal grafts have increasingly been accepted for transplantation over the past decade. However, concerns about early graft dysfunction due to warm ischemic injury before organ recovery have resulted in a general reluctance to expand the use of DCD kidneys to its full potential. The extent of ischemic injury suffered by these kidneys varies widely and does not necessarily correspond to the period of absolute warm ischemia, because inconsistent renal perfusion during cardiopulmonary resuscitation and withdrawal of supportive treatment and the variable efficacy of renal cooling during in situ preservation also contribute to the ischemic injury. Therefore, accurate assessment of the extent of ischemic injury before implantation is needed and may increase the confidence to transplant DCD kidneys (1).

Several studies have focused on the assessment of perfusate biomarker concentrations of machine-perfused kidneys as potential viability markers before transplantation (2-7). Others have focused on machine perfusion characteristics, such as renovascular resistance $(8,9)$. However, these tests are unreliable predictors of transplantation outcome (10). Biomarker viability testing of donor kidneys before procurement is not or only rarely done and may be a valuable tool to estimate the viability of donor kidneys.

The protein neutrophil gelatinase-associated lipocalin (NGAL), also known as lipocalin-2, has recently been discovered as a novel biomarker of acute kidney injury (11). In kidney transplantation, NGAL concentration in recipient urine on the first postoperative day held remarkable diagnostic accuracy for the prediction of delayed graft function (AURC 0.90) (12). Furthermore, the intensity of immunohistochemical staining for NGAL in kidney biopsies taken at reperfusion correlated with graft function (13). The concentration of NGAL increases dramatically in response to tubular injury and precedes the elevation of classical biomarkers for kidney damage, such as serum creatinine (14). This study therefore aims to examine the diagnostic value of plasma NGAL concentration in the organ donor for early postoperative graft function after kidney transplantation.

\section{MATERIALS AND METHODS}

\section{Study design}

All deceased donor kidneys in our procurement area and deceased donor kidneys transplanted at our transplantation center from March 2009 until May 2011 were included in this study. Plasma NGAL concentration was determined in whole EDTA blood, routinely drawn for tissue typing, virological screening and other 
laboratory tests. In uncontrolled DCD donors, blood samples were taken during or after resuscitation, during which ischemia injury already occurred. In controlled DCD and DBD donors, blood samples were taken prior to cardiac arrest and organ preservation, respectively. Plasma NGAL concentration (in $\mathrm{ng} / \mathrm{mL}$ ) was determined by trained personnel. The medical staff involved in the donation and transplantation process was blinded for NGAL measurements. A small sample of left-over EDTA blood stored at room temperature was examined with the Triage MeterPro fluorescenceimmunoassay (Alere, Tilburg, The Netherlands), within 24 hours after sampling. The assay device is a single-use plastic cartridge that contains an NGAL-specific monoclonal antibody conjugated to a fluorescent NGAL antigen immobilized on a solid phase. The test is performed by pipetting a small sample $(250 \mathrm{~mL})$ of EDTA blood onto a port in the cassette where a filter separates cells from plasma. The plasma then reacts with the fluorescent antibody conjugates and flows through the test device by capillary action. NGAL present in the specimen prevents binding of the fluorescent conjugates to the solid phase on the detection zone, such that the NGAL concentration is inversely related to the fluorescence detected. The cassette is then inserted into the Triage MeterPro, a portable fluorescence spectrometer, and quantitative measurements of NGAL concentration in the range from 60 to $1300 \mathrm{ng} /$ $\mathrm{mL}$ are displayed on the meter screen.

The NGAL assay used had a lower limit of detection of $60 \mathrm{ng} / \mathrm{mL}$, and manufacturer quoted 95th percentile of $149 \mathrm{ng} / \mathrm{mL}$. Because of the lower detection limit, groups with different NGAL concentrations were created $(<60,60-149$ and $>149$ $\mathrm{ng} / \mathrm{mL})$.

All kidneys from uncontrolled donors after cardiac death (Maastricht category I and II) and selected kidneys from controlled donors after cardiac death (Maastricht category III) were preserved with machine pulsatile perfusion and perfusion characteristics were recorded. Early postoperative graft function of the kidneys from all deceased donors was categorized as immediate function (IF; no dialysis necessary after transplantation), delayed graft function (DGF; temporary dialysis therapy initiated in the first week after transplantation) or primary non-function (PNF; inadequate renal function, necessitating continuation of dialysis treatment or retransplantation). Glomerular filtration rate at 3 months and 1 year was estimated from serum creatinine using the MDRD formula (15). All clinical data were anonymously extracted from a prospectively kept database intended for internal quality control.

The primary endpoint of this study was the correlation between plasma NGAL concentration in organ donors and early postoperative graft function. Secondary endpoints were the correlation of plasma NGAL concentration with glomerular filtration rate at 3 months and 1 year after transplantation and with perfusion characteristics during organ preservation. 


\section{Ethics}

This study did not need approval from an institutional review board. Collection, storage and use of tissue and patient data are performed in agreement with the codes of conduct 'Use of data in health research' and 'Proper secondary use of human tissue' put forward by The federation of Dutch medical scientific societies (http://www.federa.org/). Furthermore, use of leftover donor samples for transplant research is in line with the Dutch act on organ donation.

\section{Statistical analyses}

Continuous variables are presented as mean \pm standard deviation (SD) if normally distributed, and as median and inter-quartile range (IQR) otherwise. Categorical variables are presented as percentages.

Baseline donor, preservation, and recipient characteristics were compared between donor types ( $D C D$ vs. $D B D$ ) with independent-samples t-tests for approximately normally distributed continuous variables, with Mann-Whitney U-tests if the distribution clearly deviated from normality and with chi-square tests for categorical variables. Donor creatinine and recipient's eGFR were compared between NGAL groups $(<60,60-149$ and $>149 \mathrm{ng} / \mathrm{mL})$ with independent-samples t-tests.

Correlations between NGAL and both donor creatinine and estimated GFR (eGRF), calculated with the abbreviated modification of diet in renal disease equation (MDRD), were evaluated with Spearman's test.

Graft survival censored for recipient death with a functioning graft was calculated with the Kaplan-Meier method; the log-rank test was used to compare the survival curves of the specific biomarker concentration between the different NGAL concentration groups.

All analyses were performed using Statistical Package for the Social Sciences (SPSS) software version 20.0; a p-value $\leq 0.05$ was considered statistically significant.

\section{RESULTS}

\section{Donor kidneys}

Baseline donor, graft, and recipient characteristics are summarized in Table 9.1. Between March 2009 and May 2011, 52 donation procedures from deceased donors were carried out in our region (101 procured kidneys), of which 10 were uncontrolled (Maastricht category I and II) DCD donors (19 kidneys), 15 controlled (category III) DCD donors (30 kidneys) and 27 DBD donors (52 kidneys). 84 kidneys 
from these donors were transplanted in the Eurotransplant region. Two kidneys were transplanted en bloc and were analyzed as 1 . A total of 17 kidneys (13 uncontrolled DCD kidneys, 4 controlled DCD kidneys) were discarded, based on (vascular) anatomy $(\mathrm{N}=3)$, macroscopic appearance $(\mathrm{N}=4)$, a tumor found during organ procurement $(\mathrm{N}$ $=2)$, or if there were no suitable recipients $(\mathrm{N}=8)$. Additionally, 17 kidneys procured elsewhere were transplanted at our center.

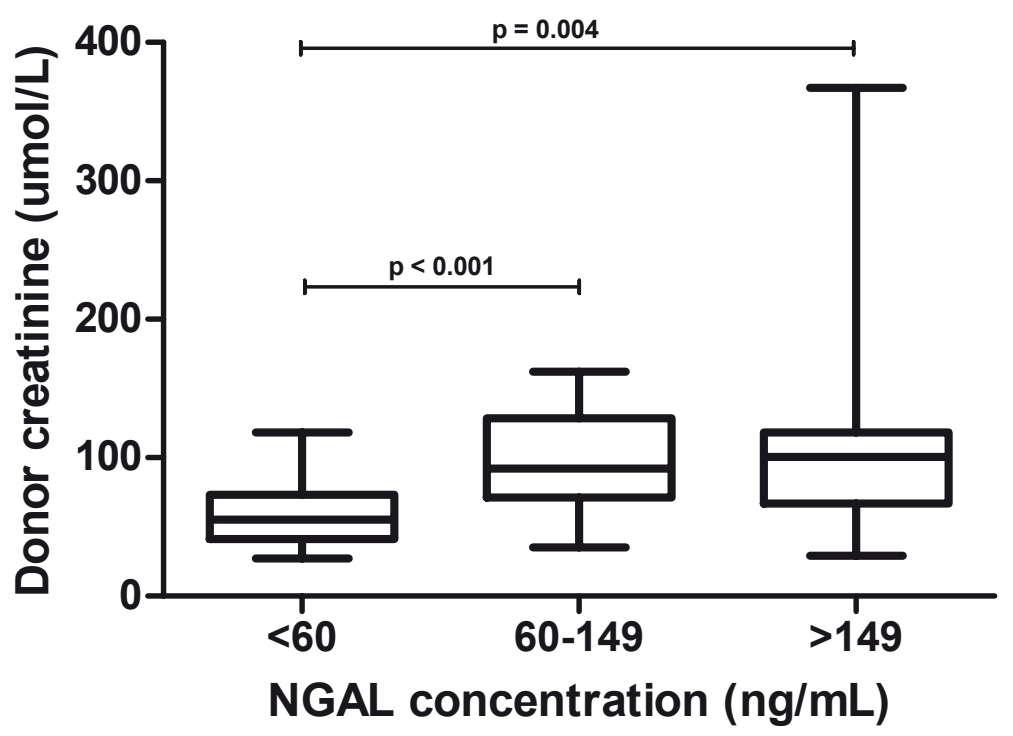

Figure 9.1 NGAL concentration, divided in groups, and the accompanying donor creatinine concentration

Donor creatinine was significantly higher in the '60-149' $\mathrm{ng} / \mathrm{mL}$ (mean $97.5 \pm$ $35.4 \mu \mathrm{mol} / \mathrm{L}, \mathrm{p}<0.001, \mathrm{~N}=21$ ) and '>149' $\mathrm{ng} / \mathrm{mL}$ (mean $105.0 \pm 68.3 \mu \mathrm{mol} / \mathrm{L}, \mathrm{p}=0.004, \mathrm{~N}$ = 20) NGAL groups compared with the ' $<60$ ' ng/mL group (mean $59.5 \pm 24.2 \mu \mathrm{mol} / \mathrm{L}$, $\mathrm{N}=24$ ) (Figure 9.1). Donor NGAL significantly correlated with donor creatinine, $\mathrm{rs}=$ $.451, p<0.001$. Donor creatinine concentration values were missing in 4 cases. 
Baseline donor, graft, and recipient characteristics

\begin{tabular}{|c|c|c|c|}
\hline & DCD & DBD & $\mathrm{p}$ \\
\hline \multicolumn{4}{|l|}{ Donor related } \\
\hline Donor age & $53 \pm 13$ & $52 \pm 15$ & 0.713 \\
\hline Donor sex (male) & $58 \%$ & $65 \%$ & 0.584 \\
\hline Donor Creatinine $(\mu \mathrm{mol} / \mathrm{L})$ & $78 \pm 35$ & $93 \pm 59$ & 0.230 \\
\hline Donor center $\quad$ (MUMC/other) ${ }^{1}$ & $69 / 31 \%$ & $79 / 21 \%$ & 0.340 \\
\hline Uncontrolled / controlled DCD kidneys & $14.3 / 85.7 \%$ & - & - \\
\hline \multicolumn{4}{|l|}{ Graft related } \\
\hline Warm ischemia time $(\mathrm{min})^{2}$ & $19.3 \pm 5.8$ & - & - \\
\hline Cold ischemia time (min) & $19 \pm 4$ & $15 \pm 5$ & 0.006 \\
\hline Anastomosis time (min) & $40 \pm 18$ & $34 \pm 9$ & 0.227 \\
\hline $\operatorname{NGAL}(\%<60 / 60-149 />149 \mathrm{ng} / \mathrm{mL})$ & $28.6 / 42.9 / 28.6 \%$ & $41.2 / 26.5 / 32.4 \%$ & 0.333 \\
\hline Shortterm graft function (\% PNF / DGF / IF) & $5.1 / 74.4 / 20.5$ & $7.5 / 35.8 / 56.6$ & 0.001 \\
\hline \multicolumn{4}{|l|}{ Recipient related } \\
\hline Recipient age & $57 \pm 11$ & $54 \pm 16$ & 0.194 \\
\hline Recipient sex (male) & $67 \%$ & $66 \%$ & 0.953 \\
\hline Transplant center (regional & $52 / 48 \%$ & $17 / 83 \%$ & $<0.001$ \\
\hline
\end{tabular}

${ }^{1}$ MUMC: Maastricht University Medical Center.

${ }^{2}$ Warm ischemia time of DCD kidneys only.

\section{Discarded and non-functioning kidneys}

NGAL concentrations of discarded kidneys were not significantly different from concentrations of transplanted kidneys, however, a trend towards significance was observed (Pearson's chi-square $\mathrm{p}=0.071$ ), with higher NGAL concentrations in the discarded kidneys. NGAL concentrations of kidneys that eventually functioned were not significantly different than of transplanted kidneys with PNF (Pearson's chisquare $p=0.375)$, however, the number of kidneys with PNF was low $(N=6)$.

\section{Short-term graft function}

Short-term graft function was significantly different between DCD and DBD kidneys (PNF: $5.1 \%$ vs. $7.5 \%$, DGF: $74.4 \%$ vs. $35.8 \%$, IF: $20.5 \%$ vs. $56.6 \%$, respectively, $\mathrm{p}=0.001$ ). NGAL concentrations were not associated with short-term graft function overall (Pearson's chi-square $p=0.267$ ). Separated analyses for DCD kidneys only and DBD kidneys only showed no association between NGAL concentrations and shortterm graft function for DCD kidneys (Pearson's chi-square $p=0.109$ ) and DBD kidneys (Pearson's chi-square $\mathrm{p}=0.232$ ). 
For functioning kidneys (PNF kidneys excluded), there was no difference in NGAL concentrations between kidneys with DGF and IF in all kidneys together (Pearson's chi-square $p=0.116$ ). NGAL concentrations did not correlate with eGFR at 3 months after transplantation ( $r=0.080, p=0.481$ ). Separated analyses for $D C D$ kidneys showed a significant difference in NGAL concentrations between DGF and IF (Pearson's chi-square $\mathrm{p}=0.049$ ), with a higher NGAL concentration being more common in the IF kidneys and a NGAL concentration of 60-149 being more common in the DGF kidneys. No correlation was found between NGAL concentrations and eGFR at 3 months after transplantation ( $r s=0.184, p=0.284$ ). The same analyses for DBD kidneys only showed no significant difference between DGF and IF ( $p=0.961)$, and no correlation between NGAL concentrations and eGFR at 3 months after transplantation ( $r s=0.019, p=0.903$ ).

After excluding donor kidneys with a NGAL concentration below the detection limit of $60 \mathrm{ng} / \mathrm{mL}$, statistical analyses were repeated with NGAL concentration as a continuous variable. Also in these analyses, there were no significant differences between NGAL concentrations and short-term graft function and no significant correlation between NGAL and eGFR at 3 months (data not shown).

\section{Long-term graft function and survival}

eGFR was not significantly different between NGAL groups at one year after transplantation (Figure 9.2), and NGAL concentration did not correlate with eGFR at 1 and 2 years after transplantation $(r s=.150, p=0.216, N=70$, and $r s=.016, p=0.941$, $\mathrm{N}=25$ ).

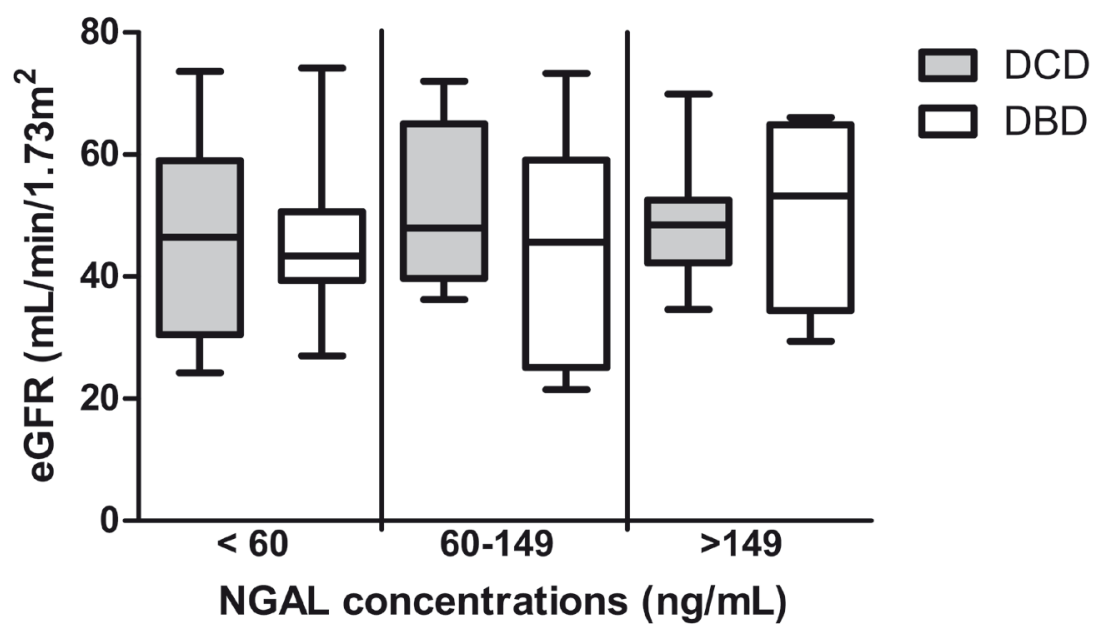

Figure 9.2 NGAL concentration, divided in groups, and renal function denoted in eGFR at one year after transplantation. 
Figure 9.3 shows graft survival of all transplanted kidneys, censored for recipient death with a functioning graft. Graft survival at 1 and 2 years after transplantation was not significantly different for the different NGAL groups, kidneys with PNF included.

Again, after excluding donor kidneys with a NGAL concentration below the detection limit of $60 \mathrm{ng} / \mathrm{mL}$, statistical analyses were repeated with NGAL concentration as a continuous variable. No correlations were found between NGAL concentrations and eGFR at 1 and 2 years after transplantation $(r=0.194, p=0.206, N$ $=44$, and $\mathrm{r}=-.272, \mathrm{p}=0.308, \mathrm{~N}=16$, respectively).

\section{Machine perfused kidneys}

A total of 22 kidneys were machine perfused. GST and LDH concentrations at 4 hours after start of machine perfusion were available from 18 kidneys. Donor NGAL did not correlate with GST and LDH levels at 4 hours after the start of machine perfusion ( $r s=.433, p=0.073$ and $r s=.107, p=0.672$ ) and with renovascular resistance at the start of machine perfusion ( $r s=.132, p=0.626, \mathrm{~N}=16$ ).

\section{DISCUSSION}

Donation after cardiac death has the potential to greatly expand the number of organ donors and thereby the kidneys available for transplantation. However, the use of these donors is limited due to the reluctance of many transplantation centers to use kidneys with acute ischemic injury that are at increased risk of early graft dysfunction.

Expanding the donor pool safely requires the selection and discard of donor kidneys with an unacceptable high risk of early graft dysfunction and the development of tools to assess kidney graft quality prior to transplantation. Graft quality can be assessed at two distinct stages during the donation process: prior to procurement and during preservation (16). For the first stage, different risk scores for donors have been developed (17-19). However, all existing donor risk scores have a low predictive accuracy and therefore, it is not appropriate to discard kidneys based on risk scores (16). 


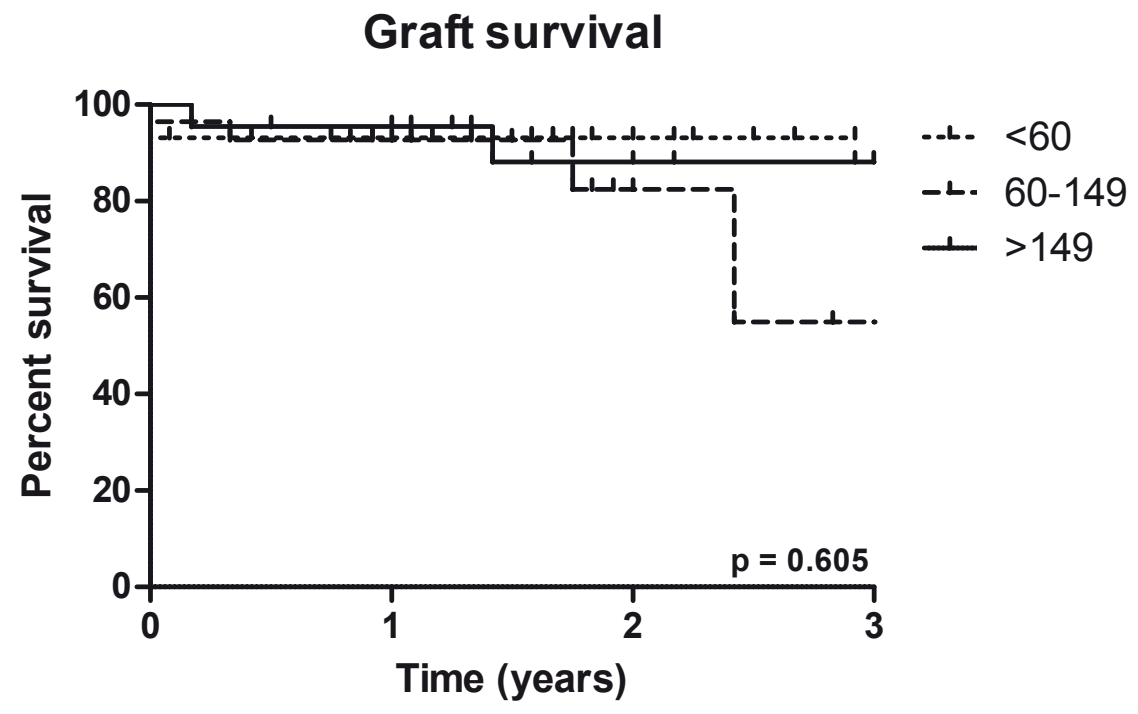

Figure 9.3 Kaplan-Meier graft survival curves for NGAL concentrations divided in groups.

Quality assessment during preservation can be performed by means of pretransplantation kidney biopsies $(16,20)$. Pre-transplantation kidney biopsies are mostly evaluated in older donors (21). In these donors, glomerular sclerosis is, among others, an important predictor for graft survival (22).

Viability testing of machine-perfused kidneys includes perfusion dynamics and perfusate biomarker concentration. Many studies have tried to identify potential viability markers, of which glutathione S-transferase (GST) and lactate dehydrogenase (LDH) are best known $(6,23,24)$. However, the predictive value of perfusate biomarkers to assess PNF remains unknown or poor (16). Machine perfusion dynamics (e.g. renovascular resistance) are associated with kidney function, but the predictive value is too low to be useful to discard kidneys for transplantation on its value alone $(8,16)$.

NGAL, also known as lipocalin-2, has recently been discovered as a biomarker of acute kidney injury (11). Moreover, NGAL released during hypothermic machine perfusion of porcine kidneys that were exposed to different warm ischemia times, seemed to be proportionate to the degree of injury due to warm ischemia, suggesting that NGAL is released from ischemically damaged kidneys, independent of neutrophil activation (25). These findings were not confirmed in machine-perfused human kidneys, showing a poor predictive value of NGAL for transplantation outcome (24). 
The predictive value of donor NGAL prior to organ donation has never been assessed in DCD donors, and it is unknown whether or not donor plasma NGAL concentration is associated with transplantation outcome in these donor kidneys. Therefore, we measured NGAL concentrations in both DCD (uncontrolled Maastricht category I and II donors and controlled Maastricht category III donors) and DBD donors and examined the value of donor plasma NGAL levels to predict post-transplant graft function. In this study, we showed that donor plasma NGAL concentration significantly correlated with donor creatinine, meaning we can detect (acute) kidney injury in the donor. However, this has no direct consequences for the recipients, because kidneys from donors with relatively high serum creatinine levels show comparable results compared with kidneys from donors with lower serum creatinine levels (26-28). This is in line with a study on DBD kidneys only (29). Only for functioning DCD kidneys, a significant difference was observed for NGAL concentrations between kidneys with DGF and IF.

A limitation of this study is the detection limit of the NGAL assay, with NGAL concentrations below the detection limit in 43 kidneys. NGAL concentrations were categorized in groups, which limited statistical power. However, the kidneys with highest NGAL concentration theoretically have the worst outcome after transplantation, and this is the group we are interested in for potential discard. Therefore, the assay sufficed to detect the relevant differences in NGAL concentration.

We have shown that donor NGAL concentrations prior to organ recovery are not associated with graft function after transplantation of both DCD and DBD kidneys, however, for functioning DCD kidneys only, a significant difference was found for NGAL concentrations between kidneys with DGF and IF. Although it is a valuable biomarker for kidney injury in intensive care patients, its value as a predictor in kidney transplantation outcome is limited. 


\section{REFERENCES}

1. Snoeijs MGJ, Pulinx B, Van Dieijen-Visser MP, Buurman WA, Van Heurn LWE, Wodzig WKWH. Characterization of the perfusate proteome of human donor kidneys. Annals of clinical biochemistry. 2013;50(2):140-6.

2. Daemen JW, Oomen AP, Janssen MA, van de Schoot $L$, van Kreel BK, Heineman $E$, et al. Glutathione $S$-transferase as predictor of functional outcome in transplantation of machine-preserved non-heartbeating donor kidneys. Transplantation. 1997 Jan 15;63(1):89-93.

3. Balupuri S, Talbot D, El-Sheikh M, Snowden C, Manas DM, Kirby J, et al. Comparison of proteolytic enzymes and glutathione S-transferase levels in non-heart-beating donors' (NHBD) kidney perfusates. Clin Chem Lab Med. 2000 Nov;38(11):1099-102.

4. Gok MA, Pelsers M, Glatz JF, Bhatti AA, Shenton BK, Peaston R, et al. Comparison of perfusate activities of glutathione S-transferase, alanine aminopeptidase and fatty acid binding protein in the assessment of non-heart-beating donor kidneys. Annals of clinical biochemistry. 2003 May;40(Pt 3):252-8.

5. Gok MA, Pelsers M, Glatz JF, Shenton BK, Peaston R, Cornell C, et al. Use of two biomarkers of renal ischemia to assess machine-perfused non-heart-beating donor kidneys. Clinical chemistry. 2003 Jan;49(1):172-5.

6. Jochmans I, Lerut E, van Pelt J, Monbaliu D, Pirenne J. Circulating AST, H-FABP, and NGAL are early and accurate biomarkers of graft injury and dysfunction in a preclinical model of kidney transplantation. Annals of surgery. 2011 Nov;254(5):784-91; discussion 91-2.

7. Moers C, Varnav OC, van Heurn E, Jochmans I, Kirste GR, Rahmel A, et al. The value of machine perfusion perfusate biomarkers for predicting kidney transplant outcome. Transplantation. 2010 Nov 15;90(9):96673.

8. de Vries EE, Hoogland ER, Winkens B, Snoeijs MG, van Heurn LW. Renovascular resistance of machineperfused DCD kidneys is associated with primary nonfunction. Am J Transplant. 2011 Dec;11(12):2685-91.

9. Mozes MF, Skolek RB, Korf BC. Use of perfusion parameters in predicting outcomes of machine-preserved kidneys. Transplantation proceedings. 2005 Jan-Feb;37(1):350-1.

10. van Smaalen TC, Hoogland ER, van Heurn LW. Machine perfusion viability testing. Current opinion in organ transplantation. $2013 \mathrm{Apr} ; 18(2): 168-73$.

11. Mishra J, Dent C, Tarabishi R, Mitsnefes MM, Ma Q, Kelly C, et al. Neutrophil gelatinase-associated lipocalin (NGAL) as a biomarker for acute renal injury after cardiac surgery. Lancet. 2005 Apr 2-8;365(9466):1231-8.

12. Parikh CR, Jani A, Mishra J, Ma Q, Kelly C, Barasch J, et al. Urine NGAL and IL-18 are predictive biomarkers for delayed graft function following kidney transplantation. Am J Transplant. 2006 Jul;6(7):1639-45.

13. Mishra J, Ma Q, Kelly C, Mitsnefes M, Mori K, Barasch J, et al. Kidney NGAL is a novel early marker of acute injury following transplantation. Pediatric nephrology (Berlin, Germany). 2006 Jun;21(6):856-63.

14. Magnusson NE, Hornum $M$, Jorgensen KA, Hansen JM, Bistrup C, Feldt-Rasmussen $B$, et al. Plasma neutrophil gelatinase associated lipocalin (NGAL) is associated with kidney function in uraemic patients before and after kidney transplantation. BMC nephrology. 2012;13:8.

15. Poge U, Gerhardt T, Palmedo H, Klehr HU, Sauerbruch T, Woitas RP. MDRD equations for estimation of GFR in renal transplant recipients. Am J Transplant. 2005 Jun;5(6):1306-11.

16. Jochmans I, Pirenne J. Graft quality assessment in kidney transplantation: not an exact science yet! Current opinion in organ transplantation. 2011 Apr;16(2):174-9.

17. Nyberg SL, Baskin-Bey ES, Kremers W, Prieto M, Henry ML, Stegall MD. Improving the prediction of donor kidney quality: deceased donor score and resistive indices. Transplantation. 2005 Oct 15;80(7):925-9.

18. Schold JD, Kaplan B, Baliga RS, Meier-Kriesche HU. The broad spectrum of quality in deceased donor kidneys. Am J Transplant. 2005 Apr;5(4 Pt 1):757-65.

19. Rao PS, Schaubel DE, Guidinger MK, Andreoni KA, Wolfe RA, Merion RM, et al. A comprehensive risk quantification score for deceased donor kidneys: the kidney donor risk index. Transplantation. $2009 \mathrm{Jul}$ 27;88(2):231-6.

20. Metzger RA, Delmonico FL, Feng S, Port FK, Wynn JJ, Merion RM. Expanded criteria donors for kidney transplantation. Am J Transplant. 2003;3 Suppl 4:114-25. 
21. Snoeijs MG, Buurman WA, Christiaans MH, van Hooff JP, Goldschmeding R, van Suylen RJ, et al. Histological assessment of preimplantation biopsies may improve selection of kidneys from old donors after cardiac death. Am J Transplant. 2008 Sep;8(9):1844-51.

22. Remuzzi G, Cravedi P, Perna A, Dimitrov BD, Turturro M, Locatelli G, et al. Long-term outcome of renal transplantation from older donors. N Engl J Med. 2006 Jan 26;354(4):343-52.

23. Bhangoo RS, Hall IE, Reese PP, Parikh CR. Deceased-donor kidney perfusate and urine biomarkers for kidney allograft outcomes: a systematic review. Nephrol Dial Transplant. 2012 Aug;27(8):3305-14.

24. Hoogland ER, de Vries EE, Christiaans MH, Winkens B, Snoeijs MG, van Heurn LW. The Value of Machine Perfusion Biomarker Concentration in DCD Kidney Transplantations. Transplantation. 2013 Jan 4.

25. Jochmans I, Monbaliu D, Pirenne J. Neutrophil gelatinase-associated lipocalin, a new biomarker candidate in perfusate of machine-perfused kidneys: a porcine pilot experiment. Transplantation proceedings. Nov;43(9):3486-9.

26. Barlow AD, Metcalfe MS, Johari Y, Elwell R, Veitch PS, Nicholson ML. Case-matched comparison of longterm results of non-heart beating and heart-beating donor renal transplants. The British journal of surgery. 2009 Jun;96(6):685-91.

27. Matsuno N, Konno YN, Jyojima Y, Akashi I, Iwamoto H, Hama K, et al. Machine perfusion preservation for kidney grafts with a high creatinine from uncontrolled donation after cardiac death. Transplantation proceedings. 2010 Jan-Feb;42(1):155-8.

28. Navarro AP, Sohrabi S, Wilson C, Sanni A, Wyrley-Birch H, Vijayanand D, et al. Renal transplants from category III non-heart-beating donors with evidence of pre-arrest acute renal failure. Transplantation proceedings. 2006 Oct;38(8):2635-6.

29. Hollmen ME, Kyllonen LE, Inkinen KA, Lalla ML, Merenmies J, Salmela KT. Deceased donor neutrophil gelatinase-associated lipocalin and delayed graft function after kidney transplantation: a prospective study. Critical care (London, England). 2011;15(3):R121. 


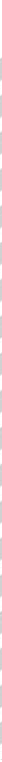
144 
CHAPTER 10

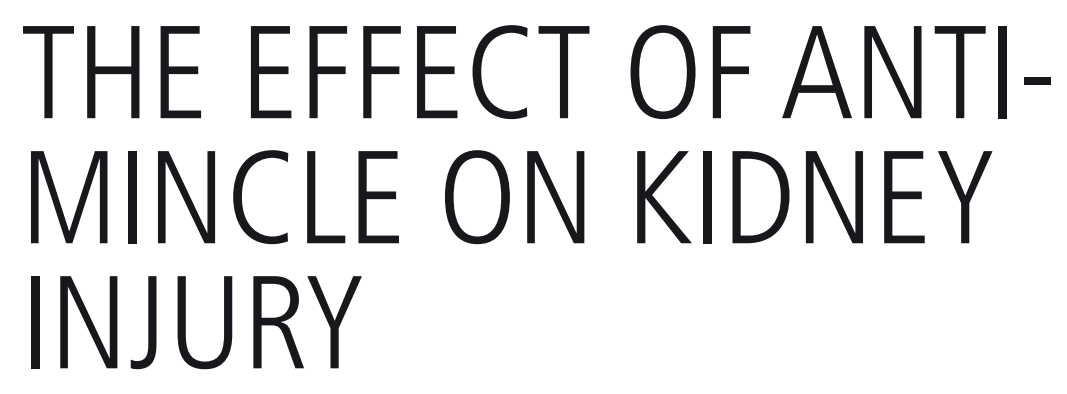




\section{ABSTRACT}

Background: Ischemia-reperfusion injury is one of the problems in kidney transplantation with kidneys from donors after cardiac death. The macrophageinducible C-type Lectin (Mincle) receptor is an important target to reduce inflammatory response after cell death. It is involved in the mediation of the inflammatory response to ischemia-reperfusion injury, and Mincle-specific antibody was associated with less infiltration of neutrophils after massive thymocyte death.

Methods: The effects of Mincle on renal ischemia-reperfusion injury and inflammatory response were studied in an ischemia-reperfusion model in mice, using 25 minutes of ischemia and 24 hours of reperfusion. The Mincle-receptor was blocked with a Mincle-specific antibody (anti-Mincle) and compared with animals, which received rat IgG as control group.

Results: Kidney function (creatinine $232 \pm 34$ vs. $211 \pm 22 \mu \mathrm{mol} / \mathrm{L}, \mathrm{p}=0.200$ and BUN $61.2 \pm 5.6$ vs. $58.2 \pm 5.9, p=0.355$, respectively), histological injury and the number of infiltrated neutrophils were similar between both groups.

Conclusion: Blocking the Mincle-receptor with specific anti-Mincle antibodies does not inhibit the inflammatory response in mice kidneys after ischemia and reperfusion and does not contribute to lesser renal injury and better renal function.

\section{Published as}

E.R.P. Hoogland, M.G.J. Snoeijs, B. de Vries, C.J. Peutz- Kootstra, W.A. Buurman, T. Saito, L.W.E. van Heurn. The effect of anti-Mincle on kidney injury. Manuscript submitted. 


\section{INTRODUCTION}

Organ donation from donation after cardiac death (DCD) donors inevitably leads to ischemia and reperfusion from cardiac arrest until reperfusion after transplantation. Ischemia-reperfusion (I/R) leads to a complex series of events, including generation of inflammatory mediators, leukocyte infiltration and, depending on the severity of the injury, ultimately to cell death by either necrosis or apoptosis $(1,2)$. Studies using animal models have demonstrated that the inflammatory responses to I/R exacerbates organ injury after transplantation (2).

Acute kidney injury $(\mathrm{AKI})$ is a frequent complication in patients on the intensive care unit (ICU), after cardiac surgery, and after ischemia and reperfusion (I/R) in renal transplantation with kidneys obtained from donors after cardiac death. AKI is a syndrome of abrupt loss of kidney function, often with oliguria, which is strongly associated with increased early and long-term patient morbidity and mortality (3). AKI occurs in up to $40 \%$ of adults after cardiac surgery, with $1-5 \%$ needing dialysis in whom the mortality rate approaches $80 \%$ (4). Pathophysiological mechanisms include diminished renal blood flow, loss of pulsatile flow, hypothermia, atheroembolism, and a generalised inflammatory response (4). In renal transplantation, AKI may result in primary non-function (PNF) and in delayed graft function (DGF), which may be associated with an increased risk of acute rejection and graft loss $(5,6)$.

Therapies that target specific inflammatory responses to $\mathrm{I} / \mathrm{R}$ are of major importance to minimize the incidence of PNF and DGF and to maximize the use of available DCD kidneys from the donor pool. Recently, it has been shown that the C-type lectin Mincle (macrophage-inducible C-type lectin) receptor recognizes a nuclear protein released by dead or dying cells and is involved in mediating inflammatory responses by the recruitment of neutrophils $(7,8)$. Yamasaki et al. developed a Mincle-specific monoclonal antibody (anti-Mincle) and showed that administering anti-Mincle results in less recruitment of neutrophils into the thymus after massive thymocyte necrosis induced by whole-body irradiation or dexamethasone treatment in mice. Given its great potential to reduce the inflammatory response after ischemia and reperfusion, we studied the effect of anti-Mincle on renal ischemia-reperfusion injury in mice.

\section{MATERIALS AND METHODS}

\section{Animals}

Wild-type male C57BL/6J mice (8-10 weeks old, 20-25 g) were obtained from Charles River (L'arbresle Cedex, France). Animals were housed in standard laboratory cages with free access to food and water throughout the experiments. 


\section{Renal ischemia and reperfusion in mice}

Mice were anesthetized with ketamine and xylazine (100 and $10 \mathrm{mg} / \mathrm{kg}$ subcutaneous, respectively). Body temperature was maintained at $37^{\circ} \mathrm{C}$ by a heating lamp and heating pad until the animals had recovered from anaesthesia. Under aseptic conditions, the animals underwent a laparotomy and 25 minutes of ischemia was induced by clamping the left renal pedicle using a non-traumatic vascular clamp (Fine Science Tools, cat. number 18055-05 curved clips), applied with a special clip applicator (Fine Science Tools, cat. number 18056-14). Upon clamp removal, the kidney was inspected for restoration of blood flow and the contralateral kidney was removed and stored for analysis. The abdomen was closed in two layers, $0.25 \%$ bupivacaine was applied topically for post-operative pain management and $1 \mathrm{~mL}$ pre-warmed PBS was given subcutaneously to prevent dehydration. Animals were euthanized $24 \mathrm{~h}$ after reperfusion, when blood was collected by puncture of the caval vein. The left kidney was recovered for further analysis. Blood was stored on ice in heparinised tubes until centrifugation at $900 \mathrm{~g}$ at $4^{\circ} \mathrm{C}$ for $10 \mathrm{~min}$.

\section{Administration of anti-Mincle and control antigens}

The monoclonal antibodies to Mincle were created by and obtained from Yamasaki et al (7). Mice were randomly assigned to receive $0.5 \mathrm{mg}$ anti-Mincle ( $\mathrm{N}=$ 8) intravenously one hour before start of ischemia, $0.5 \mathrm{mg}$ rat $\lg$ (BD Biosciences, Franklin Lakes, USA) isotype control $(\mathrm{N}=8)$ or were sham-operated $(\mathrm{N}=5)$.

\section{Histological assessment of renal tissue}

Renal tissue was formalin-fixed and embedded in paraffin. Tissue sections were stained with periodic acid-Schiff for blinded assessment of renal injury by two experienced nephropathologists. Tubular dilatation, casts and debris, brush border loss and necrosis at the corticomedullary junction were scored in $8-10$ fields at 400x magnification on a scale of 0 to 5 ( 0 is normal; 1 involves $<10 \%$ of cortex; 2 involves $10-25 \%$ of cortex; 3 involves $25-50 \%$ of cortex; 4 involves $50-75 \%$ of cortex; and 5 involves $>75 \%$ of cortex) (9).

To quantify renal neutrophil infiltration, tissue sections were incubated with polyclonal rabbit anti-human myeloperoxidase (MPO) antibodies as described previously (5). Neutrophil infiltration was assessed quantitatively by counting the number of positive cells at the corticomedullary junction at 200x magnification over 5 - 10 fields by two blinded investigators. 


\section{Renal function}

Serum creatinine and blood urea nitrogen (BUN) concentrations were measured in the clinical chemistry laboratory.

\section{Statistical analysis}

Continuous variables are presented as mean and standard deviation if normally distributed, and as median and inter-quartile range (IQR) otherwise. Independent samples t-tests were used to compare continuous variables between experimental groups and Mann-Whitney $U$ test was used for nonparametric values. All analyses were performed using Statistical Package for the Social Sciences (SPSS) software version 20.0 for Windows, and a $p$-value $<0.05$ was considered statistically significant.

A

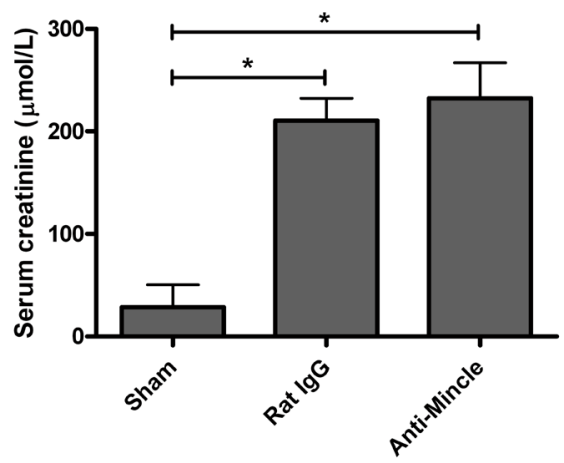

B

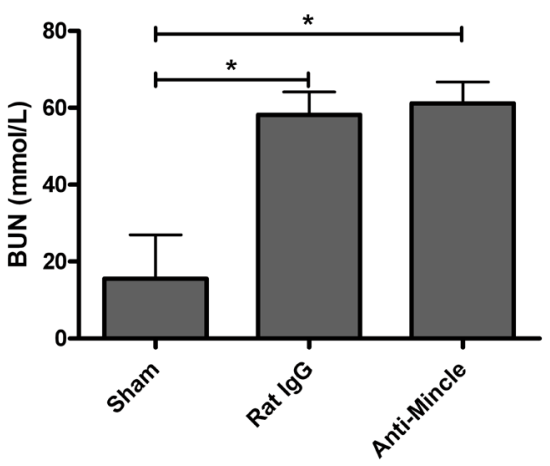

Figure 10.1 Kidney function of kidneys subjected to 25 minutes of ischemia and 24 hours of reperfusion in sham-operated mice $(N=5)$, mice subjected to rat $\lg G(N=6)$ and anti-Mincle ( $N$ = 8). (A) Serum creatinine concentration is equal to the isotype control group (rat lgG). (B) Blood urea nitrogen concentration is equal to the isotype control group. ${ }^{*} p<0.001$ compared to shamoperated mice.

\section{Ethics}

In vivo experiments were approved by the local laboratory animal review boards (DEC 2011-012) and were conducted in accordance with the NIH principles of laboratory animal care. 


\section{RESULTS}

Effect of anti-Mincle on renal function and ischemia and reperfusion injury

Two mice in the rat IgG control group died at the end of the ischemic period. Temporary renal ischemia induced severe kidney dysfunction as indicated by increased plasma concentrations of creatinine and BUN at 24 hours after reperfusion in both the anti-Mincle as the rat IgG control group (creatinine $232 \pm 34$ vs. $211 \pm 22 \mu \mathrm{mol} / \mathrm{L}$ and BUN $61.2 \pm 5.6$ vs. $58.2 \pm 5.9$, respectively) (Figure 10.1). Mice treated with antiMincle experienced a similar extent of renal dysfunction after I/R compared with the rat lgG control group ( $p=0.200$ for creatinine and $p=0.355$ for $B U N$ ).

\section{Histological assessment}

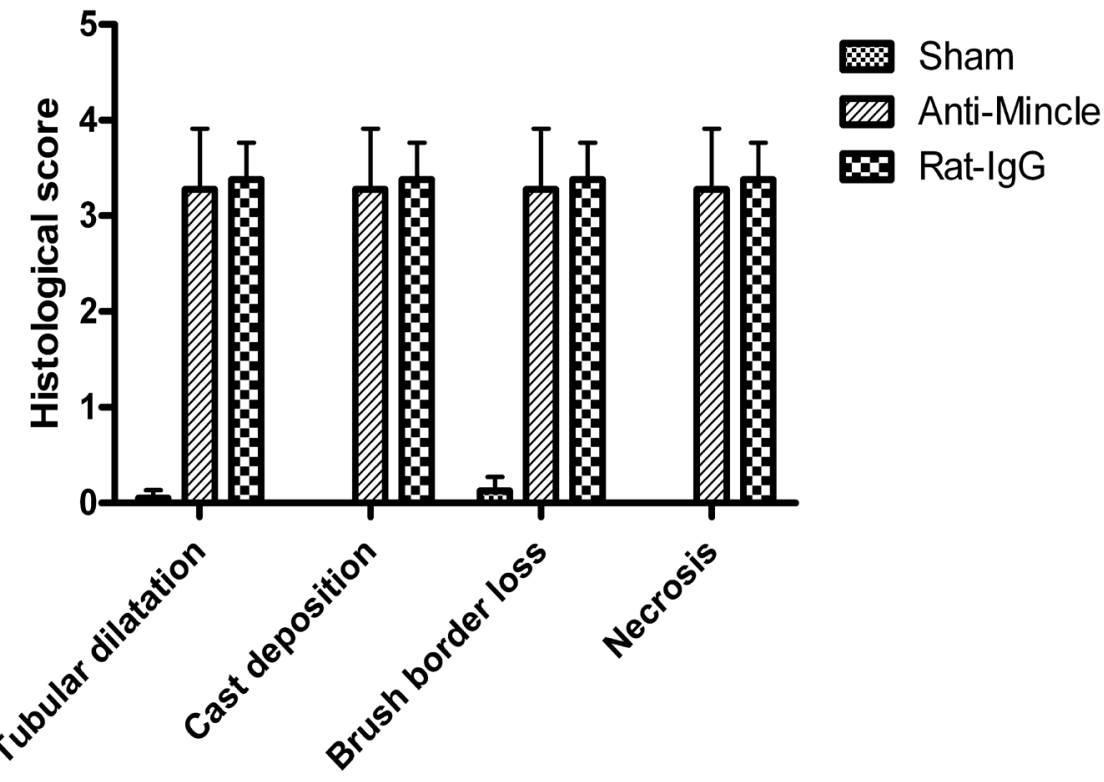

Figure 10.2 Histological assessment of renal injury of sham-operated mice $(\mathrm{N}=5)$ and mice treated with rat $\lg G(\mathrm{~N}=6)$ and anti-Mincle $(\mathrm{N}=8)$. Tubular dilatation, casts deposition, brush border loss and necrosis were blindly scored by an experienced nephropathologist on a scale of 0 to 5 (9). P< 0.001 for the anti-Mincle and rat IgG group compared to the sham-operated group.

Furthermore, substantial renal injury was observed on histological assessment of tissue sections after $\mathrm{I} / \mathrm{R}$, indicated by tubular dilatation, cast deposition, brush border loss and necrosis at the corticomedullary junction (Figure 10.2). Renal injury after I/R was equivalent in mice treated with anti-Mincle compared with the control 
group ( $p=0.721$ for tubular dilatation, cast deposition, brush border loss and necrosis).

\section{Effect of anti-Mincle on neutrophil infiltration}

Influx of neutrophils into the kidney occurs relatively early after reperfusion and exacerbates ischemic acute renal injury (5). In this study, renal ischemia and reperfusion resulted in accumulation of neutrophils around the injured tubules at the corticomedullary junction (Figure 10.3A). The extent of neutrophil infiltration was similar for the anti-Mincle and the rat IgG control group (Figure 10.3B and 10.3C) (Mann-Whitney $U \mathrm{p}=0.770$ ).
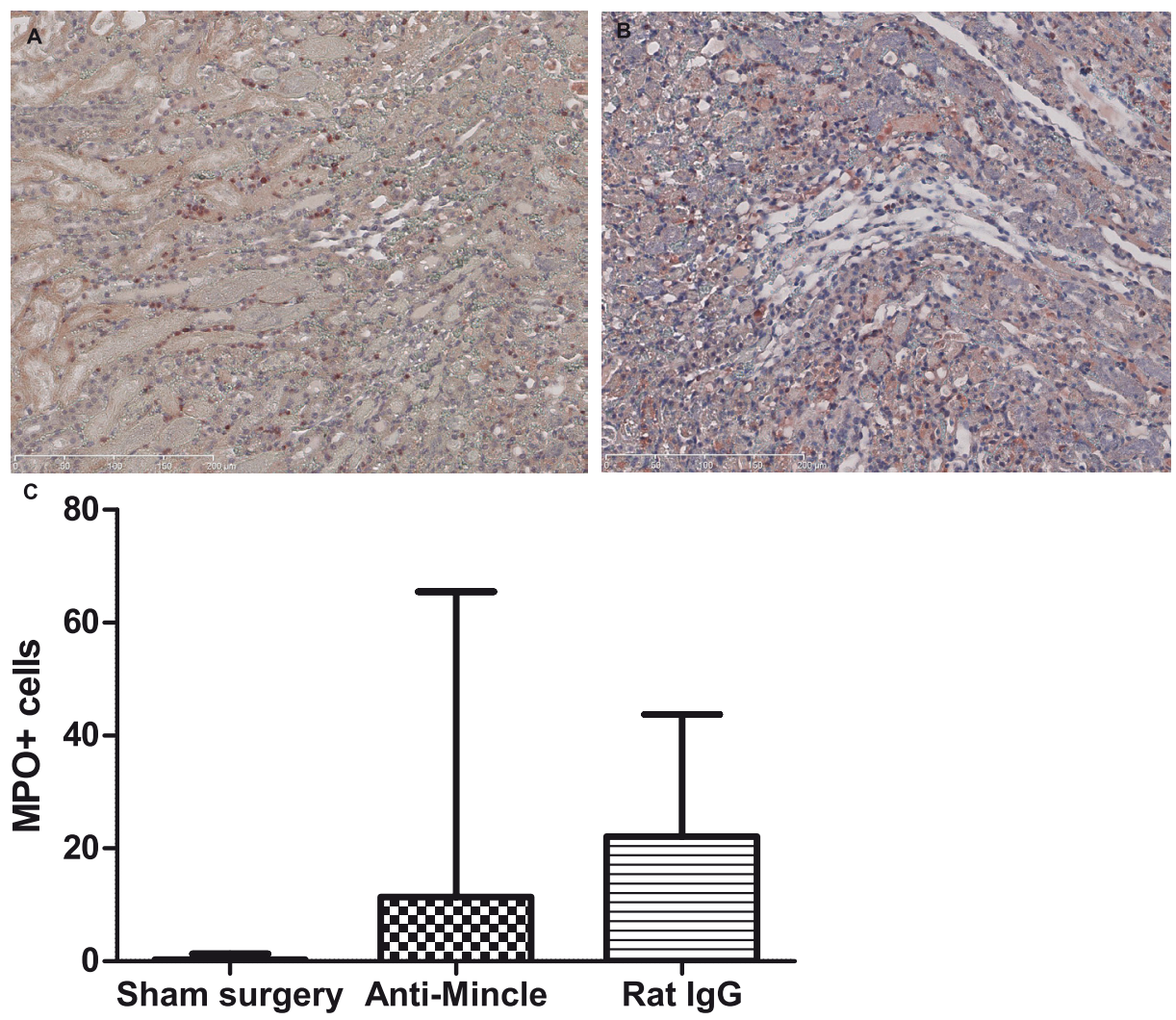

Figure 10.3 Neutrophil infiltration into the kidney. Mice treated with anti-Mincle $(A)$ have a similar extent of neutrophil infiltration into the kidney compared with the $\lg G$ control group (B). Data are presented as median and inter-quartile range (C). 


\section{DISCUSSION}

Ischemia and reperfusion of deceased donor kidneys is an inevitable consequence of renal transplantation, which frequently leads to acute kidney injury (AKI). AKI is a serious clinical complication with high mortality, morbidity and costs $(10,11)$. Interventions that protect kidneys from ischemia-reperfusion injury may improve early graft function in particularly kidneys from donors after cardiac death, which suffer prolonged ischemia before transplantation.

Ischemia-reperfusion leads to a complex series of events, including generation of inflammatory mediators, leukocyte infiltration and, depending on the severity of the injury, ultimately in cell death by either necrosis or apoptosis $(12,13)$. Inefficient clearance of apoptotic cells leads to necrosis, which is characterized by the disruption of cellular membranes and the release of cytoplasmic and nuclear components (8). The receptors and mechanisms that lead to inflammation after necrotic cell death are poorly understood. In instances of sterile inflammation, neutrophil recruitment is mediated by the release of 'danger signals' or damage-associated molecular pattern molecules (DAMPs) from disrupted cells and tissues (14). Understanding the role of candidate DAMPs released from damaged cells could reveal novel drug targets for inhibiting the inflammatory response or promoting repair processes in (renal) I/R injury (15). As the knowledge and understanding of these molecules and pathways evolves, information on precise therapeutic targets will likely lead to improved outcomes after transplantation (15).

The Toll-like receptor (TLR) family has been reported to recognize self-ligands released from necrotic cells. Some of the TLR-self ligand interactions have been shown to contribute to inflammatory disease (7). Another family of receptors that may be involved in sensing dead cells is the C-type lectins. Recent data show that the C-type lectin Mincle-receptor is involved in this process. Mincle recognizes the soluble factor spliceosome-associated protein 130 (SAP130), a nuclear protein released by necrotic cells, triggering inflammatory cytokine responses, which leads to the recruitment of neutrophils $(7,8)$. Although incompletely understood, renal tubular necrosis, apoptosis and inflammation during and after renal ischemia-reperfusion contribute significantly to the pathogenesis of ischemic acute kidney injury (11). Therefore, we studied whether blocking the Mincle-receptor with a Mincle-specific antibody would result in improved renal function and a less severe inflammatory response after ischemia-reperfusion compared with a control group.

Tissue injury activates the innate immune system and leads to infiltration of inflammatory cells into the damaged tissue (2). Influx of neutrophils into the kidney occurs relatively early after reperfusion and has been shown to exacerbate ischemic acute renal injury (16).

Mice models of warm renal ischemia and reperfusion share important similarities with human ischemia-reperfusion injury (12) and have been used before by our research group $(5,17,18)$. 
We studied the most optimal ischemia time in a pilot study. An ischemia time of 25 minutes provides the best association with AKI according to serum levels of creatinine and BUN in combination with histological assessment. Serum creatinine and BUN did not increase further with longer ischemia times. Therefore, a warm ischemia time of 25 minutes was used in the present study.

Male mice were used in this study, because female mice are more resistant to I/R induced kidney injury. This protection is believed to be caused by testosterone, which could be responsible for enhanced renal inflammation and endothelial and tubular cell injury (19).

The current study is the first to investigate the involvement of the Minclereceptor in the inflammatory response after renal ischemia-reperfusion injury in mice. We show that renal function did not improve after ischemia-reperfusion and blocking the Mincle receptor. Additionally, no differences were seen in cellular damage and inflammation.

Our findings seem to contradict previously reported data on inflammatory responses after blocking of the Mincle-receptor (7). These conflicting findings may be caused by differences in the applied experimental models, in the difference of the studied organ, by unknown pathways by which post I/R inflammation is initiated, or the number of dead or dying cells triggering the Mincle-pathway.

We conclude that blocking the Mincle-receptor with specific anti-Mincle antibodies does not inhibit the inflammatory response in the kidney after ischemia and reperfusion and consequently does not contribute to minimize renal injury and better renal function. 


\section{REFERENCES}

1. Bonventre JV, Zuk A. Ischemic acute renal failure: an inflammatory disease? Kidney international. 2004 Aug;66(2):480-5.

2. Thurman JM. Triggers of inflammation after renal ischemia/reperfusion. Clinical immunology (Orlando, Fla. 2007 Apr;123(1):7-13.

3. Li PK, Burdmann EA, Mehta RL. Acute kidney injury: global health alert. Kidney international. 2013 Jan 9.

4. Mishra J, Dent C, Tarabishi R, Mitsnefes MM, Ma Q, Kelly C, et al. Neutrophil gelatinase-associated lipocalin (NGAL) as a biomarker for acute renal injury after cardiac surgery. Lancet. 2005 Apr 2-8;365(9466):1231-8.

5. Snoeijs MG, Hoogland PR, Boonen B, Coffman TM, Peutz-Kootstra CJ, Buurman WA, et al. Thromboxane receptor signalling in renal ischemia reperfusion injury. Free Radic Res. 2011 Jun;45(6):699-706.

6. Yarlagadda SG, Coca SG, Formica RN, Jr., Poggio ED, Parikh CR. Association between delayed graft function and allograft and patient survival: a systematic review and meta-analysis. Nephrol Dial Transplant. 2009 Mar;24(3):1039-47.

7. Yamasaki S, Ishikawa E, Sakuma M, Hara H, Ogata K, Saito T. Mincle is an ITAM-coupled activating receptor that senses damaged cells. Nature immunology. 2008 Oct;9(10):1179-88.

8. Brown GD. Sensing necrosis with Mincle. Nature immunology. 2008 Oct;9(10):1099-100.

9. Leemans JC, Stokman G, Claessen N, Rouschop KM, Teske GJ, Kirschning CJ, et al. Renal-associated TLR2 mediates ischemia/reperfusion injury in the kidney. The Journal of clinical investigation. 2005 Oct;115(10):2894-903.

10. Faubel S. Acute kidney injury and multiple organ dysfunction syndrome. Minerva urologica e nefrologica $=$ The Italian journal of urology and nephrology. 2009 Sep;61(3):171-88.

11. Lee HT, Park SW, Kim M, Ham A, Anderson LJ, Brown KM, et al. Interleukin-11 protects against renal ischemia and reperfusion injury. American journal of physiology Renal physiology. 2012;303(8):1216-24

12. Kennedy SE, Erlich JH. Murine renal ischaemia-reperfusion injury. Nephrology (Carlton, Vic. 2008 Oct;13(5):390-6.

13. Bonventre JV, Weinberg JM. Recent advances in the pathophysiology of ischemic acute renal failure. J Am Soc Nephrol. 2003 Aug;14(8):2199-210.

14. Pittman K, Kubes P. Damage-associated molecular patterns control neutrophil recruitment. Journal of innate immunity. 2013;5(4):315-23.

15. Rosin DL, Okusa MD. Dangers within: DAMP responses to damage and cell death in kidney disease. J Am Soc Nephrol. 2011 Mar;22(3):416-25.

16. Kelly KJ, Williams WW, Jr., Colvin RB, Meehan SM, Springer TA, Gutierrez-Ramos JC, et al. Intercellular adhesion molecule-1-deficient mice are protected against ischemic renal injury. The Journal of clinical investigation. 1996 Feb 15;97(4):1056-63.

17. de Vries B, Walter SJ, Wolfs TG, Hochepied T, Rabina J, Heeringa P, et al. Exogenous alpha-1-acid glycoprotein protects against renal ischemia-reperfusion injury by inhibition of inflammation and apoptosis. Transplantation. 2004 Oct 27;78(8):1116-24.

18. De Vries B, Matthijsen RA, Wolfs TG, Van Bijnen AA, Heeringa P, Buurman WA. Inhibition of complement factor C5 protects against renal ischemia-reperfusion injury: inhibition of late apoptosis and inflammation. Transplantation. 2003 Feb 15;75(3):375-82.

19. Park KM, Kim Jl, Ahn Y, Bonventre AJ, Bonventre JV. Testosterone is responsible for enhanced susceptibility of males to ischemic renal injury. The Journal of biological chemistry. 2004 Dec 10;279(50):52282-92. 
THE EFFECT OF ANTI-MINCLE ON KIDNEY INJURY 


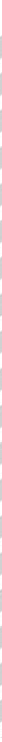


CHAPTER 11

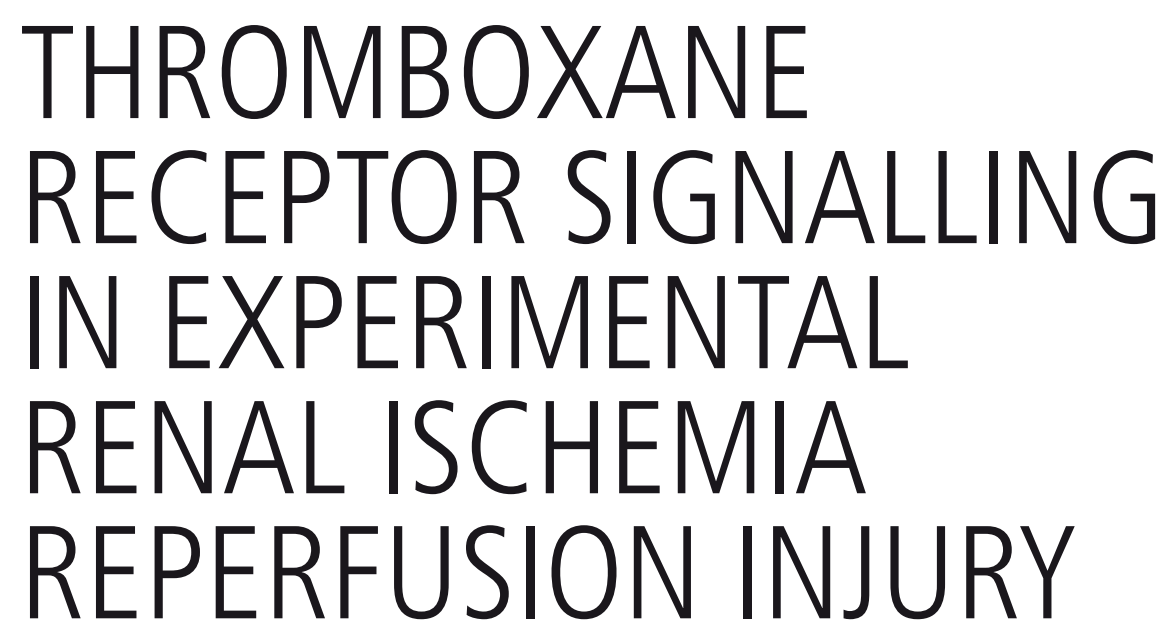




\section{ABSTRACT}

Background: F2-isoprostanes are formed by oxidative modification of arachidonic acid and are the gold standard for detection of oxidative stress in vivo. F2isoprostanes are biologically active compounds that signal through the thromboxane A2 (TP) receptor; infusion of F2-isoprostanes reduces glomerular filtration in the kidney by constricting afferent arterioles. We investigated whether endogenous F2isoprostanes contribute to the pathogenesis of ischemic acute kidney injury, which is associated with oxidative stress and reduced glomerular filtration.

Methods: TP-receptor knockout mice - that lack F2-isoprostanes and thromboxane A2 signalling - and wild-type control mice underwent 30 minutes of renal ischemia and 24 hours of reperfusion.

Results: Kidney dysfunction, histological injury and the number of infiltrated neutrophils were similar between the two mouse strains, whereas TP-receptor knockout mice had significantly more apoptotic cells and lipid peroxidation than their wild-type counterparts. F2-isoprostanes and thromboxane B2 were readily detectable in urine collections after surgery.

Conclusion: Our findings indicate that F2-isoprostanes and thromboxane A2 signalling do not contribute critically to the pathogenesis of ischemic acute kidney injury, and more generally provide evidence against a prominent role for F2isoprostanes signalling in exacerbating acute disease states associated with oxidative stress.

\section{Published as}

Maarten G.J. Snoeijs, Pieter R. Hoogland, Bas Boonen, Thomas M. Coffman, Carine J. Peutz- Kootstra, Wim A. Buurman, L.W. Ernest van Heurn. Thromboxane receptor signalling in renal ischemia reperfusion injury. Free Rad Res 2011; 45(6): 699-706 


\section{INTRODUCTION}

Acute kidney injury is a frequent complication after ischemia and reperfusion due to cardiovascular surgery and hemorrhagic shock and is independently associated with increased in-hospital mortality (1). In renal transplantation, acute kidney injury results in delayed graft function which is associated with an increased incidence of acute rejection and graft loss (2). At reperfusion, reintroduction of oxygen to the ischemic kidney rapidly leads to the formation of reactive oxygen species that may damage cellular lipids, proteins and DNA when anti-oxidant defences have been exhausted. The resulting oxidative stress is an important cause of acute kidney injury, since administration of various anti-oxidants has been shown to attenuate renal dysfunction and histological injury in animal models of renal ischemia and reperfusion (3-5).

F2-isoprostanes are formed by oxidative modification of arachidonic acid in cell membranes. They are cleaved and released into the plasma by platelet-activating factor acetylhydrolase $(6,7)$. Measurement of plasma and urinary F2-isoprostanes has become accepted as the gold standard for detection of oxidative stress in vivo (8), and their production has been demonstrated in a rat model of renal ischemia and reperfusion (9). Interestingly, next to being accurate biomarkers of oxidative stress, F2-isoprostanes are biologically active compounds that signal through the thromboxane A2 (TP) receptor (10). Intra-arterial administration of F2-isoprostanes to rats and pigs results in dose-dependent reductions in renal blood flow and glomerular filtration rate due to vasoconstriction of afferent glomerular arterioles $(9,11)$. This renal vasoconstriction has also been observed in human acute kidney injury (12).

Taken together, the vasoconstrictive properties of locally produced F2isoprostanes may contribute to the reduction of glomerular filtration rate in ischemic acute kidney injury and may explain the protective effects of anti-oxidants in animal models of renal ischemia and reperfusion. To address this hypothesis, we studied the effects of genetic disruption of the TP-receptor - which eliminates F2-isoprostanes signalling (13) - in a mouse model of renal ischemia and reperfusion.

\section{MATERIALS AND METHODS}

\section{Renal ischemia and reperfusion in mice}

Homozygous TP-receptor knockout breeding pairs (backcrossed on C57BL/6J mice for 13 generations) were provided by dr. T.M. Coffman (14). Wild-type C57BL/6J mice were obtained from Charles River (L'arbresle Cedex, France). Animals were housed in standard laboratory cages with free access to food and water. In random order, male wild-type and TP-receptor knockout mice aged 9-11 weeks were anaesthetized with ketamine and xylazine (100 and $10 \mathrm{mg} / \mathrm{kg}$ s.c., respectively). 
Body temperature was maintained at $37^{\circ} \mathrm{C}$ by a heating lamp until the animals had recovered from anaesthesia. Ischemia was induced by clamping the left renal pedicle for 30 minutes using a non-traumatic vascular clamp through a midline abdominal incision. The surgeon was blinded for mouse genotype. Upon clamp removal, the kidney was inspected for restoration of blood flow and the contralateral kidney was excised. The abdomen was closed in 2 layers, $0.25 \%$ bupivacaine was applied topically for post-operative pain management and $1 \mathrm{~mL}$ pre-warmed PBS was given subcutaneously to prevent dehydration. Animals were euthanized at 24 hours after reperfusion, when blood was collected by puncture of the vena cava. The left kidney was recovered for further analysis. Blood was stored on ice in heparanized tubes until centrifugation at $900 \mathrm{~g}$ at $4{ }^{\circ} \mathrm{C}$ for $10 \mathrm{~min}$. Plasma creatinine and blood urea nitrogen (BUN) concentrations were measured. In a separate set of experiments, the contralateral kidney was left in situ and the animals were housed in metabolic cages to collect urine for 24 hours before and after surgery.

\section{Histological assessment of renal tissue}

Renal tissue was formalin-fixed and stained with periodic acid-Schiff for blinded assessment of renal injury by an experienced nephropathologist. Tubular dilation, casts and debris, brush border loss and necrosis at the corticomedullary junction were scored in 10 fields at $400 x$ magnification in a scale of 0 to 5 ( 0 is normal; 1 involves $<10 \%$ of cortex; 2 involves $10-25 \%$ of cortex; 3 involves $25-50 \%$ of cortex; 4 involves $50-75 \%$ of cortex; and 5 involves $>75 \%$ of cortex (15)). For detection of neutrophils, tissue sections were incubated with polyclonal rabbit anti-human myeloperoxidase (MPO) antibodies (1:50 dilution; Hycult Biotech, Uden, The Netherlands) for 2 hours and with biotinylated polyclonal swine anti-rabbit IgG antibodies (1:500 dilution; Dako, Glostrup, Denmark) for 30 minutes. Endogenous peroxidase activity and non-specific binding were blocked with $0.6 \% \mathrm{H} 2 \mathrm{O} 2$ and $10 \%$ normal pig serum. After incubation with streptavidin and horseradish peroxidase conjugated biotin (Dako), slides were developed with $\mathrm{H} 2 \mathrm{O} 2$ and $\mathrm{AEC}$ and were counterstained with haematoxylin. The number of positive cells at the corticomedullary junction were counted in 10 fields at $400 x$ magnification by a blinded investigator.

Apoptotic cells were detected by terminal deoxynucleotidyl transferase (TdT)-mediated dUTP nick-end labelling (TUNEL; in situ cell death detection kit; Roche Diagnostics, Indianapolis, IN) according to the manufacturer's instructions (16). Before labelling, nuclei were permeabilized by incubating the tissue sections with $300 \mu \mathrm{g} / \mathrm{mL}$ proteinase K (Sigma-Aldrich, St. Louis, MO) for 15 minutes. Endogenous peroxidase activity and non-specific binding were blocked with $0.6 \% \mathrm{H} 2 \mathrm{O} 2$ and $3 \%$ bovine serum albumin. The slides were developed with $\mathrm{H} 2 \mathrm{O} 2$ and $\mathrm{AEC}$ and the number of positive nuclei at the corticomedullary junction were counted in 10 fields at $400 x$ magnification by a blinded investigator. 


\section{TP-receptor genotyping}

Genomic DNA was isolated from renal tissue according to the manufacturer's instructions (Wizard genomic DNA purification kit; Promega, Madison, WI). DNA was amplified using the primers 5'-GGGGGTAGCTATGGTGTTC-3' (for the wild-type allele), 5'-CTTCCTCGTGCTTTACGGTA-3' (for the mutant allele with PGK-neomycin insert) and $5^{\prime}$-GTGAGAAGGGCCGTGTGAT-3' (for both alleles) in 30 cycles at $94{ }^{\circ} \mathrm{C}, 60^{\circ} \mathrm{C}$ and 72 ${ }^{\circ} \mathrm{C}$ (60 seconds each). The PCR product was run on a $1.2 \%$ agarose gel with a DNA basepair ladder. The predicted amplicon sizes from the wild-type and mutant alleles were 150 and 700 base pairs, respectively.

\section{Measurement of urine thromboxane B2 and F2-isoprostanes}

Urine was collected on ice for 24 hours before and after surgery, centrifuged at $900 \mathrm{~g}$ at $4{ }^{\circ} \mathrm{C}$ for 10 minutes and stored at $-80^{\circ} \mathrm{C}$. Urinary thromboxane $\mathrm{B} 2$ and F2-isoprostanes concentrations were measured using commercially available enzyme immunoassays (Cayman Chemical, Ann Arbor, MI) according to the manufacturer's instructions and were adjusted for urinary creatinine concentrations.

\section{Measurement of tissue malondialdehyde}

Malondialdehyde (MDA) was measured in homogenized renal tissue that was sampled and snap-frozen at $24 \mathrm{~h}$ after reperfusion and stored at $-80^{\circ} \mathrm{C}$ until analysis. A $100 \mu \mathrm{L}$ sample was added to $900 \mu \mathrm{L}$ reagent (0.12 M 2-thiobarbituric acid, $0.32 \mathrm{M}$ O-phosphoric acid, $0.68 \mathrm{mM}$ butylated hydroxytoluene, $0.01 \%$ EDTA) and incubated for 1 hour at $100^{\circ} \mathrm{C}$. MDA products were extracted with $500 \mu \mathrm{L}$ butanol and their concentrations were determined by HPLC using a Nucleosil C18 column (150 X 3.2 $\mathrm{mm}, 5 \mu \mathrm{m}$ particle size; Supelco) eluted with $35 \%$ methanol in $25 \mathrm{mM}$ phosphate buffer ( $\mathrm{pH}$ 4.8). Detection was done by fluorescence using excitation at $532 \mathrm{~nm}$ and emission at $553 \mathrm{~nm}$. Malonaldehyde bis(diethylacetal) was used as internal standard.

\section{Laboratory animal use and ethical considerations}

Assuming a standard deviation of plasma creatinine of $15 \%$ of the mean, 10 mice per experimental group are necessary to detect a $20 \%$ difference between groups with statistical significance; we consider this difference to be biologically relevant. In vivo experiments were approved by local laboratory animal and national genetically modified organism review boards (DEC 2007-139 and GGO IG 07-110).

\section{Statistical methods}

Continuous variables are presented as mean and standard deviation. Independent samples t-test was used to compare continuous variables between experimental groups. For comparisons of continuous variables within experimental groups, paired samples t-test was used. $p<0.05$ was considered statistically significant. 

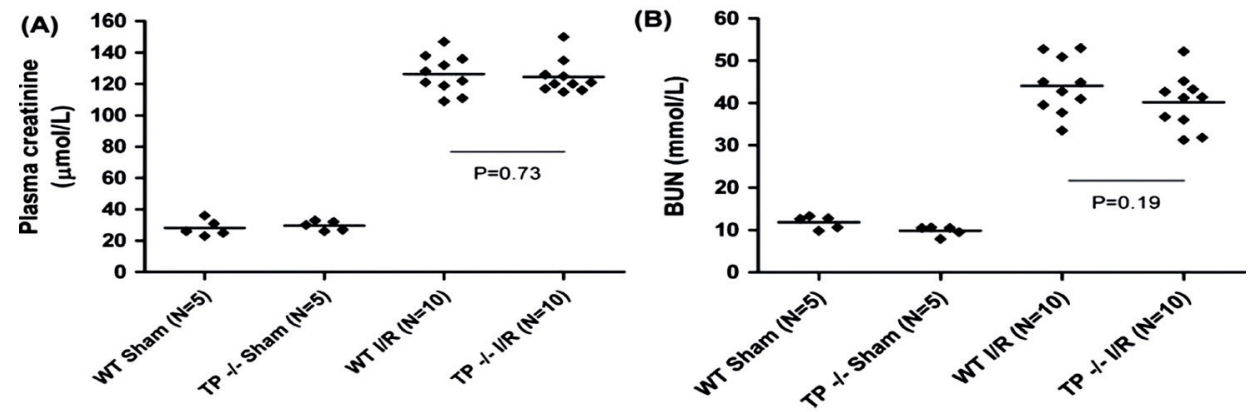

Figure 11.1 Kidney function is impaired to a similar extent in TP-receptor knockout (TP -/-) and wildtype control mice (WT) after 30 minutes of renal ischemia and 24 hours of reperfusion (I/R). (A) Plasma creatinine concentration. (B) Blood urea nitrogen (BUN) concentration. Diamonds and lines represent individual mice and group means, respectively.

\section{RESULTS}

\section{Effects of TP-receptor genotype on renal ischemia and reperfusion injury}

Homozygous TP-receptor knockout mice and wild-type controls were randomly subjected to 30 minutes of renal ischemia ( $\mathrm{N}=10$ per group) or sham surgery $(\mathrm{N}=5$ per group). No complications occurred during surgery and all animals survived until euthanasia at 24 hours after reperfusion. Mean body weight of TP-receptor knockout and wild-type mice was $24 \pm 0.8$ and $24 \pm 1.2 \mathrm{~g}$, respectively, before surgery and $22 \pm 1.5$ and $23 \pm 1.0 \mathrm{~g}$ at euthanasia. TP receptor genotype of each animal was confirmed by PCR of genomic DNA (data not shown).

Temporary renal ischemia induced severe kidney dysfunction as indicated by increased plasma concentrations of creatinine and BUN at 24 hours after reperfusion (Figure 11.1). TP-receptor knockout and wild-type control mice experienced a similar extent of renal dysfunction after ischemia and reperfusion ( $p=0.73$ for creatinine and $\mathrm{p}=0.19$ for BUN). Furthermore, substantial renal injury was observed on histological assessment of tissue sections after ischemia and reperfusion, indicated by tubular dilatation, cast deposition, brush border loss and necrosis at the corticomedullary junction (Figure 11.2). In line with its effect on renal function, disruption of the TPreceptor gene did not significantly reduce the extent of tissue injury after ischemia and reperfusion ( $p=0.58$ for tubular dilatation, $p=0.06$ for cast deposition, $p=0.32$ for brush border loss and $\mathrm{p}=0.06$ for necrosis). 

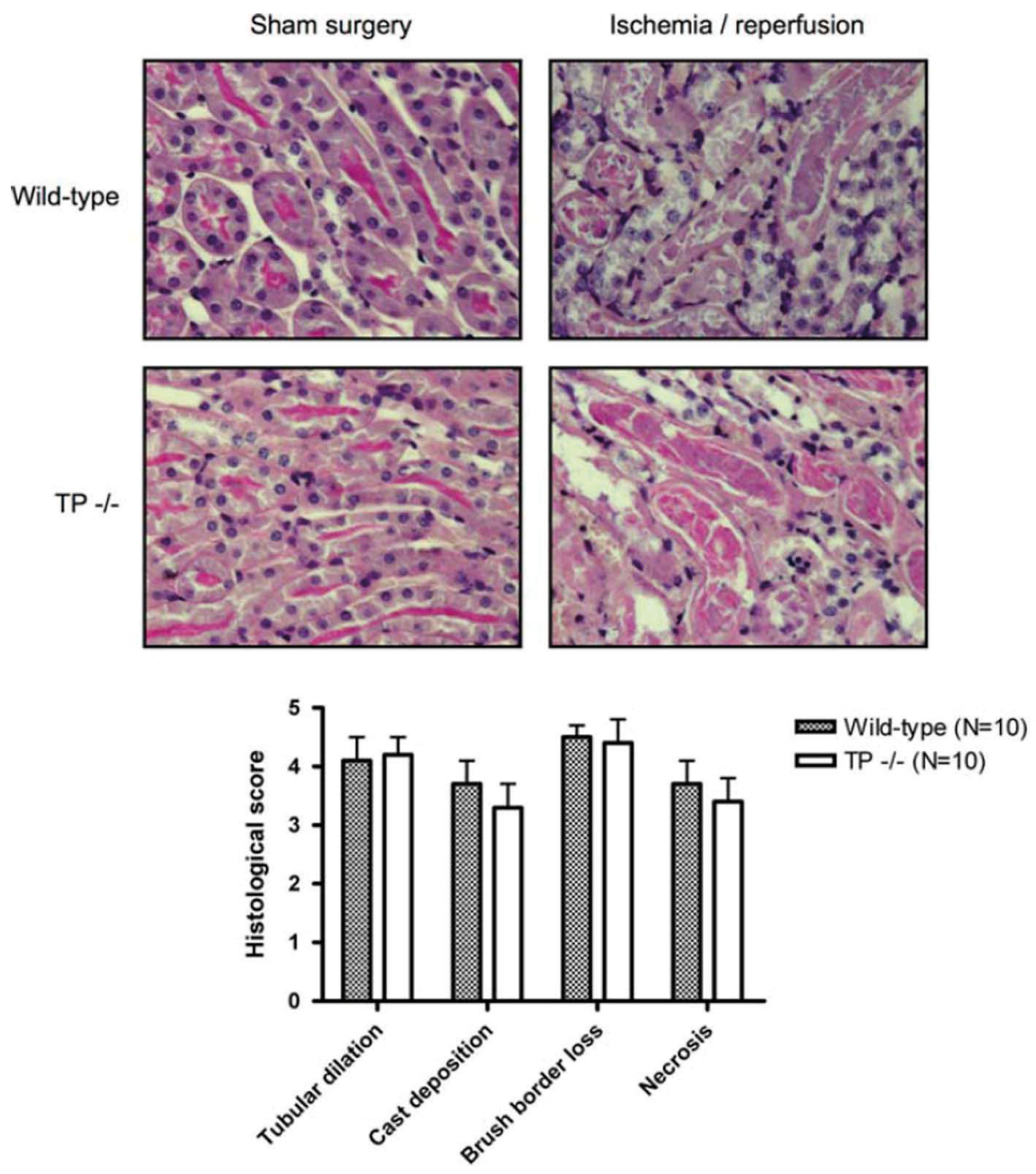

Figure 11.2 TP-receptor knockout (TP -/-) and wild-type control mice experience a similar extent of renal injury after 30 minutes of ischemia and 24 hours of reperfusion. Representative pictures of periodic acid-Schiff stained tissue sections at 400x magnification are shown. Tubular dilatation, casts deposition, brush border loss and necrosis were blindly scored by an experienced nephropathologist on a scale of 0 to 5 (15). Data are presented as mean and standard deviation.

\section{Effect of TP-receptor genotype on neutrophil infiltration, apoptosis and lipid peroxidation}

Tissue injury activates innate immunity and leads to infiltration of inflammatory cells into the damaged tissue (17). Influx of neutrophils into the kidney occurs relatively early after reperfusion and has been shown to exacerbate ischemic acute renal injury (18). In our experiment, renal ischemia and reperfusion resulted in massive 
accumulation of neutrophils around the injured tubules at the corticomedullary junction (Figure 11.3A). The extent of neutrophil infiltration was similar for TPreceptor knockout and wild-type control mice $(p=0.96)$. Furthermore, after renal ischemia and reperfusion, tubular epithelial cells undergo apoptotic cell death which may aggravate acute kidney injury (19). In line with our other findings, disruption of the TP-receptor gene did not attenuate the induction of apoptosis in tubular epithelial cells at the corticomedullary junction after renal ischemia and reperfusion. On the contrary, TP-receptor knockout mice had significantly more apoptotic cells than their wild-type counterparts $(p=0.01$, Figure $11.3 B)$. Finally, we measured MDA concentrations in renal tissue to study lipid peroxidation after ischemic acute kidney injury. Unexpectedly, renal MDA concentrations were significantly higher in TPreceptor knockout mice that in wild-type animals, both at baseline ( $76 \pm 23$ vs $43 \pm 11$ $\mathrm{nmol} / \mathrm{g}, \mathrm{p}=0.02$ ) and at 24 hours after reperfusion ( $66 \pm 25$ vs $45 \pm 7 \mathrm{nmol} / \mathrm{g}, \mathrm{p}=0.02$ ).

\section{Production of F2-isoprostanes and thromboxane A2}

Production of the TP-receptor ligands F2-isoprostanes and thromboxane A2 increases after renal ischemia and reperfusion in rats $(9,20)$. Since genetic disruption of the TP-receptor did not alter the susceptibility to ischemic acute kidney injury in mice, we investigated whether TP-receptor ligands were present in our experimental model. In urine collections before and after temporary renal ischemia, F2-isoprostanes and thromboxane B2 (the stable metabolite of thromboxane A2) concentrations from TP-receptor knockout and wild-type control mice were similar (Table 11.1). Urine thromboxane B2 concentrations increased by $44 \pm 35 \%$ following renal ischemia and reperfusion $(p=0.01)$, whereas urine $F 2$-isoprostanes concentrations were constant $(p=0.27)$. These findings confirm the presence of the two major TP-receptor ligands after renal ischemia and reperfusion.

F2-isoprostanes and thromboxane B2 concentrations ( $\mathrm{ng} / \mathrm{mg}$ creatinine) in 24-hour urine collections before and after renal ischemia and reperfusion. ${ }^{a}$

\begin{tabular}{lccc}
\hline & $\begin{array}{l}\text { Before ischemia and } \\
\text { reperfusion }\end{array}$ & $\begin{array}{l}\text { After ischemia and } \\
\text { reperfusion }\end{array}$ & $\mathbf{p ~}$ \\
\hline F $_{2}$-ISOPROSTANES & $4.1 \pm 2.1$ & $3.3 \pm 0.8$ & \\
\hline Wild-type controls & $4.2 \pm 1.3$ & $3.4 \pm 1.1$ & 0.27 \\
\hline TP-receptor knockouts & $8.8 \pm 2.3$ & $12.2 \pm 3.1$ & \\
\hline THROMBOXANE B & $8.8 \pm 2.3$ & $11.5 \pm 1.7$ & 0.01 \\
\hline Wild-type controls & & \\
\hline TP-receptor knockouts & &
\end{tabular}

a Data are presented as mean (standard deviation). P-values represent comparisons of urine concentrations before and after renal ischemia and reperfusion after pooling of both mouse strains. 


\section{DISCUSSION}

The current study was designed to establish the biological effects of locally produced F2-isoprostanes in a mouse model of renal ischemia and reperfusion. We found that mice with genetic deletion of the TP-receptor - which eliminates F2isoprostanes and thromboxane A2 signalling (13) - suffered renal dysfunction of similar severity as wild-type mice with the same genetic background at 24 hours after reperfusion. Furthermore, the degree of histological injury and the number of neutrophils in the outer renal medulla were comparable between the two groups of mice. TP-receptor knockout mice had significantly more apoptosis and a trend towards less necrosis than their wild-type counterparts, suggesting a change in the mode of cell death after renal ischemia and reperfusion when TP signalling is lost. Taken together, however, F2-isoprostanes and thromboxane A2 signaling do not seem to contribute critically to the development of ischemic acute kidney injury.

The biological effects of F2-isoprostanes have been studied in various experimental models. Administration of synthetic F2-isoprostanes increases systemic blood pressure in rodents and causes vasoconstriction of human arteries and veins in vitro $(13,21,22)$. The vasoconstrictive actions of F2-isoprostanes are particularly evident in the renal microcirculation: intrarenal arterial administration of $1 \mu \mathrm{g} / \mathrm{kg} /$ min 15-F2-isoprostane acutely reduces glomerular filtration rate by $35 \%$ in pigs and $49 \%$ in rats, whereas systemic haemodynamic effects are not observed until administration of $10 \mu \mathrm{g} / \mathrm{kg} / \mathrm{min} 15-\mathrm{F} 2$-isoprostane $(9,11,13)$. Other biological effects of F2-isoprostanes include stimulation of leukocyte adhesion to endothelium and proliferation of endothelial and vascular smooth muscle cells, promoting angiogenesis and atherosclerosis in vivo $(23,24)$. Conflicting reports have been published on the effects of F2-isoprostanes on platelets, some groups finding increased activation of platelets, whereas others report that F2-isoprostanes prevent aggregation of platelets in vitro $(13,25)$. These paradoxical effects may be explained by partial agonistic activity of F2-isoprostanes on TP-receptors or by the presence of a second, inhibitory F2-isoprostanes receptor on platelets (10).

It has been established that administration of synthetic F2-isoprostanes causes a variety of biological that are highly comparable to the actions of other TP-receptor agonists. It has repeatedly been proposed that endogenous formation of F2-isoprostanes as a result of oxidative stress may elicit similar effects, thereby contributing to the pathogenesis of conditions as diverse as ischemia-reperfusion injury, atherosclerosis, tumour angiogenesis and asthmatic bronchoconstriction. However, biological actions of synthetic F2-isoprostanes have typically been observed after adding these compounds at concentrations two to three orders of magnitude greater than the physiological plasma concentrations of F2-isoprostanes in healthy volunteers. At sites of oxidative stress, F2-isoprostanes may nevertheless reach concentrations at which adverse biological effects have been observed (26). 

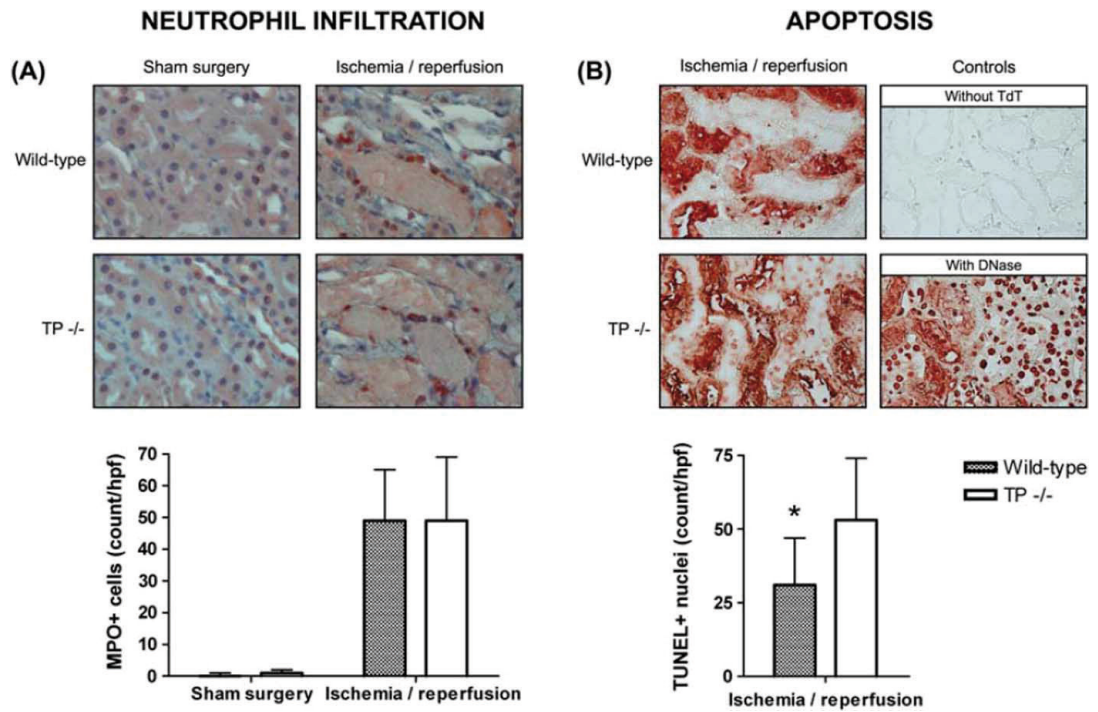

Figure 11.3 TP-receptor knockout (TP -/-) mice have similar extent of (A) neutrophil infiltration into the kidney and (B) significantly more tubular epithelial cell apoptosis after 30 minutes of renal ischemia and 24 hours of reperfusion as compared to wild-type control mice. Representative pictures of myeloperoxidase (MPO) and terminal deoxynucleotidyl transferase (TdT)-mediated dUTP nick-end labeling (TUBEL) stained tissue sections at 400x magnification are shown. Tubular debris was diffusely positive for TUNEL staining and was not taken into account when quantifying apoptotic nuclei. Data are presented as mean and standard deviation; the asterisk indicates statistical significance $(p=0.01)$.

The current study is the first to investigate the pathogenic actions of locally produced F2-isoprostanes in renal ischemia-reperfusion injury. This experimental model is well suited for assessment of the biological effects of F2-isoprostanes, since oxidative stress plays an important role in the pathophysiology of ischemic acute kidney injury and because the actions of F2-isoprostanes are particularly evident in the renal microcirculation $(9,11)$. The haemodynamic effects of F2-isoprostanes are entirely mediated by TP-receptors that are expressed in the glomeruli and intrarenal arteries of human and rodent kidneys (27-29). Mice with genetic deletion of the TP-receptor are viable and are characterized by normal renal haemodynamics with attenuated renal vasoconstriction after administration of endotoxin or angiotensinII $(14,30,31)$. In the current study, we found that ischemia and reperfusion induces acute kidney injury in TP receptor knockout mice to a similar extent as in wild-type mice, indicating that neither F2-isoprostanes nor thromboxane A2 signalling is critically involved in the pathophysiology of ischemic acute kidney injury. Our study does not account for potential TP-receptor-independent actions of F2-isoprostanes. It has been proposed that esterified F2-isoprostanes may cause cellular injury in the absence of TP-receptors by disruption of the fluidity and integrity of cell membranes, similar to other products of lipid peroxidation (32). 
Our findings seem to contradict previous experiments that have suggested thromboxane $A 2$ signalling to contribute to the pathogenesis of ischemic acute kidney injury (33). Specific inhibitors of thromboxane A2 synthase have been shown to attenuate acute kidney injury in rodent models of renal ischemia and reperfusion (33). However, inhibition of thromboxane A2 synthesis increases the production of the vasodilator prostacyclin as a result of the increased availability of their common precursor prostaglandin $\mathrm{H} 2$ - a phenomenon termed endoperoxide shunting (34). Since the beneficial effects of thromboxane A2 synthase inhibitors on ischemic acute kidney injury were eliminated when prostacyclin synthesis was blocked (35), these effects may have been caused by an increase in prostacyclin signalling as a result of endoperoxide shunting rather than by a decrease in thromboxane $A 2$ signalling. A separate study found that pharmacological inhibition of TP-receptor signalling attenuated renal dysfunction in a rat model of 60 minutes of renal ischemia followed by 6 hours of reperfusion (20). In contrast, we observed no effect of genetic deletion of TP-receptors on acute kidney injury after 30 minutes of renal ischemia and 24 hours of reperfusion in mice. These conflicting findings may be caused by differences in the applied experimental models or by cross-reactivity of the drug used to inhibit TP-receptor signalling (36).

Finally, we observed increased lipid peroxidation in kidneys of TP-receptor knockout mice as compared to those of wild-type animals, both at baseline and after renal ischemia and reperfusion. This novel and unexpected finding suggests that TPreceptor signalling by $\mathrm{F}$-isoprostanes may induce endogenous anti-oxidant defence mechanisms that limit lipid peroxidation in the kidney. It would be interesting to study this hypothesis on negative feedback on anti-oxidant regulation by F2-isoprostanes in future studies.

Taken together, we conclude that F2-isoprostanes and thromboxane A2 signalling do not contribute critically to the pathogenesis of ischemic acute kidney injury. Tissue injury due to ischemia and reperfusion is characterized by extensive oxidative stress and the biological actions of F2-isoprostanes are particularly evident in the renal microcirculation. Therefore, our findings more generally argue against a prominent role for $\mathrm{F} 2$-isoprostanes signalling in exacerbating acute disease states associated with oxidative stress. 


\section{REFERENCES}

1. Chertow GM, Burdick E, Honour M, Bonventre JV, Bates DW. Acute kidney injury, mortality, length of stay, and costs in hospitalized patients. J Am Soc Nephrol. 2005 Nov;16(11):3365-70.

2. Yarlagadda SG, Coca SG, Formica RN, Jr., Poggio ED, Parikh CR. Association between delayed graft function and allograft and patient survival: a systematic review and meta-analysis. Nephrol Dial Transplant. 2009 Mar;24(3):1039-47.

3. Paller MS, Hoidal JR, Ferris TF. Oxygen free radicals in ischemic acute renal failure in the rat. J Clin Invest. 1984 Oct;74(4):1156-64.

4. Koyama I, Bulkley GB, Williams GM, Im MJ. The role of oxygen free radicals in mediating the reperfusion injury of cold-preserved ischemic kidneys. Transplantation. 1985 Dec;40(6):590-5.

5. Baker GL, Corry RJ, Autor AP. Oxygen free radical induced damage in kidneys subjected to warm ischemia and reperfusion. Protective effect of superoxide dismutase. Ann Surg. 1985 Nov;202(5):628-41.

6. Stafforini DM, Sheller JR, Blackwell TS, Sapirstein A, Yull FE, McIntyre TM, et al. Release of free F2isoprostanes from esterified phospholipids is catalyzed by intracellular and plasma platelet-activating factor acetylhydrolases. J Biol Chem. 2006 Feb 24;281(8):4616-23.

7. Morrow JD, Hill KE, Burk RF, Nammour TM, Badr KF, Roberts LJ, 2nd. A series of prostaglandin F2-like compounds are produced in vivo in humans by a non-cyclooxygenase, free radical-catalyzed mechanism. Proc Natl Acad Sci U S A. 1990 Dec;87(23):9383-7.

8. Kadiiska MB, Gladen BC, Baird DD, Germolec D, Graham LB, Parker CE, et al. Biomarkers of oxidative stress study II: are oxidation products of lipids, proteins, and DNA markers of $\mathrm{CCl} 4$ poisoning? Free Radic Biol Med. 2005 Mar 15;38(6):698-710.

9. Takahashi K, Nammour TM, Fukunaga M, Ebert J, Morrow JD, Roberts LJ, 2nd, et al. Glomerular actions of a free radical-generated novel prostaglandin, 8-epi-prostaglandin F2 alpha, in the rat. Evidence for interaction with thromboxane A2 receptors. J Clin Invest. 1992 Jul;90(1):136-41.

10. Khasawneh FT, Huang JS, Mir F, Srinivasan S, Tiruppathi C, Le Breton GC. Characterization of isoprostane signaling: evidence for a unique coordination profile of 8-iso-PGF(2alpha) with the thromboxane $A(2)$ receptor, and activation of a separate cAMP-dependent inhibitory pathway in human platelets. Biochem Pharmacol. 2008 Jun 15;75(12):2301-15.

11. Krier JD, Rodriguez-Porcel M, Best PJ, Romero JC, Lerman A, Lerman LO. Vascular responses in vivo to 8-epi PGF(2alpha) in normal and hypercholesterolemic pigs. Am J Physiol Regul Integr Comp Physiol. 2002 Aug;283(2):R303-8.

12. Alejandro V, Scandling JD, Jr., Sibley RK, Dafoe D, Alfrey E, Deen W, et al. Mechanisms of filtration failure during postischemic injury of the human kidney. A study of the reperfused renal allograft. The Journal of clinical investigation. $1995 \mathrm{Feb} ; 95(2): 820-31$.

13. Audoly LP, Rocca B, Fabre JE, Koller BH, Thomas D, Loeb AL, et al. Cardiovascular responses to the isoprostanes $\mathrm{IPF}(2 \mathrm{alpha})-\mathrm{III}$ and $\mathrm{iPE}(2)-\mathrm{III}$ are mediated via the thromboxane $\mathrm{A}(2)$ receptor in vivo. Circulation. 2000 Jun 20;101(24):2833-40.

14. Thomas DW, Mannon RB, Mannon PJ, Latour A, Oliver JA, Hoffman M, et al. Coagulation defects and altered hemodynamic responses in mice lacking receptors for thromboxane A2. J Clin Invest. 1998 Dec 1;102(11):1994-2001.

15. Leemans JC, Stokman G, Claessen N, Rouschop KM, Teske GJ, Kirschning CJ, et al. Renal-associated TLR2 mediates ischemia/reperfusion injury in the kidney. The Journal of clinical investigation. 2005 Oct;115(10):2894-903.

16. Kelly KJ, Sandoval RM, Dunn KW, Molitoris BA, Dagher PC. A novel method to determine specificity and sensitivity of the TUNEL reaction in the quantitation of apoptosis. Am J Physiol Cell Physiol. 2003 May;284(5):C1309-18.

17. Thurman JM. Triggers of inflammation after renal ischemia/reperfusion. Clinical immunology (Orlando, Fla. 2007 Apr;123(1):7-13.

18. Kelly KJ, Williams WW, Jr., Colvin RB, Meehan SM, Springer TA, Gutierrez-Ramos JC, et al. Intercellular 
adhesion molecule-1-deficient mice are protected against ischemic renal injury. The Journal of clinical investigation. 1996 Feb 15;97(4):1056-63.

19. Daemen MA, van 't Veer C, Denecker G, Heemskerk VH, Wolfs TG, Clauss M, et al. Inhibition of apoptosis induced by ischemia-reperfusion prevents inflammation. J Clin Invest. 1999 Sep;104(5):541-9.

20. Kramer HJ, Mohaupt MG, Pinoli F, Backer A, Meyer-Lehnert H, Schlebusch H. Effects of thromboxane A2 receptor blockade on oliguric ischemic acute renal failure in conscious rats. J Am Soc Nephrol. 1993 Jul;4(1):50-7.

21. Cracowski JL, Stanke-Labesque F, Devillier P, Chavanon O, Hunt M, Souvignet C, et al. Human internal mammary artery contraction by isoprostaglandin $\mathrm{f}(2 \mathrm{alpha})$ type-III [8-iso-prostaglandin $\mathrm{F}(2 \mathrm{alpha})$ ]. Eur J Pharmacol. 2000 May 26;397(1):161-8.

22. Gardan B, Cracowski JL, Sessa C, Hunt M, Stanke-Labesque F, Devillier P, et al. Vasoconstrictor effects of iso-prostaglandin F2alpha type-III (8-iso-prostaglandin F2alpha) on human saphenous veins. J CardiovasC Pharmacol. 2000 May;35(5):729-34.

23. Benndorf RA, Schwedhelm E, Gnann A, Taheri R, Kom G, Didie M, et al. Isoprostanes inhibit vascular endothelial growth factor-induced endothelial cell migration, tube formation, and cardiac vessel sprouting in vitro, as well as angiogenesis in vivo via activation of the thromboxane $A(2)$ receptor: a potential link between oxidative stress and impaired angiogenesis. Circ Res. 2008 Oct 24;103(9):1037-46.

24. Tang M, Cyrus T, Yao Y, Vocun L, Pratico D. Involvement of thromboxane receptor in the proatherogenic effect of isoprostane F2alpha-III: evidence from apolipoprotein E- and LDL receptor-deficient mice. Circulation. 2005 Nov 1;112(18):2867-74.

25. Minuz P, Andrioli G, Degan M, Gaino S, Ortolani R, Tommasoli R, et al. The F2-isoprostane 8-epiprostaglandin F2alpha increases platelet adhesion and reduces the antiadhesive and antiaggregatory effects of NO. Arterioscler Thromb Vasc Biol. 1998 Aug;18(8):1248-56.

26. Iuliano L, Pratico D, Greco C, Mangieri E, Scibilia G, FitzGerald GA, et al. Angioplasty increases coronary sinus F2-isoprostane formation: evidence for in vivo oxidative stress during PTCA. J Am Coll Cardiol. 2001 Jan;37(1):76-80.

27. Abe T, Takeuchi K, Takahashi N, Tsutsumi E, Taniyama Y, Abe K. Rat kidney thromboxane receptor: molecular cloning, signal transduction, and intrarenal expression localization. J Clin Invest. 1995 Aug;96(2):657-64.

28. Mannon RB, Coffman TM, Mannon PJ. Distribution of binding sites for thromboxane A2 in the mouse kidney. Am J Physiol. 1996 Dec;271(6 Pt 2):F1131-8.

29. Brown GP, Venuto RC. Thromboxane receptors in human kidney tissues. Prostaglandins Other Lipid Mediat. 1999 Jun;57(4):179-88.

30. Boffa JJ, Just A, Coffman TM, Arendshorst WJ. Thromboxane receptor mediates renal vasoconstriction and contributes to acute renal failure in endotoxemic mice. J Am Soc Nephrol. 2004 Sep;15(9):2358-65.

31. Kawada N, Dennehy K, Solis G, Modlinger P, Hamel R, Kawada JT, et al. TP receptors regulate renal hemodynamics during angiotensin II slow pressor response. Am J Physiol Renal Physiol. 2004 Oct;287(4):F753-9.

32. Niki E. Lipid peroxidation: physiological levels and dual biological effects. Free Radic Biol Med. 2009 Sep 1;47(5):469-84.

33. Lelcuk S, Alexander F, Kobzik L, Valeri CR, Shepro D, Hechtman HB. Prostacyclin and thromboxane A2 moderate postischemic renal failure. Surgery. 1985 Aug;98(2):207-12.

34. Nowak J, FitzGerald GA. Redirection of prostaglandin endoperoxide metabolism at the platelet-vascular interface in man. J Clin Invest. 1989 Feb;83(2):380-5.

35. Klausner JM, Paterson IS, Kobzik L, Rodzen C, Valeri CR, Shepro D, et al. Vasodilating prostaglandins attenuate ischemic renal injury only if thromboxane is inhibited. Ann Surg. 1989 Feb;209(2):219-24.

36. Narumiya S, FitzGerald GA. Genetic and pharmacological analysis of prostanoid receptor function. J Clin Invest. 2001 Jul;108(1):25-30. 


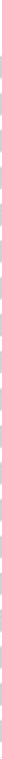


CHAPTER 12

$$
\begin{aligned}
& \text { GENERAL DISCUSSION } \\
& \text { AND SUMMARY }
\end{aligned}
$$




\section{INTRODUCTION}

Kidney transplantation is the treatment of choice for patients with end-stage renal disease. Due to the shortage of conventional brain-dead donor kidneys, and the increasing incidence of end-stage renal disease, waiting lists are still growing. Kidney donation from donors after cardiac death increases the number of available donor kidneys for transplantation. The pool of controlled donors after cardiac death is limited. The number of patients who die after failed resuscitation is much higher, but there is a general reluctance to use these donors for kidney donation and transplantation, because of a relatively high incidence of delayed graft function and primary non-function compared to conventional donors after brain death. Therefore, this thesis intends to describe the outcome of primarily uncontrolled DCD kidneys and to define clinically applicable methods to assess kidney viability and to reduce the incidence of primary non-function of DCD kidneys. In this chapter, we summarize and interpret the main findings of this thesis.

\section{DEFINITION OF DONATION AFTER CARDIAC DEATH}

Donation after cardiac death (DCD) refers to organ donation by deceased patients who do not meet strict criteria for brain death, but instead die from circulatory arrest after unsuccessful cardiopulmonary resuscitation (Maastricht category I and II) or after withdrawal of futile medical supportive treatment (Maastricht category III) (see also Table 1.1). The Maastricht categories were put together during the first international conference on non-heart-beating donation in Maastricht in 1995 (1). Maastricht category I donors constitute of patients declared dead outside the hospital and are subsequently transferred to the hospital with the purpose of organ donation. Maastricht category II donors are patients who die in the hospital, mostly in the emergency department, after unsuccessful resuscitation. Both categories are also referred to as uncontrolled DCD donation, since both situations occur unexpectedly and require swift actions of the donation team. Maastricht category III donors are patients in intensive care units (ICU) who do not meet brain death criteria but suffer from severe neurological damage, which makes medical supportive treatment futile. These patients in whom cardiac arrest is awaited are referred to as controlled DCD donors. The latter category, Maastricht category IV, consists of brain-dead donors who die of unexpected cardiac arrest before organ procurement.

In contrast to organs from brain-dead donors (donation after brain death, DBD), DCD kidneys suffer from warm ischemic injury during the period from circulatory arrest until organ preservation. This ischemic damage results in a relatively high incidence of primary non-function (PNF) and delayed graft function (DGF) after transplantation of the kidney, compared to kidney transplantation from conventional brain-dead donors (Chapter 2) (2). These early complications associated with DCD kidney transplantation have led to a general reluctance to use these kidneys for transplantation despite good results (Chapter 2) (3). 


\section{RESULTS OF KIDNEY TRANSPLANTATION FROM DONORS AFTER CARDIAC DEATH}

It is commonly known that kidney transplantation results in longer life expectancy and superior quality of life compared to dialysis treatment $(4,5)$. Therefore, kidney transplantation is the treatment of choice for many patients with end-stage renal disease (3). Procurement of kidneys from donors after cardiac death holds the potential to expand the donor pool 2.5 to 4 times (6). Only a small proportion of intensive care patients who are not brain-dead and in whom further medical treatment is considered to be futile, meet donor criteria. The number of patients who die after failed resuscitation is much higher (7) and are therefore a great potential to expand the donor pool.

Snoeijs et al. studied the survival benefit of patients who received a kidney from a DCD donor compared to patients who stay on dialysis treatment and wait for a conventional kidney from a brain-dead donor, in a large cohort study, which included 2.575 patients who were registered on the Dutch waiting list for a first kidney transplantation (8). Graft failure during the first 3 months after transplantation was twice as likely for DCD kidneys as for DBD kidneys. However, standard-criteria DCD kidney transplantation was associated with a $56 \%$ reduced risk of mortality, compared with continuing dialysis treatment and waiting for a DBD kidney. This reduction in mortality translates into a 2.4-month additional expected lifetime during the first 4 years after a kidney transplantation from a DCD donor. However, the long-term results of uncontrolled DCD kidney transplantation specifically remained to be established.

To address this issue, we studied the long-term outcome of uncontrolled DCD kidneys that were transplanted within the Eurotransplant region after being recovered in our organ procurement area from 1981 until 2009 and compared the results with controlled DCD kidney transplantation (Chapter 2). This study demonstrates that the initial function and long-term outcome of kidneys from uncontrolled DCDs is comparable with the outcome of kidneys from controlled donors. For both groups, a careful selection of both donor kidneys and recipients remains mandatory to reduce the risk of non-functioning grafts (7).

These findings show that uncontrolled DCD kidneys are a valuable expansion of the donor pool with good long-term results. However, drastic measures to reduce the percentage of primary non-function are necessary. It is not clear which factors influence the outcome of uncontrolled DCD kidney transplantation. Most studies which assessed DCD kidney transplantation outcomes analyzed either controlled DCD kidneys or uncontrolled and controlled DCD kidneys together. Because of the increased popularity, it is essential to know which uncontrolled DCD kidneys can be accepted for transplantation and which kidneys better can be discarded. To describe the opportunities and limits of uncontrolled DCD kidney transplantations, we assessed the results of our uncontrolled DCD program and determined which factors are associated with PNF or inferior graft function after transplantation of uncontrolled donor kidneys (Chapter 3). In this relatively large study with 135 uncontrolled DCD kidneys we focused on the association of different donor, graft 
and recipient characteristics with primary non-function. Only donor age shows to be an independent risk factor for PNF in the univariate analysis (OR 1.035, 95\% Cl 1.004$1.068, p=0.028$ ) and remains strongly associated with PNF in the multivariate analysis (OR $1.064,95 \% \mathrm{Cl} 1.013-1.118, \mathrm{p}=0.014$ ). Further analysis of donor age, using the ROC-curve and its accompanying table, showed the strongest association with PNF from an age of 54 years and older with an odds ratio of 2.857 (95\% Cl $1.242-6.571$; $\mathrm{p}=0.013)$. Kidneys from donors of 54 years and older have a higher percentage of PNF compared with younger donor kidneys ( $35 \%$ vs. $16 \%, p=0.012$, respectively). However, the predictive value of donor age is poor with an area under the receiver operating characteristics curve of $0.640,95 \% \mathrm{Cl} 0.553-0.721$. From Chapter 3, it cannot be excluded that there are more risk factors for poor uncontrolled DCD kidney function than old donor age. Despite the relatively high percentage of primary non-function, which increases the power to identify potential risk factors and, compared to other studies, the large group of uncontrolled DCD kidney transplantations, the number of analyzed donor kidneys remains relatively small to identify all possible risk factors for primary non-function. Taken together, Chapter 3 shows that donor age is associated with graft function of uncontrolled DCD kidneys and therefore, donor age remains an important criteria which may influence the decision to either accept or discard an uncontrolled DCD kidney.

\section{PITFALLS OF KIDNEY TRANSPLANTATION FROM DONORS AFTER CARDIAC DEATH}

Even though DCD kidney transplantation confers a survival benefit to wait-listed dialysis patients, the relatively high percentage of never functioning grafts provides a strong incentive to improve the current practice of DCD kidney transplantation.

Kidneys from DCD donors have higher risks of developing PNF and DGF compared to kidneys from DBD donors (8-10). Delayed graft function is a serious complication of kidney transplantation. It often leads to prolonged hospital stay, increased costs, increased risks of graft loss and recipients have to stay on dialysis treatment until the transplanted kidney regains function. However, DGF is not the most important parameter in DCD kidney transplantation, since it has little clinical implications, as long-term survival rates of DCD kidneys with DGF do not significantly differ from DCD kidneys with IF $(2,11-13)$. PNF on the other hand is a major complication, which is associated with the unnecessary risk of surgery, immunosuppression and recipients may become sensitized to donor antigens which decreases the opportunities for retransplantation (14). 


\section{IMPROVEMENTS IN DCD KIDNEY TRANSPLANTATION}

As primary non-function is a serious complication of kidney transplantation, measures to reduce the incidence of PNF to a minimum are of major importance. To make optimal use of DCD kidneys without increasing the percentage PNF, studies have been performed to identify potential risk factors for primary non-function and methods to reduce the chance on PNF.

The Maastricht University Medical Center (MUMC) started a kidney transplantation program in 1980. At that moment, only excellent donor kidneys from young, brain-dead donors were used for transplantation. While the waiting list for kidney transplantation was growing, the number of organ donors remained stable. Therefore, the need for additional sources of organ donors became more important and the pool of donor organs was expanded by the use of kidneys from donors after cardiac death. In the early years of the transplant program, DCD kidneys were only used occasionally. However, the demand for donor organs increased and DCD kidney transplantation was stimulated. We started using organs from older DCD donors and with longer periods of warm ischemia for transplantation. In the early nineties, $25 \%$ of the deceased donors were DCD donors. Unfortunately, the expansion of the donor pool with more marginal kidneys was accompanied with an increase in primary non-function. Therefore, we evaluated the quality of care at our center and assessed if improvements could be made to reduce the high rate of primary non-function without the reduction in the number of DCD donors (Chapter 4).

Potential risk factors for primary non-function that were analyzed included donor age, DCD category, warm ischemia time and duration of cold ischemia time. Previous studies from our group showed that DCD kidneys from donors aged 60 years or older showed a higher incidence of PNF and inferior graft survival compared to kidneys from younger donors (15), uncontrolled DCD donors were no significant risk factor for primary non-function (Chapter 2), prolonged in situ preservation was associated with a higher percentage of primary non-function and direct cannulation of the aorta was superior to in situ preservation for controlled donors $(16,17)$.

Based on these data, changes in our transplantation program were implemented in order to reduce the incidence of primary non-function. These changes included firstly routine biopsies for donor kidneys older than 60 years of age. In donors older than 60 years, the decision to transplant a kidney, to use both kidneys as dual transplant or to discard the donor kidney was made with the help of preimplantation histology. Secondly, donor kidneys with ISP insertion time longer than 30 minutes were generally discarded. Thirdly, for controlled DCD donors, direct aortic cannulation rather than ISP became the preservation method of choice. Fourthly, extra attention was paid to emphasize the importance of shorter CIT by reducing waiting time for operating theatre availability. Due to these implemented changes, we were able to reduce the incidence of primary non-function of DCD kidneys back to $5 \%$, without the reduction in the number of DCD donors. This percentage is equivalent with results of other groups $(9,10,18)$. 
Taken together, a liberal approach to accept marginal DCD donors for transplantation may contribute to a more widespread strategy to transplant DCD kidneys with a reduction of the number of patients on the waiting list with the dialysis associated mortality. However, such strategy requires careful monitoring of transplant outcome to guarantee that results remain within the limits of acceptable practice.

\section{DIAGNOSTIC TOOLS TO ASSESS GRAFT VIABILITY OF KIDNEYS FROM DONORS AFTER CARDIAC DEATH}

Pre-transplant assessment of kidney graft viability may help clinicians to decide whether to accept or discard a kidney for transplantation. Proper selection of suitable kidneys for transplantation is important to reduce the risk of primary nonfunction and delayed graft function after transplantation, which is associated with an increased risk of graft loss, acute rejection, longer hospital stay and high costs (19-22). Additionally, without reliable tools to assess graft viability, potential viable kidneys may be discarded. Therefore, diagnostic tools to assess graft viability before transplantation are of major importance.

\section{Viability assessment of machine perfused kidneys}

In recent years, kidney preservation by hypothermic machine perfusion has experienced renewed interest. In addition to the intended benefit of improved tissue preservation, machine perfusion also provides the opportunity to assess organ viability with the help of perfusion parameters and biomarkers in the perfusate (23, 24). Perfusate biomarkers glutathione S-transferase (GST) and lactate dehydrogenase (LDH) are promising or accepted tools to accept or discard kidneys for transplantation (25-27). However, most studies which assess the value of perfusate biomarkers as predictors of organ viability assessed this in selected kidneys and described the improvement of the results of DCD kidney transplantation after the introduction of perfusate biomarkers to assess organ viability, or included a limited number of kidneys with an a priori good prognosis and therefore lack power (Chapter 5).

In Chapter 5, we evaluated the predictive value of the potential biomarkers GST, LDH, heart-type fatty acid binding protein (H-FABP), redox-active iron, interleukin (IL)-18 and neutrophil gelatinase-associated lipocalin (NGAL) of a large $(\mathrm{N}=335)$ unselected group of DCD kidneys with a relative poor prognosis and a high incidence of graft failure. In this cohort, only LDH and IL-18 were associated with PNF in the multivariate analysis (OR $1.001,95 \% \mathrm{Cl} 1.000-1.002, p=0.005$ and $1.001,95 \%$ Cl $1.000-1.002, p=0.003$, respectively). However, the diagnostic accuracy for primary non-function was 'poor' for all biomarkers. Therefore, the diagnostic accuracy of the perfusate biomarkers GST, LDH, H-FABP, redox-active iron, IL-18 and NGAL should not lead to the discard of DCD kidneys. 
Next to the assessment of perfusate biomarkers, machine perfusion also provides the opportunity to determine perfusion parameters, including perfusion pressure, renal flow and renovascular resistance. These parameters have been advocated to predict graft function after transplantation (28-31). However, the value of machine perfusion characteristics to predict primary non-function was relatively unknown. Therefore, we assessed the value of renovascular resistance in predicting organ viability in a large cohort of marginal machine perfused DCD kidneys in which perfusion characteristics were not used to discard the organs (Chapter 6). We showed that renovascular resistance at the start of machine perfusion was significantly and independently associated with primary non-function (OR 2.040, 95\% Cl 1.362-3.056, $\mathrm{p}=0.001$ ). However, the predictive quality was moderate. Therefore, marginal kidneys should not be discarded based on renovascular resistance only.

The period of warm ischemia can lead to capillary damage due to thrombosis, vasoconstriction and oedema and may consequently result in a decreased renovascular circulating volume. Therefore, pre-implantation renovascular circulating volume of the kidney may be associated with the severity of warm ischemic injury and could be a valuable predictor of transplant outcome. The dilution technique is used to measure circulating volume in hemodialyzer fibre bundles. It determines the dilution of an injected saline bolus with ultrasound flow probes before and after transit of the dialyzer. In hemodialyzer volume assessment this technique is accurate and its results reproducible (32-35). The dilution technique is a relatively simple method to measure intravascular volume and has not been used before in transplant surgery. Therefore we determined the repeatability and the validity of this technique and we assessed the effect of warm ischemia on renovascular circulating volume in machine perfused porcine kidneys (Chapter 7). This technique is a reproducible way to assess renovascular circulating volume of machine perfused porcine kidneys and is suitable to detect differences in warm ischemia time. However, further studies are necessary to assess the value of the dilution technique and renovascular volume measurements in human transplantation.

Unfortunately, the 'viability tests' for machine perfused DCD kidneys described in this thesis and other recent studied potential viability markers have insufficient diagnostic accuracy to be clinically useful in deciding whether to transplant or discard DCD kidneys that have suffered from warm ischemia (Chapter 8). Assessment of renovascular circulating volume of machine perfused kidneys with the hemodialyzer technique may be a valuable tool to assess organ viability but future studies in human kidney transplantation are necessary.

\section{Viability assessment of kidneys before organ procurement}

Viability testing of machine perfused kidneys has been extensively studied. Machine perfusion characteristics and perfusate biomarkers often correlate with the transplant outcome, but the present viability tests are not reliable predictors of transplant outcome. Viability assessment of kidneys before organ procurement, however, has been studied less. 
The protein neutrophil gelatinase-associated lipocalin (NGAL), also known as lipocalin-2, has recently been discovered as a novel biomarker of acute kidney injury (36). The concentration of NGAL increases dramatically in response to tubular injury and precedes the elevation of classical biomarkers for kidney damage, such as serum creatinine (37). Therefore, we measured NGAL concentrations in both DCD (uncontrolled Maastricht category I and II donors and controlled Maastricht category III donors) and DBD donors and examined the value of donor plasma NGAL to predict post-transplant graft function (Chapter 9). We have shown for the first time that donor NGAL concentrations prior to organ recovery are not associated with graft function after transplantation, however, for functioning DCD kidneys only, a significant difference was found for NGAL concentrations between kidneys with DGF and IF. Although it is a valuable biomarker for kidney injury in intensive care patients, its value as a predictor in kidney transplantation outcome is limited.

\section{TREATMENT OF ISCHEMIC ACUTE KIDNEY INJURY IN ANIMAL MODELS}

DCD kidney transplantation is currently limited to kidneys that have suffered relatively short periods of warm ischemia. Reducing renal injury after ischemia and reperfusion holds the potential to reduce the incidence of early graft dysfunction and as a result it may contribute to an expansion of the donor pool with kidneys which have suffered prolonged ischemic injury. Therefore, we have studied novel potential therapies for ischemic acute kidney injury in experimental mice models with the eventual goal to improve early graft function in DCD kidney transplantation.

Ischemia-reperfusion leads to a complex series of events, including generation of inflammatory mediators, leukocyte infiltration and, depending on the severity of the injury, ultimately cell death by either necrosis or apoptosis $(38,39)$. Inefficient clearance of apoptotic cells leads to necrosis, which is characterized by the disruption of cellular membranes and the release of cytoplasmic and nuclear components (40). The mechanisms that lead to inflammation after necrotic cell death are poorly understood. Recent data show that C-type lectin Mincle is involved in this process. Mincle recognizes the soluble factor spliceosome-associated protein 130 (SAP130), a nuclear protein released by necrotic cells, triggering inflammatory cytokine responses, which leads to the recruitment of neutrophils $(40,41)$. Although incompletely understood, renal tubular necrosis, apoptosis and inflammation during and after renal ischemia-reperfusion contribute significantly to the pathogenesis of ischemic acute kidney injury (42). Taken together, blocking the Mincle receptor may result in a less severe inflammatory response, leading to less severe injury after nonhomeostatic cell death. Therefore, we studied the effect of anti-Mincle on renal ischemia-reperfusion injury in mice in Chapter 10. The effects of Mincle on renal ischemia-reperfusion injury and inflammatory response were studied in an ischemia-reperfusion model in mice, using 25 minutes of ischemia and 24 hours of reperfusion. The Mincle-receptor was 
blocked with a Mincle-specific antibody (anti-Mincle) and compared with animals receiving rat lgG as control group. Kidney function (creatinine $232 \pm 34$ vs. $211 \pm 22$ $\mu \mathrm{mol} / \mathrm{L}, \mathrm{p}=0.200$ and BUN $61.2 \pm 5.6$ vs. $58.2 \pm 5.9, \mathrm{p}=0.355$, respectively), histological injury and the number of infiltrated neutrophils were similar between both groups. In conclusion, blocking the Mincle-receptor with specific anti-Mincle antibodies does not inhibit the inflammatory response in mice kidneys after ischemia and reperfusion and does not contribute to lesser renal injury and better renal function.

During cold ischemia and at reperfusion, generation of reactive oxygen species is considered to contribute significantly to ischemic acute kidney injury, it causes renal vasoconstriction and damages cellular lipids, proteins and DNA, leading to tubular epithelial cell death, when there is no anti-oxidant defense (43-45). In Chapter 11 we studied the pathophysiology of vasoconstriction due to oxidative stress and a possible method to prevent this. We described that oxidative modification of arachidonic acid in cell membranes leads to formation of stable F2-isoprostanes that are cleaved and released into the plasma and then possess biological activity by signaling through the thromboxane A2 receptor $(46,47)$. Previous studies showed a reduction in renal blood flow and glomerular filtration rate due to vasoconstriction of afferent glomerular arterioles after administration of F2-isoprostanes to rats and pigs $(48,49)$. Mice with genetic disruption of the Thromboxane A2 receptor, which eliminates F2-isoprostanes signaling, were not protected from ischemic acute kidney injury when compared to wild-type mice, though F2-isoprostanes were detected in urine collections after surgery. Therefore, we think that F2-isoprostanes signaling does not have a great impact on the pathogenesis of ischemic acute kidney injury.

\section{FUTURE PERSPECTIVES IN DCD KIDNEY DONATION AND TRANSPLANTATION}

Targeted interventions to organ damage due to brain death or ischemia may reduce or attenuate ischemia-reperfusion injury after transplantation. Modifying inflammatory reactions and innate immunity may play an important role in this in the future. Novel treatment strategies may improve the quality of the organs, and so increase the number of organs that can be safely accepted for transplantation. Interventions can be applied in the donor, but also between organ procurement and transplantation during cold machine preservation or during warm preservation. In the latter, the metabolism is higher which theoretically enables better modification of the organ.

As described in Chapter 8 normothermic machine perfusion (NMP) may provide new and other opportunities to assess the quality of a donor organ before transplantation. Furthermore, NMP may ameliorate ischemic damage and resuscitate the organ instead of doing further harm and preventing the graft from injury during the preservation period (50). The major advantage of NMP to test organ viability 
is the possibility of measuring functional parameters, like diuresis and creatinine clearance.

\section{CONCLUSION}

In the current thesis, we describe the utilization of organs from donors after cardiac death, especially uncontrolled Maastricht category II donors, the long-term results and ways to improve transplant outcome. Despite the higher incidence of primary non-function of uncontrolled DCD kidneys, long-term results are equal to controlled DCD kidneys. The risk of primary non-function can be reduced by identifying marginal organ donors by age, histological assessment of pre-implantation biopsies of old donor kidneys, donor category, WIT and CIT, justifying the expansion of the donor pool with uncontrolled donors to reduce the still growing waiting list for renal transplantations and stimulating the implementation of uncontrolled kidney donation programs.

Ischemia-reperfusion leads to a complex series of events. Therefore, treatment of ischemically damaged kidneys is likely to require a combination of interventions targeting different pathophysiological pathways. In this thesis, possible treatments of single elements of the pathophysiology of ischemia-reperfusion were studied, with no positive effects. A combination of interventions however, may be successful in future studies.

With the results presented in this thesis the use of kidneys from DCD donors, especially uncontrolled DCD donors, may be further expanded. However, major efforts should continue to be made to improve the quality of DCD kidneys and thereby expand the utilization of this large pool of donor kidneys to its full potential. 


\section{REFERENCES}

1. Kootstra G, Daemen JH, Oomen AP. Categories of non-heart-beating donors. Transplantation proceedings. 1995 Oct;27(5):2893-4.

2. Wijnen RM, Booster MH, Stubenitsky BM, de Boer J, Heineman E, Kootstra G. Outcome of transplantation of non-heart-beating donor kidneys. Lancet. 1995 Apr 29;345(8957):1067-70.

3. Snoeijs MGJ, Heurn LWEv, Mook NKAv, Christiaans MH, Hooff JPv. Controlled donation after cardiac death: a European perspective. Transplant rev. 2007;21(4):219-29.

4. Wolfe RA, Ashby VB, Milford EL, Ojo AO, Ettenger RE, Agodoa LY, et al. Comparison of mortality in all patients on dialysis, patients on dialysis awaiting transplantation, and recipients of a first cadaveric transplant. N Engl J Med. 1999 Dec 2;341(23):1725-30.

5. Evans RW, Manninen DL, Garrison LP, Jr., Hart LG, Blagg CR, Gutman RA, et al. The quality of life of patients with end-stage renal disease. N Engl J Med. 1985 Feb 28;312(9):553-9.

6. Daemen JW, Oomen AP, Kelders WP, Kootstra G. The potential pool of non-heart-beating kidney donors. Clinical transplantation. 1997 Apr;11(2):149-54.

7. Hoogland ER, Snoeijs MG, Winkens B, Christaans MH, van Heurn LW. Kidney Transplantation from Donors after Cardiac Death: Uncontrolled versus Controlled Donation. Am J Transplant. 2011 Jul;11(7):1427-34.

8. Snoeijs MG, Schaubel DE, Hene R, Hoitsma AJ, Idu MM, ljzermans JN, et al. Kidneys from donors after cardiac death provide survival benefit. J Am Soc Nephrol. 2010 Jun;21(6):1015-21.

9. Barlow AD, Metcalfe MS, Johari Y, Elwell R, Veitch PS, Nicholson ML. Case-matched comparison of longterm results of non-heart beating and heart-beating donor renal transplants. The British journal of surgery. 2009 Jun;96(6):685-91.

10. Sanchez-Fructuoso AI, Prats D, Torrente J, Perez-Contin MJ, Fernandez C, Alvarez J, et al. Renal transplantation from non-heart beating donors: a promising alternative to enlarge the donor pool. J Am Soc Nephrol. 2000 Feb;11(2):350-8.

11. Renkens JJ, Rouflart MM, Christiaans MH, van den Berg-Loonen EM, van Hooff JP, van Heurn LW. Outcome of nonheart-beating donor kidneys with prolonged delayed graft function after transplantation. Am J Transplant. 2005 Nov;5(11):2704-9.

12. Weber M, Dindo D, Demartines N, Ambuhl PM, Clavien PA. Kidney transplantation from donors without a heartbeat. N Engl J Med. 2002 Jul 25;347(4):248-55.

13. Sanchez-Fructuoso Al, Marques M, Prats D, Conesa J, Calvo N, Perez-Contin MJ, et al. Victims of cardiac arrest occurring outside the hospital: a source of transplantable kidneys. Annals of internal medicine. 2006 Aug 1;145(3):157-64.

14. Snoeijs MG, Schaefer S, Christiaans MH, van Hooff JP, van den Berg-Loonen PM, Peutz-Kootstra CJ, et al. Kidney transplantation using elderly non-heart-beating donors: a single-center experience. Am J Transplant. 2006 May;6(5 Pt 1):1066-71.

15. Snoeijs MG, Buurman WA, Christiaans MH, van Hooff JP, Goldschmeding R, van Suylen RJ, et al. Histological assessment of preimplantation biopsies may improve selection of kidneys from old donors after cardiac death. Am J Transplant. 2008 Sep;8(9):1844-51.

16. Snoeijs MG, Dekkers AJ, Buurman WA, van den Akker L, Welten RJ, Schurink GW, et al. In situ preservation of kidneys from donors after cardiac death: results and complications. Annals of surgery. 2007 Nov;246(5):844-52.

17. Wind J, Snoeijs MG, van der Vliet JA, Winkens B, Christiaans MH, Hoitsma AJ, et al. Preservation of kidneys from controlled donors after cardiac death. The British journal of surgery. 2011 Jun;98(9):1260-6.

18. Wells AC, Rushworth L, Thiru S, Sharples L, Watson CJ, Bradley JA, et al. Donor kidney disease and transplant outcome for kidneys donated after cardiac death. The British journal of surgery. 2009 Mar;96(3):299-304.

19. Yarlagadda SG, Coca SG, Formica RN, Jr., Poggio ED, Parikh CR. Association between delayed graft function and allograft and patient survival: a systematic review and meta-analysis. Nephrol Dial Transplant. 2009 Mar;24(3):1039-47. 
20. Huang $Y$, Samaniego M. Preemptive kidney transplantation: Has it come of age? Nephrologie \& therapeutique. Nov;8(6):428-32.

21. Perico N, Cattaneo D, Sayegh MH, Remuzzi G. Delayed graft function in kidney transplantation. Lancet. 2004 Nov 13-19;364(9447):1814-27.

22. Bhangoo RS, Hall IE, Reese PP, Parikh CR. Deceased-donor kidney perfusate and urine biomarkers for kidney allograft outcomes: a systematic review. Nephrol Dial Transplant. Aug;27(8):3305-14.

23. Jochmans I, Moers C, Smits JM, Leuvenink HG, Treckmann J, Paul A, et al. Machine perfusion versus cold storage for the preservation of kidneys donated after cardiac death: a multicenter, randomized, controlled trial. Annals of surgery. 2010 Nov;252(5):756-64.

24. Moers C, Smits JM, Maathuis MH, Treckmann J, van Gelder F, Napieralski BP, et al. Machine perfusion or cold storage in deceased-donor kidney transplantation. N Engl J Med. 2009 Jan 1;360(1):7-19.

25. St Peter SD, Imber CJ, Friend PJ. Liver and kidney preservation by perfusion. Lancet. 2002 Feb 16;359(9306):604-13.

26. Navarro AP, Sohrabi S, Colechin E, Griffiths C, Talbot D, Soomro NA. Evaluation of the ischemic protection efficacy of a laparoscopic renal cooling device using renal transplantation viability assessment criteria in a porcine model. The Journal of urology. 2008 Mar;179(3):1184-9.

27. Daemen JW, Oomen AP, Janssen MA, van de Schoot L, van Kreel BK, Heineman E, et al. Glutathione S-transferase as predictor of functional outcome in transplantation of machine-preserved non-heartbeating donor kidneys. Transplantation. 1997 Jan 15;63(1):89-93.

28. Matsuno N, Konno O, Mejit A, Jyojima Y, Akashi I, Nakamura Y, et al. Application of machine perfusion preservation as a viability test for marginal kidney graft. Transplantation. 2006 Dec 15;82(11):1425-8.

29. Sung RS, Christensen LL, Leichtman AB, Greenstein SM, Distant DA, Wynn JJ, et al. Determinants of discard of expanded criteria donor kidneys: impact of biopsy and machine perfusion. Am J Transplant. 2008 Apr;8(4):783-92.

30. Nyberg SL, Baskin-Bey ES, Kremers W, Prieto M, Henry ML, Stegall MD. Improving the prediction of donor kidney quality: deceased donor score and resistive indices. Transplantation. 2005 Oct 15;80(7):925-9.

31. Mozes MF, Skolek RB, Korf BC. Use of perfusion parameters in predicting outcomes of machine-preserved kidneys. Transplantation proceedings. 2005 Jan-Feb;37(1):350-1.

32. Krivitski NM. Novel method to measure access flow during hemodialysis by ultrasound velocity dilution technique. Asaio J. 1995 Jul-Sep;41(3):M741-5.

33. Krivitski NM, Kislukhin VV, Snyder JW, MacGibbon DR, Kuznetsova OA, Reasons AM, et al. In vivo measurement of hemodialyzer fiber bundle volume: theory and validation. Kidney international. 1998 Nov;54(5):1751-8.

34. Krivitski NM. Theory and validation of access flow measurement by dilution technique during hemodialysis. Kidney international. 1995 Jul;48(1):244-50.

35. Stewart GN. Researches on the Circulation Time and on the Influences which affect it. The Journal of physiology. 1897 Nov 20;22(3):159-83.

36. Mishra J, Dent C, Tarabishi R, Mitsnefes MM, Ma Q, Kelly C, et al. Neutrophil gelatinase-associated lipocalin (NGAL) as a biomarker for acute renal injury after cardiac surgery. Lancet. 2005 Apr 2-8;365(9466):1231-8.

37. Magnusson NE, Hornum M, Jorgensen KA, Hansen JM, Bistrup C, Feldt-Rasmussen B, et al. Plasma neutrophil gelatinase associated lipocalin (NGAL) is associated with kidney function in uraemic patients before and after kidney transplantation. BMC nephrology. 2012;13:8.

38. Kennedy SE, Erlich JH. Murine renal ischaemia-reperfusion injury. Nephrology (Carlton, Vic. 2008 Oct;13(5):390-6.

39. Bonventre JV, Weinberg JM. Recent advances in the pathophysiology of ischemic acute renal failure. J Am Soc Nephrol. 2003 Aug;14(8):2199-210.

40. Brown GD. Sensing necrosis with Mincle. Nature immunology. 2008 0ct;9(10):1099-100.

41. Yamasaki S, Ishikawa E, Sakuma M, Hara H, Ogata K, Saito T. Mincle is an ITAM-coupled activating receptor that senses damaged cells. Nature immunology. 2008 Oct;9(10):1179-88. 
42. Lee HT, Park SW, Kim M, Ham A, Anderson LJ, Brown KM, et al. Interleukin-11 protects against renal ischemia and reperfusion injury. American journal of physiology Renal physiology. 2012;303(8):1216-24.

43. Salahudeen AK. Cold ischemic injury of transplanted kidneys: new insights from experimental studies. Am J Physiol Renal Physiol. 2004 Aug;287(2):F181-7.

44. Paller MS, Hoidal JR, Ferris TF. Oxygen free radicals in ischemic acute renal failure in the rat. J Clin Invest. 1984 Oct;74(4):1156-64.

45. Schnackenberg CG. Physiological and pathophysiological roles of oxygen radicals in the renal microvasculature. American journal of physiology Regulatory, integrative and comparative physiology. 2002 Feb;282(2):R335-42.

46. Morrow JD, Hill KE, Burk RF, Nammour TM, Badr KF, Roberts LJ, 2nd. A series of prostaglandin F2-like compounds are produced in vivo in humans by a non-cyclooxygenase, free radical-catalyzed mechanism. Proc Natl Acad Sci U S A. 1990 Dec;87(23):9383-7.

47. Audoly LP, Rocca B, Fabre JE, Koller BH, Thomas D, Loeb AL, et al. Cardiovascular responses to the isoprostanes $\operatorname{IPF}(2$ alpha)-III and $\mathrm{iPE}(2)-$ III are mediated via the thromboxane $\mathrm{A}(2)$ receptor in vivo. Circulation. 2000 Jun 20;101(24):2833-40.

48. Takahashi K, Nammour TM, Fukunaga M, Ebert J, Morrow JD, Roberts LJ, 2nd, et al. Glomerular actions of a free radical-generated novel prostaglandin, 8-epi-prostaglandin F2 alpha, in the rat. Evidence for interaction with thromboxane A2 receptors. J Clin Invest. 1992 Jul;90(1):136-41.

49. Krier JD, Rodriguez-Porcel M, Best PJ, Romero JC, Lerman A, Lerman LO. Vascular responses in vivo to 8-epi PGF(2alpha) in normal and hypercholesterolemic pigs. Am J Physiol Regul Integr Comp Physiol. 2002 Aug;283(2):R303-8.

50. Hosgood SA, Nicholson HF, Nicholson ML. Oxygenated kidney preservation techniques. Transplantation. 2012 Mar 15;93(5):455-9. 


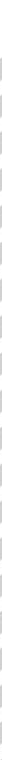


SAMENVATTING 


\section{INLEIDING}

Niertransplantatie is de voorkeursbehandeling bij patiënten met eindstadium nierfalen. Door het tekort aan de conventionele hersendode nierdonoren en een toenemende incidentie van eindstadium nierfalen, blijven de wachtlijsten voor niertransplantatie groeien. Naast nierdonatie van hersendode donoren, kan orgaandonatie na hartstilstand het aantal beschikbare donornieren vergroten. Voornamelijk orgaandonatie na een niet-succesvolle reanimatie kan tot een forse toename in het aantal donoren leiden. In tegenstelling tot nieren van hersendode donoren, worden organen van donoren na hartstilstand blootgesteld aan een periode van afwezige doorbloeding; warme ischemie. Hierdoor ontstaat acute nierschade, waardoor er na transplantatie een verhoogde kans op vertraagde transplantaatfunctie of primaire non-functie. Hierdoor is terughoudendheid opgetreden bij de acceptatie van deze nieren voor transplantatie. In dit proefschrift worden de lange termijnresultaten beschreven van voornamelijk nierdonatie na een niet-succelvolle reanimatie. Tevens worden klinisch toepasbare methoden gezocht om de kans op primaire non-functie te verkleinen.

\section{DEFINITIE VAN ORGAANDONATIE NA HARTSTILSTAND}

Donatie na hartstilstand verwijst naar orgaandonatie bij patiënten die niet voldoen aan strikte hersendoodcriteria, maar die komen te overlijden door een hartstilstand na niet-succesvolle reanimatie (Maastricht categorieën I en II), of na het staken van een medisch zinloze behandeling bij patiënten met ernstige hersenschade (Maastricht categorie III) (zie tabel 1.1). Deze Maastricht-categorieën zijn samengesteld tijdens het eerste internationale congres over orgaandonatie na hartstilstand in Maastricht in 1995 (1). Maastricht categorie I donoren bestaan uit patiënten die buiten het ziekenhuis overleden worden verklaard en vervolgens voor orgaandonatie naar het ziekenhuis worden vervoerd. Maastricht categorie II donoren zijn patiënten die binnen het ziekenhuis, meestal op de spoedeisende hulp, overlijden na een niet-succesvolle reanimatie. Beide categorieën worden ook wel 'ongecontroleerde donoren' genoemd, aangezien in beide situaties het overlijden onverwacht optreedt en er snel en adequaat gehandeld moet worden door het donatieteam. Maastricht categorie III donoren zijn patiënten op de afdeling intensieve zorg (IC) die niet voldoen aan de hersendoodcriteria, maar bij wie door ernstig hersenletsel verdere medische behandeling zinloos is. Bij deze patiënten, ook wel 'gecontroleerde donoren' wordt de behandeling gestaakt en wordt hartstilstand afgewacht De laatste categorie, Maastricht categorie IV, zijn hersendode patiënten die onverwacht aan een hartstilstand komen te overlijden voor de geplande orgaandonatie.

In tegenstelling tot organen van hersendode donoren, lijden organen van donoren na hartstilstand aan een periode van afwezige bloedcirculatie, warme 
ischemie, vanaf hartstilstand tot het spoelen van de organen met een koude perfusievloeistof. Door deze warme ischemie treedt er acute nierschade op, waardoor er na transplantatie een verhoogde kans bestaat op primaire non-functie of vertraagde transplantaatfunctie in vergelijking met getransplanteerde nieren van hersendode donoren (Hoofdstuk 2) (2). Deze vroege complicaties hebben geleid tot een terughoudendheid bij het accepteren van deze nieren voor transplantatie (Hoofdstuk 2) (3).

\section{RESULTATEN NA NIERTRANSPLANTATIE VAN DONOREN NA EEN HARTSTILSTAND}

Het is algemeen bekend dat niertransplantatie leidt tot een langere levensverwachting en betere kwaliteit van leven, in vergelijking met dialysebehandeling $(4,5)$. Daarom heeft een niertransplantatie de eerste voorkeur in de behandeling van patiënten met eindstadium nierfalen (3). Donatie van nieren na overlijden aan een hartstilstand kan de hoeveelheid beschikbare nieren met 2,5-4 maal vergroten (6). Slechts een klein aantal patiënten dat overlijdt op de intensive care na het staken van een zinloze medische behandeling komt in aanmerking als orgaandonor (7). Het aantal patiënten dat overlijdt na een niet succesvolle reanimatie is veel groter, en omvat daardoor een groter potentieel om het aantal orgaandonoren uit te breiden.

Snoeijs et al. (2010) hebben het overlevingsvoordeel van patiënten die een nier van een donor na hartstilstand kregen vergeleken met de patiënten die bleven dialyseren en wachtten op een conventionele nier na hersendood. In die studie werd een groot cohort van patiënten onderzocht; 2575 patiënten geregistreerd op de Nederlandse wachtlijst voor niertransplantatie (8). De kans op falen van de transplantatienier binnen 3 maanden na transplantatie was tweemaal zo groot voor donornieren na een hartstilstand in vergelijking met donornieren na hersendood. Het risico op overlijden na niertransplantatie van standaard donoren na hartstilstand is echter $56 \%$ lager vergeleken met het voortzetten van dialysebehandeling en wachten op een conventionele donornier na hersendood. Dit lagere risico vertaald zich in een 2,4 maanden langere levensverwachting na niertransplantatie van donoren na hartstilstand gedurende de eerste 4 jaar na transplantatie. De lange termijn resultaten van niertransplantaties van ongecontroleerde donoren na hartstilstand zijn echter onbekend.

Om deze reden hebben we de lange termijn uitkomsten van niertransplantaties van ongecontroleerde donoren na hartstilstand uit regio Maastricht die zijn getransplanteerd in de Eurotransplant regio tussen 1981 en 2009 vergeleken met niertransplantaties van gecontroleerde donoren na hartstilstand (Hoofdstuk 2). In deze studie laten we zien dat de initiële functie en lange termijn resultaten tussen beide groepen vergelijkbaar zijn. Echter, een nauwkeurige selectie van zowel de donornieren als de ontvangers blijft belangrijk om het risico op falen van de getransplanteerde nier te verkleinen (7). 
Bovenstaande bevindingen laten zien dat ongecontroleerde nierdonoren na hartstilstand een waardevolle uitbreiding zijn van het aantal donoren, met goede lange-termijn resultaten. Drastische maatregelen zijn echter nodig om het percentage primaire non-functie te reduceren. Het is niet exact duidelijk welke factoren invloed hebben op de uitkomst van ongecontroleerde donornieren na hartstilstand. De meeste studies die transplantatie-uitkomsten beschrijven hebben alleen gecontroleerde donornieren na hartstilstand, of gecontroleerde en ongecontroleerde donornieren na hartstilstand samen, bestudeerd. Bij een toegenomen populariteit van ongecontroleerde donornieren na hartstilstand is het echter essentieel welke nieren kunnen worden geaccepteerd voor transplantatie en welke nieren afgewezen dienen te worden. Om de mogelijkheden en limieten van ongecontroleerde donornieren na hartstilstand te beschrijven hebben we de resultaten van transplantaties van deze nieren bestudeerd en gekeken naar welke factoren geassocieerd zijn met primaire non-functie of verminderde functie na transplantatie (Hoofdstuk 3). In deze relatief grote studie met 135 ongecontroleerde donornieren na hartstilstand hebben we gefocust op de associatie van verschillende donor-, nier- en ontvanger karakteristieken met primaire non-functie. Alleen donorleeftijd bleek een onafhankelijke risicofactor voor primaire non-functie in een univariate analyse (OR 1.035, 95\% Cl 1.004-1.068, $\mathrm{p}=0.028)$ en bleef sterk geassocieerd met primaire non-functie in een multivariate analyse (OR $1.064,95 \% \mathrm{Cl} 1.013-1.118$, $\mathrm{p}=0.014)$. Verdere analyse van donorleeftijd, met gebruik van de ROC-grafiek en de bijbehorende tabel, toonde dat de grootste associatie met primaire non-functie optreedt vanaf een leeftijd van 54 jaar (OR 2.857, 95\% Cl $1.242-6.571 ; p=0.013$ ). Nieren van ongecontroleerde donoren na hartstilstand ouder dan 54 jaar hebben een hoger percentage primaire non-functie in vergelijking met jongere donoren (35\% vs. $16 \%, p=0.012$, respectievelijk). De voorspellende waarde van donorleeftijd is echter matig, met een AURC van $0.640,95 \% \mathrm{Cl} 0.553-0.721$. Uit Hoofdstuk 3 kan niet worden geconcludeerd dat er meerdere factoren een rol spelen voor een slechte nierfunctie na transplantatie. Ondanks het relatief hoge percentage primaire non-functie en de relatief grote populatie ongecontroleerde nierdonoren, is het moeilijk om alle mogelijke risicofactoren voor primaire non-functie te identificeren. Samengevat laat Hoofdstuk 3 zien dat donorleeftijd van ongecontroleerde donoren na hartstilstand geassocieerd is met nierfunctie na transplantatie en daarom blijft donorleeftijd een belangrijk criterium om een nier te accepteren of af te wijzen voor transplantatie.

\section{VALKUILEN BIJ NIERTRANSPLANTATIES VAN DONOREN NA HARTSTILSTAND}

Ondanks het feit dat niertransplantaties van donoren na hartstilstand een overlevingsvoordeel brengt voor dialysepatiënten op de wachtlijst voor een niertransplantatie, blijft het relatief hoge percentage primaire non-functie een prikkel om het huidige transplantatiebeleid omtrent nieren van donoren na hartstilstand te verbeteren. 
Nieren van donoren na hartstilstand hebben een grotere kans op het ontwikkelen van primaire non-functie en vertraagde nierfunctie in vergelijking met nieren van hersendode donoren (8-10). Vertraagde nierfunctie is een serieuze complicatie na transplantatie. Het leidt vaak tot een langere opnameduur, oplopende medische kosten en een vergroot risico op nierfalen. Tevens blijven deze patiënten langer afhankelijk van dialyse. Een vertraagde nierfunctie na transplantatie is echter niet de meest belangrijke parameter om op te selecteren, omdat het in de praktijk weinig consequenties met zich meebrengt $(2,11-13)$. De lange termijn resultaten van nieren van donoren na hartstilstand met een vertraagde functie na transplantatie verschillen niet significant van getransplanteerde nieren die direct functioneren. Primaire non-functie daarentegen is een ernstige complicatie, hetgeen is geassocieerd met het onnodige risico van de operatie en de immunosuppressieve behandeling. Tevens kunnen ontvangers immunologisch gesensibiliseerd raken tegen antigenen van de donor, waardoor de kans op een succesvolle her-transplantatie afneemt (14). Strategieën om het risico op primaire non-functie te beperken zijn daarom van groot belang.

\section{VERBETERINGEN IN NIERTRANSPLANTATIES VAN DONOREN NA HARTSTILSTAND}

Zoals hierboven reeds vermeld, is primaire non-functie een grote complicatie na een niertransplantatie en daarom zijn er verbeteringen noodzakelijk om de incidentie van primaire non-functie te verlagen. Om optimaal gebruik te maken van donoren na hartstilstand zonder het percentage primaire non-functie te verhogen, hebben we meerdere studies verricht om potentiële risicofactoren voor primaire nonfunctie te identificeren en om methoden te zoeken om de kans hierop te verminderen.

In het Maastricht University Medical Center (MUMC+) werd gestart met het niertransplantatie programma in 1980. In die periode werden alleen donornieren van perfecte kwaliteit van jonge donoren na hersendood getransplanteerd. De wachtlijst voor niertransplantaties bleef echter groeien, terwijl het aantal nierdonoren stabiel bleef. Om die reden werd er gezocht naar additionele soorten orgaandonoren. Men kwam uit bij de donoren na hartstilstand. In de eerste jaren van het transplantatie programma werden nieren van donoren na hartstilstand zelden gebruikt. De vraag naar donororganen bleef echter groeien waardoor het gebruik van donoren na hartdood werd gestimuleerd. In ons centrum werd begonnen met het accepteren van oudere donoren na hartdood en donoren met langere warme ischemie tijden. In het begin van de jaren negentig bestond ongeveer $25 \%$ van de overleden donoren uit donoren na hartdood. Het uitbreiden van het totaal aantal donoren met donoren van mindere kwaliteit werd echter gecompliceerd door een stijging in het percentage primaire non-functie. Daarom hebben we de kwaliteit van zorg in ons centrum geëvalueerd en hebben we bestudeerd welke verbeteringen gemaakt konden worden om het hoge percentage primaire non-functie te reduceren zonder het aantal donoren na hartdood te verminderen (Hoofdstuk 4). 
Potentiële risicofactoren voor primaire non-functie die werden geanalyseerd waren donorleeftijd, donorcategorie, warme ischemie tijd en duur van de koude ischemie. Eerdere studies van onze groep lieten zien dat nieren van donoren na hartstilstand van 60 jaar en ouder een hogere incidentie van primaire non-functie hadden en een slechtere overleving van de getransplanteerde nier ten opzichte van jongere donoren (15). De categorie ongecontroleerde donoren na hartstilstand vertoonde geen groter risico op primaire non-functie (Hoofdstuk 2), langere duur van in situ preservatie was geassocieerd met een hoger percentage primaire nonfunctie en directe cannulatie van de aorta was superieur ten opzichte van in situ preservatie voor gecontroleerde donoren na hartstilstand $(16,17)$.

Met bovengenoemde gegevens werden er verbeteringen in ons centrum ingevoerd om het percentage primaire non-functie te verminderen. De veranderingen bestonden uit 1) routine biopten van nieren van donoren ouder dan 60 jaar. Van deze donoren werd de beslissing om één nier te transplanteren, beide nieren samen in één ontvanger of beide nieren niet te accepteren voor transplantatie gebaseerd op de uitkomst van de biopten die voor de transplantatie werden afgenomen. 2) donoren met een in situ preservatie tijd langer dan 30 minuten werden in principe niet geaccepteerd voor transplantatie. 3) voor gecontroleerde donoren na hartstilstand werd directe cannulatie van de aorta de voorkeursmethode in plaats van in situ preservatie. 4) extra aandacht werd besteed aan kortere koude ischemie tijden door de beschikbaarheid van de operatiezaal te versnellen.

Door deze veranderingen is in ons centrum het percentage van primaire non-functie van nieren van donoren na hartstilstand verlaagd tot $5 \%$, zonder het aantal donoren na hartstilstand te verkleinen. Dit percentage is vergelijkbaar met de resultaten van andere transplantatiecentra $(9,10,18)$.

Samengevat, een liberale acceptatie van marginale donoren na hartstilstand kan bijdragen aan een wijdverspreide strategie om nieren van donoren na hartstilstand te transplanteren, met een reductie van het aantal patiënten op de wachtlijst die de met een hogere mortaliteit geassocieerde dialyse ondergaan. Echter, een dergelijke strategie behoeft zorgvuldige controle van de transplantatie uitkomsten om te garanderen dat de resultaten binnen de geaccepteerde limieten van goede klinische zorg blijven.

\section{DIAGNOSTISCHE HULPMIDDELEN OM DE KWALITEIT VAN NIEREN VAN DONOREN NA HARTSTILSTAND TE BEOORDELEN}

Beoordeling van kwaliteit van een donornier vóór het transplanteren kan clinici helpen bij het besluiten om een nier te accepteren of af te wijzen voor transplantatie. Adequate selectie van geschikte nieren voor transplantatie is cruciaal om het risico op primaire non-functie en vertraagde transplantaatfunctie te 
reduceren, hetgeen geassocieerd is met een verhoogd risico op falen, acute rejectie, verlengde ziekenhuisopname en hogere kosten (19-22). Daarnaast zouden, zonder betrouwbare methoden om de kwaliteit en viabiliteit van donornieren te kunnen bepalen, potentieel geschikte nieren afgewezen kunnen worden. Daarom zijn diagnostische methoden om de viabiliteit van donornieren vóór transplantatie te kunnen bepalen van groot belang.

\section{Beoordeling van viabiliteit van door machine geperfuseerde nieren}

In de afgelopen jaren is nierpreservatie door hypothermische machine perfusie opnieuw in de belangstelling gekomen. Naast het veronderstelde voordeel van verbeterd weefsel preservatie, zorgt machineperfusie ook voor de mogelijkheid om de kwaliteit van een donornier te beoordelen met behulp van perfusie parameters en biomarkers in het perfusaat $(23,24)$. Perfusaat biomarkers glutathione S-transferase (GST) en lactaat dehydrogenase (LDH) zijn veelbelovende of geaccepteerde methoden om nieren te accepteren of af te wijzen voor transplantatie (25-27). Echter, de meeste studies die de waarde van perfusaat biomarkers als voorspellers van de viabiliteit beoordelen, hebben dit beoordeeld in een geselecteerde groep nieren en beschrijven de verbeteringen van de resultaten van niertransplantatie na hartstilstand na de introductie van perfusaat biomarkers om viabiliteit te beoordelen, of hebben een beperkt aantal nieren geïncludeerd die een a priori goede prognose hebben en daardoor een te lage power hebben (Hoofdstuk 5).

In Hoofdstuk $\mathbf{5}$ hebben we de voorspellende waarde van potentiële biomarkers GST, LDH, heart-type fatty acid binding protein (H-FABP), redox-actief ijzer, interleukine (IL)-18 en neutrophil gelatinase-associated lipocalin (NGAL) beoordeeld in een grote $(\mathrm{N}=335)$ niet geselecteerde groep van nieren van donoren na hartdood met een relatief slechte prognose en een hoge incidentie van transplantaatfalen. In dit cohort waren alleen LDH en IL-18 geassocieerd met primaire non-functie in de multivariate analyse (OR $1.001,95 \% \mathrm{Cl} 1.000-1.002, \mathrm{p}=0.005$ and $1.001,95 \% \mathrm{Cl}$ $1.000-1.002, p=0.003$, respectievelijk). Echter, de diagnostische nauwkeurigheid voor primaire non-functie was matig voor alle onderzochte biomarkers. Daarom moet de diagnostische nauwkeurigheid van de perfusaat biomarkers GST, LDH, H-FABP, redoxactief ijzer, IL-18 en NGAL niet leiden tot het afwijzen van nieren van donoren na hartstilstand.

Naast de beoordeling van perfusaat biomarkers, biedt machine perfusie ook de mogelijkheid om perfusie parameters te bepalen, waaronder perfusiedruk, de perfusiesnelheid en de vaatweerstand in de nier. Deze parameters kunnen mogelijk de viabiliteit na transplantatie voorspellen (28-31). De waarde van machine perfusie karakteristieken om primaire non-functie te voorspellen is echter relatief onbekend. Zodoende hebben we onderzocht of de vaatweerstand is geassocieerd met primaire non-functie in een groot cohort van marginale machine geperfundeerde nieren van donoren na hartstilstand, waarin perfusie karakteristieken niet gebruikt worden om de organen af te wijzen (Hoofdstuk 6). De resultaten laten zien dat vaatweerstand in het begin van machine perfusie significant en onafhankelijk is geassocieerd met 
primaire non-functie (OR 2.040,95\% Cl 1.362 - 3.056, p=0.001). De voorspellende waarde is echter beperkt. Daarom zouden marginale nieren niet afgewezen moeten worden enkel gebaseerd op vaatweerstand.

De periode van warme ischemie kan leiden tot capillaire schade door trombose, vasoconstrictie en oedeem, en kan vervolgens resulteren in een verminderd circulerend volume in de nier. Het beoordelen van het circulerend volume vóór transplantatie zou mogelijk geassocieerd kunnen worden met de ernst van ischemische schade en zou dus een waardevolle voorspeller van transplantatie uitkomst kunnen zijn. De 'ultrasound dilution technique' werd oorspronkelijk gebruikt om het circulerend volume in hemodialyse apparatuur te bepalen. Hierbij is deze techniek accuraat en zijn de resultaten reproduceerbaar (32-35). Het is een relatief makkelijke methode om intravasculair volume te meten en is nog niet toegepast in transplantatie chirurgie. Daarom hebben wij de reproduceerbaarheid en validiteit van deze techniek bepaald en hebben we de effecten van warme ischemie op het circulerend volume beoordeeld in machine geperfundeerde varkensnieren (Hoofdstuk 7). We laten zien dat de 'ultrasound dilution technique' een reproducerende manier is om renovasculair circulerend volume te bepalen in machine geperfuseerde varkensnieren en dat deze techniek geschikt is om verschillen in warme ischemie tijd te detecteren. Echter, meer onderzoek is nodig om de waarde van deze techniek als voorspeller van transplantatie uitkomst in humane nieren te beoordelen.

De bovenstaande 'viabiliteitstesten' voor machine geperfundeerde nieren van donoren na hartstilstand en andere recent onderzochte potentiële viabiliteitstesten hebben helaas onvoldoende diagnostische nauwkeurigheid om klinisch bruikbaar te zijn in de beslissing om een nier te transplanteren of af te wijzen (Hoofdstuk 8).

\section{Beoordeling van nierschade vóór orgaandonatie}

Kwaliteitstesten voor machine geperfundeerde nieren zijn uitgebreid bestudeerd. Machine perfusie karakteristieken en perfusaat biomarkers correleren met de uitkomst van transplantatie, maar de huidige onderzoeken zijn geen betrouwbare voorspellers van transplantatie uitkomst. Het bestuderen van de kwaliteit van nieren vóór orgaandonatie is echter minder bestudeerd.

Het eiwit neutrophil gelatinase-associated lipocalin (NGAL), ook wel bekend als lipocalin-2, is onlangs ontdekt als een nieuwe biomarker voor acute nierschade (36). De concentratie van NGAL stijgt enorm na acute nierschade en gaat vooraf aan de stijging van klassieke biomarkers voor nierletsel, zoals serum creatinine (37). Daarom hebben wij NGAL concentraties gemeten in zowel donoren na hartstilstand (ongecontroleerde Maastricht categorie I en II donoren en gecontroleerde Maastricht categorie III donoren) als in donoren na hersendood en onderzochten de waarde van NGAL als voorspeller voor transplantatie uitkomst (Hoofdstuk 9). In dat hoofdstuk laten we zien dat de NGAL concentratie vóór orgaandonatie niet geassocieerd is met transplantaatfunctie na transplantatie. Voor nieren na harststilstand echter, werd een 
significant verschil gevonden voor NGAL concentratie tussen nieren met vertraagde transplantaat functie en onmiddellijke functie. Hoewel het een waardevolle biomarker is voor nierletsel in patiënten op de intensive care, is de waarde als voorspeller van transplantatie uitkomst beperkt.

\section{BEHANDELING VAN ACUUT ISCHEMISCHE NIERSCHADE IN DIERMODELLEN}

Niertransplantatie na hartstilstand is op dit moment beperkt tot nieren die relatief korte periodes van warme ischemie hebben geleden. Het reduceren van nierletsel na ischemie en reperfusie kan potentieel leiden tot het reduceren van de incidentie van vroege transplantaat dysfunctie en kan resulteren in het bijdragen van de uitbreiding van de donorpool met nieren die langdurig ischemische schade hebben opgelopen. Daarom hebben wij nieuwe potentiële therapieën onderzocht voor acute ischemische schade in experimentele muis modellen met het uiteindelijke doel om vroege transplantaat functie te verbeteren in niertransplantatie na hartstilstand.

Ischemie-reperfusie leidt tot een complexe reeks van gebeurtenissen, waaronder het ontstaan van ontstekingsmediatoren, leukocyten infiltratie en, afhankelijk van de ernst van de schade, uiteindelijk tot celdood door ofwel necrose of apoptose $(38,39)$. Inefficiënte opruiming van apoptotische cellen leidt tot necrose, wat is gekarakteriseerd door de onderbreking van het celmembraan en het vrijkomen van de celinhoud (40). De mechanismen die leiden tot ontsteking na necrotische celdood zijn maar gedeeltelijk bekend. Recente data laat zien dat het C-type lectine 'Mincle' betrokken is bij dit proces. Mincle herkent het eiwit SAP130 wat vrijkomt uit necrotische cellen, en activeert de ontsteking via cytokine afgifte, hetgeen leidt tot het aantrekken van neutrofielen $(40,41)$. De volledige ontstekingscyclus is nog niet bekend, maar we weten dat necrotische niercellen, apoptose en ontsteking gedurende en na ischemie-reperfusie significant bijdragen aan de pathogenese van acute ischemische nierschade (42). Het blokkeren van de Mincle-receptor kan resulteren in een minder heftige ontstekingsrespons, wat kan leiden tot minder nierschade na celdood. Daarom hebben wij het effect van 'anti-Micle' op ischemiereperfusie schade aan de nier onderzocht in een muizenmodel (Hoofdstuk 10). De effecten van Mincle op ischemie-reperfusie schade en de ontstekingsrespons zijn bestudeerd in een ischemie-reperfusie muizenmodel, gebruik makend van 25 minuten ischemie en 24 uur reperfusie. De Mincle-receptor werd geblokkeerd met een Mincle-specifiek antilichaam (anti-Mincle) en vergeleken met dieren die rat IgG als controle kregen. Nierfunctie (creatinine $232 \pm 34$ vs. $211 \pm 22 \mu \mathrm{mol} / \mathrm{L}, \mathrm{p}=0.200$ en ureum $61.2 \pm 5.6$ vs. $58.2 \pm 5.9, p=0.355$, respectievelijk), histologische schade en de hoeveelheid geïnfiltreerde neutrofielen waren vergelijkbaar tussen beide groepen. Concluderend, het blokkeren van de Mincle-receptor met specifiek anti-Mincle antilichaam verhindert de ontstekingsrespons in een muizenmodel niet na ischemiereperfusie en draagt niet bij aan verminderde nierschade en verbeterde nierfunctie. 
Het vrijkomen van vrije zuurstofradicalen gedurende koude ischemie en bij reperfusie leidt tot oxidatieve stress en wordt algemeen beschouwd als een belangrijke bijdrage aan ischemische nierschade en het veroorzaakt vaatvernauwing en veroorzaakt beschadiging aan cellulaire vetten, eiwitten en DNA, hetgeen uiteindelijk kan leiden tot celdood van het tubulusepitheel wanneer de natuurlijke verdediging tegen vrije zuurstofradicalen uitgeput raakt (43-45). In Hoofdstuk 11 bestudeerden we het mechanisme achter het ontstaan van vaatvernauwing bij oxidatieve stress en het voorkomen hiervan. We beschreven dat oxidatieve modificatie van arachidonzuur in celmembranen lijdt tot de formatie van stabiele F2-isoprostanen die vrijkomen in het plasma en daar actief zijn door signalering via thromboxaan A2 receptoren $(46,47)$. Eerdere studies laten een afname van de doorbloeding van de nier en glomerulaire filtratiesnelheid zien door vaatvernauwing in de aanvoerende glomerulaire arteriolen, na het toedienen van F2-isoprostanes aan ratten en varkens $(48,49)$. In de muizen zonder Thromboxaan A2 receptoren, waardoor signalering van F2-isoprostanes niet mogelijk is, zagen we geen bescherming tegen acute ischemische nierschade, hoewel F2-isoprostanes aanwezig waren in urine na ischemie-reperfusie. Hieruit concluderen we dat F2-isoprostanes geen grote invloed hebben op het ontstaan van acute ischemische nierschade.

\section{TOEKOMSTPERSPECTIEVEN IN NIERDONATIE EN TRANSPLANTATIE NA HARTSTILSTAND}

Gerichte interventies kunnen orgaanschade als gevolg van hersendood of ischemie-reperfusie verminderen na transplantatie. Het beïnvloeden van ontstekingsreacties en aangeboren immuniteit kan hierin een belangrijke rol spelen in de toekomst. Nieuwe behandelstrategieën kunnen de kwaliteit van de organen verbeteren en op die manier het aantal organen dat veilig kan worden geaccepteerd voor transplantatie verhogen. Interventies kunnen toegepast worden in de donor, maar ook tussen orgaandonatie en transplantatie gedurende koude machine preservatie of gedurende warme, ook wel normotherme, machine preservatie. In het geval van laatstgenoemde is het metabolisme hoger waardoor theoretisch gezien een betere modificatie van het orgaan mogelijk is.

Zoals beschreven in Hoofdstuk 8 zou normotherme machine perfusie (NMP) nieuwe en andere mogelijkheden kunnen bieden om de kwaliteit van een donororgaan te beoordelen voor transplantatie. Ook kan NMP ischemische schade herstellen in plaats van verdere schade toe te brengen (50). Het belangrijkste voordeel van NMP is de mogelijkheid van het meten van functionele parameters zoals diurese en creatinine klaring. 


\section{CONCLUSIE}

In dit proefschrift beschrijven we het gebruik van organen van donoren na hartstilstand, met name de ongecontroleerde Maastricht categorie II donoren, de lange termijn resultaten en mogelijkheden om transplantatie uitkomsten te verbeteren. Ondanks de hogere incidentie van primaire non-functie bij nieren van ongecontroleerde donoren na hartstilstand, zijn de lange-termijn resultaten vergelijkbaar met nieren van gecontroleerde donoren na hartstilstand. Het risico op primaire non-functie kan worden gereduceerd door het identificeren van marginale orgaandonoren met leeftijd, histologische beoordeling van pre-implantatie biopten van oude donornieren, donorcategorie en warme- en koude ischemietijd. Hierdoor kan de donorpool uitgebreid worden met ongecontroleerde donoren om de nog steeds groeiende wachtlijst voor niertransplantatie te reduceren.

Ischemie-reperfusie leidt tot een complexe serie van gebeurtenissen. Daarom vereist behandeling van acute ischemische schade aan nieren een combinatie van interventies die gericht zijn op verschillende pathofysiologische onderdelen. In dit proefschrift zijn mogelijke behandelingen van losse elementen van de pathofysiologie van ischemie-reperfusie bestudeerd zonder positieve effecten. Een combinatie van interventies daarentegen zou wel succesvol kunnen zijn in toekomstige studies.

Met de in dit proefschrift gepresenteerde resultaten kan het gebruik van nieren van donoren na hartstilstand, vooral ongecontroleerde donoren na hartstilstand, verder uitgebreid worden. Echter, grote inspanningen blijven cruciaal om de kwaliteit van deze nieren te verbeteren en hierbij deze groep donoren te gebruiken naar zijn volledige potentieel. 


\section{REFERENTIES}

1. Kootstra G, Daemen JH, Oomen AP. Categories of non-heart-beating donors. Transplantation proceedings. 1995 Oct;27(5):2893-4.

2. Wijnen RM, Booster MH, Stubenitsky BM, de Boer J, Heineman E, Kootstra G. Outcome of transplantation of non-heart-beating donor kidneys. Lancet. 1995 Apr 29;345(8957):1067-70.

3. Snoeijs MGJ, Heurn LWEv, Mook NKAv, Christiaans MH, Hooff JPv. Controlled donation after cardiac death: a European perspective. Transplant rev. 2007;21(4):219-29.

4. Wolfe RA, Ashby VB, Milford EL, Ojo AO, Ettenger RE, Agodoa LY, et al. Comparison of mortality in all patients on dialysis, patients on dialysis awaiting transplantation, and recipients of a first cadaveric transplant. N Engl J Med. 1999 Dec 2;341(23):1725-30.

5. Evans RW, Manninen DL, Garrison LP, Jr., Hart LG, Blagg CR, Gutman RA, et al. The quality of life of patients with end-stage renal disease. N Engl J Med. 1985 Feb 28;312(9):553-9.

6. Daemen JW, Oomen AP, Kelders WP, Kootstra G. The potential pool of non-heart-beating kidney donors. Clinical transplantation. 1997 Apr;11(2):149-54.

7. Hoogland ER, Snoeijs MG, Winkens B, Christaans MH, van Heurn LW. Kidney Transplantation from Donors after Cardiac Death: Uncontrolled versus Controlled Donation. Am J Transplant. 2011 Jul;11(7):1427-34.

8. Snoeijs MG, Schaubel DE, Hene R, Hoitsma AJ, Idu MM, lizzermans JN, et al. Kidneys from donors after cardiac death provide survival benefit. J Am Soc Nephrol. 2010 Jun;21(6):1015-21.

9. Barlow AD, Metcalfe MS, Johari Y, Elwell R, Veitch PS, Nicholson ML. Case-matched comparison of longterm results of non-heart beating and heart-beating donor renal transplants. The British journal of surgery. 2009 Jun;96(6):685-91.

10. Sanchez-Fructuoso AI, Prats D, Torrente J, Perez-Contin MJ, Fernandez C, Alvarez J, et al. Renal transplantation from non-heart beating donors: a promising alternative to enlarge the donor pool. J Am Soc Nephrol. 2000 Feb;11(2):350-8.

11. Renkens JJ, Rouflart MM, Christiaans MH, van den Berg-Loonen EM, van Hooff JP, van Heurn LW. Outcome of nonheart-beating donor kidneys with prolonged delayed graft function after transplantation. Am J Transplant. 2005 Nov;5(11):2704-9.

12. Weber M, Dindo D, Demartines N, Ambuhl PM, Clavien PA. Kidney transplantation from donors without a heartbeat. N Engl J Med. 2002 Jul 25;347(4):248-55.

13. Sanchez-Fructuoso Al, Marques M, Prats D, Conesa J, Calvo N, Perez-Contin MJ, et al. Victims of cardiac arrest occurring outside the hospital: a source of transplantable kidneys. Annals of internal medicine. 2006 Aug 1;145(3):157-64.

14. Snoeijs MG, Schaefer S, Christiaans MH, van Hooff JP, van den Berg-Loonen PM, Peutz-Kootstra CJ, et al. Kidney transplantation using elderly non-heart-beating donors: a single-center experience. Am J Transplant. 2006 May;6(5 Pt 1):1066-71.

15. Snoeijs MG, Buurman WA, Christiaans MH, van Hooff JP, Goldschmeding R, van Suylen RJ, et al. Histological assessment of preimplantation biopsies may improve selection of kidneys from old donors after cardiac death. Am J Transplant. 2008 Sep;8(9):1844-51.

16. Snoeijs MG, Dekkers AJ, Buurman WA, van den Akker L, Welten RJ, Schurink GW, et al. In Situ Preservation of Kidneys From Donors After Cardiac Death: Results and Complications. Ann Surg. 2007 Nov;246(5):84452.

17. Wind J, Snoeijs MG, van der Vliet JA, Winkens B, Christiaans MH, Hoitsma AJ, et al. Preservation of kidneys from controlled donors after cardiac death. The British journal of surgery. 2011 Jun;98(9):1260-6.

18. Wells AC, Rushworth L, Thiru S, Sharples L, Watson CJ, Bradley JA, et al. Donor kidney disease and transplant outcome for kidneys donated after cardiac death. The British journal of surgery. 2009 Mar;96(3):299-304.

19. Yarlagadda SG, Coca SG, Formica RN, Jr., Poggio ED, Parikh CR. Association between delayed graft function and allograft and patient survival: a systematic review and meta-analysis. Nephrol Dial Transplant. 2009 Mar;24(3):1039-47. 
20. Huang Y, Samaniego M. Preemptive kidney transplantation: Has it come of age? Nephrologie \& therapeutique. Nov;8(6):428-32.

21. Perico N, Cattaneo D, Sayegh MH, Remuzzi G. Delayed graft function in kidney transplantation. Lancet. 2004 Nov 13-19;364(9447):1814-27.

22. Bhangoo RS, Hall IE, Reese PP, Parikh CR. Deceased-donor kidney perfusate and urine biomarkers for kidney allograft outcomes: a systematic review. Nephrol Dial Transplant. 2012 Aug;27(8):3305-14.

23. Jochmans I, Moers C, Smits JM, Leuvenink HG, Treckmann J, Paul A, et al. Machine perfusion versus cold storage for the preservation of kidneys donated after cardiac death: a multicenter, randomized, controlled trial. Annals of surgery. 2010 Nov;252(5):756-64.

24. Moers C, Smits JM, Maathuis MH, Treckmann J, van Gelder F, Napieralski BP, et al. Machine perfusion or cold storage in deceased-donor kidney transplantation. N Engl J Med. 2009 Jan 1;360(1):7-19.

25. St Peter SD, Imber CJ, Friend PJ. Liver and kidney preservation by perfusion. Lancet. 2002 Feb 16;359(9306):604-13.

26. Navarro AP, Sohrabi S, Colechin E, Griffiths C, Talbot D, Soomro NA. Evaluation of the ischemic protection efficacy of a laparoscopic renal cooling device using renal transplantation viability assessment criteria in a porcine model. The Journal of urology. 2008 Mar;179(3):1184-9.

27. Daemen JW, Oomen AP, Janssen MA, van de Schoot L, van Kreel BK, Heineman E, et al. Glutathione S-transferase as predictor of functional outcome in transplantation of machine-preserved non-heartbeating donor kidneys. Transplantation. 1997 Jan 15;63(1):89-93.

28. Matsuno N, Konno O, Mejit A, Jyojima Y, Akashi I, Nakamura Y, et al. Application of machine perfusion preservation as a viability test for marginal kidney graft. Transplantation. 2006 Dec 15;82(11):1425-8.

29. Sung RS, Christensen LL, Leichtman AB, Greenstein SM, Distant DA, Wynn JJ, et al. Determinants of discard of expanded criteria donor kidneys: impact of biopsy and machine perfusion. Am J Transplant. 2008 Apr;8(4):783-92.

30. Nyberg SL, Baskin-Bey ES, Kremers W, Prieto M, Henry ML, Stegall MD. Improving the prediction of donor kidney quality: deceased donor score and resistive indices. Transplantation. 2005 Oct 15;80(7):925-9.

31. Mozes MF, Skolek RB, Korf BC. Use of perfusion parameters in predicting outcomes of machine-preserved kidneys. Transplantation proceedings. 2005 Jan-Feb;37(1):350-1.

32. Krivitski NM. Novel method to measure access flow during hemodialysis by ultrasound velocity dilution technique. Asaio J. 1995 Jul-Sep;41(3):M741-5.

33. Krivitski NM, Kislukhin VV, Snyder JW, MacGibbon DR, Kuznetsova OA, Reasons AM, et al. In vivo measurement of hemodialyzer fiber bundle volume: theory and validation. Kidney international. 1998 Nov;54(5):1751-8.

34. Krivitski NM. Theory and validation of access flow measurement by dilution technique during hemodialysis. Kidney international. 1995 Jul;:48(1):244-50.

35. Stewart GN. Researches on the Circulation Time and on the Influences which affect it. The Journal of physiology. 1897 Nov 20;22(3):159-83.

36. Mishra J, Dent C, Tarabishi R, Mitsnefes MM, Ma Q, Kelly C, et al. Neutrophil gelatinase-associated lipocalin (NGAL) as a biomarker for acute renal injury after cardiac surgery. Lancet. 2005 Apr 2-8;365(9466):1231-8.

37. Magnusson NE, Hornum M, Jorgensen KA, Hansen JM, Bistrup C, Feldt-Rasmussen B, et al. Plasma neutrophil gelatinase associated lipocalin (NGAL) is associated with kidney function in uraemic patients before and after kidney transplantation. BMC nephrology. 2012;13:8.

38. Kennedy SE, Erlich JH. Murine renal ischaemia-reperfusion injury. Nephrology (Carlton, Vic. 2008 Oct;13(5):390-6.

39. Bonventre JV, Weinberg JM. Recent advances in the pathophysiology of ischemic acute renal failure. J Am Soc Nephrol. 2003 Aug;14(8):2199-210.

40. Brown GD. Sensing necrosis with Mincle. Nature immunology. 2008 0ct;9(10):1099-100.

41. Yamasaki S, Ishikawa E, Sakuma M, Hara H, Ogata K, Saito T. Mincle is an ITAM-coupled activating receptor that senses damaged cells. Nature immunology. 2008 0ct;9(10):1179-88. 
42. Lee HT, Park SW, Kim M, Ham A, Anderson LJ, Brown KM, et al. Interleukin-11 protects against renal ischemia and reperfusion injury. American journal of physiology Renal physiology. 2012;303(8):1216-24.

43. Salahudeen AK. Cold ischemic injury of transplanted kidneys: new insights from experimental studies. Am J Physiol Renal Physiol. 2004 Aug;287(2):F181-7.

44. Paller MS, Hoidal JR, Ferris TF. Oxygen free radicals in ischemic acute renal failure in the rat. J Clin Invest. 1984 Oct;74(4):1156-64.

45. Schnackenberg CG. Physiological and pathophysiological roles of oxygen radicals in the renal microvasculature. American journal of physiology Regulatory, integrative and comparative physiology. 2002 Feb;282(2):R335-42.

46. Morrow JD, Hill KE, Burk RF, Nammour TM, Badr KF, Roberts LJ, 2nd. A series of prostaglandin F2-like compounds are produced in vivo in humans by a non-cyclooxygenase, free radical-catalyzed mechanism. Proc Natl Acad Sci U S A. 1990 Dec;87(23):9383-7.

47. Audoly LP, Rocca B, Fabre JE, Koller BH, Thomas D, Loeb AL, et al. Cardiovascular responses to the isoprostanes $\operatorname{IPF}(2$ alpha)-III and $\mathrm{iPE}(2)-$ III are mediated via the thromboxane $A(2)$ receptor in vivo. Circulation. 2000 Jun 20;101(24):2833-40.

48. Takahashi K, Nammour TM, Fukunaga M, Ebert J, Morrow JD, Roberts LJ, 2nd, et al. Glomerular actions of a free radical-generated novel prostaglandin, 8-epi-prostaglandin F2 alpha, in the rat. Evidence for interaction with thromboxane A2 receptors. J Clin Invest. 1992 Jul;90(1):136-41.

49. Krier JD, Rodriguez-Porcel M, Best PJ, Romero JC, Lerman A, Lerman LO. Vascular responses in vivo to 8-epi PGF(2alpha) in normal and hypercholesterolemic pigs. Am J Physiol Regul Integr Comp Physiol. 2002 Aug;283(2):R303-8.

50. Hosgood SA, Nicholson HF, Nicholson ML. Oxygenated kidney preservation techniques. Transplantation. 2012 Mar 15;93(5):455-9. 


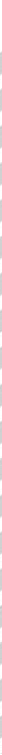

\section{0}


DANKWOORD 


\section{DANKWOORD}

ledereen die me een beetje kent weet dat ik iemand ben van weinig woorden. Daarom wil ik iedereen bedanken die op enigerlei heeft bijgedragen aan het tot stand komen van dit proefschrift. Omdat dit toch een beetje kort door de bocht is ga ik mij wagen aan het, in mijn ogen, moeilijkste deel van het proefschrift; een uitgebreider dankwoord om een aantal mensen specifiek te bedanken.

Allereerst natuurlijk mijn promotor Prof. Dr. L.W.E. van Heurn; Ernst, enorm bedankt voor je begeleiding, steun, ideeën en eindeloze enthousiasme. Dankzij dat alles en de vrijheid die je me hebt gegeven hebben de afgelopen jaren geleid tot dit werk.

Maarten Snoeijs, dankzij jou ben ik terecht gekomen op de plek die heeft geleid tot dit resultaat. Ik heb enorm veel van je geleerd en ook nu, na het afronden van deze thesis, blijf ik van je leren in de kliniek.

Leden van de promotiecommissie, Prof. dr. G.W.H. Schurink, Prof. dr. J.A. Bradley, Prof. dr. L.P.S. Stassen, Prof. dr. J.N.M. IJzermans, Prof. dr. J.P. van Hooff, hartelijk dank voor het plaatsnemen in mijn promotiecommissie en het beoordelen van mijn proefschrift.

Jeroen van den Berg, bedankt voor het bewerken van mijn proefschrift.

Jaren geleden ben ik als kidney-racer beland op het preservatielab en later als arts-onderzoeker/transplantatiecoördinator teruggekeerd. Dankzij mijn collega's, Wim, Tineke, Maarten, Marloes, Monique Willems, Monique Kouters-Lenssen, Eva, Tim en Ruud, was het een super periode. Bedankt voor de gezelligheid bij de vele liters koffie die we gedronken hebben. Dankzij jullie was het een leerzame periode in een supergezellig sfeertje. Wim, beste paranimf, bedankt dat je je ook voor mij in je favoriete kleding wil hijsen. Tim, bedankt voor de productieve en luchtige 'na-vijven' en vrijdagmiddag-gesprekken. Samen met Jasper zal het een mooie en productieve tijd worden. Succes beiden! Ook alle kidney-racers wil ik bedanken voor de inzet die gevraagd werd bij onderdelen van deze thesis.

Collega's van de onderzoeksafdeling van de heelkunde, Tim Lubbers, Kim van Wijck, Tim Wolfs, Joep, Geertje, Kostan, Iris, Sander, Annemarie, Froukje, Johanne, Mo, Caroline, Jacco, Nina, Marc, Bas, Kaatje, Stephanie, Maartje, Ruben Visschers, Liliane, Kirsten, Simon, Irma, Hans, Babs, Bart, Aron, Lai, Kevin, Ruben Vogels, Filip, Sofia, Givan, Yee Lai, Rob, Mark, Tiara, Dirk, Mechteld, Edgar, Freek, Dennis, Renske, Inca, Irene Fleur, Rutger, Paul, Kirsten, Evelien, Toine, Aart, Luc, Milou, RobertJan, Marlou, Lori, Ralph, Joyce-Manyi, Junfang, Kim van Mierlo. Bedankt voor de wetenschappelijke bijdrage aan mijn proefschrift, de gezellige uitjes, het op het laatste moment nog aanleren van ELISA's en PCR enz. Zonder die actieve bijdrage had ik waarschijnlijk nu nog op het preservatielab gezeten. Charlotte, bedankt voor de vele bemoedigende gesprekken en de etentjes samen met Philip. Voor jou zit het 
einde van je promotie-onderzoek er ook aan te komen; succes met de laatste loodjes. Guy, samen met jou na het werk nog even de fiets op voor mooie tochtjes door het heuvelland en soms de nodige frustraties eruit fietsen.... Heerlijk!

Carine Peutz-Kootstra en Bart de Vries, hartelijk dank voor het beoordelen van de vele coupes en de nuttige bijdrage aan een aantal artikelen.

Maarten Christiaans, bedankt voor de samenwerking en de kritische blik op de artikelen. Samen met Mariëlle Gelens, Elly van Duijnhoven en de transplantatieverpleegkundigen wil ik jullie bedanken voor de medewerking en de gastvrijheid op de transplantatie afdeling gedurende de gecompliceerde klinische studie de op dit moment nog gaande is.

Nadat ik in 2013 voor het grootste deel klaar was met het onderzoek ben ik weer in het Atrium MC te Heerlen terecht gekomen, waar ik jaren eerder al als semi-arts aan de gang kon. Dit maal als onervaren ANIOS. De omschakeling van een aantal jaar onderzoek naar de kliniek viel niet mee. Dankzij de gezellige werksfeer, de borrels, de laagdrempeligheid binnen het team, de gezellige verpleegafdelingen, het onderwijs enz. sta ik nu zelfverzekerd als arts op de afdeling.

Folkert, Frans, Freek, Laurens, Pierre en Rutger; bedankt voor de nodige ontspanning gedurende de studie en mijn onderzoeksperiode. Bedankt voor de gezellige ploeghappen, jullie eeuwige interesse in mijn onderzoek en bedankt voor de steun in een zware periode.

Bart, Matthijs en Pierre, wat zou mijn studenten- en onderzoeksperiode geweest zijn zonder jullie. De mooie avondjes met inhoudsloze gesprekken, apathisch voor een stomme film zitten, bier drinken, frikandellen eten, uitgaan, sporten en soms ook nog een beetje samen studeren. Bart, ondanks dat je mij na onze eerste ontmoeting bij de luchtmacht-keuring niet meer herkende in Maastricht zijn we toch dikke maten geworden. We vulden elkaar perfect aan en hebben elkaar gek gemaakt met het fiets- en kitesurfvirus. Bedankt voor de fantastische tijd! Matthijs, Mattie, op dit moment zit jij lekker in de zon als eerste specialist van ons allen. Helaas staan de lamme avondjes en het mountainbiken enz daardoor op een laag pitje, maar zodra je terug bent moeten we dat zeker weer even inhalen gedurende een mannenweekendje. Pierre, Pierke, beste paranimf, dankzij het niet maken van een opdracht in jaar 1 en vervolgens aan elkaar gekoppeld worden als buddies om die opdracht alsnog in te halen is onze vriendschap gegroeid en sta je hier nu naast me. $\mathrm{Na}$ onze fantastische en onvergetelijke trip naar Australië is dat alleen maar hechter geworden en hebben we lief en leed gedeeld. Bedankt dat je me altijd hebt gesteund en er ook vandaag weer bent.

Ellen en Martijn; Bizar hoe een vriendschap kan groeien na een ingrijpende gebeurtenis. Bedankt voor jullie onuitputtelijke steun, vriendschap en gezellige etentjes. Martijn, hopelijk kunnen we nog vaak samen de Limburgse (en buitenlandse) heuvels onveilig maken op de fiets. Ik zal proberen je niet nogmaals te laten crashen... 
Veel geluk met jullie aankomende huwelijk!

Luc, Irma, Tom, Marloes, Stijn en aanhang, wat moeten jullie wel niet van me denken. Zijn we weer eens een weekendje in Doetinchem, kan ik alleen maar uitgeput en onderuitgezakt op de bank liggen. Dankzij de afstand was naar jullie toe fietsen vanuit Maastricht een goed tijdverdrijf en een goede training voor de lange tochten door het Heuvelland waar jullie, Luc en Irma, steevaste aanmoedigers zijn!

Lieve pap en mam, daar sta ik dan; van kleine ukkepuk tot arts in een apenpakkie op mijn verdediging. Jullie hebben het allemaal mogelijk gemaakt. Dankzij jullie losse opvoeding en onvoorwaardelijke steun in wat we ook wilden doen ben ik gekomen tot waar ik nu sta. Marije en Hester, hoe relaxed is het als je na een drukke week gezellig naar het strand kan gaan om met $z^{\prime} n$ allen te gaan kitesurfen. Heerlijk even verstand op nul, elkaar dingen bijleren enz. Dit heeft voor mij voor de nodige ontspanning gezorgd waardoor het mogelijk was om alles op een relaxte manier te voltooien. Hopelijk krijgen we nog veel van dat soort weekendjes. Renske, wie had gedacht dat je na al mijn gepest als grote broer, mij toch achterna zou gaan naar Maastricht. Bedankt dat ik je altijd mag klieren. Veel succes met jullie veelbelovende toekomst binnen de geneeskunde en sport.

Opa Syb, jouw enorme interesse in je kleinkinderen vertaalde zich in het feit dat je na lange tijd vaak nog precies wist waar iedereen precies mee bezig was. Onderwerpen uit mijn promotie-onderzoek wist je na lange tijd feilloos op te noemen. De trots op je gezicht bij mijn afstuderen zal ik nooit vergeten. Helaas ben je niet bij mijn verdediging, je had het prachtig gevonden.

Lieve Rinske, nooit gezeur als ik weer eens laat van werk kwam of als ik onverwacht weer ergens heen moest. Het was niet altijd makkelijk voor je, maar altijd heb je me met volle overgave gesteund in mijn werk en onderzoek. Als ik weer eens geen motivatie had wist jij me de juiste schop onder m'n kont te geven om toch weer even aan de gang te gaan. En als ik wat vrije tijd had liet je me zonder te mokken m'n eigen ding doen. Je laat je niet zomaar uit het veld slaan en weet je zelfs uit de diepste dalen weer omhoog te werken. Dat heeft enorm gemotiveerd en ik kan daar zeker nog wat van leren. Ik ben gek op je! 


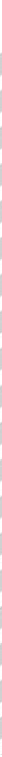

\section{6}


CURRICULUM VITAE 


\section{CURRICULUM VITAE}

Pieter Hoogland werd op 18 oktober 1984 geboren te Rotterdam. Na het behalen van het atheneum aan het Koningin Wilhelmina College te Culemborg (1996 - 2002) ging hij Lucht- en Ruimtevaarttechniek te Delft studeren. Na een jaar werd hij ingeloot voor de studie geneeskunde te Maastricht. In het eerste jaar heeft hij een bijbaan gevonden als 'kidney-racer' bij het Bureau orgaandonatie en -transplantatie in het Maastricht Universitair Medisch Centrum (2004 - 2006). Tijdens het co-schap chirurgie (Roermond) en het keuze-coschap traumachirurgie in Southport, Australië, was de interesse voor de chirurgie definitief gewekt en startte hij het laatste studiejaar als semi-arts chirurgie in het Atrium MC te Heerlen. Na het afstuderen (2009) is hij begonnen als arts-onderzoeker met promotie-onderzoek naar nierdonatie en -transplantatie onder leiding van Prof. dr. L.W.E. van Heurn. Gedurende dezelfde periode is hij werkzaam geweest als transplantatiecoördinator. In februari 2013 is hij begonnen als ANIOS chirurgie in het Atrium MC te Heerlen, waar hij nu nog werkzaam is. 


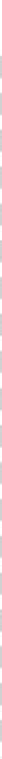

\section{0}


LIST OF PUBLICATIONS 


\section{LIST OF PUBLICATIONS}

\section{Scientific output, Published papers}

Hoogland ER, Snoeijs MG, van Heurn LW. DCD kidney transplantation: results and measures to improve outcome. Curr Opin Organ Transplant 2010; 15(2):177-82.

Wind J, Hoogland ER, van Heurn LE. Preservation techniques for donors after cardiac death. Curr Opin Organ Transplant 2011; 16(2):157-61.

Snoeijs MG, Hoogland PR, Boonen B, Coffman TM, Peutz-Kootstra CJ, Buurman WA, van Heurn LW. Thromboxane receptor signalling in renal ischemia reperfusion injury. Free Rad Res 2011; 45(6):699-706.

Hoogland ER, Snoeijs MG, Winkens B, Christiaans MH, van Heurn LW. Kidney transplantation from donors after cardiac death: uncontrolled versus controlled donation. Am J Transplant 2011; 11(7):1427-34.

de Vries EE, Hoogland ER, Winkens B, Snoeijs MG, van Heurn LW. Renovascular resistance of machine-perfused DCD kidneys is associated with primary non-function. Am J Transplant 2011; 11(12):2685-91.

Hoogland ER, Christiaans MH, van Heurn LW. Letter to the editor in response to: Uncontrolled donation after cardiac death: Potential for Future by Sharma et al. Am J Transplant 2012; 12(6):1661.

de Vries EE, Hoogland ER, Wind J, Snoeijs MG, van Heurn LW. Kidney transplantation from paediatric DCD donors: a comparison with DBD donors. Nephrol Dial Transplant. 2013; 28(1): 220-6

Hoogland ER, de Vries EE, Christiaans MH, Winkens B, Snoeijs MG, van Heurn LW. The value of machine perfusion biomarker concentration in DCD kidney transplantation. Transplantation. 2013; 95(4):603-10.

van Smaalen TC, Hoogland ER, van Heurn LW. Machine perfusion viability testing. Curr Opin Organ Transplant. 2013; 18(2):168-73.

de Vries EE, van Smaalen TC, Boer J, Hoogland ER, Krivitski NM, Snoeijs MG, van Heurn LW. Measurement of renovascular circulating volume during hypothermic organ perfusion. Transplantation. 2013;95(9):1100-4

E.R.P. Hoogland, T.C. van Smaalen, M.H.L. Christiaans, L.W.E. van Heurn. Kidneys from uncontrolled donors after cardiac death: which kidneys do worse? Transpl Int. 2013; 26(5):477-84.

Hoogland ER, Snoeijs MG, Habets MA, Brandsma DS, Peutz-Kootstra CJ, Christiaans MH, van Heurn LW. Improvements in DCD kidney transplantation. Clin Transplant. 2013; 27(3):E295-301.

\section{Submitted manuscripts}

Van Rijn R, Hoogland ERP, Lehner F, Van Heurn LWE, Porte RJ. Liver transplantation with paediatric donors after cardiac and brain death; a comparative study. Manuscript submitted

E.R.P. Hoogland, M.G.J. Snoeijs, L.W.E. van Heurn. Plasma neutrophil gelatinase-associated lipocalin of deceased donors as a predictor of post-transplant kidney function. Manuscript submitted

E.R.P. Hoogland, M.G.J. Snoeijs, B. de Vries, C.J. Peutz- Kootstra, W.A. Buurman, T. Saito, L.W.E. van Heurn. The effect of anti-Mincle on ischemia-reperfusion injury in mice. Manuscript submitted. 


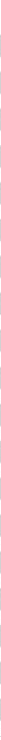


ABBREVIATIONS 


\section{ABBREVIATIONS}

3DUS Three dimensional ultrasound

AKI Acute kidney injury

Ala-AP Alanine aminopeptidase

AST Aspartate transaminase

ATP Adenosine triphosphate

AUC Area under the curve

AURC Area under the ROC-curve

BUN Blood urea nitrogen

CEUS Contrast-enhanced ultrasound

CIT Cold ischemia time

CPR Cardiopulmonary resuscitation

CS Cold storage

CV Coefficient of variation

DAMPs Damage-associated molecular pattern molecules

DBD Donation/donor after brain death

DBTL Double-balloon triple-lumen

DCD Donation/donor after cardiac death

DEC Animal experiments committee

DGF Delayed graft function

ECD Expanded criteria donors

ECMO Extracorpereal membrane oxygenation

eGFR estimated glomerular filtration rate

GSH Glutathione S-transferase

H-FABP Heart-type fatty acid binding protein

HLA Human leukocyte antigen

HMP Hypothermic machine perfusion

HR Hazards ratio

HTK Histidine-tryptophan-ketoglutarate

ICU Intensive care unit

IF Immediate function

IL Interleukin

IQR Interquartile range

I/R Ischemia reperfusion

IRB Institutional review board

ISP In situ preservation

LDH Lactate dehydrogenase

LPOP Lipid peroxidation products

MDA Malondialdehyde

MDRD Modification of diet in renal disease

Mincle Macrophage-inducible C-type Lectin

MPO Myeloperoxidase

MRS Magnetic resonance spectrometry

MTT Mean transit time 
MUMC Maastricht University Medical Center

NAG N-acetyl-b-D-glucosaminidase

NGAL Neutrophil gelatinase-associated lipocalin

NMP Normothermic machine perfusion

NPV Negative predictive value

OPTN Organ Procurement and Transplantation Network

OR Odds ratio

PNF Primary non-function

PPV Positive predictive value

PRA Panel reactive antibody

ROC Receiver operating characteristics

RR Renovascular resistance

SCD Standard criteria donors

SD Standard deviation

SPSS Statistical Package for the Social Sciences

TAS Total antioxidant status

TLR Toll-like receptor

UW University of Winsconsin

UW-MPS University of Winsconsin - machine preservation solution

WIT Warm ischemia time

WLST Withdrawal of life-supporting treatment 
